Florida International University FIU Digital Commons

\title{
Novel Hybrid Columns Made of Ultra-High Performance Concrete and Fiber Reinforced Polymers
}

Pedram Zohrevand

Florida International University, pzohr001@fiu.edu

DOI: $10.25148 /$ etd.FI12050233

Follow this and additional works at: https://digitalcommons.fiu.edu/etd

\section{Recommended Citation}

Zohrevand, Pedram, "Novel Hybrid Columns Made of Ultra-High Performance Concrete and Fiber Reinforced Polymers" (2012). FIU Electronic Theses and Dissertations. 627.

https://digitalcommons.fiu.edu/etd/627 


\section{FLORIDA INTERNATIONAL UNIVERSITY}

Miami, Florida

\section{NOVEL HYBRID COLUMNS MADE OF ULTRA-HIGH PERFORMANCE CONCRETE AND FIBER REINFORCED POLYMERS}

A dissertation submitted in partial fulfillment of the requirements for the degree of DOCTOR OF PHILOSOPHY

in

CIVIL ENGINEERING

by

Pedram Zohrevand 
To: Dean Amir Mirmiran

College of Engineering and Computing

This dissertation, written by Pedram Zohrevand, and entitled Novel Hybrid Columns Made of Ultra-High Performance Concrete and Fiber Reinforced Polymers, having been approved in respect to style and intellectual content, is referred to you for judgment.

We have read this dissertation and recommend that it be approved.

Ton-Lo Wang

Arindam Gan Chowdhury

Syed M. Ahmed

Amir Mirmiran, Major Professor

Date of Defense: March 26, 2012

The Dissertation of Pedram Zohrevand is approved.

Dean Amir Mirmiran

College of Engineering and Computing

Dean Lakshmi N. Reddi

University Graduate School

Florida International University, 2012 
(C) Copyright 2012 by Pedram Zohrevand

All rights reserved. 


\section{DEDICATION}

I dedicate this dissertation to my loving mother, Mahnaz Salehzadeh, and my sister, Pantea Zohrevand. Without their love, support, and patience, this dream would not have come true. 


\section{ACKNOWLEDGMENTS}

I owe my deepest gratitude to my advisor, Dr. Amir Mirmiran, for his invaluable guidance and support throughout my Ph.D. studies. He has by far been the most influential and inspiring teacher and advisor I have had the privilege of working with. Indeed he has been the predominant source of the academic and professional expertise I have acquired throughout my Ph.D. I am also grateful to Dr. Ton-Lo Wang, Dr. Arindam Gan Chowdhury, and Dr. Syed M. Ahmed for serving on my advisory committee.

I also want to acknowledge Edgar Polo, Brandon Mintz, Masood Hajali, and all personnel and students at the Titan America Structures and Construction Testing Laboratory of the Florida International University for their assistance during the experimental program of this research.

The support of NSF-Network for Earthquake Engineering Simulation Research (NEESR) program for providing funding, Lafarge North America for providing the Ductal $^{\circledR}$ (UHPC) materials, and NOV Fiber Glass Systems for providing the FRP tubes are acknowledged. I am also thankful to the Florida International University Graduate School for providing me with a dissertation year fellowship to complete my doctoral work.

Last but not the least, I would like to thank my dear friends for their endless support and encouragement. 


\section{ABSTRACT OF THE DISSERTATION \\ NOVEL HYBRID COLUMNS MADE OF ULTRA-HIGH PERFORMANCE \\ CONCRETE AND FIBER REINFORCED POLYMERS}

by

Pedram Zohrevand

Florida International University, 2012

Miami, Florida

\section{Professor Amir Mirmiran, Major Professor}

The application of advanced materials in infrastructure has grown rapidly in recent years mainly because of their potential to ease the construction, extend the service life, and improve the performance of structures. Ultra-high performance concrete (UHPC) is one such material considered as a novel alternative to conventional concrete. The material microstructure in UHPC is optimized to significantly improve its material properties including compressive and tensile strength, modulus of elasticity, durability, and damage tolerance. Fiber-reinforced polymer (FRP) composite is another novel construction material with excellent properties such as high strength-to-weight and stiffness-to-weight ratios and good corrosion resistance. Considering the exceptional properties of UHPC and FRP, many advantages can result from the combined application of these two advanced materials, which is the subject of this research.

The confinement behavior of UHPC was studied for the first time in this research. The stress-strain behavior of a series of UHPC-filled fiber-reinforced polymer (FRP) tubes with different fiber types and thicknesses were tested under uniaxial compression. The FRP confinement was shown to significantly enhance both the ultimate strength and 
strain of UHPC. It was also shown that existing confinement models are incapable of predicting the behavior of FRP-confined UHPC. Therefore, new stress-strain models for FRP-confined UHPC were developed through an analytical study.

In the other part of this research, a novel steel-free UHPC-filled FRP tube (UHPCFFT) column system was developed and its cyclic behavior was studied. The proposed steel-free UHPCFFT column showed much higher strength and stiffness, with a reasonable ductility, as compared to its conventional reinforced concrete (RC) counterpart. Using the results of the first phase of column tests, a second series of UHPCFFT columns were made and studied under pseudo-static loading to study the effect of column parameters on the cyclic behavior of UHPCFFT columns. Strong correlations were noted between the initial stiffness and the stiffness index, and between the moment capacity and the reinforcement index. Finally, a thorough analytical study was carried out to investigate the seismic response of the proposed steel-free UHPCFFT columns, which showed their superior earthquake resistance, as compared to their RC counterparts. 


\section{TABLE OF CONTENTS}

CHAPTER

PAGE

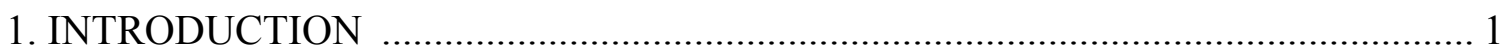

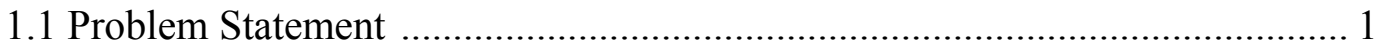

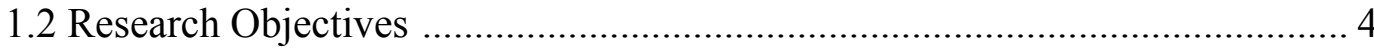

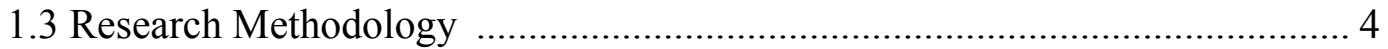

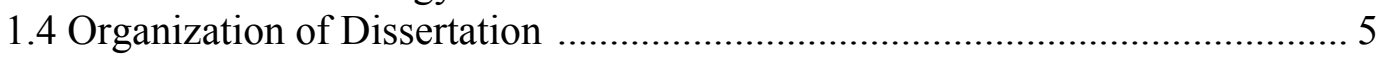

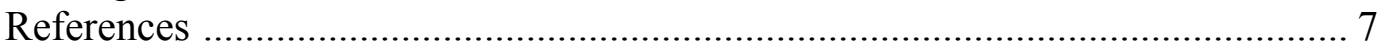

2. BEHAVIOR OF ULTRA-HIGH PERFORMANCE CONCRETE CONFINED BY

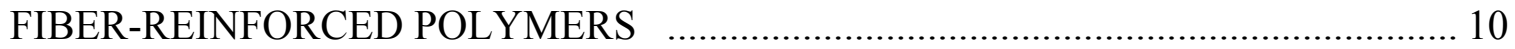

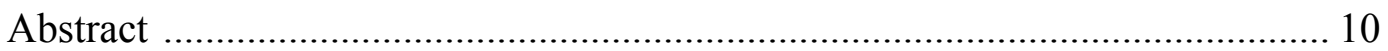

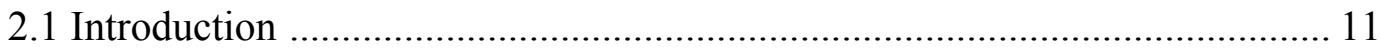

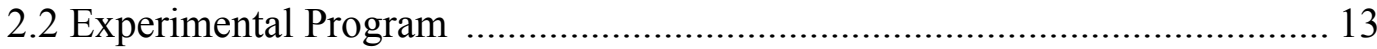

2.2.1 Test Specimens and Materials .................................................... 13

2.2.2 Specimen Fabrication ............................................................. 14

2.2.3 Instrumentation and Test Setup ................................................. 15

2.2.4 Test Observations ................................................................... 15

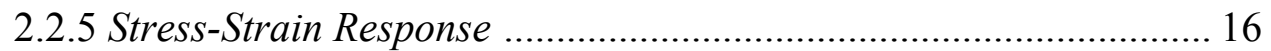

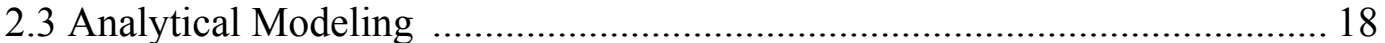

2.3.1 Stress-Strain Relationship .......................................................... 18

2.3.2 Ultimate Strength and Strain ..................................................... 20

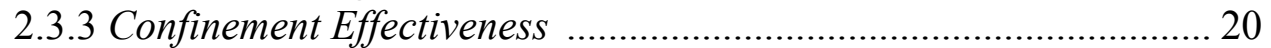

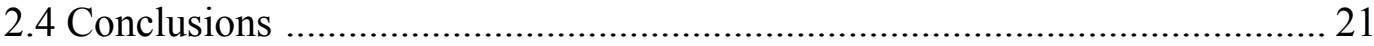

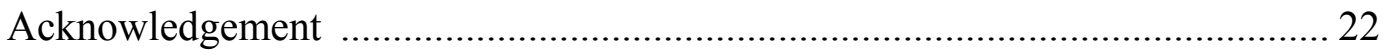

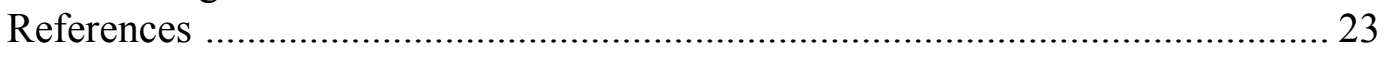

\section{STRESS-STRAIN MODEL OF ULTRA-HIGH PERFORMANCE CONCRETE} CONFINED BY FIBER-REINFORCED POLYMERS ............................................. 36

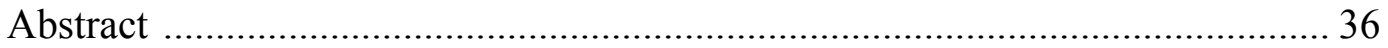

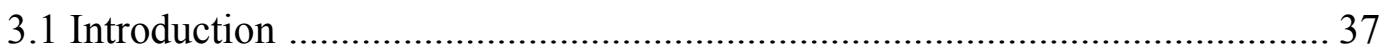

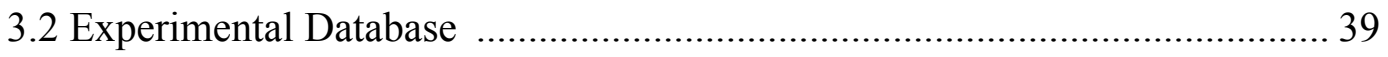

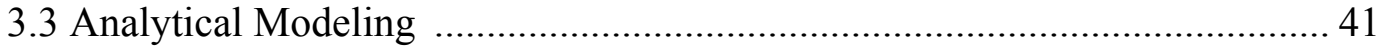

3.3.1 Recalibrated Model of Samaan ..................................................... 41

3.3.2 Recalibrated Model of Lam and Teng ........................................... 44

3.3.3 Modified Model of Lam and Teng ................................................. 46

3.3.4 Comparison of the Models ........................................................... 47

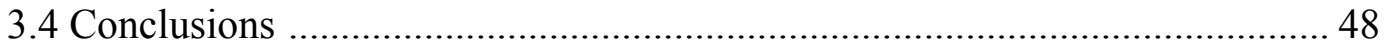

Acknowledgements ................................................................................... 49

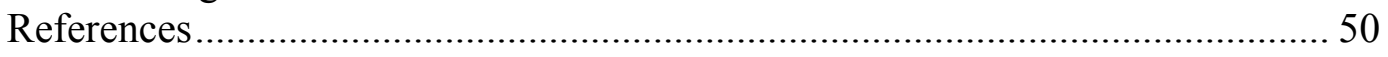




\section{CYCLIC BEHAVIOR OF HYBRID COLUMNS MADE OF ULTRA-HIGH PERFORMANCE CONCRETE AND FIBER-REINFORCED POLYMERS .............. 65}

Abstract 65

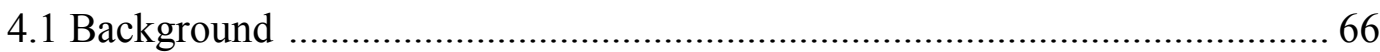

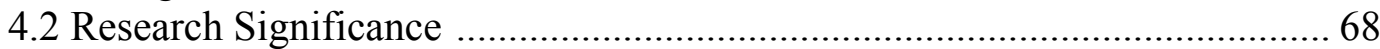

4.3 Experimental Program ................................................................................. 68

4.3.1 Test Matrix and Specimen Preparation ....................................... 68

4.3.2 Test Setup and Instrumentation .................................................... 71

4.3.3 Test Procedure and Observations .............................................. 72

4.4 Test Results and Discussion ..................................................................... 73

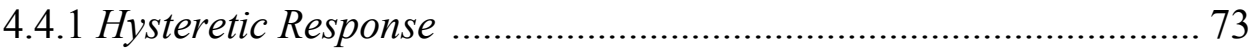

4.4.2 Response Envelope ...................................................................... 75

4.4.3 Energy Dissipation ....................................................................... 75

4.4.4 Performance Measures of Stiffness and Ductility ........................ 76

4.4.5 Load-Strain Response and Plastic Hinge Zone ............................. 77

4.4.6 Slippage and Residual Deflections ................................................ 78

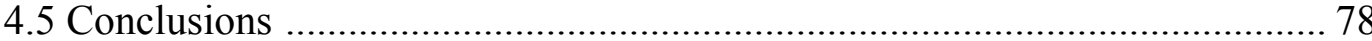

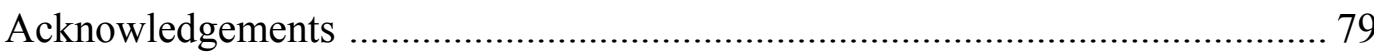

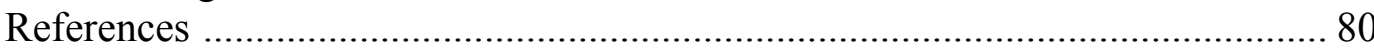

\section{EFFECT OF COLUMN PARAMETERS ON CYCLIC BEHAVIOR OF ULTRA-} HIGH PERFORMANCE CONCRETE-FILLED FRP TUBES .................................. 95

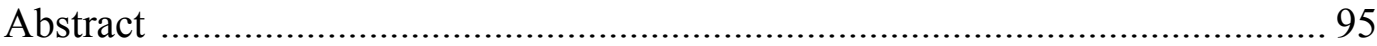

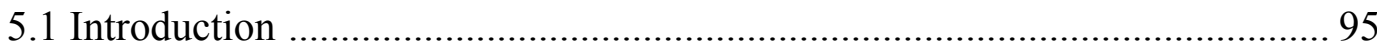

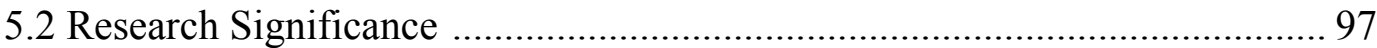

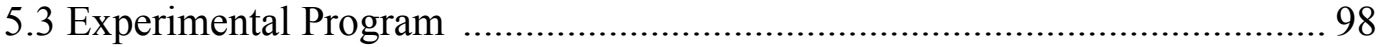

5.3.1 Test Matrix and Material Properties ............................................ 98

5.3.2 Reinforcement and Stiffness Index ............................................ 100

5.3.3 Test Setup and Instrumentation ................................................. 101

5.3.4 Test Procedure .......................................................................... 102

5.4 Experimental Results and Discussion .......................................................... 103

5.4.1 Hysteretic Response and Failure Mode ....................................... 103

5.4.2 Response Envelope .................................................................... 104

5.4.3 Initial Stiffness ...................................................................... 104

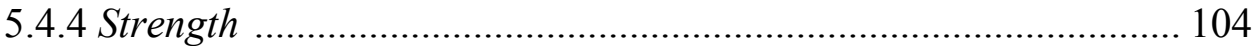

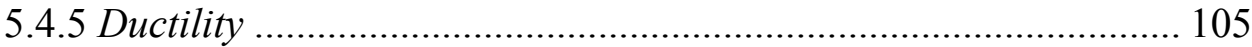

5.4.6 Energy Dissipation and Damping Ratio ..................................... 105

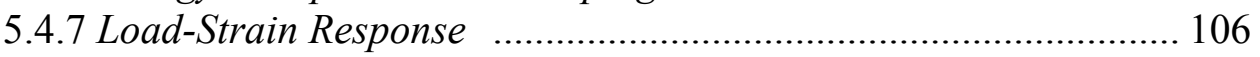

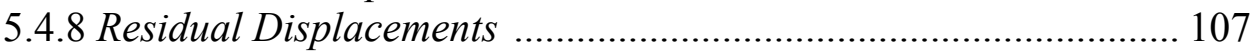

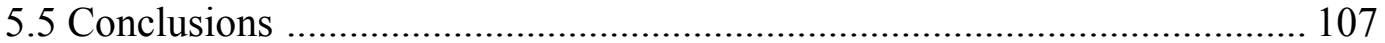

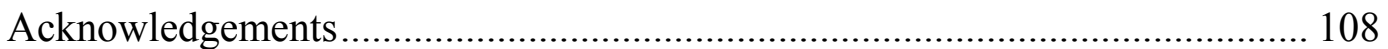

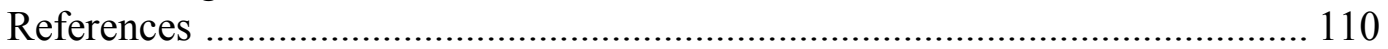




\section{SEISMIC RESPONSE OF ULTRA-HIGH PERFORMANCE CONCRETE-}

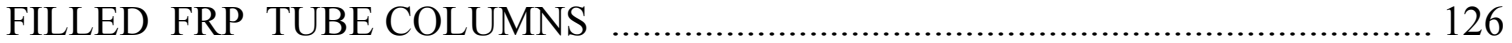

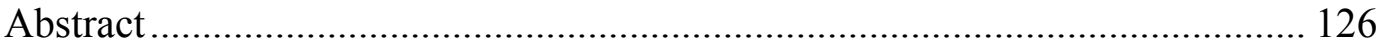

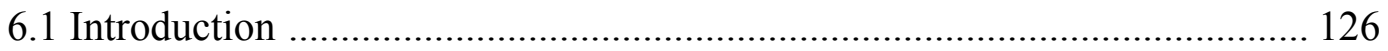

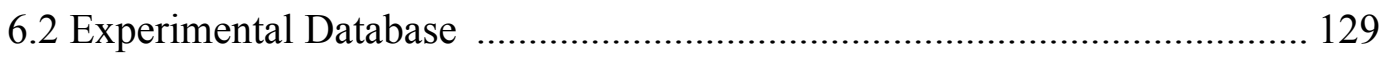

6.3 Seismic Response Analysis ................................................................... 130

6.3.1 Cyclic Performance Measures .................................................... 130

6.3.2 Earthquake Response Spectrum .................................................. 131

6.3.2.1 Elastic Design Response Spectrum ............................... 131

6.3.2.2. Inelastic Design Response Spectrum ........................... 133

6.3.3 Estimation of Maximum Ground Acceleration Capacity ............... 133

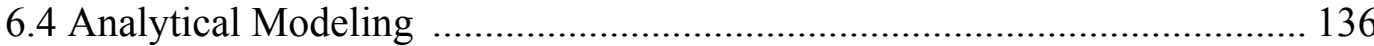

6.4.1 Modeling of the Columns ............................................................. 136

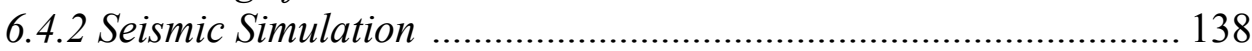

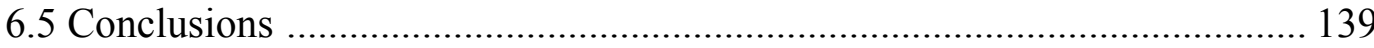

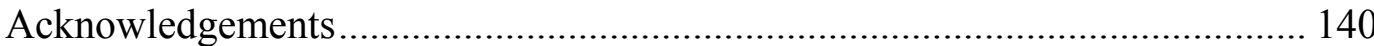

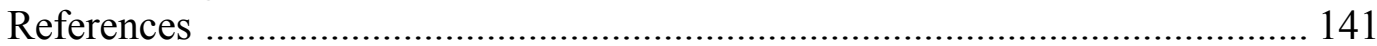

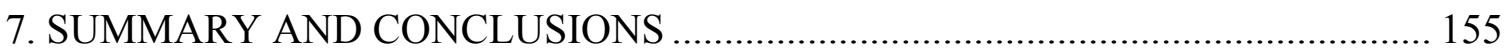

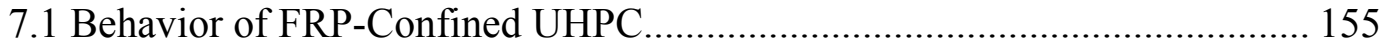

7.2 Novel Hybrid UHPCFFT Column Systems ................................................. 157

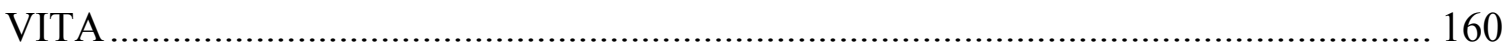




\section{LIST OF TABLES}

TABLE

PAGE

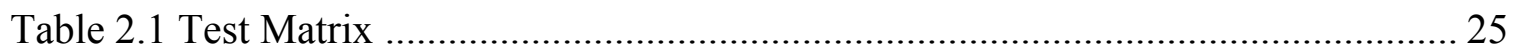

Table 2.2 Mechanical Properties of FRP Tubes …………………………………..... 25

Table 2.3 Summary of Test Results.......................................................................... 26

Table 2.4 Goodness of Fit for the Confinement Models .................................................. 26

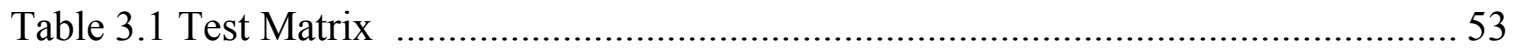

Table 3.2 Mechanical Properties of FRP Tubes …………………………................ 53

Table 3.3 Summary of Test Results …………………............................................. 54

Table 3.4 Predicted Values of the Ultimate Strength and Strain .................................... 54

Table 3.5 Comparison of the Models with respect to the Stress-Strain Curve and Ultimate

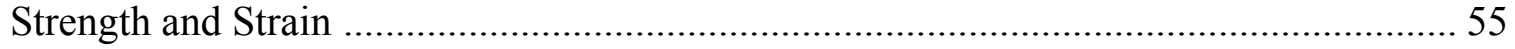

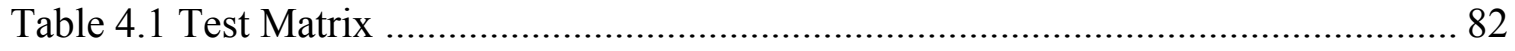

Table 4.2 Mechanical Properties of FRP Tube ………………………...................... 83

Table 4.3 Performance Measures of Stiffness and Ductility ………………………..... 83

Table 5.1 Specimen Test Matrix ............................................................................. 112

Table 5.2 Reinforcement Ratio, Reinforcement Index, and Stiffness Index of

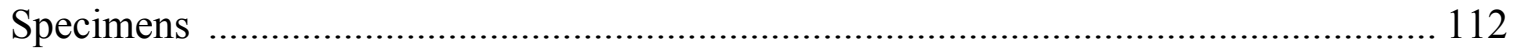

Table 5.3 Performance Measures of Initial Stiffness, Moment and Displacement Capacities, and Ductility ................................................................................... 113

Table 6.1 Specimen Test Matrix of the Experimental Study ......................................... 143

Table 6.2 Performance Measures of the Columns Tested in the Experimental Study . 144

Table 6.3 Estimation of the Maximum Ground Acceleration Capacity ........................ 144 


\section{LIST OF FIGURES}

FIGURE

PAGE

Figure 2.1 Preparation of FRP-Confined UHPC: (a) FRP Tubes; (b) UHPC-Filled GFRP Tubes; and (c) UHPC-Filled CFRP Tubes ................................................................ 27

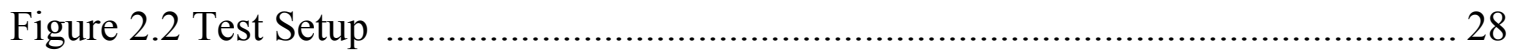

Figure 2.3 Typical Failure of (a) Unconfined UHPC; (b) UHPC-Filled GFRP Tube; and (c) UHPC-Filled CFRP Tube 29

Figure 2.4 Average Stress-Strain Response Curves for Unconfined UHPC (Group P

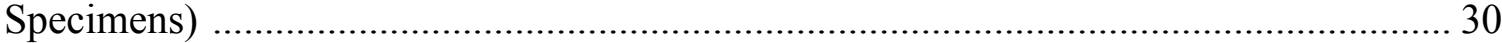

Figure 2.5 Average Stress-Strain Response Curves for Each Group of Specimens ........ 31

Figure 2.6 Average Ultimate Strains versus Confinement Ratios for Each Group of

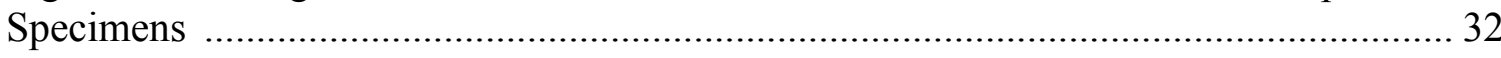

Figure 2.7 Comparison of Stress-Strain Predictions for Specimens: (a) G3; (b) G4; (c)

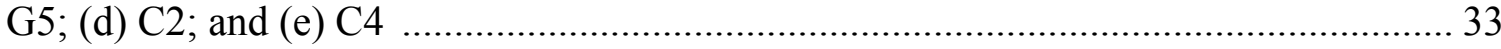

Figure 2.8 Comparison of Confinement Models for Predicting Ultimate Strengths ....... 34

Figure 2.9 Comparison of Confinement Models for Predicting Ultimate Strains ........... 34

Figure 2.10 Confinement Effectiveness versus Confinement Ratio .............................. 35

Figure 3.2(a) UHPC-Filled GFRP Tubes, (b) UHPC-Filled CFRP Tubes, and (b) Test

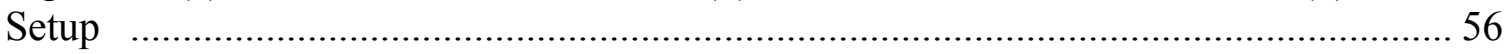

Figure 3.2 Average Stress-Strain Response Curves for UHPC Specimens: (a)

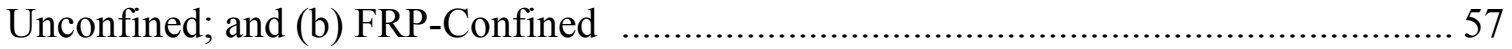

Figure 3.3 Ultimate Strengths $\left(f_{c u}^{\prime}\right)$ Predicted by the Recalibrated Model of Samaan

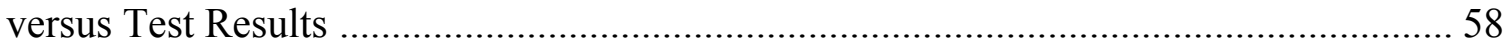

Figure 3.4 Schematic Stress-Strain Model of Samaan ................................................. 58

Figure 3.5 Second Slopes $\left(E_{2}\right)$ Predicted by the Recalibrated Model of Samaan versus

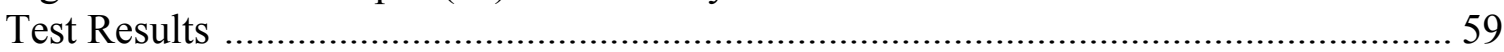

Figure 3.6 Intercept Stresses $\left(f_{o}\right)$ Predicted by the Recalibrated Model of Samaan versus

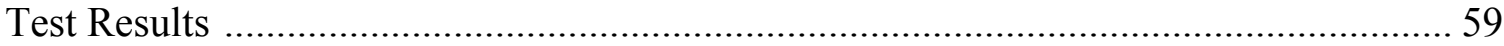


Figure 3.7 Ultimate Strains $\left(\varepsilon_{c u}\right)$ Predicted by the Recalibrated Model of Samaan versus

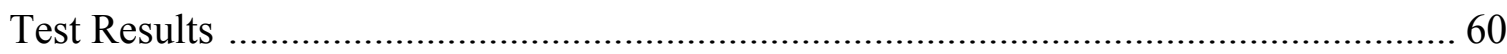

Figure 3.8 Comparison of Predicted Stress-Strain Responses for Specimens: (a) G3; (b)

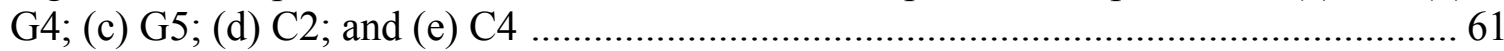

Figure 3.9 Ultimate Strengths $\left(f_{c u}^{\prime}\right)$ Predicted by the Recalibrated Model of Lam and

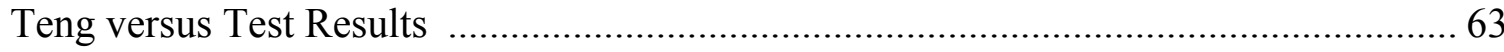

Figure 3.10 Ultimate Strains $\left(\varepsilon_{c u}\right)$ Predicted by the Recalibrated Model of Lam and Teng

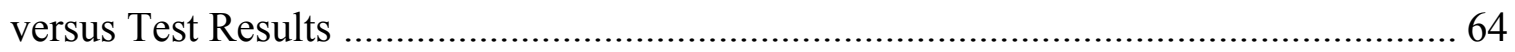

Figure 3.11 Schematic Stress-Strain Model of Lam and Teng ……………………....... 64

Figure 4.1 Reinforcement Cages for Specimens RC and RUHPC …………………..... 84

Figure 4.2 Embedded FRP Tubes for Specimens CFFT and UHPCFFT …………….... 85

Figure 4.3 Shear Connectors and Screen at the Bottom of FRP Tube ............................ 86

Figure 4.4 Typical Axial Stress-Strain Curve of UHPC …………………………...... 87

Figure 4.5 Typical Test Setup (Specimen CFFT) ……………....................................... 88

Figure 4.6 Instrumentation Plan: (a) Specimens RC and RUHPC, (b) Specimens CFFT

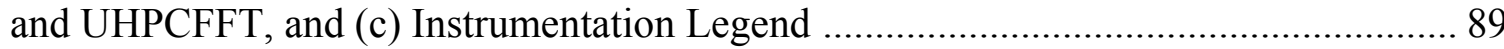

Figure 4.7 Hysteretic Moment-Deflection Response for (a) Specimen RC, (b) Specimen RUHPC, (c) Specimen CFFT, and (d) Specimen UHPCFFT …………………….......... 90

Figure 4.8 Moment-Drift Ratio Envelope Curves ……………………………….......... 91

Figure 4.9 Comparison of Cumulative Dissipated Energy .............................................. 91

Figure 4.10 Longitudinal Rebar Strain Profile for Specimen RUHPC ……………….... 92

Figure 4.11 Moment-Slippage for Specimens: (a) CFFT, and (b) UHPCFFT ................ 93

Figure 4.12 Comparison of Residual Drift Ratios ........................................................ 94

Figure 5.3 Layout of Column Specimens and Instrumentation Plan (Note: all dimensions

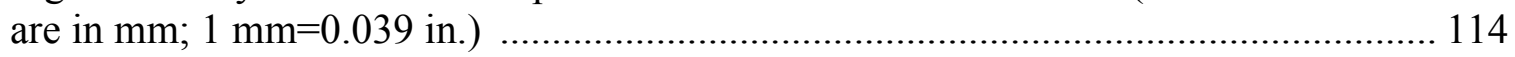

Figure 5.2 Embedment of FRP Tubes into the Footing ............................................. 115

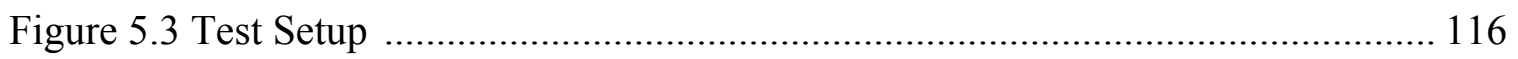


Figure 5.4 Reverse Cyclic Loading Regime (Note: $1 \mathrm{~mm}=0.039$ in.)

Figure 5.5 Hysteretic Moment-Deflection Response for Specimens (a) RC, (b) UF1, (c) UF2, (d) UF3, (e) RUF1, (f) and RUF2 (Notes: $1 \mathrm{~mm}=0.039$ in.; $1 \mathrm{kN} . \mathrm{m}=8.85$ kips.in)

Figure 5.6 Failure Mode in (a) Specimen RC, (b) and UHPCFFT Specimens 120

Figure 5.7 Moment-Deflection Envelope Curves (Notes: $1 \mathrm{~mm}=0.039$ in.; $1 \mathrm{kN} . \mathrm{m}=$ 8.85 kips.in)

Figure 5.8 Effect of Total Stiffness Index on Initial Stiffness of UHPCFFT Specimens 122

Figure 5.9 Effect of Total Reinforcement Index on the Strength of UHPCFFT Specimens

Figure 5.10 Comparison of Ductility in UHPCFFT Specimens ................................ 123

Figure 5.11 Cumulative Dissipated Energy versus Drift Ratio .................................. 123

Figure 5.12 Damping Ratio versus Drift Ratio..................................................... 124

Figure 5.13 Ultimate FRP Tensile Strain Profiles in UHPCFFT Specimens (Note: $1 \mathrm{~mm}=0.039$ in. $)$

Figure 5.14 Residual Drift Ratio versus Drift Ratio .............................................. 125

Figure 6.1 Schematic Force-Deflection Response Curves of Two Nonlinear Systems with

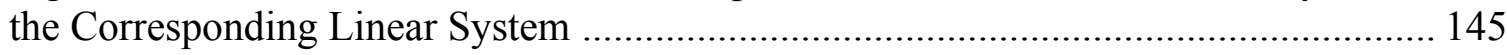

Figure 6.2 Layout of Column Specimens (All dimensions are in $\mathrm{mm}$ ) ....................... 146

Figure 6.3 Reverse Cyclic Loading Regime ...................................................... 147

Figure 6.4 Load-Deflection Envelope Curves of the Column Specimens .................... 147

Figure 6.5 Schematic Load-Deflection Curves of the Actual System and its Idealized

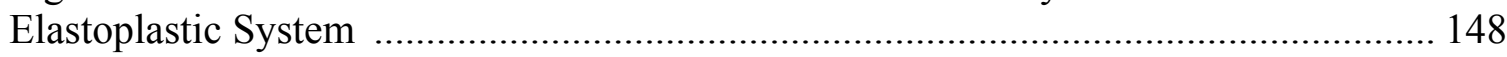

Figure 6.6 Variation of Damping Ratio Relative to Drift Ratio for Tested Columns ... 148 Figure 6.7 Schematic Linear Response Spectrum for a Specific Ground Motion and Damping Ratio

Figure 6.8 Idealized Elastic Design Response Spectrum Following Newmark and Hall (1982) 
Figure 6.9 Inelastic Design Response Spectrum Following Chopra (2008)

Figure 6.10 Maximum Ground Acceleration Capacities of Tested Columns 151

Figure 6.11 Comparison of Analytical and Experimental Load-Deflection Response Envelopes for (a) Specimen RC and (b) Specimen UF1 152

Figure 6.12 Ground Acceleration Record of 1978 Tabas, Iran Earthquake 153

Figure 6.13 Time History of the Column Base Shear Response for Specimen RC 154

Figure 6.14 Time History of the Column Base Shear Response for Specimen UF1 154 


\section{INTRODUCTION}

\subsection{Problem Statement}

Since the early adoption of reinforced concrete (RC) structures in infrastructure, many studies have been carried out to alleviate the deficiencies of concrete, including its low tensile strength, brittle behavior, and high shrinkage. The development of fiber-reinforced concrete (FRC) materials was the first such attempt in this area (ACI Committee 544 1973). Further studies on the microstructure of the materials resulted in high performance cementitious composites (HPFRCC), which exhibit tensile strain hardening with high strain capacity and distributed cracking pattern (Parra-Montesinos 2005). The most recent type of HPFRCCs in which the material microstructure is optimized to reach a significant enhancement in material properties, e.g., compressive and tensile strengths, elastic modulus, ductility, and durability, is named ultra-high performance concrete (UHPC). Such exceptional properties make UHPC a promising material for structural applications (Graybeal 2006).

Application of UHPC in steel-reinforced structures can prevent both brittle failure and bond splitting failure. It may also result in higher ductility, smaller crack widths and enhanced damage tolerance (Fukuyama et al. 2000). Furthermore, higher shear resistance and self confining behavior of UHPC can reduce the required transverse and shear reinforcement (Parra-Montesinos and Chompreda 2007). Energy dissipation capacity in steel-reinforced UHPC columns is significantly enhanced, as compared to their steelreinforced conventional concrete counterparts (Fischer et al. 2002, Billington and Yoon 2002, and Saiidi et al. 2009). However, longitudinal steel reinforcement is still necessary for UHPC columns to achieve a reasonable hysteretic behavior and ductility level. 
Recently, the Japan Society of Civil Engineers (JSCE) published the first and only design guidelines for high performance fiber-reinforced composites worldwide (JSCE 2008). Although many issues such as test methods and structural design regulations are addressed in these guidelines, there is no guidance on HPFRCC confinement. This is due primarily to the lack of adequate experimental database in this field. Similarly, although previous studies have shown the benefits of UHPC application in structural members, there is no study investigating the behavior of confined UHPC. Subsequently, there is no recommendation on the amount of confinement reinforcement needed for UHPC columns, specifically in regions with high seismicity. Therefore, studying the stress-strain behavior of confined UHPC material is necessary to develop design guidelines for UHPC columns, which shapes a part of this research study. Owing to the fact that previous studies have proven the superior confinement effect of fiberreinforced polymers (FRP) over other confinement devices, FRP-confined UHPC would be the subject of the confinement study.

Another innovative achievement in structural systems over the last two decades is the concrete-filled fiber-reinforced polymer (FRP) tube (CFFT). The CFFT system has the same advantages as concrete-filled steel tube (CFST), including significant enhancement in strength, ductility and energy absorption. On the other hand, replacing steel with FRP composites helps resolve the disadvantages of CFST system, i.e., the premature buckling of steel tube, the initial separation of the two materials, and the corrosion of steel (Mirmiran and Shahawy 1995 and 1997). Using the FRP tube as a stay-in-place formwork, protective jacket, confinement device, and shear and flexural 
reinforcement speeds up the construction, and eliminates the costs of conventional formwork and maintenance requirements for steel protection.

Several studies during the last decade have shown the good performance of CFFT systems under flexural and axial-flextural loading (Fam et al. 2002, 2005 and 2007, Mirmiran et al. 1998, 2000, 2001, and 2002). However, studies on the seismic performance of CFFTs have shown that the energy absorption and cyclic behavior of CFFT without longitudinal steel reinforcement would be very limited, and that the failure would be governed by the premature failure of the tube (Seible et al. 1996). Shao and Mirmiran (2005) confirmed this finding with tests on CFFT beam-column specimens under cyclic loading. They indicated that higher ductility and energy absorption could be achieved using FRP tubes with off-axis fibers and a moderate amount of internal steel reinforcement.

Although CFFTs would simplify and speed up the construction procedure and reduce the construction costs associated with conventional concrete columns, they still require longitudinal steel reinforcement in order to exhibit adequate seismic behavior. Hence, if one improves the CFFT system in such a way that the internal reinforcement may be eliminated altogether for various applications including moderate seismicity, the new system will have substantial advantages over existing ones. Given the exceptional properties of UHPC materials, replacing conventional concrete with UHPC inside the FRP tube in a CFFT system may allow eliminating or reducing the longitudinal reinforcement. This idea shapes the hypothesis of this research. 


\subsection{Research Objectives}

The following objectives are established for this research study:

1. Studying the behavior of confined UHPC, and developing a stress-strain model for FRP-confined UHPC.

2. Developing a steel-free novel hybrid FRP-UHPC column with the comparable cyclic behavior to that of a conventional RC column.

3. Determining the effect of column parameters, including the cross section, type of FRP tube, and amount of longitudinal steel reinforcement, on the cyclic behavior of the novel hybrid FRP-UHPC column for its design optimization.

4. Evaluating the seismic response of the novel hybrid FRP-UHPC column system.

\subsection{Research Methodology}

A series of UHPC-filled FRP tubes (UHPCFFT) with different types and thicknesses of FRP were made and tested under uniaxial compression to investigate the confinement behavior of UHPC. The stress-strain responses of FRP-confined UHPC specimens were compared to those of unconfined UHPC specimens to assess effectiveness of confinement with FRP for UHPC. The stress-strain responses were then compared with existing confinement models proposed for conventional concrete, and a new stress-strain model was developed for FRP-confined UHPC through an analytical study.

Two series of quarter-scale bridge columns were built and tested under pseudostatic loading. The feasibility and effectiveness of a novel hybrid UHPC-filled FRP tube (UHPCFFT) column system was investigated in the first phase. The cyclic behavior of 
the proposed UHPCFFT column was compared to that of its RC counterpart with respect to the strength, stiffness, ductility, energy dissipation, and residual deflection. Using the experimental results of the first phase, the UHPCFFT column specimens of the second phase were designed with different FRP tubes, steel reinforcement ratios, and column diameters. Accordingly, the effect of column parameters (cross section, type of FRP tube, and amount of longitudinal steel reinforcement) on the cyclic behavior of UHPCFFT columns was investigated in this phase. Finally, the seismic response of the proposed UHPCFFT column system was evaluated and compared with its RC counterpart through an analytical study using the results of pseudo-static tests. The results of this analytical study were also verified using seismic simulation of the columns under a major earthquake record.

\subsection{Organization of Dissertation}

This dissertation consists of seven chapters. Except for this first chapter of introduction and the last chapter (Chapter 7), which includes conclusions of the present study and recommendations for the future research, the other chapters (2-6) represent papers from this study published, in press, or in review. Chapter 2 presents an experimental study on the stress-strain behavior of a series of UHPC-filled FRP tubes. The ability of a number of existing confinement models to predict the behavior of FRPconfined UHPC is further evaluated in this chapter. Chapter 3 comprises of an analytical study on the experimental results achieved from the uniaxial compression testing of the UHPC-filled FRP tubes to develop a new stress-strain model for FRP-confined UHPC. Chapter 4 proposes a novel hybrid UHPC-filled FRP tube (UHPCFFT) column system as an alternative to conventional reinforced concrete (RC) columns, and reports on an 
experimental study on its cyclic behavior. Chapter 5 includes an experimental study on the effect of column parameters, i.e., cross section, type of FRP tube, and amount of longitudinal steel reinforcement, on the cyclic behavior of UHPCFFT columns. Chapter 6 proposes an analytical procedure to determine the seismic response of a column based on the experimental results achieved from its pseudo-static tests. Using the proposed analytical procedure, the seismic responses of the tested UHPCFFT columns are evaluated and compared to that of their RC counterpart in this chapter. 


\section{References}

ACI Committee 544 (1973). "State-of-the-Art Report on Fiber Reinforced Concrete." ACI Journal, 70(11), 729-744.

Parra-Montesinos, G.J. (2005). "High-performance fiber reinforced cement composites: a new alternative for seismic design of structures." ACI Structural Journal, 102 (5), 668-675.

Graybeal, B.A. (2006). "Material Property Characterization of Ultra-High Performance Concrete." Report No. FHWA-HRT-06-103, Federal Highway Administration, Washington, D.C.

Fukuyama, H., Sato, Y., Li, V.C., Matsuzaki, Y., and Mihashi, H. (2000). "Ductile Engineered Cementitious Composite Elements for Seismic Structural Applications." Proceedings of the 12th World Conference on Earthquake Engineering, Auckland, New Zeland, Paper 1672.

Parra-Montesinos, G., and Chompreda, P. (2007). "Deformation Capacity and Shear Strength of Fiber-Reinforced Cement Composite Flexural Members Subjected to Displacement Reversals." Journal of Structural Engineering, ASCE, 133(3), 421431.

Fischer, G., Fukuyama, H., and Li, V.C. (2002). "Effect of Matrix Ductility on the Performance of Reinforced ECC Column Members under Reversed Cyclic Loading Conditions." Proceedings of the JCI International Workshop on Ductile Fiber Reinforced Cementitious Composites (DFRCC) - Application and Evaluation (DRFCC-2002), Takayama, Japan, 269-278.

Billington, S.L., and Yoon, J. (2002). "Cyclic Behavior of Precast Post-Tensioned Segmental Concrete Columns with ECC." Proceedings of the JCI International Workshop on Ductile Fiber Reinforced Cementitious Composites (DFRCC) Application and Evaluation (DRFCC-2002), Takayama, Japan, 279-288.

Saiidi, M., O'Brien, M., and Mahmoud, S. (2009). "Cyclic Response of Concrete Bridge Columns using Superelastic Nitinol and Bendable Concrete." Structural Journal, ACI, 106(1), 69-77.

Japan Society of Civil Engineers (JSCE) (2008). "Recommendation for design and construction of high performance fiber reinforced cement composite." Japan Society of Civil Engineers, Japan.

Mirmiran, A., and Shahawy, M. (1995). "Novel FRP-Concrete Composite Construction for the Infrastructure." Proceedings of the Structures Congress, ASCE, Vol. 2, 1663-1666. 
Mirmiran, A., and Shahawy, M. (1997). "Behavior of concrete columns confined by fiber composites.” Journal of Structural Engineering, ASCE, 123(5), 583-590.

Shao, Y., and Mirmiran, A. (2005). "Experimental Investigation of Cyclic Behavior of Concrete-Filled Fiber Reinforced Polymer Tubes." Journal of Composites for Construction, ASCE, 9(3), 263-273.

Shao, Y., and Mirmiran, A. (2005). "Experimental investigation of cyclic behavior of concrete-filled fiber reinforced polymer tubes." Journal of Composites for Construction, ASCE, 9(3), 263-273.

Li, B. (2008). "Seismic performance of fiber reinforced polymer-concrete pier frame systems.” Ph.D. Dissertation, Florida International University, Miami, Fl.

Shi, Y., Li,B., and Mirmiran, A. (2011). "Combined Shear and Flexural Behavior of Hybrid FRP-Concrete Beams Previously Subjected To Cyclic Loading." Journal of Composites for Construction, ASCE, 15(5), 841-849.

Fam, A., and Rizkalla, S.H. (2002). "Flexural behavior of concrete-filled fiber-reinforced polymer circular tubes." Journal of Composites for Construction, ASCE, 6(2), 123-132.

Fam, A., Mandal, S., and Rizkalla, S. (2005). "Rectangular filament-wound glass fiber reinforced polymer tubes filled with concrete under flexural and axial loading: Analytical modeling." Journal of Composites for Construction, ASCE, 9(1), 3443.

Fam, A., Cole, B., and Mandal, S. (2007). "Composite tubes as an alternative to steel spirals for concrete members in bending and shear." Journal of Construction \& Building Materials, Elsevier, 21(2), 347-355.

Mirmiran, A., Samaan, M., Cabrera, S., and Shahawy, M. (1998). "Design, manufacture and testing of a new hybrid column." Journal of Construction \& Building Materials, Elsevier, 12(1), 39-49.

Mirmiran, A., Shahawy, M., El Khoury, C., and Naguib, W. (2000). "Large beam-column tests on concrete-filled composite tubes." Structural Journal, ACI, 97(2), 268276.

Mirmiran, A., Shahawy, M., and Beitleman, T. (2001). "Slenderness limit for hybrid FRP-concrete columns." Journal of Composites for Construction, ASCE, 5(1), 26-34. 
Mirmiran, A., Shao, Y., and Shahawy, M. (2002). "Analysis and field tests on the performance of composite tubes under pile driving impact." Journal of Composite Structures, Elsevier, 55(2), 127-135.

Seible, F., Burgueño, R., Abdallah, M.G., and Nuismer, R. (1996). "Development of Advanced Composite Carbon Shell Systems for Concrete Columns in Seismic Zones." Proceedings of the 11th World Conference on Earthquake Engineering, Pergamon-Elsevier Science, 1375, Oxford, U.K. 


\title{
2. BEHAVIOR OF ULTRA-HIGH PERFORMANCE CONCRETE CONFINED BY FIBER-REINFORCED POLYMERS
}

\author{
Pedram Zohrevand and Amir Mirmiran \\ Published in ASCE Journal of Materials in Civil Engineering
}

\begin{abstract}
Over a decade of studies have demonstrated the benefits of ultra-high performance concrete (UHPC) in terms of damage tolerance, energy absorption, crack distribution, and deformation capacity. However, there is little information available on the confinement behavior of UHPC, especially when confined with fiber-reinforced polymers (FRP). Sixteen UHPC-filled FRP tubes with different fiber type and tube thickness were tested under monotonic uniaxial compression. All specimens failed by rupture of the tube at or near the mid-height. Similar to conventional concrete, test results showed significant enhancements in the ultimate strength and strain of UHPC - up to $98 \%$ and $195 \%$, respectively, as compared to its unconfined counterpart. The experimental results were compared with a number of available confinement models. Although one of the models provided a reasonable fit for the stress-strain response in most cases, all models generally underestimated the effectiveness of FRP confinement at higher confinement ratios. The study demonstrated the need for confinement models that could accurately predict the behavior of FRP-confined UHPC in terms of stress-strain relationship and the respective ultimate strengths and strains.
\end{abstract}

Keywords: Concrete; Confinement; Fiber-reinforced polymers (FRP); Tubes; Ultra-high performance concrete (UHPC) 


\subsection{Introduction}

Ultra-high performance concrete (UHPC) offers an innovative alternative in concrete technology, in which the material microstructure is optimized to reach a significant enhancement in material properties, e.g., compressive and tensile strengths, ductility, toughness fracture energy, deformation capacity, and durability. Higher compressive strength (e.g., up to five times that of conventional concrete) and modulus of elasticity of UHPC can lead to significantly smaller cross section for structural members, as compared to conventional concrete (Graybeal 2005). Also, multiple cracking characteristics, bond strength, spalling resistance, and deformability make UHPC a promising material for structural applications in seismic regions.

Over a decade of studies has been devoted to establishing material properties of UHPC, including such fundamental aspects as its constitutive model. Kabele (2002) developed one such model representing the stress-strain behavior of UHPC based on micromechanics of an equivalent continuum with similar mechanical characteristics. Han et al. (2003) developed a comprehensive constitutive model based on cyclic response of UHPC materials. The model proved accurate in the analytical simulation of cantilever beams tested by Fischer and Li (2003).

Other studies have focused on structural applications of UHPC. For example, Fischer et al. (2002) tested reinforced UHPC columns under cyclic lateral loading, and showed significant enhancements in strength, energy dissipation, and damage tolerance. In another study, Billington and Yoon (2002) demonstrated that higher energy dissipation and damage tolerance may be achieved up to a drift ratio of 3-6\% in bridge piers with UHPC within their plastic hinge regions. A recent study by Saiidi et al. (2009) clearly 
showed that using UHPC within the plastic hinge region of a column may lead to much lower residual displacements than those seen in conventional reinforced concrete (RC) columns.

Despite a decade of studies on UHPC, little is known about its confinement behavior. It is well established that confinement of conventional concrete improves both its strength and ductility. Accordingly, several models have been developed to predict the stress-strain response of confined conventional concrete. As the application of fiberreinforced polymers (FRP) rapidly grew in the last two decades, the accuracy of steelbased confinement models (e.g., Mander et al. 1988) in representing the stress-strain behavior of FRP-confined conventional concrete was questioned (Mirmiran and Shahawy 1997). Subsequently, new models were proposed for confinement by FRP (Samaan at al. 1998, Toutanji 1999, and Lam and Teng 2003).

Unlike conventional concrete, confinement of high-strength concrete (HSC) does not lead to a significant improvement in its strength and ductility, primarily because of its low dilation tendency (Mandal et al. 2005). On the other hand, due to its unique properties, UHPC is expected to have a considerable dilation capacity, hence a better confinement behavior than HSC. Therefore, studying the behavior of confined UHPC seems imperative for design optimization. Moreover, such a study may help develop recommendations on the amount of confinement reinforcement needed for UHPC columns, especially in regions of high seismicity.

This paper reports on an experimental study on the behavior of FRP-confined UHPC. Test results are compared with four existing confinement models that were developed for conventional concrete. The significance of this study is that it provides, for 
the first time, experimental evidence on the effectiveness of confinement with FRP for UHPC, and that it demonstrates the need for confinement models that could accurately predict the behavior of FRP-confined UHPC. Although the experiments were limited to UHPC, the findings of the present study together with the state of the art from the literature point to the unique confinement behavior of UHPC in contrast to conventional concrete and HSC.

\subsection{Experimental Program}

\subsubsection{Test Specimens and Materials}

Test matrix for this experimental study (Table 2.1) consisted of 19 cylindrical specimens; 16 of which were UHPC-filled FRP tubes with $191 \mathrm{~mm}$ height and $108 \mathrm{~mm}$ core diameter; and the other three were unconfined UHPC with the height and diameter of $203 \mathrm{~mm}$ and $102 \mathrm{~mm}$, respectively. Two different types of fibers were considered; glass and carbon, both of which were unidirectional and wrapped only in the hoop direction. Four tube thicknesses of glass (GFRP) and two tube thicknesses of carbon (CFRP) were used. Identical specimens were made for each thickness of GFRP and CFRP tubes to ensure repeatability of test results.

The unidirectional carbon and glass fiber sheets were SikaWrap Hex 103C and Hex 100G, respectively, both made by Sika Corp. of Lyndhurst, NJ. Sikadur 300, a twopart epoxy made by the same manufacturer was used as the resin for all tubes. The thickness of each ply of GFRP and CFRP laminates was $1.02 \mathrm{~mm}$. Table 2.2 presents the mechanical properties of the FRP tubes and each of their individual components, as reported by the manufacturer. 
The UHPC used in this study was an available commercial product, Ductal ${ }^{\circledR}$, which is composed of premix powder, water, superplasticizer, and metallic fibers $(2 \%$ in volume). The premix powder included cement, silica fume, ground quartz, and sand. The steel fibers had a length of $13 \mathrm{~mm}$ and a tensile strength of 2,800 MPa. All specimens were cast using a single batch of UHPC with a 28-day compressive strength measured as $189 \mathrm{MPa}$.

\subsubsection{Specimen Fabrication}

FRP tubes were made in the laboratory by wrapping resin-impregnated fabrics around cardboard sonotubes with the outside diameter of $108 \mathrm{~mm}$ and the length of 203 $\mathrm{mm}$. The sonotubes were first cut longitudinally, and then taped back tightly to make a stiff formwork for FRP wrapping, while allowing easy removal of the tube after the FRP cured. The sonotubes were then covered with a layer of wax paper, so that the cured FRP tubes can be easily detached. The fabric sheets were cut to appropriate lengths for each layer of wraps, with a minimum of $102 \mathrm{~mm}$ of overlap. The two components of epoxy were mixed for 5 minutes. Using a brush and a roller, the fabric was fully saturated with the epoxy. The saturated fabric was then wrapped around the sonotube. Additional epoxy was applied as an overcoat to ensure full wetting of the fabric. Excess epoxy and potential voids were rolled out on the surface.

After seven days, the cardboard tubes were removed, and the bottoms of all FRP tubes were plugged using plastic caps so that they could act as molds. The UHPC was cast into the FRP tubes, as shown in Figure 2.1. All specimens were covered with plastic sheets and air cured in the laboratory. After 28 days, the top and bottom surfaces of each specimen were grinded smooth for the compression tests. 


\subsubsection{Instrumentation and Test Setup}

To measure the longitudinal strains, two 30-mm long strain gages (PFL-30-11 of Tokyo Sokki Kenkyujo Co., Ltd.) were attached vertically at the mid-height of each specimen, $180^{\circ}$ degree apart. A linear variable differential transducer (LVDT) was also used in the axial direction. Moreover, one 60-mm long strain gage (PL-60-11 of Tokyo Sokki Kenkyujo Co., Ltd.) was attached at the mid height of each specimen in the hoop direction to monitor lateral strains. The longer strain gage was placed in the hoop direction to help capture an average of the non-uniform hoop displacement of FRP tube in a more reliable manner.

All cylinders were tested under uniaxial compression using a 3,500 kN universal testing machine (Figure 2.2) at the Materials Office of the Florida Department of Transportation in Gainesville, FL. Specimens were loaded at a constant rate of 120 $\mathrm{kN} / \mathrm{min}$. Axial load and displacement as well as strains were all monitored at a frequency of $1 \mathrm{~Hz}$.

\subsubsection{Test Observations}

Failure of unconfined UHPC specimens was marked by gradual widening of multiple distributed cracks, without any spalling or crushing, as expected (Figure 2.3a). On the other hand, all FRP-confined UHPC specimens failed by sudden rupture of FRP tube at or near mid-height. Rupture of the inner layers of the GFRP tubes could be heard sequentially, while approaching the failure. Conversely, it seemed as though all layers of CFRP tubes ruptured simultaneously at about mid-height, followed by unzipping of the entire length of the tubes towards both ends. Figures $2.3 \mathrm{~b}$ and $2.3 \mathrm{c}$ show the typical failure of specimens with glass and carbon FRP tubes, respectively. 
One of the G5 specimens with five layers of GFRP showed a different behavior than its two identical counterparts. This was attributed to the nonuniformity of the FRP tube thickness caused by the slippage of layers of the FRP fabric on each other during the fabrication of that specimen. As a result, the data from that specimen was excluded from any further analysis.

\subsubsection{Stress-Strain Response}

The summary of test results including ultimate strengths and strains are presented in Table 2.3, where $f_{r}$ is the ultimate confinement pressure, as given by:

$$
f_{r}=\frac{2 f_{j} t_{j}}{D}
$$

where $f_{j}$ is the hoop strength of FRP tube, $t_{j}$ is the tube thickness, and $D$ is the core diameter. The table also presents the confinement ratio $(C R)$, which is defined as the ratio of confinement pressure to the unconfined strength $\left(f^{\prime}{ }_{c}\right)$ of UHPC core; and the confinement effectiveness, as measured by the ratio of the confined strength $\left(f^{\prime}{ }_{c u}\right)$ of UHPC to its unconfined value. The longitudinal strains were measured by calculating the average of the readings obtained from the two vertical strain gages. The results were verified by the strains calculated based on the displacement data from the LVDT. The ultimate strength and strain were measured at the peak point of the response curve for each specimen. The data shown in the table represents the average of identical specimens with similar FRP tubes. The relative standard deviations are presented for the ultimate strengths and strains as a measure of variability of the data in each group of identical specimens with the same level of confinement. 
As expected, FRP tubes ruptured before reaching the manufacturer reported tensile strengths. This is typically attributed to the tube curvature, non-uniform expansion of the core, and the overlapping areas of the fabric (Teng and Lam 2004). Hence, the actual hoop rupture strengths were used in subsequent analysis instead of the manufacturer data. The average stress-strain curves for the unconfined and FRP-confined UHPC specimens are shown in Figures 2.4 and 2.5, respectively. In contrast with conventional concrete, the stress-strain response of unconfined UHPC is almost linear up to its peak strength, after which the strength sharply drops.

FRP-confined UHPC specimens in Figure 2.5 show a bilinear stress-strain response with three distinct regions. The first region is quite similar to that of an unconfined UHPC, implying that FRP is not yet activated, which in turn is a result of insignificant dilation of UHPC at the early stages of loading. Through an increase in the micro-cracks along with dilation of the UHPC core, a transition zone emerges whereby FRP is activated. The third and last region corresponds to full activation of FRP, effectively resisting the progressive dilation of UHPC. Accordingly, the behavior of specimen in this region is highly dependent on the properties of FRP.

Figure 2.5 also shows that except for Specimens G2 that had a low confinement ratio, FRP confinement enhanced the average ultimate strengths by $20 \%, 45 \%, 59 \%$, 35\%, and 98\% in Specimens G3, G4, G5, C2, and C4, respectively, as compared to unconfined UHPC (Specimens P). Likewise, ultimate strains were increased by 121\%, $172 \%, 195 \%, 74 \%$, and $169 \%$ for Specimens G3, G4, G5, C2, and C4, respectively, as compared to Specimens P. In contrast with the findings of Mandal et al. (2005) on HSC, the UHPC specimens of the present study showed a significant increase in both strength 
and ductility. This may be attributed to the superior dilation capacity of UHPC, and may be considered as a great advantage of UHPC over HSC.

Figure 2.6 shows the average ultimate strains of each group of FRP-confined UHPC specimens relative to their confinement ratios. GFRP-confined specimens are shown as a solid line, whereas CFRP-confined specimens are illustrated as a dashed line. Comparing Specimens G3 and C2 with almost the same confinement ratios, Specimens G3 achieved a higher strain capacity than that of Specimens C2. Similarly, even with a much lower confinement ratio, Specimens G5 achieved a higher ultimate strain, as compared to Specimens C4. The higher strain capacity of GFRP-confined specimens may be attributed to the lower stiffness of GFRP, which appears to match the dilation capacity of UHPC better, as it leads to a higher deformability.

\subsection{Analytical Modeling}

\subsubsection{Stress-Strain Relationship}

Figure 2.7 compares the stress-strain responses of Specimens G3, G4, G5, C2, and C4 with four existing constitutive models developed by Mander et al. (1988), Samaan et al. (1998), Toutanji (1999), and Lam and Teng (2003). Test results for identical specimens in each group are also shown to represent the data range. Except for the Mander's model which was developed based on steel confinement for conventional concrete, the other three models are based on FRP confinement for conventional concrete. For each specimen group, the predicted stress-strain curves resulted from the confinement models are presented only within the range of the respective test results. The accuracy of the models in predicting the ultimate strength and strain will be assessed in 
the next section. Since the effect of FRP confinement was found negligible in Specimens G2, that group was excluded from the analysis.

The figure shows that most models do not accurately predict the stress-strain response of FRP-confined UHPC. The same models generally perform better in predicting the response of FRP-confined conventional concrete (Matthys et al. 2006, and Teng and Lam 2004). This may be attributed to the difference in the stress-strain response of UHPC and conventional concrete.

In general, the confinement models of Mander and Lam-Teng relatively fit the experimental results better than those of Toutanji and Samaan. The model of Toutanji consistently overestimated test results, while the model of Samaan underestimated them. Within the confinement range studied here, an increase in confinement pressure appears to enhance the stress-strain response of UHPC at a higher rate than that expected in conventional concrete, based on which these confinement models were developed.

In order to quantitatively estimate the accuracy of each model for predicting the stress-strain curves, the goodness of the fit or the coefficient of determination $\left(R^{2}\right)$ was calculated for each specimen. The average values of $R^{2}$ for each group of specimens with the same FRP onfinement are presented in Table 2.4. The $R^{2}$ generally varies between 0 and 1, where the latter represents the best fit. Table 2.4 quantitatively compares the ability of each model to predict the stress-strain behavior of the tested specimens. Generally, the model of Lam-Teng represented the best fit, followed by the models of Mander, Toutanji, and Samaan. The only exception was for Specimens C4 with the highest confinement ratio, where the model of Mander provided the best fit. This may be 
attributed to the different trends in the confinement of UHPC and conventional concrete. Further explanation on this issue is provided in the next section.

\subsubsection{Ultimate Strength and Strain}

Figure 2.8 compares the performance of each confinement model in predicting the ultimate strengths of each group of specimens. Average experimental results were used for each group of specimens with the same FRP confinement. All models exhibit a descending trend which clearly shows that by increasing the confinement ratio, the ultimate strength increases at a higher rate than that predicted by all models. This is similar to the pattern observed earlier in the stress-strain relationships. The model of Lam-Teng showed the lowest average error of $6 \%$, while the model of Mander had the highest average error of $20 \%$.

Figure 2.9 compares the performance of each confinement model in predicting the ultimate strains of each group of specimens. Again, the average test results were used for each group of specimens with the same FRP confinement. In contrast to the predicted ultimate strengths, no clear trend was observed for the predicted ultimate strains. Model of Samaan showed the highest average error, while the other three models performed about the same with an average error of $20 \%$. None of the models provided a reasonable prediction for the ultimate strains, implying the need to develop models that could more accurately predict the response of FRP-confined UHPC.

\subsubsection{Confinement Effectiveness}

Figure 2.10 shows a plot of confinement effectiveness versus confinement ratio for all specimens. The confinement models are also shown in the figure for comparison. The figure shows that higher confinement ratio leads to the higher confinement 
effectiveness at an increasing rate. On the other hand, most confinement models predict lower increases for the confinement effectiveness with respect to the confinement ratio. This is clear from the constant slope of the model of Samaan and the descending slopes of models of Mander, Toutanji, and Lam-Teng. This major difference between test results and the model predictions shows that within the confinement range studied, contrary to conventional concrete, FRP confinement is more effective for UHPC at higher confinement ratios. As such, none of the existing models seems to accurately predict the confinement effectiveness of FRP-confined UHPC.

\subsection{Conclusions}

Effects of FRP confinement on UHPC was investigated by testing sixteen FRPconfined and three unconfined UHPC cylinders under uniaxial compression. The experimental results were compared with four existing confinement models. The following conclusions may be drawn based on test results and the analytical modeling:

1. All confined UHPC specimens failed by the rupture of FRP tube at or near the mid-height. Whereas layers of GFRP tubes seemed to unzip sequentially from inside out, all layers of CFRP tubes appear to rupture at once.

2. Similar to the FRP-confined conventional concrete, but in contrast with the findings of Mandal et al. (2005) on HSC, the UHPC specimens of the present study showed a significant increase in both strength and ductility. This may be attributed to the superior dilation capacity of UHPC over HSC, and may be considered as a great advantage.

3. Among the four confinement models studied, the model of Lam-Teng provided the best fit for the stress-strain response of most specimens. It also predicted the 
ultimate strengths with the lowest average error. However, all models tend to underestimate the ultimate strengths at higher confinement ratios. Furthermore, none of the models could yield reasonable predictions of ultimate strains for FRP-confined UHPC specimens.

4. Within the confinement range studied here, an increase in confinement pressure enhances the confinement effectiveness in UHPC at a higher rate than that expected in conventional concrete, based on which these confinement models were developed.

It is therefore recommended that further research in this field should focus on developing a reliable confinement model for UHPC within the practical confinement ratios.

\section{Acknowledgement}

This study was sponsored by the NSF-Network for Earthquake Engineering Simulation Research (NEESR) program, as part of the multi-university Grant No. CMS0420347. The writers are grateful to the Materials Office of the Florida Department of Transportation for testing the specimens; Lafarge, Inc. for providing the Ductal ${ }^{\circledR}$ (UHPC) materials; and Sika Corp. for providing the FRP materials. Findings and opinions expressed here, however, are those of the authors alone, and not necessarily the views of sponsoring agencies. 


\section{References}

Billington, S.L., and Yoon, J. (2002). "Cyclic Behavior of Precast Post-Tensioned Segmental Concrete Columns with ECC." Proceedings of the JCI International Workshop on Ductile Fiber Reinforced Cementitious Composites (DFRCC) Application and Evaluation (DRFCC-2002), Takayama, Japan, 279-288.

Fischer, G., Fukuyama, H., and Li, V.C. (2002). "Effect of Matrix Ductility on the Performance of Reinforced ECC Column Members under Reversed Cyclic Loading Conditions." Proceedings of the JCI International Workshop on Ductile Fiber Reinforced Cementitious Composites (DFRCC) - Application and Evaluation (DRFCC-2002), Takayama, Japan, 269-278.

Fischer, G., and Li, V.C. (2003). "Deformation Behavior of Fiber-Reinforced Polymer Reinforced Engineered Cementitious Composite (ECC) Flexural Members under Reversed Cyclic Loading Conditions." Structural Journal, ACI, 100(1), 25-35.

Graybeal, B. (2005). "Characterization of the Behavior of Ultra-High Performance Concrete." PhD Dissertation, University of Maryland, College Park, MD.

Han, T., Feenstra, P.H., and Billington, S.L. (2003). "Simulation of Highly Ductile FiberReinforced Cement-Based Composite Components under Cyclic Loading." Structural Journal, ACI, 100(6), 749-757.

Kabele, P. (2002). "New Developments in Analytical Modeling of ECCs' Structural Behavior." Proceedings of the JCI International Workshop on Ductile Fiber Reinforced Cementitious Composites (DFRCC) - Application and Evaluation (DRFCC-2002), Takayama, Japan, 239-248.

Lam L., and Teng J.G. (2003). "Design-Oriented Stress-Strain Model for FRP-Confined Concrete." Construction \& Building Materials, 17(6-7), 471-89.

Mandal, S., Hoskin, A., and Fam, A. (2005). "Influence of Concrete Strength on Confinement Effectiveness of Fiber-Reinforced Polymer Circular Jackets." Structural Journal, ACI, 102(3), 383-392.

Mander, J.B., Priestley, M. J.N., and Park, R. (1988). "Theoretical Stress-Strain Model for Confined Concrete.” Journal of Structural Engineering, ASCE, 114(8), 18041826.

Matthys, S., Toutanji, H., and Taerwe, L. (2006). "Stress-Strain Behavior of Large-Scale Circular Columns Confined with FRP Composites." Journal of Structural Engineering, ASCE, 132(1), 123-33. 
Mirmiran, A., and Shahawy, M. (1997). "Dilation Characteristics of Confined Concrete." Mechanics of Cohesive-Frictional Materials, 2(3), 237-249.

Saiidi, M., O'Brien, M., and Mahmoud, S. (2009). "Cyclic Response of Concrete Bridge Columns using Superelastic Nitinol and Bendable Concrete." Structural Journal, ACI, 106(1), 69-77.

Samaan, M., Mirmiran, A., and Shahawy, M. (1998). "Model of Concrete Confined by Fiber Composites.” Journal of Structural Engineering, ASCE, 124(9), 1025-1031.

Teng, J.G., and Lam, L. (2004). "Behavior and Modeling of Fiber Reinforced PolymerConfined Concrete." Journal of Structural Engineering, ASCE, 130(11), 1713-23.

Toutanji, H.A. (1999). "Stress-Strain Characteristics of Concrete Columns Externally Confined with Advanced Fiber Composite Sheets." Materials Journal, ACI, 96(3), 397-404. 
Table 2.1 Test Matrix

\begin{tabular}{ccccccc}
\hline \hline $\begin{array}{c}\text { Specimen } \\
\text { Group }\end{array}$ & $\begin{array}{c}\text { Number of } \\
\text { Identical } \\
\text { Specimens }\end{array}$ & $\begin{array}{c}\text { Type of } \\
\text { FRP }\end{array}$ & $\begin{array}{c}\text { Core } \\
\text { Diameter } \\
(\mathrm{mm})\end{array}$ & $\begin{array}{c}\text { Height } \\
(\mathrm{mm})\end{array}$ & $\begin{array}{c}\text { Number } \\
\text { of FRP } \\
\text { Layers }\end{array}$ & $\begin{array}{c}\text { Tube } \\
\text { Thickness } \\
(\mathrm{mm})\end{array}$ \\
\hline $\mathrm{P}$ & 3 & None & 102 & 203 & $\mathrm{~N} / \mathrm{A}$ & N/A \\
\hline $\mathrm{G} 2$ & 3 & & & & 2 & 2.04 \\
$\mathrm{G} 3$ & 3 & Hex & 108 & 191 & 3 & 3.06 \\
$\mathrm{G} 4$ & 3 & $100 \mathrm{G}^{*}$ & & & 4 & 4.08 \\
$\mathrm{G} 5$ & 3 & & & & 5 & 5.10 \\
\hline $\mathrm{C} 2$ & 2 & Hex & 108 & 191 & 2 & 2.04 \\
$\mathrm{C} 4$ & 2 & $103 \mathrm{C}^{*}$ & & & 4 & 4.08 \\
\hline \hline
\end{tabular}

$\widetilde{\text { Unidirectional fabric wrapped in the hoop direction }}$

Table 2.2 Mechanical Properties of FRP Tubes ${ }^{*}$

\begin{tabular}{cccccc}
\hline \hline Type & $\begin{array}{c}\text { Glass } \\
\text { Fibers } \\
(\text { Hex 100G) }\end{array}$ & $\begin{array}{c}\text { Carbon } \\
\text { Fibers } \\
(\text { Hex 103C) }\end{array}$ & $\begin{array}{c}\text { Epoxy } \\
\text { Resin } \\
(\text { Hex 300) }\end{array}$ & $\begin{array}{c}\text { GFRP } \\
\text { Laminate } \\
\text { with Epoxy }\end{array}$ & $\begin{array}{c}\text { CFRP } \\
\text { Laminate } \\
\text { with Epoxy }\end{array}$ \\
\hline $\begin{array}{c}\text { Tensile Strength } \\
(\mathrm{MPa})\end{array}$ & 2,275 & 3,790 & 72.4 & 610 & 850 \\
\hline $\begin{array}{c}\text { Tensile Modulus } \\
(\mathrm{GPa})\end{array}$ & 72.4 & 334 & 3.17 & 26.1 & 70.6 \\
\hline \hline
\end{tabular}

* As reported by the manufacturer 
Table 2.3 Summary of Test Results*

\begin{tabular}{ccccccccccc}
\hline \hline $\begin{array}{c}\text { Specimen } \\
\text { Group }\end{array}$ & $\begin{array}{c}f_{r}^{* *} \\
(\mathrm{MPa})\end{array}$ & $\begin{array}{c}\text { Confinement } \\
\text { Ratio } \\
\left(f_{r} / f_{c}^{\prime}\right)\end{array}$ & $\begin{array}{c}\text { Ultimate } \\
\text { Load } \\
(\mathrm{kN})\end{array}$ & $\begin{array}{c}\text { Ultimate } \\
\text { Strength } \\
(\mathrm{MPa})\end{array}$ & $\begin{array}{c}\text { Relative } \\
\text { Standard } \\
\text { Deviation } \\
(\%)\end{array}$ & $\begin{array}{c}\text { Ultimate } \\
\text { Axial } \\
\text { Strain }\end{array}$ & $\begin{array}{c}\text { Relative } \\
\text { Standard } \\
\text { Deviation } \\
(\%)\end{array}$ & $\begin{array}{c}\text { Ultimate } \\
\text { Hoop } \\
\text { Strain }\end{array}$ & $\begin{array}{c}\text { Relative } \\
\text { Standard } \\
\text { Deviation } \\
(\%)\end{array}$ & $\begin{array}{c}\text { Confinement } \\
\text { Effectiveness } \\
\left(f^{\prime} / f_{c}^{\prime}\right)\end{array}$ \\
\hline P & N/A & N/A & 1,526 & 188.2 & 3.0 & 0.0039 & 6.8 & 0.0009 & 9.3 & N/A \\
\hline G2 & 12.9 & 0.07 & 1,725 & 188.4 & 2.3 & 0.0040 & 3.4 & 0.0010 & 12.2 & 1.00 \\
\hline G3 & 19.4 & 0.10 & 2,073 & 226.6 & 1.2 & 0.0086 & 11.9 & 0.0120 & 13.5 & 1.20 \\
\hline G4 & 25.9 & 0.14 & 2,502 & 273.5 & 2.5 & 0.0106 & 14.9 & 0.0135 & 10.1 & 1.45 \\
\hline G5 & 32.3 & 0.17 & 2,736 & 298.9 & 0.7 & 0.0115 & 5.7 & 0.0140 & 6.2 & 1.58 \\
\hline C2 & 20.4 & 0.11 & 2,386 & 254.1 & 4.0 & 0.0068 & 24.1 & 0.0069 & 9.0 & 1.35 \\
\hline C4 & 40.8 & 0.22 & 3,407 & 372.2 & 1.8 & 0.0105 & 6.3 & 0.0080 & 8.3 & 1.97 \\
\hline *
\end{tabular}

${ }^{*}$ Average for identical specimens in each group

${ }^{* *}$ Confinement pressure

Table 2.4 Goodness of Fit for the Confinement Models

\begin{tabular}{ccccc}
\hline \hline \multirow{2}{*}{$\begin{array}{c}\text { Specimen } \\
\text { Group }\end{array}$} & $\begin{array}{c}\text { Mander } \\
\text { Model }\end{array}$ & $\begin{array}{c}\text { Samaan } \\
\text { Model }\end{array}$ & $\begin{array}{c}\text { Toutanji } \\
\text { Model }\end{array}$ & $\begin{array}{c}\text { Lam-Teng } \\
\text { Model }\end{array}$ \\
\cline { 2 - 5 } G3 & 0.70 & 0.65 & 0.66 & 0.85 \\
\hline G4 & 0.81 & 0.48 & 0.80 & 0.88 \\
\hline G5 & 0.80 & 0.54 & 0.65 & 0.87 \\
\hline C2 & 0.68 & 0.60 & 0.69 & 0.92 \\
\hline C4 & 0.94 & 0.45 & 0.88 & 0.72 \\
\hline \hline
\end{tabular}




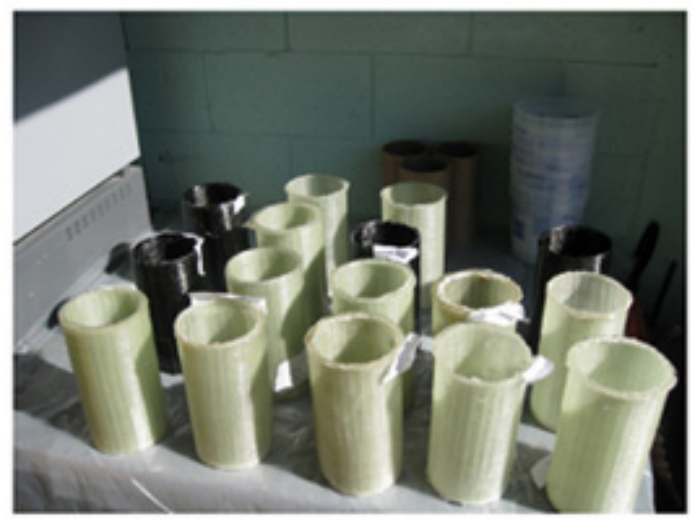

(a)

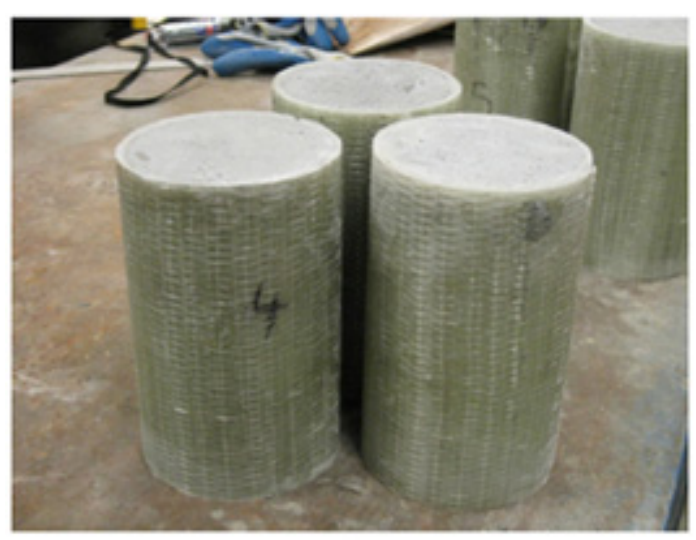

(b)

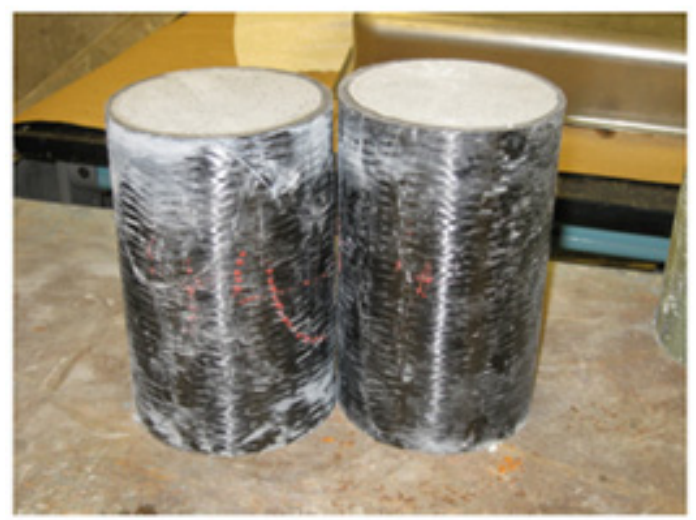

(c)

Figure 2.4 Preparation of FRP-Confined UHPC: (a) FRP Tubes; (b) UHPC-Filled GFRP Tubes; and (c) UHPC-Filled CFRP Tubes 


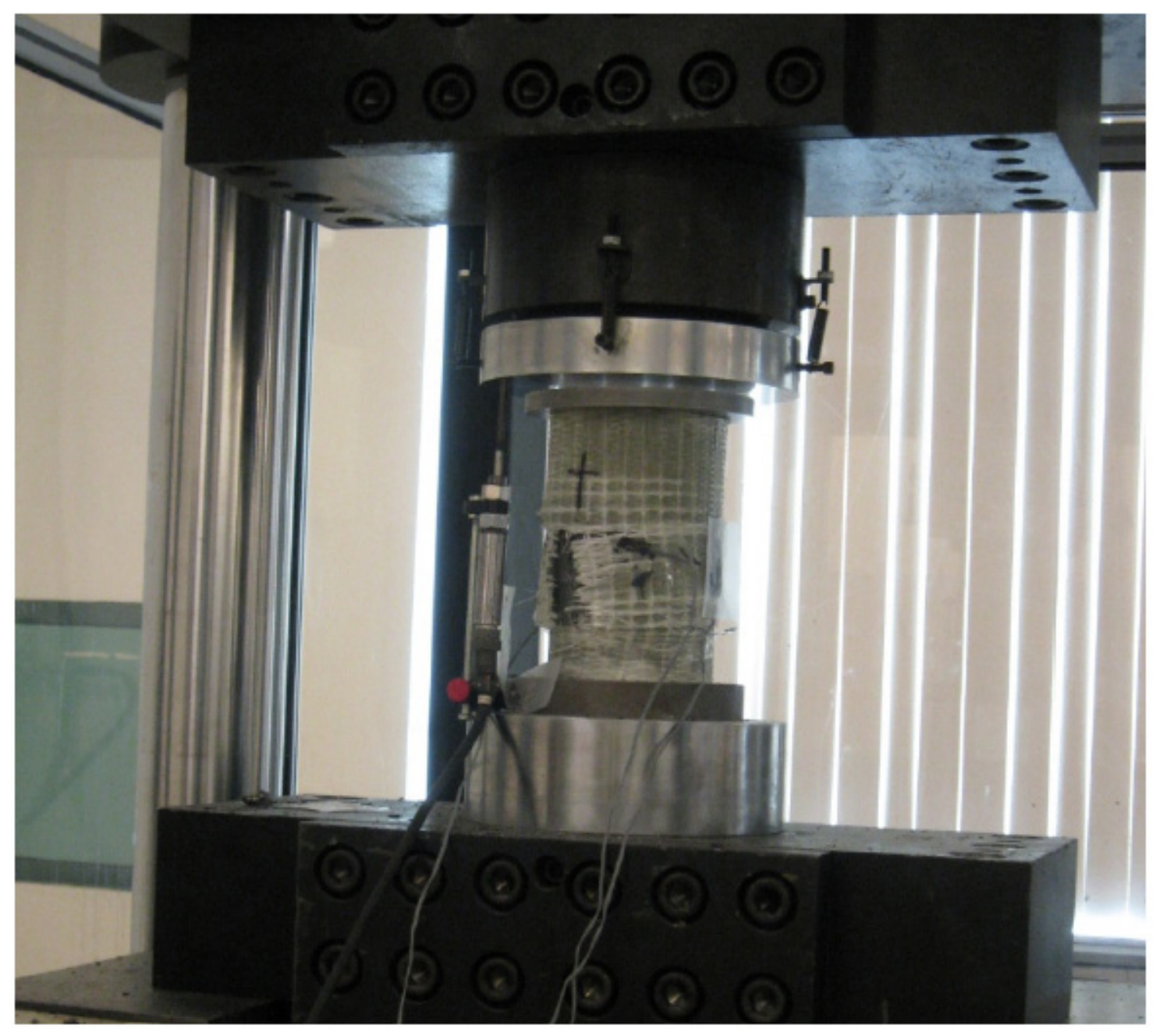

Figure 2.2 Test Setup 


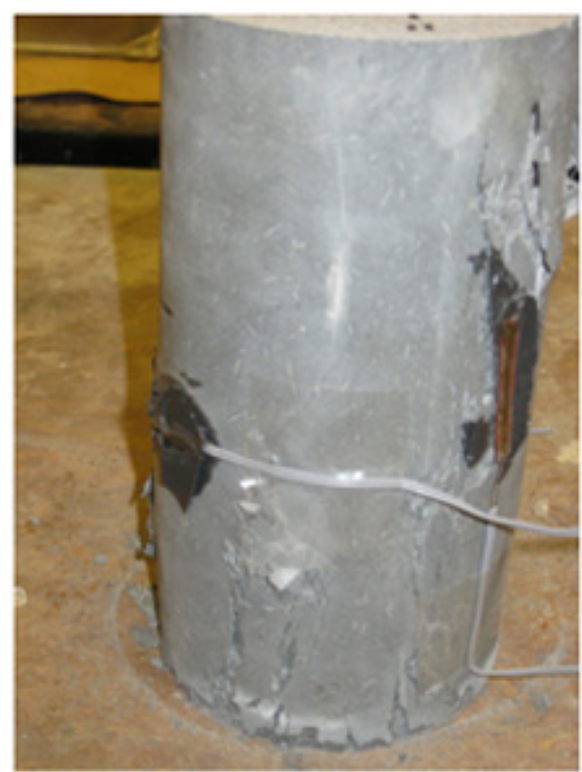

(a)

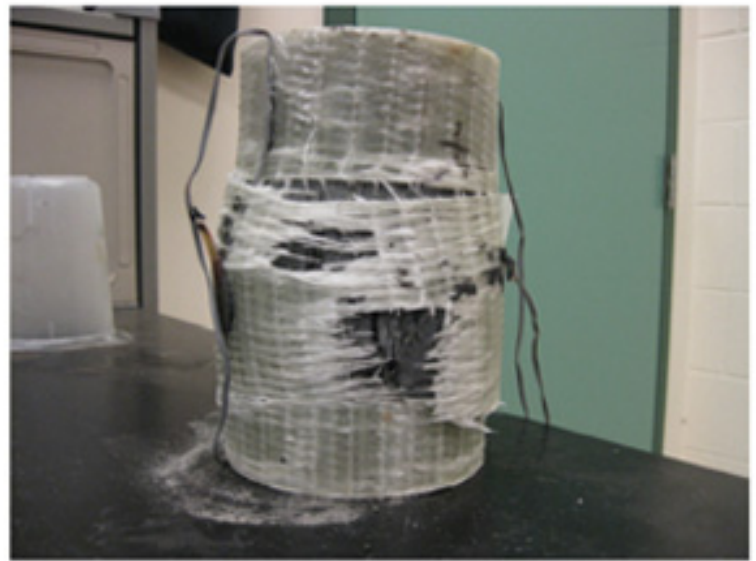

(b)

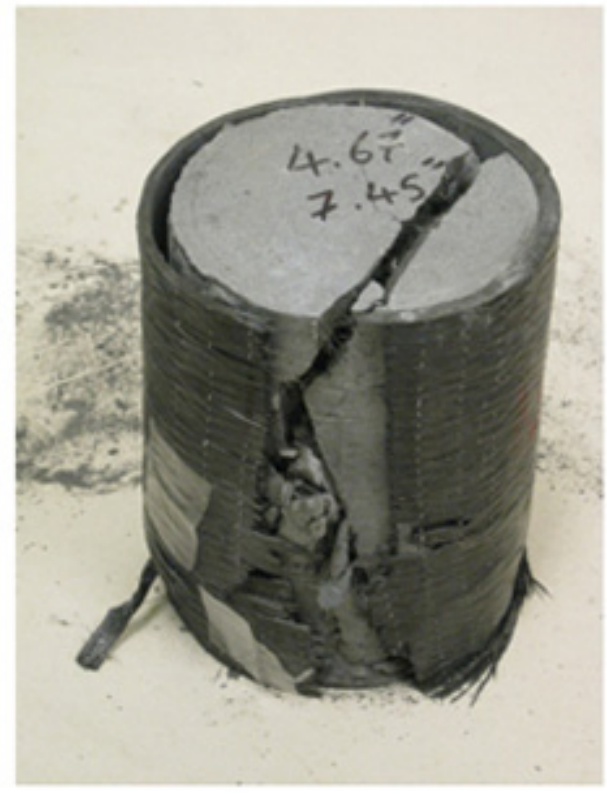

(c)

Figure 2.3 Typical Failure of (a) Unconfined UHPC; (b) UHPC-Filled GFRP Tube; and (c) UHPC-Filled CFRP Tube 


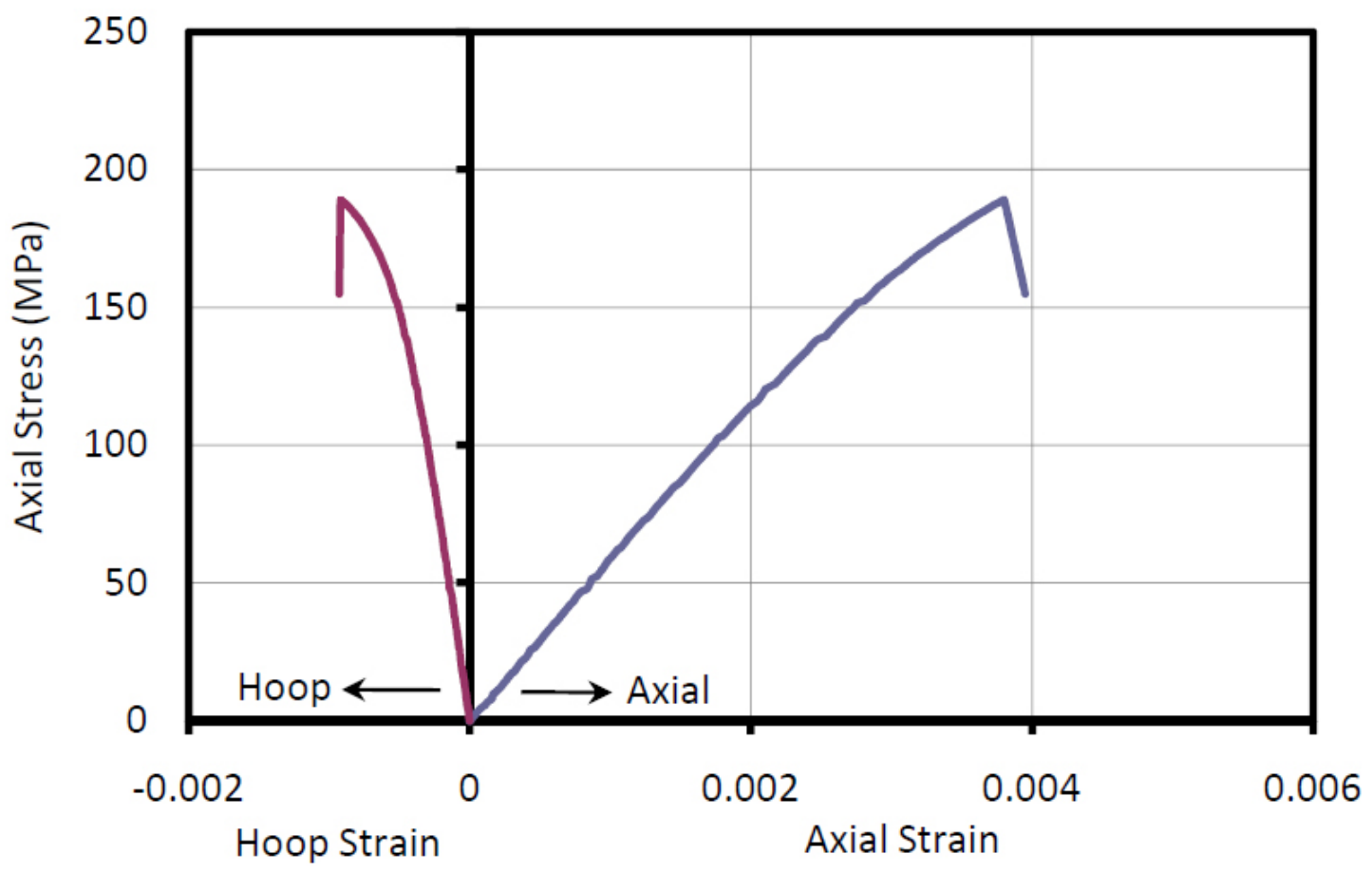

Figure 2.4 Average Stress-Strain Response Curves for Unconfined UHPC (Group P Specimens) 


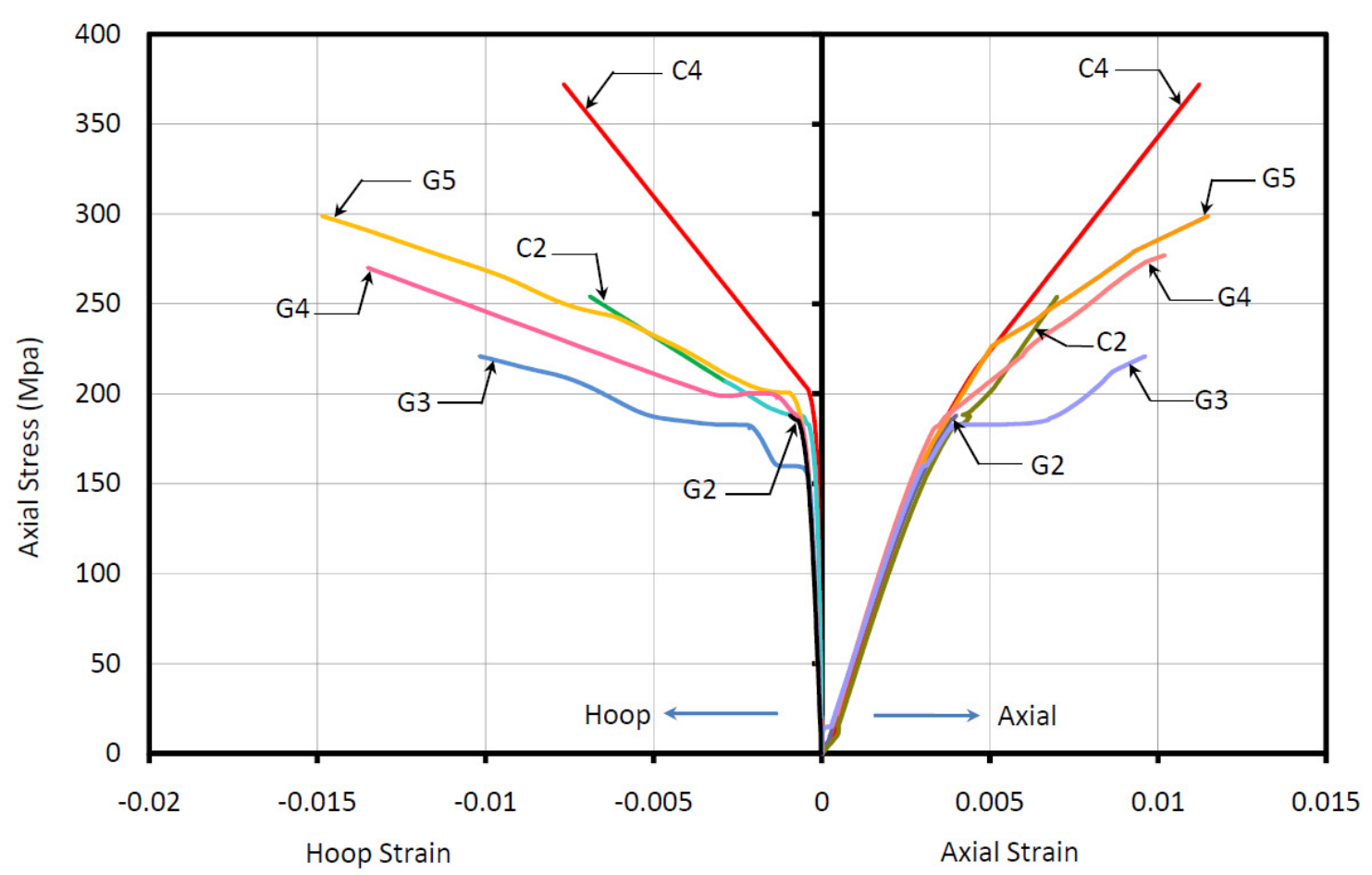

Figure 2.5 Average Stress-Strain Response Curves for Each Group of Specimens 


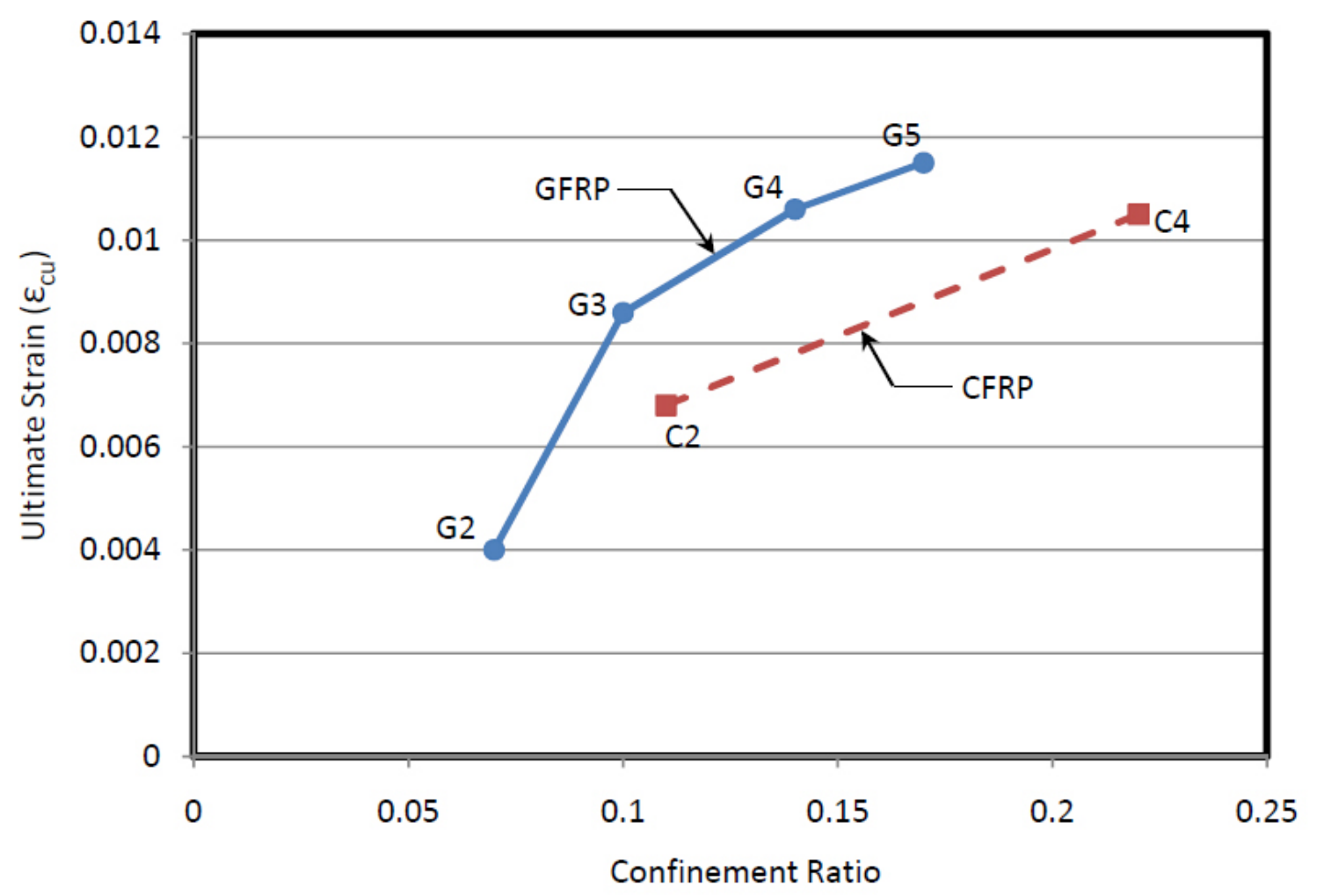

Figure 2.6 Average Ultimate Strains versus Confinement Ratios for Each Group of Specimens 


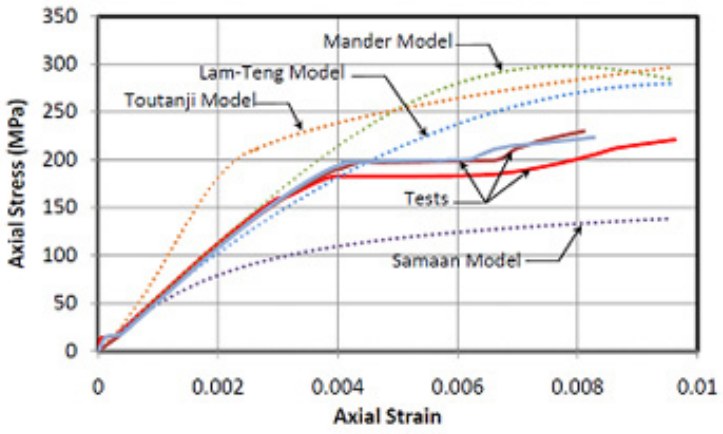

(a)

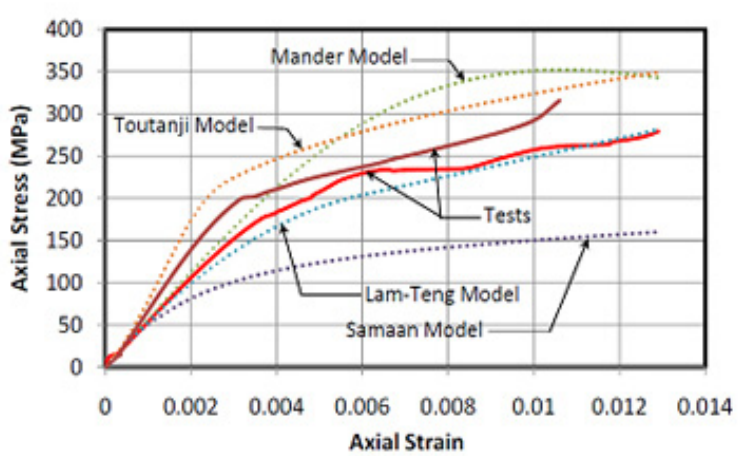

(c)

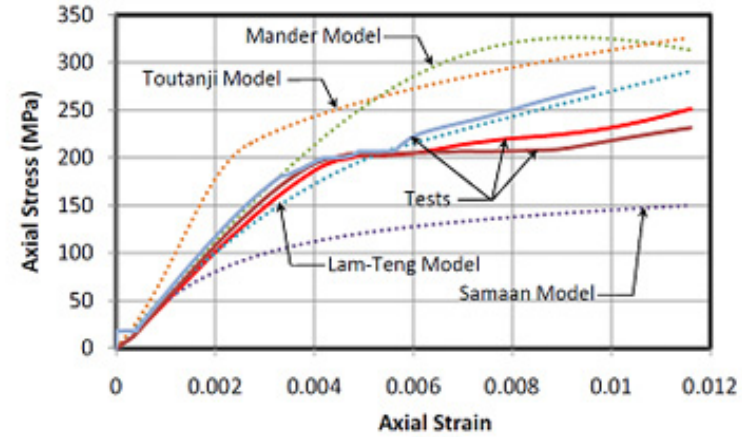

(b)

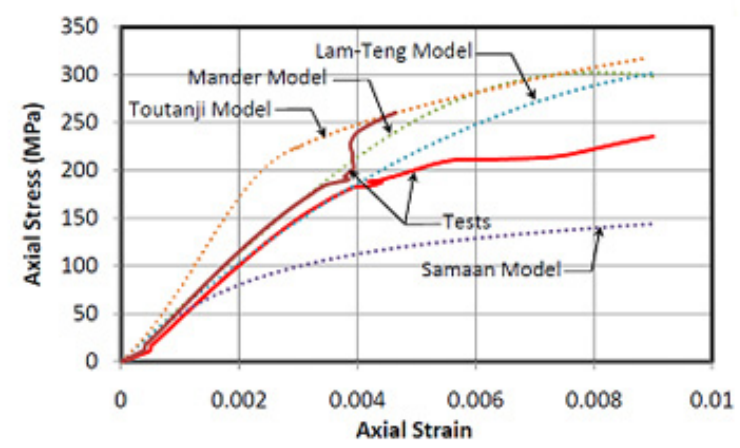

(d)

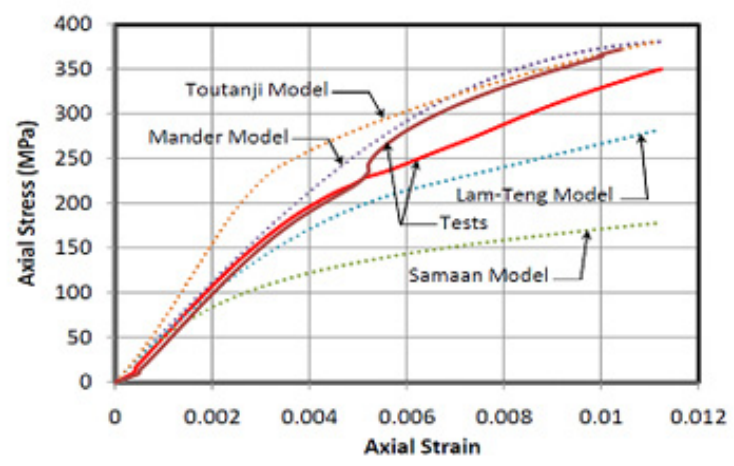

(e)

Figure 2.7 Comparison of Stress-Strain Predictions for Specimens: (a) G3; (b) G4; (c) G5; (d) C2; and (e) C4 


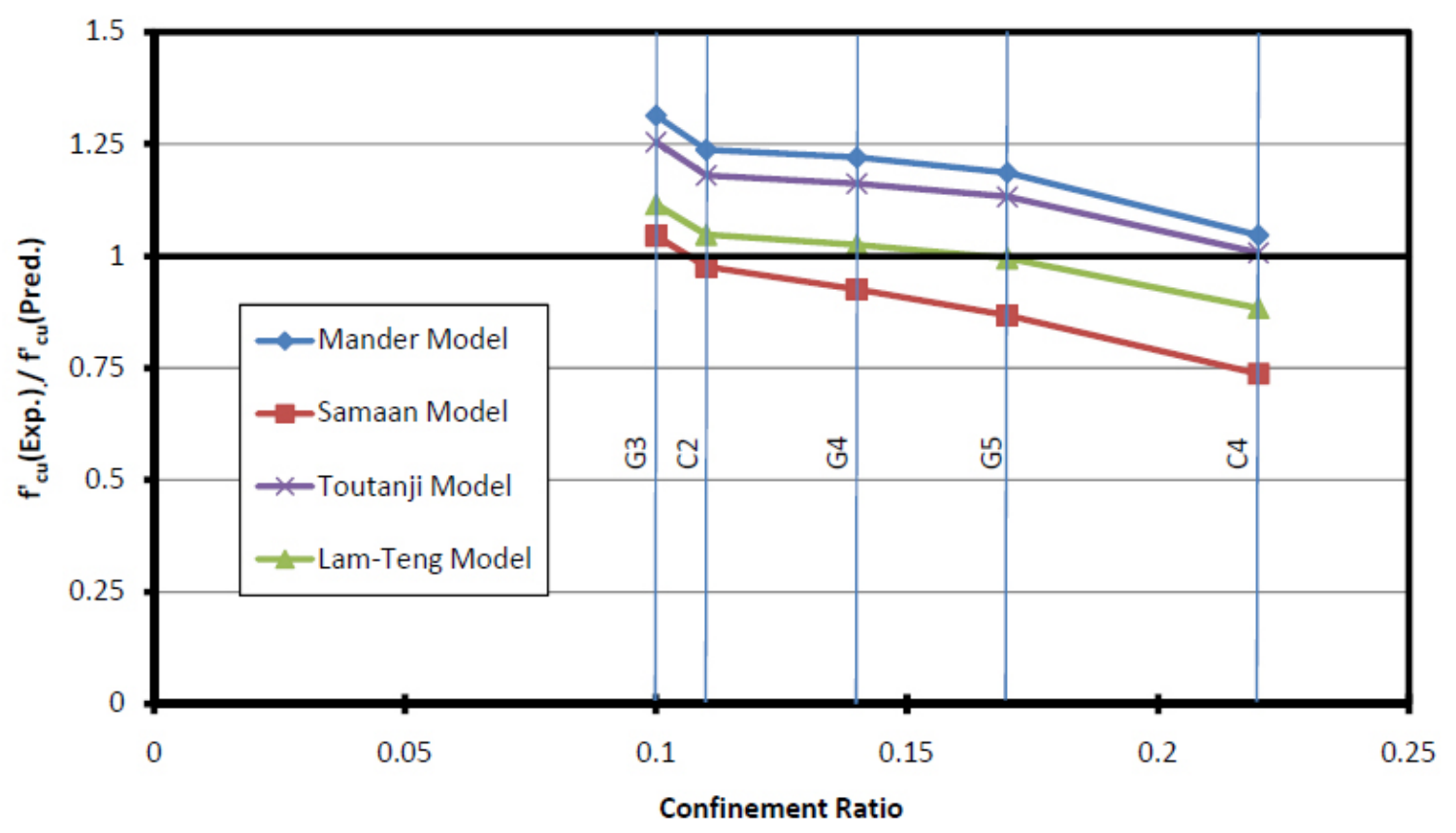

Figure 2.8 Comparison of Confinement Models for Predicting Ultimate Strengths

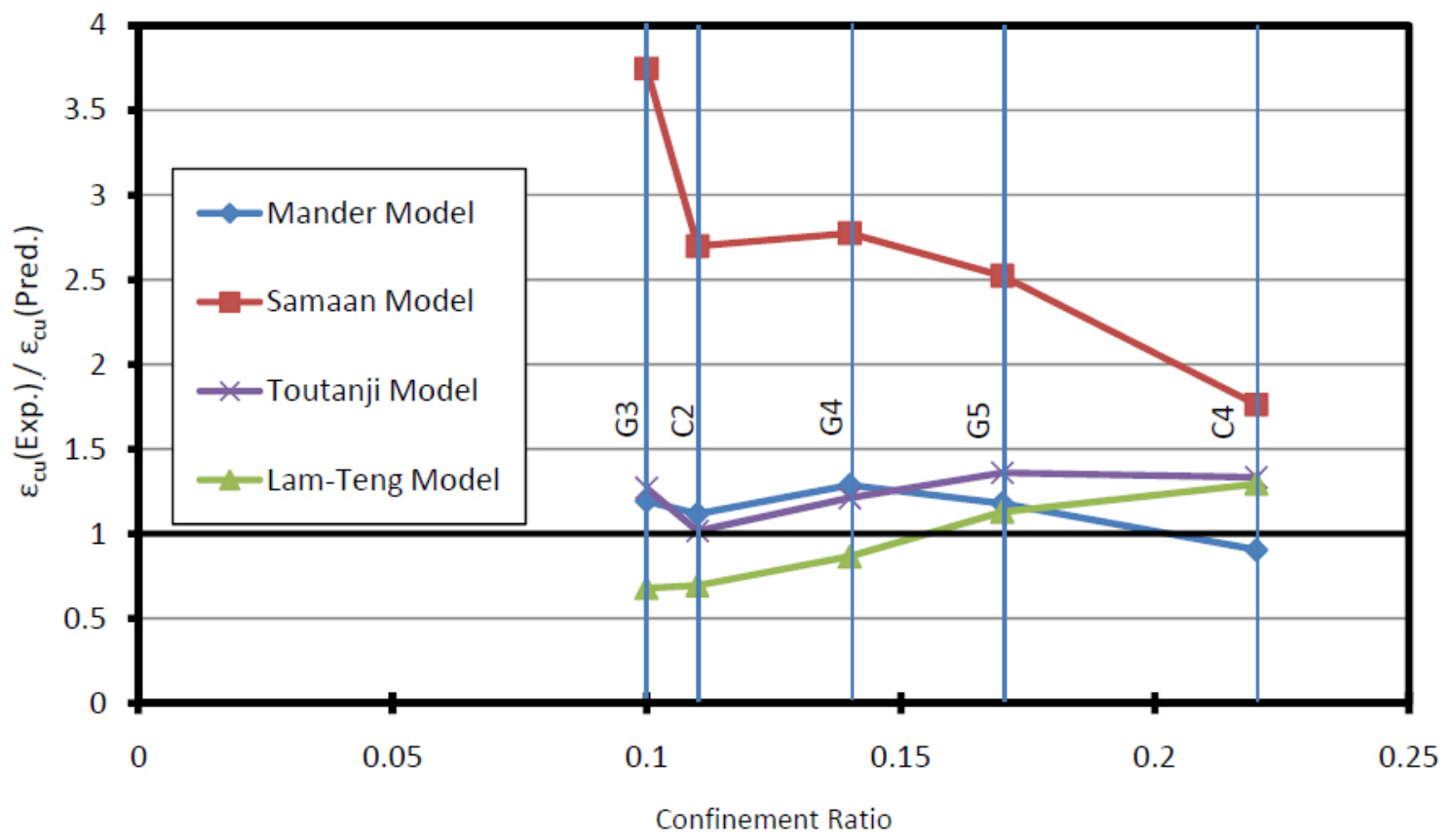

Figure 2.9 Comparison of Confinement Models for Predicting Ultimate Strains 


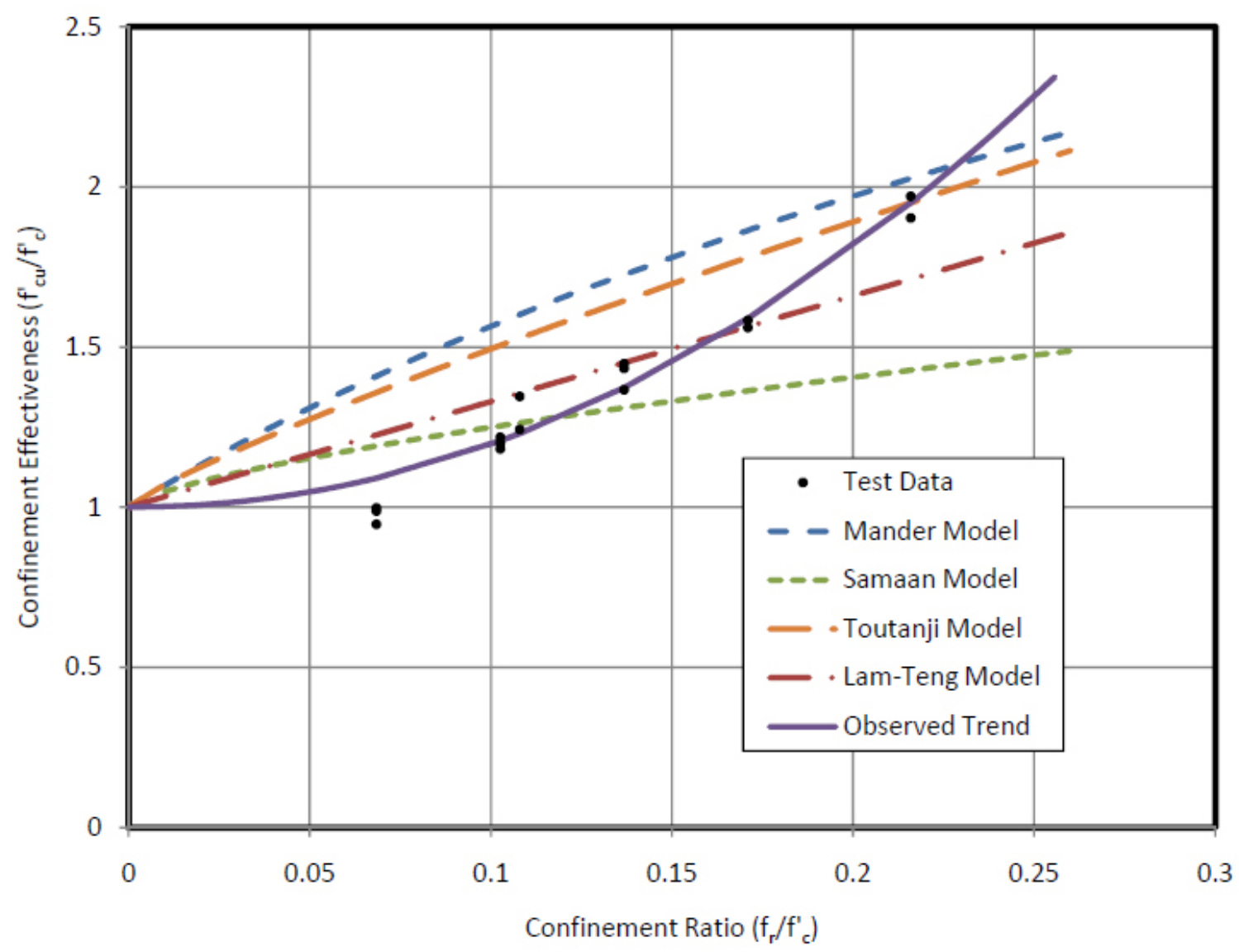

Figure 2.10 Confinement Effectiveness versus Confinement Ratio 


\title{
3. STRESS-STRAIN MODEL OF ULTRA-HIGH PERFORMANCE CONCRETE CONFINED BY FIBER-REINFORCED POLYMERS
}

\author{
Pedram Zohrevand and Amir Mirmiran
}

Submitted to ASCE Journal of Materials in Civil Engineering

\begin{abstract}
The application of ultra-high performance concrete (UHPC) as an alternative to conventional concrete has grown rapidly in recent years. However, to date, little is known about the confinement behavior of UHPC, knowledge which is necessary to develop design guidelines for UHPC columns. In a previous study, the authors investigated the stress-strain behavior of a series of UHPC-filled fiber-reinforced polymer (FRP) tubes with different fiber types and thicknesses under uniaxial compression. The FRP confinement was shown to significantly enhance both the ultimate strength and strain of UHPC. It was also shown that the existing confinement models are incapable of predicting the behavior of FRP-confined UHPC. Therefore, in this study, two commonly used FRP confinement models, Samaan and Lam and Teng, are recalibrated based on test results of FRP-confined UHPC. The model of Lam and Teng was further modified based on the stress-strain model of unconfined UHPC to better capture the linear response of UHPC before the activation of FRP confinement. Comparison of the three models showed that the recalibrated model of Samaan provides the most accurate prediction of the stress-strain behavior of FRP-confined UHPC in terms of the stress-strain curve and ultimate strength and strain.
\end{abstract}


Keywords: Concrete; Confinement; Fiber-reinforced polymers (FRP); Stress-strain model; Tubes; Ultra-high performance concrete (UHPC).

\subsection{Introduction}

The exceptional properties of ultra-high performance concrete (UHPC) including its significantly high compressive strength, modulus of elasticity, and usable tensile strength, and considerable durability and damage tolerance make it an excellent alternative to conventional concrete (Graybeal 2005). Studies have proven UHPC to be effective for rehabilitation and retrofit of reinforced concrete (RC) structures (Habel et al. 2007, Brühwiler and Denarié 2008, Massicotte and Boucher-Proulx 2010). Yang et al. (2010) showed that UHPC can significantly improve flexural strength, ductility, and cracking behavior in beams. UHPC has also been shown to enhance energy absorption, displacement capacity, and damage tolerance in columns (Billington and Yoon 2002, Saiidi et al. 2009). Recently, the application of UHPC has grown in the U.S., especially in bridge construction. Prestressed UHPC I-girders were used in simple-span bridges in Iowa and Virginia, and prestressed deck-bulb-double-tee UHPC girders were used in a bridge in Iowa (Graybeal 2011).

Considering the excellent material properties of fiber-reinforced polymers (FRP) such as high strength-to-weight and stiffness-to-weight ratios and good corrosion resistance (Mertz et al. 2003), the authors recently developed a novel hybrid column combining UHPC and FRP materials (Zohrevand and Mirmiran 2011a). The column was made of an FRP tube filled with UHPC within the plastic hinge length and conventional concrete for the remainder of the column length, while no steel reinforcement was used in the column. The steel-free UHPC-filled FRP tube (UHPCFFT) was studied under reverse 
cyclic lateral loading and showed considerably higher flexural strength, lower residual drift, and similar energy dissipation, as compared to its RC counterpart (Zohrevand and Mirmiran 2011a).

Knowing the confinement behavior of UHPC is necessary to develop design guidelines for UHPC columns. It is proven that confinement improves both the strength and ductility of conventional concrete. To date, several models have been developed to predict the stress-strain behavior of confined conventional concrete. Many of these models, such as those presented by Ahmad and Shah (1982), Scott et al. (1982) and Mander et al. (1988) are based on confinement by transverse steel. The growing application of FRP composites in RC structures has led to the development of new models for FRP confinement (Karbhari and Gao 1997, Samaan et al. 1998, Toutanji 1999, and Lam and Teng 2003). The confinement of UHPC was studied by the authors for the first time (Zohrevand and Mirmiran 2011b). Similar to conventional concrete, but in contrast with high strength concrete (HSC), the confined UHPC specimens showed a significant increase in both the ultimate strength and strain, up to $98 \%$ and $195 \%$, respectively. The experimental results were further compared with four existing confinement models, all of which failed in predicting the stress-strain response and ultimate strength and strain of FRP-confined UHPC specimens. This revealed the need for a new confinement model that could accurately predict the behavior of FRP-confined UHPC (Zohrevand and Mirmiran 2011b).

Accordingly, in this paper, two commonly used FRP confinement models, i.e., Samaan et al. (1998) and Lam and Teng (2003), are recalibrated based on test results of FRP-confined UHPC (Zohrevand and Mirmiran 2011b). In addition, the model of Lam 
and Teng (2003) is modified based on the model of unconfined UHPC by Graybeal (2007) to better capture the stress-strain behavior before the activation of FRP confinement. Eventually, the three models are compared with each other and the model with the highest accuracy in predicting the stress-strain response curve and ultimate strength and strain is identified.

\subsection{Experimental Database}

Nineteen cylindrical specimens, including sixteen UHPC-filled FRP tubes with $191 \mathrm{~mm}$ height and $108 \mathrm{~mm}$ core diameter and three unconfined UHPC with a height and diameter of $203 \mathrm{~mm}$ and $102 \mathrm{~mm}$, respectively, were tested under uniaxial compression. The test matrix is shown in Table 3.1. Two different types of unidirectional FRP sheets, glass and carbon, with different number of layers were used. The glass FRP (GFRP) and carbon FRP (CFRP) sheets were SikaWrap Hex 100G and Hex 103C, respectively, made by Sika Corp. of Lyndhurst, NJ. A two-part epoxy, Sikadur 300, made by the same manufacturer was used as adhesive. The mechanical properties of fibers, epoxy resin, and laminates are presented in Table 3.2. FRP tubes were made by wrapping resinimpregnated fabrics around cardboard sonotubes, which were removed after a 7-day curing. FRP tubes were plugged with plastic caps at the bottom before casting the UHPC.

The UHPC used in this study was Ductal ${ }^{\circledR}$, made by Lafarge North America of Calgary, AB, Canada, and composed of cement, silicafume, ground quartz, and sand (no coarse aggregate), water, superplasticizer, and $2 \%$ metallic fibers by volume. A single batch of UHPC with a 28-day compressive strength of $189 \mathrm{MPa}$ was used for all specimens. Figures 3.1(a) and (b) show UHPC-filled FRP tube specimens before testing. 
A uniaxial compression load was applied at a rate of $120 \mathrm{kN} / \mathrm{min}$, while monitoring the load, displacement, and axial and hoop strains. The test setup is shown in Figure 3.1(c).

Failure in all FRP-confined UHPC specimens was governed by FRP tube rupture at or near the mid-height. Due to a significant deviation in the behavior of one of the G5 specimens, as compared to its two identical specimens, the data from that specimen was ignored in the analysis. Test results are presented in Table 3.3, where confinement pressure $\left(f_{r}\right)$, confinement ratio $(C R)$, and confinement effectiveness $(C E)$ are given by:

$f_{r}=\frac{2 f_{j} t_{j}}{D}$

$C R=\frac{f_{r}}{f_{c o}^{\prime}}$

$C E=\frac{f_{c u}^{\prime}}{f_{c o}^{\prime}}$

in which $f_{j}$ is the hoop strength of the FRP tube, $t_{j}$ is the tube thickness, $D$ is the core diameter, $f_{c o}^{\prime}$ is the ultimate strength of unconfined UHPC core, and $f_{c u}^{\prime}$ is the ultimate strength of confined UHPC. Presented in the table is the average of identical specimens in each group. It should also be noted that the hoop strengths of FRP tubes were measured corresponding to their actual hoop rupture which were lower than the tensile strengths reported by the manufacturer, as discussed by Zohrevand and Mirmiran (2011b).

Figures 3.2(a) and (b) show the average stress-strain curves for the unconfined and FRP-confined UHPC specimens, respectively. Unconfined UHPC specimens exhibited mostly a linear response confirming the material model proposed by Graybeal (2007) for UHPC. All FRP-confined UHPC specimens showed a bilinear stress-strain 
response while both their ultimate strength and strain were significantly enhanced by FRP confinement. The exception was for Specimens G2, which had a low confinement ratio. Details of the experimental study are presented elsewhere [Zohrevand and Mirmiran $2011 b]$.

\subsection{Analytical Modeling}

Using the above experimental database, new stress-strain models for FRPconfined UHPC are developed in this section based on two well-known FRP confinement models; Samaan et al. (1998) and Lam and Teng (2003), both proposed for conventional concrete.

\subsubsection{Recalibrated Model of Samaan}

Samaan et al. (1998) used the following general equation to calculate the ultimate strength of FRP-confined conventional concrete:

$f_{c u}^{\prime}=f_{c o}^{\prime}+k_{1} f_{r}$

in which $k_{1}$ is related to the confinement pressure, as:

$k_{1}=\alpha f_{r}^{\beta}$

where $\alpha$ and $\beta$ are constants to be identified. Accordingly, the regression analysis of the experimental data resulted in the following equation to calculate the ultimate strength of FRP-confined UHPC:

$f_{c u}^{\prime}=f_{c o}^{\prime}+0.107 f_{r}^{2}$

for which the coefficient of determination $\left(R^{2}\right)$ is 0.97 . Figure 3.3 shows the predicted ultimate strengths versus test results for FRP-confined UHPC specimens. Dashed lines in the figure show a $\pm 10 \%$ margin of error. 
Similar to the model of Samaan, the bilinear response of FRP-confined UHPC can be represented using a single equation, based on the four-parameter relationship of Richard and Abott (1975), as:

$$
f_{c}=\frac{\left(E_{1}-E_{2}\right) \varepsilon_{c}}{\left[1+\left(\frac{\left(E_{1}-E_{2}\right) \varepsilon_{c}}{f_{o}}\right)^{1.5}\right]^{\frac{1}{n}}}
$$

where $f_{c}$ and $\varepsilon_{c}$ are the axial stress and strain of FRP-confined UHPC, respectively, $E_{1}$ and $E_{2}$ are the first and second slopes, respectively, $f_{o}$ is the intercept of the second slope with the stress axis, and $n$ is the parameter for the curvature of the transition zone. Figure 3.4 shows the shape of the model as well as its parameters. Using stress-strain responses of FRP-confined UHPC specimens, the curve-shape parameter $n$ was selected as 12, and other parameters $\left(E_{1}, E_{2}\right.$, and $\left.f_{o}\right)$ are recalibrated below.

The similarity between the initial stiffness of all UHPC-filled FRP tubes, as seen in Figure 3.2, implies that FRP tubes are not yet activated in the first portion of the stressstrain response, when stresses are lower than the peak strength of unconfined UHPC. Therefore, the first slope $\left(E_{1}\right)$ can be defined as the modulus of elasticity of unconfined UHPC which can be calculated using the following equation proposed by Graybeal (2007):

$$
E_{1}=3,840 \sqrt{f_{c o}^{\prime}}
$$

The second part of the stress-strain responses of UHPC-filled FRP tubes emerges by the full activation of FRP tubes resisting the progressive dilation of UHPC. Therefore, similar to the model of Samaan, the second slope $\left(E_{2}\right)$ depends primarily on the stiffness of FRP tube, and to a lesser extent, on the unconfined strength of UHPC. The equation to 
estimate $E_{2}$ was recalibrated based on the experimental results achieved from FRPconfined UHPC specimens, as:

$$
E_{2}=1,350.76 f_{c o}^{\prime 0.2}+5.675 \frac{E_{j} t_{j}}{D}
$$

with $R^{2}=0.97$, and where $E_{j}$ is the modulus of elasticity of the FRP tube in the hoop direction. The predicted versus experimental values of $E_{2}$ are shown in Figure 3.5.

Based on the model of Samaan, the intercept stress $\left(f_{o}\right)$ can be specified as a function of the strength of unconfined UHPC and the confining pressure developed by FRP tube. Accordingly, the equation to calculate $f_{o}$ was recalibrated as:

$f_{o}=0.7862 f_{c o}^{\prime}+0.455 f_{r}$

with $R^{2}=0.98$. Figure 3.6 shows the predicted versus experimental values of $f_{o}$.

Finally, the ultimate strain $\left(\varepsilon_{c u}\right)$ can be given by:

$$
\varepsilon_{c u}=\frac{f_{c u}^{\prime}-f_{o}}{E_{2}}
$$

The predicted versus experimental values of $\varepsilon_{c u}$ are shown in Figure 3.7.

Figure 3.8 shows the predicted stress-strain response of each group of specimens resulted from the recalibrated model of Samaan. The experimental stress-strain responses are also shown for the comparison. It should be mentioned that due to the insignificant FRP confinement effect, Specimens G2 were excluded from the figure. The predicted values of the ultimate strength and strain of FRP-confined UHPC specimens are presented in Table 3.4. 


\subsubsection{Recalibrated Model of Lam and Teng}

Lam and Teng (2003) adopted the form of Eq. (4) to estimate the ultimate strength of FRP-confined conventional concrete. However, it was shown that there is a linear relation between $f_{c u}^{\prime}$ and $f_{r}$. In other words, they suggested $k_{1}$ in Eq. (4) to be a constant. As such, Eq. (4) was recalibrated using the experimental database as:

$f_{c u}^{\prime}=f_{c o}^{\prime}+3.2519 f_{r}$

with $R^{2}=0.84$. Figure 3.9 shows the predicted versus measured ultimate strengths of FRPconfined UHPC specimens.

It was shown by Lam and Teng (2003) that the ultimate strain of FRP-confined conventional concrete is dependent on the stiffness and rupture strain of FRP. Accordingly, they proposed the following general equation to estimate the ultimate strain:

$\frac{\varepsilon_{c u}}{\varepsilon_{c o}}=\beta+\gamma\left(\frac{2 E_{j} t_{j}}{E_{\mathrm{sec}} D}\right)^{\lambda}\left(\frac{\varepsilon_{r u p}}{\varepsilon_{c o}}\right)^{\theta}$

where $\varepsilon_{c o}$ is the axial strain at the peak stress of unconfined concrete, $E_{\text {sec }}$ is the secant modulus of elasticity of concrete, $\varepsilon_{r u p}$ is the hoop rupture strain of the FRP, $\beta$ and $\gamma$ are constants, and $\lambda$ and $\theta$ are exponents to be identified. Based on this general form and using regression analysis of the test data, the ultimate strain of FRP-confined UHPC can be predicted as:

$\frac{\mathcal{\varepsilon}_{c u}}{\varepsilon_{c o}}=1.1075+8.836\left(\frac{E_{j} t_{j}}{E_{U H P C} D}\right)\left(\frac{\mathcal{E}_{r u p}}{\varepsilon_{c o}}\right)^{2}$

with $R^{2}=0.91$. It should be mentioned that due to the almost linear behavior of UHPC, $E_{\mathrm{sec}}$ was replaced by the modulus of elasticity of UHPC $\left(E_{U H P C}\right)$ which can be calculated 
using Eq. (8). Based on the UHPC model which was proposed by Graybeal (2007), the ultimate strain of unconfined UHPC $\left(\varepsilon_{c o}\right)$ can be calculated as:

$\varepsilon_{c o}=-0.0039+2.2548\left(\frac{f_{c o}^{\prime}}{E_{U H P C}}\right)$

The predicted versus experimental ultimate strains are shown in Figure 3.10.

Similar to the model of Lam and Teng, the bilinear stress-strain curve of FRPconfined UHPC can be represented in two distinct portions (Figure 3.11); a parabola and a straight line, as:

$$
\begin{aligned}
& f_{c}=E_{1 l} \varepsilon_{c}-\frac{\left(E_{1 l}-E_{2 l}\right)^{2}}{4 f_{o l}} \varepsilon_{c}{ }^{2} \text { for } 0 \leq \varepsilon_{c} \leq \varepsilon_{t} \\
& f_{c}=f_{o l}+E_{2 l} \varepsilon_{c} \text { for } \varepsilon_{t} \leq \varepsilon_{c} \leq \varepsilon_{c u}
\end{aligned}
$$

where $E_{1 l}$ is the elastic modulus of unconfined UHPC which can be calculated using Eq. $(8), E_{2 l}$ is the slope of the linear second portion, $f_{o l}$ is the stress at which the linear second portion intersects the stress axis, and $\varepsilon_{t}$ is the strain of the point at which the parabolic first portion coincides with the linear second portion. It should be noted that although $E_{2 l}$ and $f_{o l}$ have the same definitions as $E_{2}$ and $f_{o}$ from the recalibrated model of Samaan, respectively, they are calculated differently in the two models. The parabolic first portion from Eq. (16a), which is based on the model of Hognestad (1951) for unconfined conventional concrete, can predict the stress-strain response up to $\varepsilon_{t}$, given by:

$\varepsilon_{t}=\frac{2 f_{o l}}{\left(E_{1 l}-E_{2 l}\right)}$

where $f_{o l}$ is assumed to be equal to the ultimate strength of unconfined UHPC, similar to the model of Lam and Teng, and $E_{2 l}$ is calculated as: 
$E_{2 l}=\frac{f_{c u}^{\prime}-f_{o l}}{\varepsilon_{c u}}$

Using the recalibrated model of Lam and Teng, the stress-strain response of each group of UHPC-filled FRP tube specimens was predicted, and is shown in Figure 3.8. Also, the predicted values of the ultimate stress and strain are presented in Table 3.4. As seen in Figure 3.8, the parabolic first portion of stress-strain responses predicted by the recalibrated model of Lam and Teng does not match the linear behavior of FRP-confined UHPC specimens. This is attributed to the different stress-strain behavior of conventional concrete as compared to UHPC since the first portion of the model of Lam and Teng is based on Hognestad's parabola representing the stress-strain curve of unconfined conventional concrete. Therefore, the model of Lam and Teng will be modified in the next section to better capture the first portion of the stress-strain response of FRPconfined UHPC.

\subsubsection{Modified Model of Lam and Teng}

In this section, the model of Lam and Teng (2003) is modified based on the stressstrain behavior of unconfined UHPC. The same equations as those recalibrated in the previous section, i.e., Eq. (12) and Eq. (14), are used to estimate the ultimate strength and strain of FRP-confined UHPC. Studying the bilinear stress-strain responses of UHPCfilled FRP tube specimens (see Figure 3.8) shows that the onset of the second portion of the response corresponds to the ultimate strain of unconfined UHPC with the average error less than $10 \%$. Besides, the linear shape of the first portion is closely similar to the response of unconfined UHPC. Accordingly, the two portions of the stress-strain model can be separated at the ultimate strain of unconfined UHPC $\left(\varepsilon_{c o}\right)$, which is estimated 
using Eq. (15). Also, the first portion can be represented by the model of unconfined UHPC proposed by Graybeal (2007), and the second portion can be modeled linearly, as:

$$
\begin{aligned}
& f_{c}=E_{U H P C} \varepsilon_{c}\left(1.011-0.011 e^{\frac{4 E_{U H P C}}{0.44 f_{c o}^{\prime c}}}\right) \text { for } 0 \leq \varepsilon_{c} \leq \varepsilon_{c o} \\
& f_{c}=f_{a}+E_{2 m}\left(\varepsilon_{c}-\varepsilon_{c o}\right) \text { for } \varepsilon_{c o} \leq \varepsilon_{c} \leq \varepsilon_{c u}
\end{aligned}
$$

where $f_{\mathrm{a}}$ and $E_{2 \mathrm{~m}}$ are:

$$
\begin{aligned}
& f_{a}=E_{U H P C} \varepsilon_{c o}\left(1.011-0.011 e^{\frac{4 E_{U H P C}}{0.44 f_{c o}^{\prime \prime}}}\right) \\
& E_{2 m}=\frac{f_{c u}^{\prime}-f_{a}}{\varepsilon_{c u}-\varepsilon_{c o}}
\end{aligned}
$$

Using the modified model of Lam and Teng, the stress-strain responses of UHPCfilled FRP tube specimens were predicted which, as shown in Figure 3.8. The figure shows that the prediction of the stress-strain response was enhanced by the modified model of Lam and Teng, as compared to the recalibrated model of Lam and Teng, especially within the first portion of the response. As mentioned before, the ultimate strengths and strains predicted by the modified model of Lam and Teng are the same as those predicted by the recalibrated model of Lam and Teng which are presented in Table 3.4.

\subsubsection{Comparison of the Models}

The accuracy of each model to predict the stress-strain response curve was quantified by calculating the coefficient of determination $\left(R^{2}\right)$, as a representative of the goodness of the fit, for each specimen. The average $R^{2}$ of the specimens in each group is presented in Table 3.5. The results show that the recalibrated model of Samaan has the highest accuracy with the average $R^{2}$ of 0.97 in predicting the stress-strain curves of FRP- 
confined UHPC specimens, whereas the recalibrated model of Lam and Teng resulted in the lowest accuracy with the average $R^{2}$ of 0.90 . The accuracy of the predicted stressstrain curves mostly increased by the modified model of Lam and Teng with the average $R^{2}$ of 0.95 , while still being lower than that of the recalibrated model of Samaan.

To comprehensively compare the models, their ability to predict the ultimate strength and strain is also assessed. Accordingly, the errors of each model in prediction of the ultimate strength and strain of each specimen are presented in Table 3.5. The data is the average of errors in each group of specimens. It should be noted that the same ultimate strength and strain were predicted by both the recalibrated and modified model of Lam and Teng. Similar to stress-strain curves, the recalibrated model of Samaan provided the most accurate predictions for ultimate strengths considering its lower average error of $2.3 \%$, as compared to the average error of $5.7 \%$ resulted from the other models. All models exhibited the same average error of $6.3 \%$ for ultimate strains indicating their same accuracy in predicting the ultimate strain.

\subsection{Conclusions}

Using the experimental results achieved from testing sixteen FRP confined and three unconfined UHPC cylindrical specimens under uniaxial compression, two commonly used FRP confinement models developed by Samaan et al. (1998) and Lam and Teng (2003) were recalibrated. The recalibrated model of Samaan could suitably predict the bilinear stress-strain curves of FRP-confined UHPC specimens, while the stress-strain curves predicted by the recalibrated model of Lam and Teng exhibited significantly different shape within the first portion of the response, as compared to the experimental results. Hence, the model of Lam and Teng was further modified based on 
the stress-strain model of unconfined UHPC, as proposed by Graybeal (2007), to better capture the stress-strain curve before the activation of FRP confinement. The accuracy of the predicted stress-strain curves improved considerably by the modification of the model of Lam and Teng. However, it was still less than the accuracy of the recalibrated model of Samaan. Similar to stress-strain curves, the ultimate strengths predicted by the recalibrated model of Samaan showed the lowest average error as compared to the other two models. On the other hand, the same level of accuracy was seen in the predicted ultimate strains resulted from all three models. Therefore, it may be concluded that the recalibrated model of Samaan outperforms the other two models, the recalibrated and modified model of Lam and Teng, in predicting both the stress-strain curve and the ultimate condition of FRP-confined UHPC. Moreover, the single-equation format of the recalibrated model of Samaan, makes it easier to use, as compared to the other two models with two-equation stress-strain models. Accordingly, the recalibrated model of Samaan is proposed as a suitable model for FRP-confined UHPC.

\section{Acknowledgements}

This study was sponsored in part by the NSF-Network for Earthquake Engineering Simulation Research (NEESR) program, as part of the multi-university Grant No. CMS-0420347. The first writer is also thankful to the University Graduate School for providing him with a dissertation year fellowship to complete his doctoral work. Findings and opinions expressed here, however, are those of the authors alone, and not necessarily the views of sponsoring agencies. 


\section{References}

Billington, S.L., and Yoon, J. (2002). "Cyclic Behavior of Precast Post-Tensioned Segmental Concrete Columns with ECC." Proceedings of the JCI International Workshop on Ductile Fiber Reinforced Cementitious Composites (DFRCC) Application and Evaluation (DRFCC-2002), Takayama, Japan, 279-288.

Fischer, G., Fukuyama, H., and Li, V.C. (2002). "Effect of Matrix Ductility on the Performance of Reinforced ECC Column Members under Reversed Cyclic Loading Conditions." Proceedings of the JCI International Workshop on Ductile Fiber Reinforced Cementitious Composites (DFRCC) - Application and Evaluation (DRFCC-2002), Takayama, Japan, 269-278.

Ahmad, S., and Shah, S. (1982). "Stress-Strain Curves of Concrete Confined by Spiral Reinforcement." ACI Journal, 79(6), 484-490.

Billington, S.L., and Yoon, J. (2002). "Cyclic Behavior of Precast Post-Tensioned Segmental Concrete Columns with ECC." Proceedings of the JCI International Workshop on Ductile Fiber Reinforced Cementitious Composites (DFRCC) Application and Evaluation (DRFCC-2002), Japan Concrete Institute, Takayama, Japan, 279-288.

Brühwiler, E., and Denarié, E. (2008). "Rehabilitation of Concrete Structures Using Ultra- High Performance Fiber-Reinforced Concrete." Proceedings of the Second International Symposium on Ultra-High Performance Concrete, Kassel, Germany, 8 pp.

Graybeal, B. (2005). "Characterization of the Behavior of Ultra-High Performance Concrete." PhD Dissertation, University of Maryland, College Park, MD.

Graybeal, B. (2007). "Compressive Behavior of Ultra-High-Performance FiberReinforced Concrete.” Materials Journal, ACI, 104(2), 146-152.

Graybeal, B. (2011). “Ultra-High Performance Concrete.” Report No. FHWA-HRT-11038, Federal Highway Administration, McLean, VA.

Habel, K., Denarié, E., and Brühwiler, E. (2007). "Experimental Investigation of Composite Ultra-High-Performance Fiber-Reinforced Concrete and Conventional Concrete Members.” Structural Journal, ACI, 104(1), 93-101.

Hognestad, E.A. (1951). "Study of Combined Bending and Axial Load in Reinforced Concrete Members." Bulletin Series No. 399, Engineering Experiment Station, University of Illinois, Urbana, IL. 
Karbhari, V., and Gao, Y. (1997). "Composite Jacketed Concrete under Uniaxial Compression - Verification of Simple Design Equations." Journal of Materials in Civil Engineering, ASCE, 9(4), 185-193.

Lam L., and Teng J.G. (2003). "Design-Oriented Stress-Strain Model for FRP-Confined Concrete.” Journal of Construction \& Building Materials, 17(6-7), 471-89.

Mander, J.B., Priestley, M.J.N., and Park, R. (1988). "Theoretical Stress-Strain Model for Confined Concrete." Journal of Structural Engineering, ASCE, 114(8), 18041826.

Massicotte,B., and Boucher-Proulx, G. (2010). "Seismic Retrofitting of Bridge Piers with UHPFRC Jackets." Designing and Building with UHPFRC: State of the Art and Development, Wiley-ISTE, London, 531-540.

Mertz, D.R., Chajes, M.J., Gillespie, Jr., J.W., Kukich, D.S., Sabol, S.A., Hawkins, N.M., Aquino, W., and Deen, T.B. (2003). "Application of Fiber Reinforced Polymer Composites to the Highway Infrastructure." NCHRP Report No. 503, Transportation Research Board, National Academy of Sciences, Washington D.C.

Richard, R.M., and Abbott, B.J. (1975). "Versatile Elastic-Plastic Stress-Strain Formula." Journal of Engineering Mechanics, ASCE, 101(4), 511-515.

Saiidi, M., O'Brien, M., and Mahmoud, S. (2009). "Cyclic Response of Concrete Bridge Columns using Superelastic Nitinol and Bendable Concrete.” Structural Journal, ACI, 106(1), 69-77.

Samaan, M., Mirmiran, A., and Shahawy, M. (1998). "Model of Concrete Confined by Fiber Composites.” Journal of Structural Engineering, ASCE, 124(9), 1025-1031.

Scott, B.D., Park, R. and Priestley, M. (1982). "Stress-Strain Behaviour of Concrete Confined by Overlapping Hoops at Low and High Strain Rates." ACI Journal, 79(1), 13-27.

Toutanji, H.A. (1999). "Stress-Strain Characteristics of Concrete Columns Externally Confined with Advanced Fiber Composite Sheets." Materials Journal, ACI, 96(3), 397-404.

Yang, H., Jon, C., and Kim, B.S. (2010). "Structural Behavior of Ultra High Performance Concrete Beams Subjected to Bending." Journal of Engineering Structures, 32(11), 3789-3800.

Zohrevand, P., and Mirmiran, A. (2011a). "Cyclic Behavior of Hybrid Columns Made of Ultra High Performance Concrete and Fiber Reinforced Polymers." Journal of Composites for Construction, ASCE, Online posting ahead of print June 2011. 
Zohrevand, P. and Mirmiran, A. (2011b) "Behavior of Ultra High Performance Concrete Confined by Fiber Reinforced Polymers." Journal of Materials in Civil Engineering, ASCE, 23(12), 1727-1734. 
Table 3.1 Test Matrix

\begin{tabular}{ccccccc}
\hline \hline $\begin{array}{c}\text { Specimen } \\
\text { Group }\end{array}$ & $\begin{array}{c}\text { Number of } \\
\text { Identical } \\
\text { Specimens }\end{array}$ & $\begin{array}{c}\text { Type of } \\
\text { FRP }\end{array}$ & $\begin{array}{c}\text { Core } \\
\text { Diameter } \\
(\mathrm{mm})\end{array}$ & $\begin{array}{c}\text { Height } \\
(\mathrm{mm})\end{array}$ & $\begin{array}{c}\text { Number } \\
\text { of FRP } \\
\text { Layers }\end{array}$ & $\begin{array}{c}\text { Tube } \\
\text { Thickness } \\
(\mathrm{mm})\end{array}$ \\
\hline P & 3 & None & 102 & 203 & N/A & N/A \\
\hline G2 & 3 & & & & 2 & 2.04 \\
G3 & 3 & Hex & 108 & 191 & 3 & 3.06 \\
G4 & 3 & $100 G^{*}$ & & & 4 & 4.08 \\
G5 & 3 & & & & 5 & 5.10 \\
\hline C2 & 2 & Hex & 108 & 191 & 4 & 4.04 \\
C4 & 2 & $103 C^{*}$ & & & \\
\hline
\end{tabular}

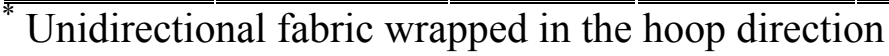

Table 3.2 Mechanical Properties of FRP Tubes ${ }^{*}$

\begin{tabular}{cccccc}
\hline Type & $\begin{array}{c}\text { Glass } \\
\text { Fibers } \\
(\text { Hex 100G) }\end{array}$ & $\begin{array}{c}\text { Carbon } \\
\text { Fibers } \\
(\text { Hex 103C) }\end{array}$ & $\begin{array}{c}\text { Epoxy } \\
\text { Resin } \\
(\text { Hex 300) }\end{array}$ & $\begin{array}{c}\text { GFRP } \\
\text { Laminate } \\
\text { with Epoxy }\end{array}$ & $\begin{array}{c}\text { CFRP } \\
\text { Laminate } \\
\text { with Epoxy }\end{array}$ \\
\hline $\begin{array}{c}\text { Tensile Strength } \\
(\mathrm{MPa})\end{array}$ & 2,275 & 3,790 & 72.4 & 610 & 850 \\
$\begin{array}{c}\text { Tensile Modulus } \\
(\mathrm{GPa})\end{array}$ & 72.4 & 334 & 3.17 & 26.1 & 70.6 \\
\hline \hline
\end{tabular}

* As reported by the manufacturer 
Table 3.3 Summary of Test Results ${ }^{*}$

\begin{tabular}{cccccccc}
\hline \hline $\begin{array}{c}\text { Specimen } \\
\text { Group }\end{array}$ & $\begin{array}{c}\text { Confinement } \\
\text { Pressure, } f_{r} \\
(\mathrm{MPa})\end{array}$ & $\begin{array}{c}\text { Confinement } \\
\text { Ratio, } C R \\
\left(f_{r} / f_{c o}^{\prime}\right)\end{array}$ & $\begin{array}{c}\text { Ultimate } \\
\text { Load } \\
(\mathrm{kN})\end{array}$ & $\begin{array}{c}\text { Ultimate } \\
\text { Strength } \\
(\mathrm{MPa})\end{array}$ & $\begin{array}{c}\text { Ultimate } \\
\text { Axial } \\
\text { Strain }\end{array}$ & $\begin{array}{c}\text { Ultimate } \\
\text { Hoop } \\
\text { Strain }\end{array}$ & $\begin{array}{c}\text { Confinement } \\
\text { Effectiveness, } \\
C E \\
\left(f_{c u}^{\prime} / f_{c o}^{\prime}\right)\end{array}$ \\
\hline P & N/A & N/A & 1,526 & 188.2 & 0.0039 & 0.0009 & N/A \\
G2 & 12.9 & 0.07 & 1,725 & 188.4 & 0.0040 & 0.0010 & 1.00 \\
G3 & 19.4 & 0.10 & 2,073 & 226.6 & 0.0086 & 0.0120 & 1.20 \\
G4 & 25.9 & 0.14 & 2,502 & 273.5 & 0.0106 & 0.0135 & 1.45 \\
G5 & 32.3 & 0.17 & 2,736 & 298.9 & 0.0115 & 0.0140 & 1.58 \\
C2 & 20.4 & 0.11 & 2,386 & 254.1 & 0.0068 & 0.0069 & 1.35 \\
C4 & 40.8 & 0.22 & 3,407 & 372.2 & 0.0105 & 0.0080 & 1.97 \\
\hline \hline
\end{tabular}

* Average for identical specimens in each group

Table 3.4 Predicted Values of the Ultimate Strength and Strain

\begin{tabular}{|c|c|c|c|c|}
\hline \multirow[b]{2}{*}{$\begin{array}{l}\text { Specimen } \\
\text { Group }\end{array}$} & \multicolumn{2}{|c|}{$\begin{array}{c}\text { Ultimate Strength, } f_{c u}^{\prime} \\
(\mathrm{MPa})\end{array}$} & \multicolumn{2}{|c|}{ Ultimate Axial Strain, $\varepsilon_{c u}$} \\
\hline & $\begin{array}{c}\text { Recalibrated } \\
\text { Model of } \\
\text { Samaan }\end{array}$ & $\begin{array}{l}\text { Recalibrated } \\
\text { and Modified } \\
\text { Model of Lam } \\
\text { and Teng }\end{array}$ & $\begin{array}{l}\text { Recalibrated } \\
\text { Model of } \\
\text { Samaan }\end{array}$ & $\begin{array}{c}\text { Recalibrated } \\
\text { and Modified } \\
\text { Model of Lam } \\
\text { and Teng }\end{array}$ \\
\hline G3 & 228.8 & 225.0 & 0.0089 & 0.0098 \\
\hline G4 & 260.0 & 272.7 & 0.0106 & 0.0115 \\
\hline G5 & 300.1 & 293.7 & 0.0127 & 0.0132 \\
\hline $\mathrm{C} 2$ & 233.1 & 255.0 & 0.0066 & 0.0078 \\
\hline $\mathrm{C} 4$ & 366.2 & 321.3 & 0.0105 & 0.0109 \\
\hline
\end{tabular}


Table 3.5 Comparison of the Models with respect to the Stress-Strain Curve and Ultimate Strength and Strain

\begin{tabular}{|c|c|c|c|c|c|c|c|}
\hline \multirow[b]{2}{*}{$\begin{array}{l}\text { Specimen } \\
\text { Group }\end{array}$} & \multicolumn{3}{|c|}{$R^{2}$ of the Predicted Stress-Strain Curve } & \multicolumn{2}{|c|}{$\begin{array}{c}\text { Error of the Predicted Ultimate } \\
\text { Strength }(\%)\end{array}$} & \multicolumn{2}{|c|}{$\begin{array}{l}\text { Error of the Predicted } \\
\text { Ultimate Strain }(\%)\end{array}$} \\
\hline & $\begin{array}{c}\text { Recalibrated } \\
\text { Model of } \\
\text { Samaan }\end{array}$ & $\begin{array}{l}\text { Recalibrated } \\
\text { Model of } \\
\text { Lam and } \\
\text { Teng } \\
\end{array}$ & $\begin{array}{l}\text { Modified } \\
\text { Model of } \\
\text { Lam and } \\
\text { Teng }\end{array}$ & $\begin{array}{c}\text { Recalibrated } \\
\text { Model of } \\
\text { Samaan }\end{array}$ & $\begin{array}{l}\text { Recalibrated } \\
\text { and Modified } \\
\text { Model of Lam } \\
\text { and Teng }\end{array}$ & $\begin{array}{l}\text { Recalibrated } \\
\text { Model of } \\
\text { Samaan }\end{array}$ & $\begin{array}{c}\text { Recalibrated } \\
\text { and Modified } \\
\text { Model of Lam } \\
\text { and Teng }\end{array}$ \\
\hline G3 & 0.99 & 0.90 & 0.97 & 1.0 & 11.1 & -3.7 & 5.9 \\
\hline G4 & 0.98 & 0.93 & 0.97 & -2.8 & 2.0 & -11.3 & -5.0 \\
\hline G5 & 0.95 & 0.90 & 0.93 & 0.6 & -1.6 & 4.6 & 8.9 \\
\hline $\mathrm{C} 2$ & 0.95 & 0.86 & 0.93 & -7.0 & 1.7 & -6.6 & 9.8 \\
\hline $\mathrm{C} 4$ & 0.97 & 0.92 & 0.92 & 0.1 & -12.2 & -5.2 & -1.8 \\
\hline $\begin{array}{l}\text { Mean Absolute } \\
\text { Error }\end{array}$ & 0.97 & 0.90 & 0.95 & 2.3 & 5.7 & 6.3 & 5.9 \\
\hline
\end{tabular}




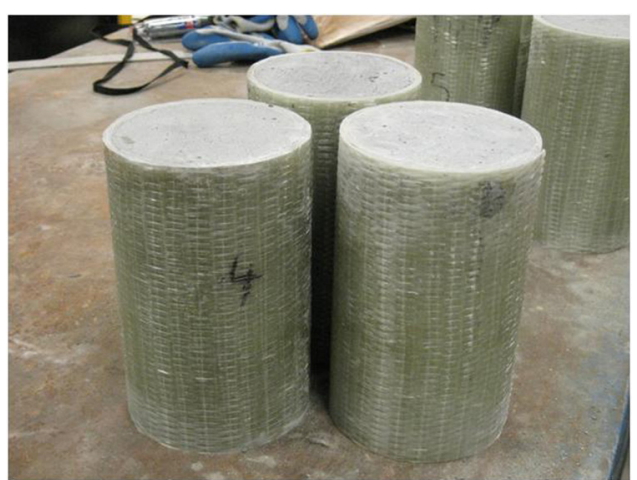

(a)

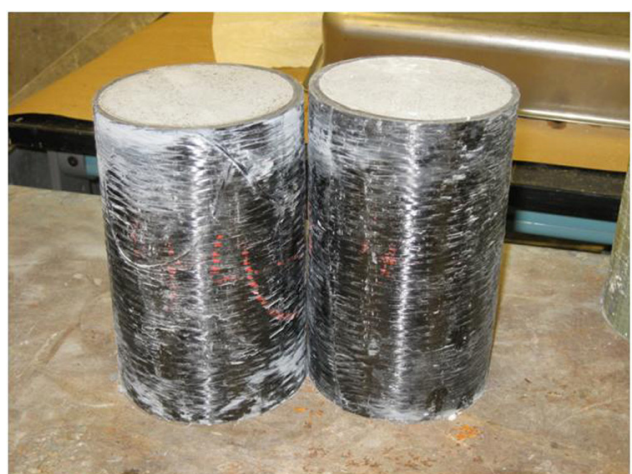

(b)

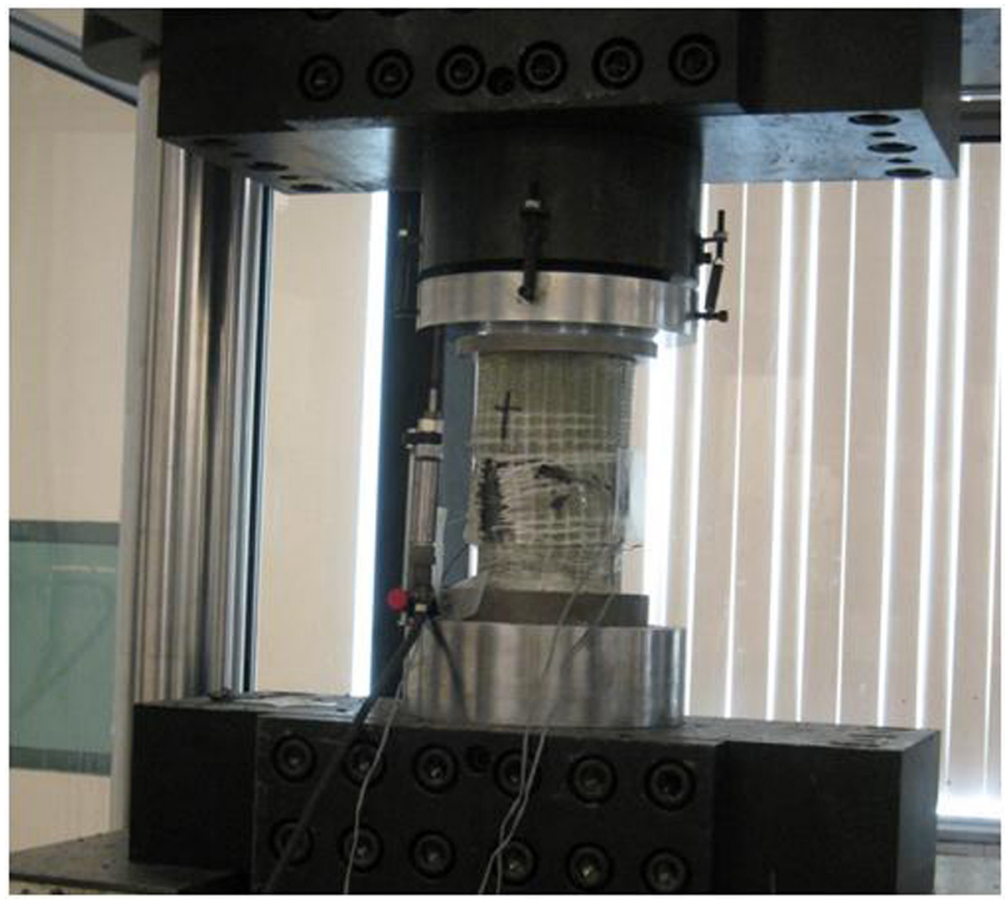

(c)

Figure 3.5(a) UHPC-Filled GFRP Tubes, (b) UHPC-Filled CFRP Tubes, and (b) Test Setup 


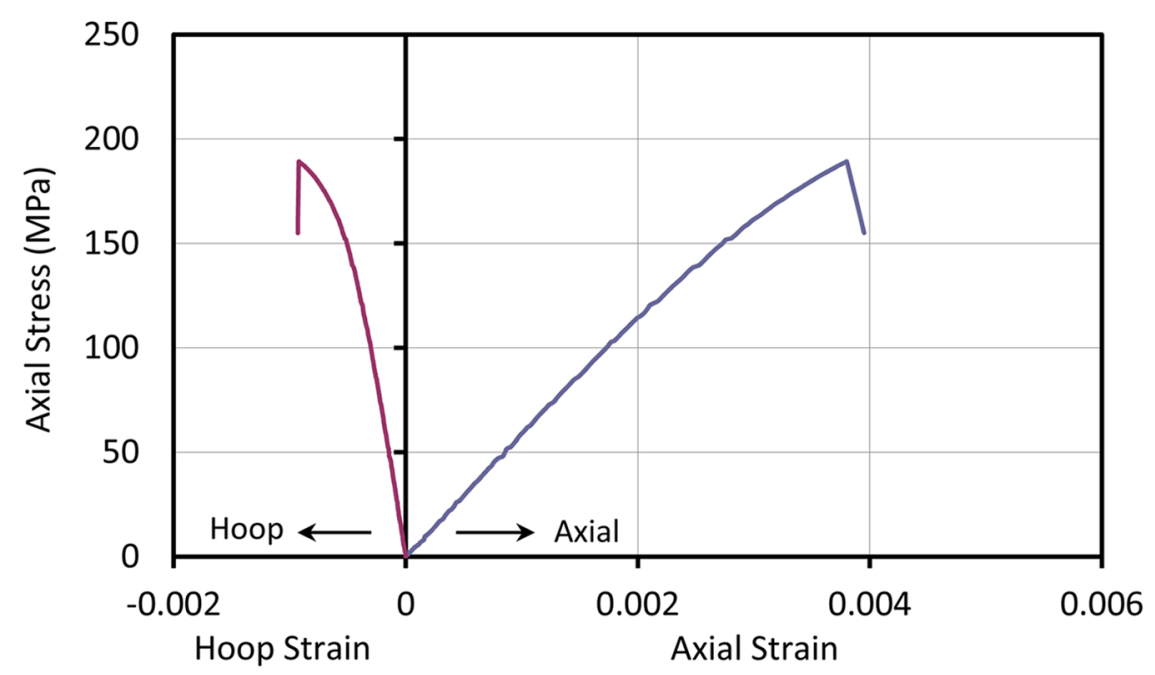

(a)

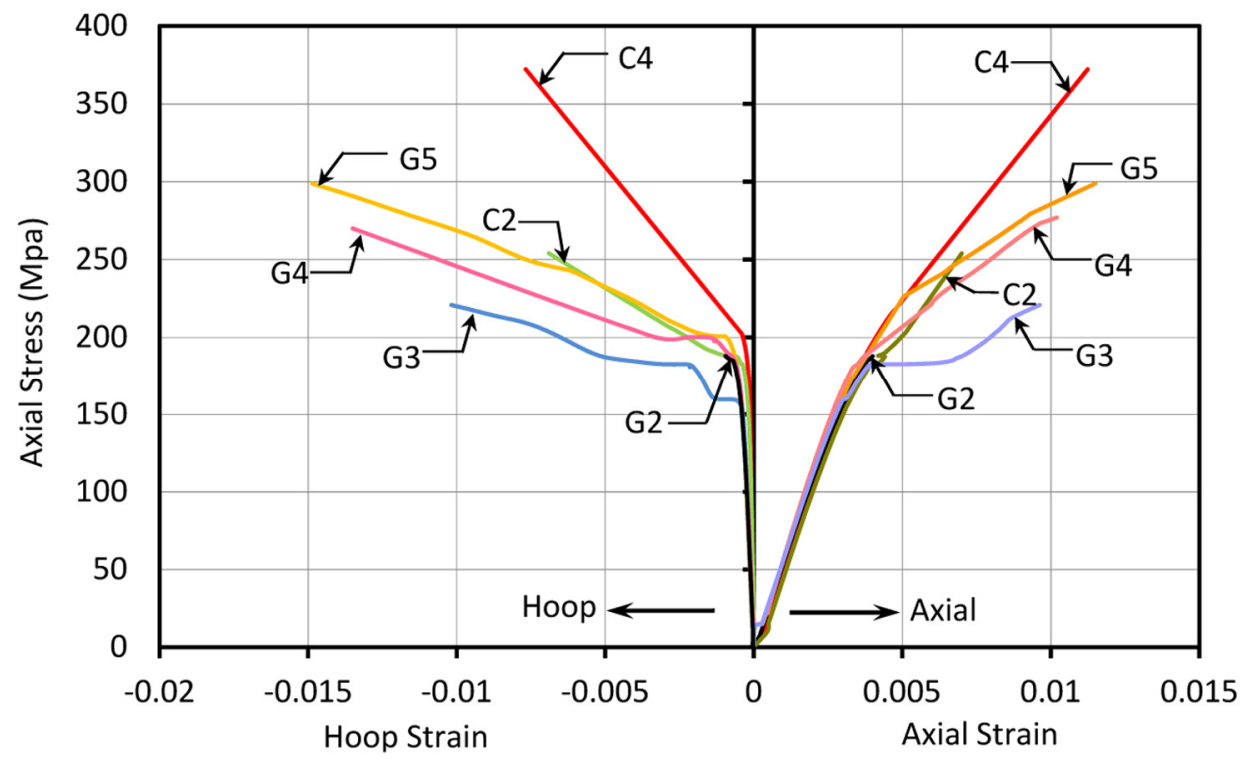

(b)

Figure 3.2 Average Stress-Strain Response Curves for UHPC Specimens: (a) Unconfined; and (b) FRP-Confined 


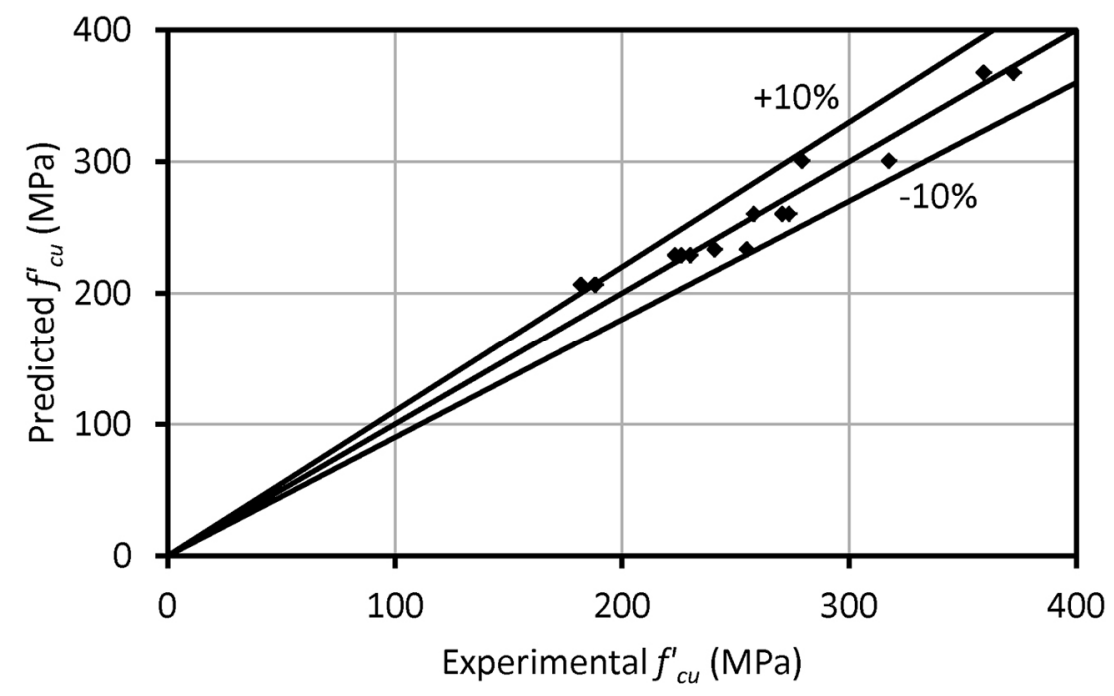

Figure 3.3 Ultimate Strengths $\left(f_{c u}^{\prime}\right)$ Predicted by the Recalibrated Model of Samaan versus Test Results

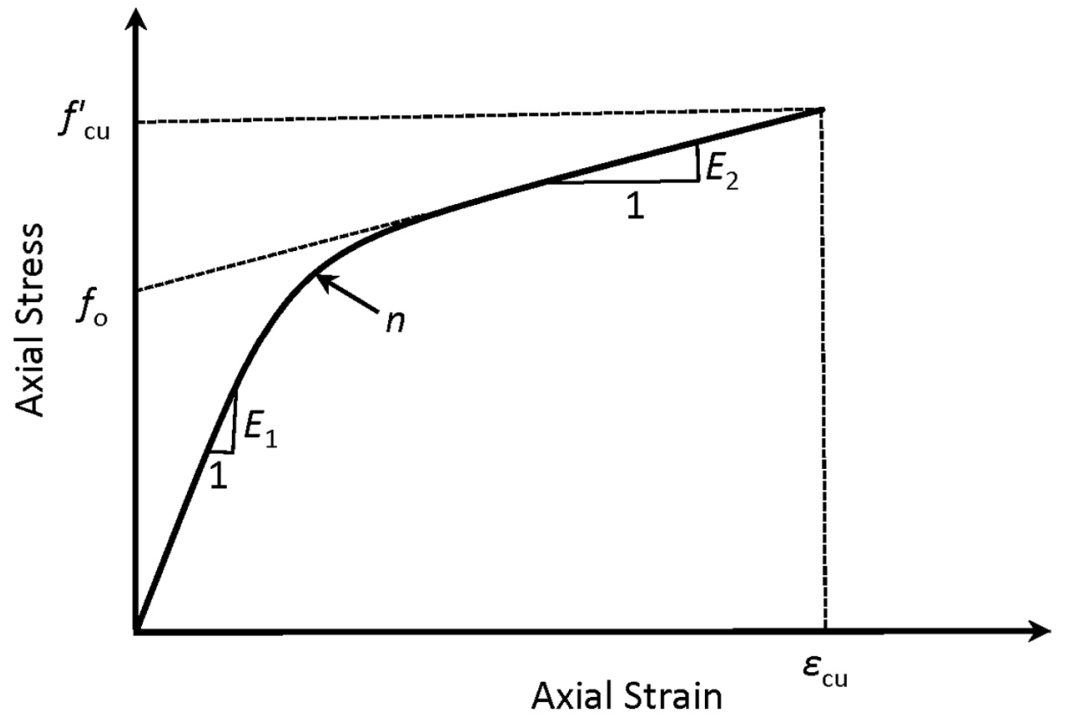

Figure 3.4 Schematic Stress-Strain Model of Samaan 


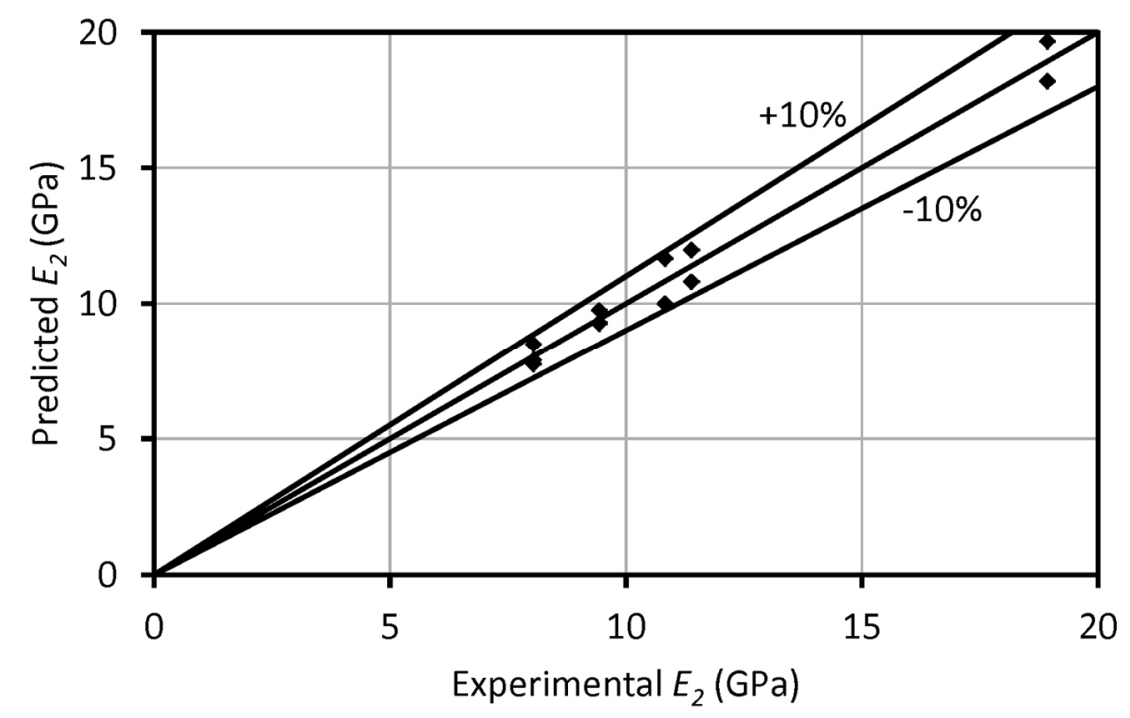

Figure 3.5 Second Slopes $\left(E_{2}\right)$ Predicted by the Recalibrated Model of Samaan versus Test Results

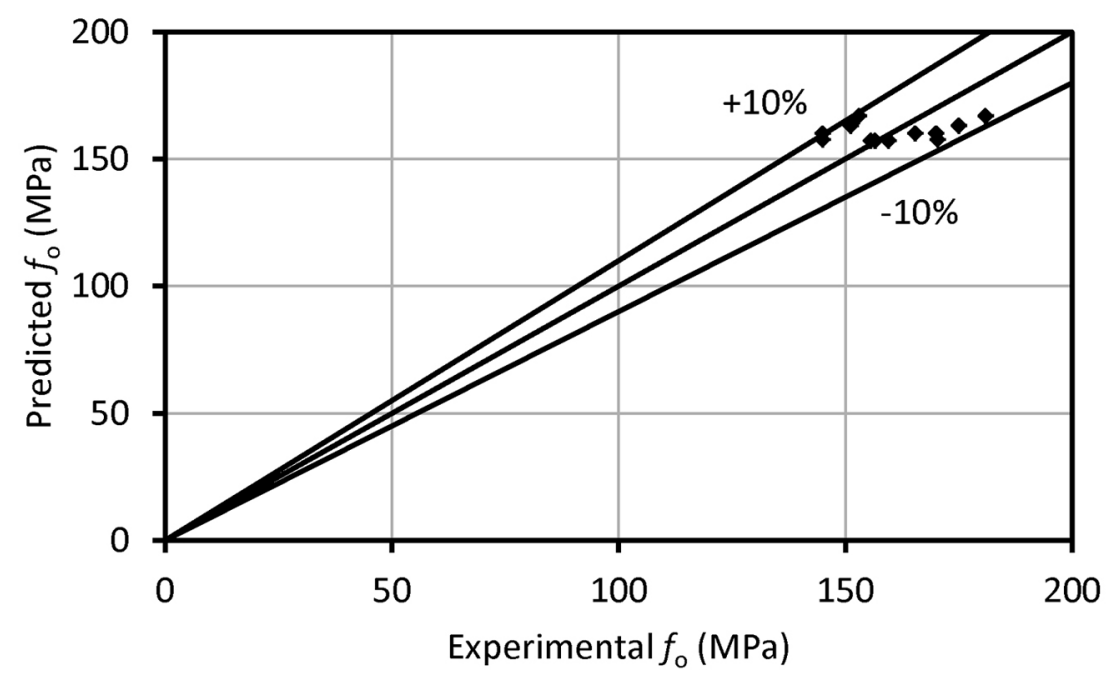

Figure 3.6 Intercept Stresses $\left(f_{o}\right)$ Predicted by the Recalibrated Model of Samaan versus Test Results 


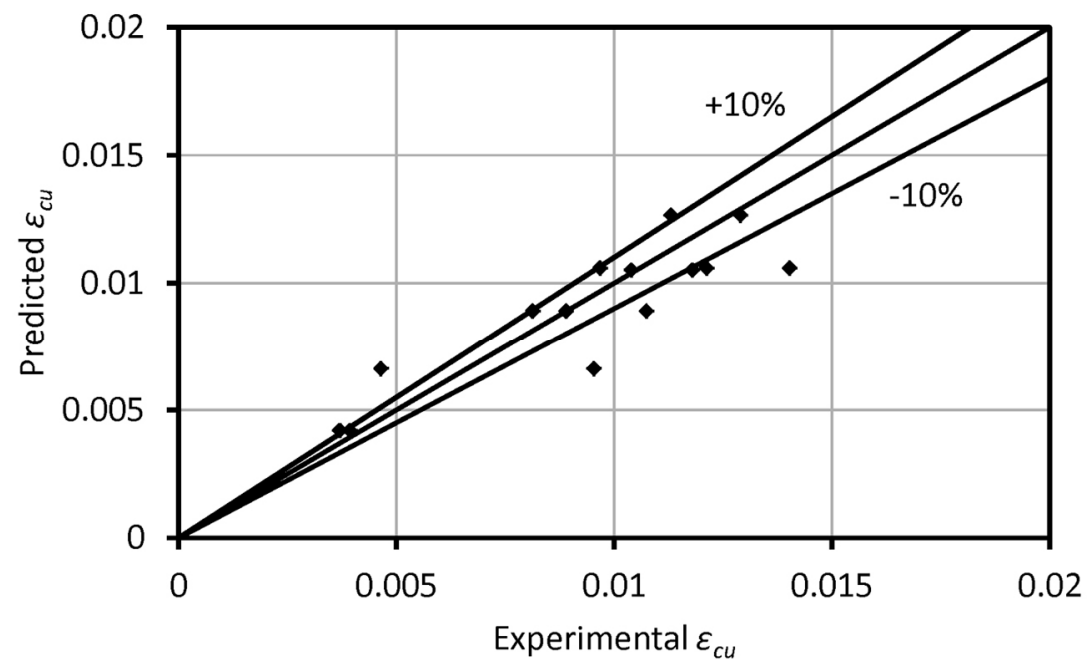

Figure 3.7 Ultimate Strains $\left(\varepsilon_{c u}\right)$ Predicted by the Recalibrated Model of Samaan versus Test Results 


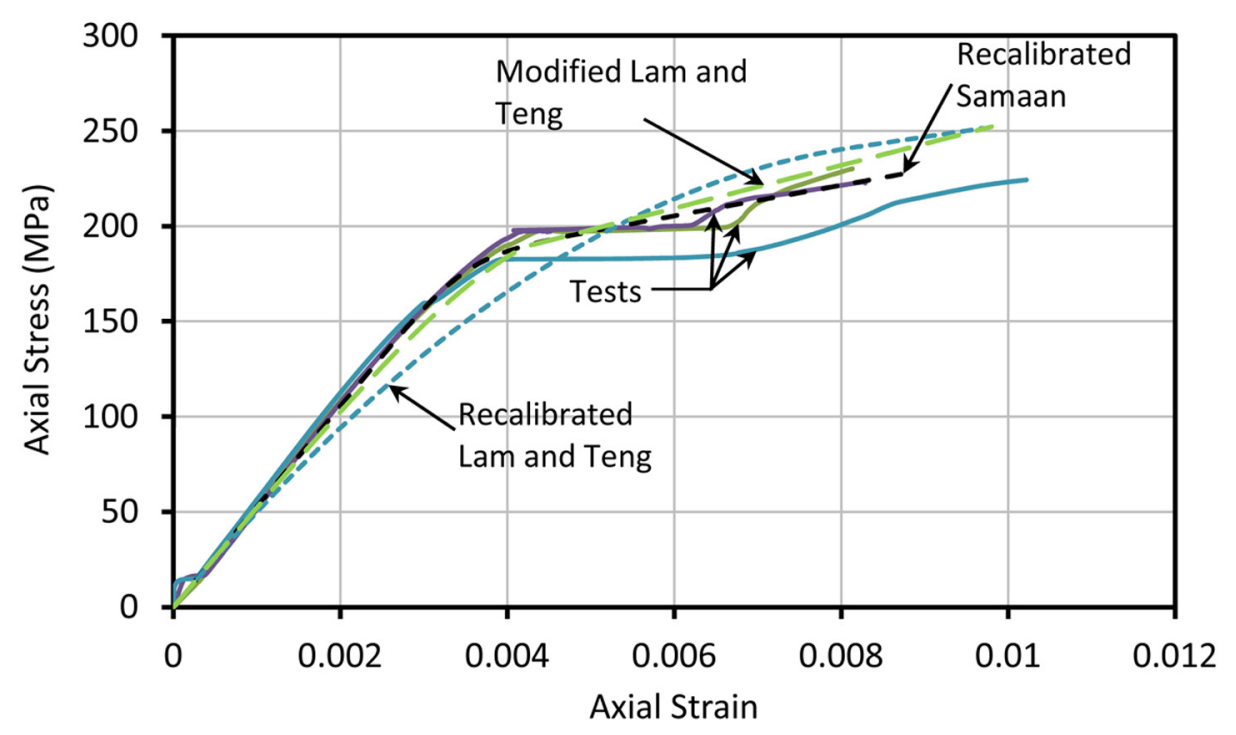

(a)

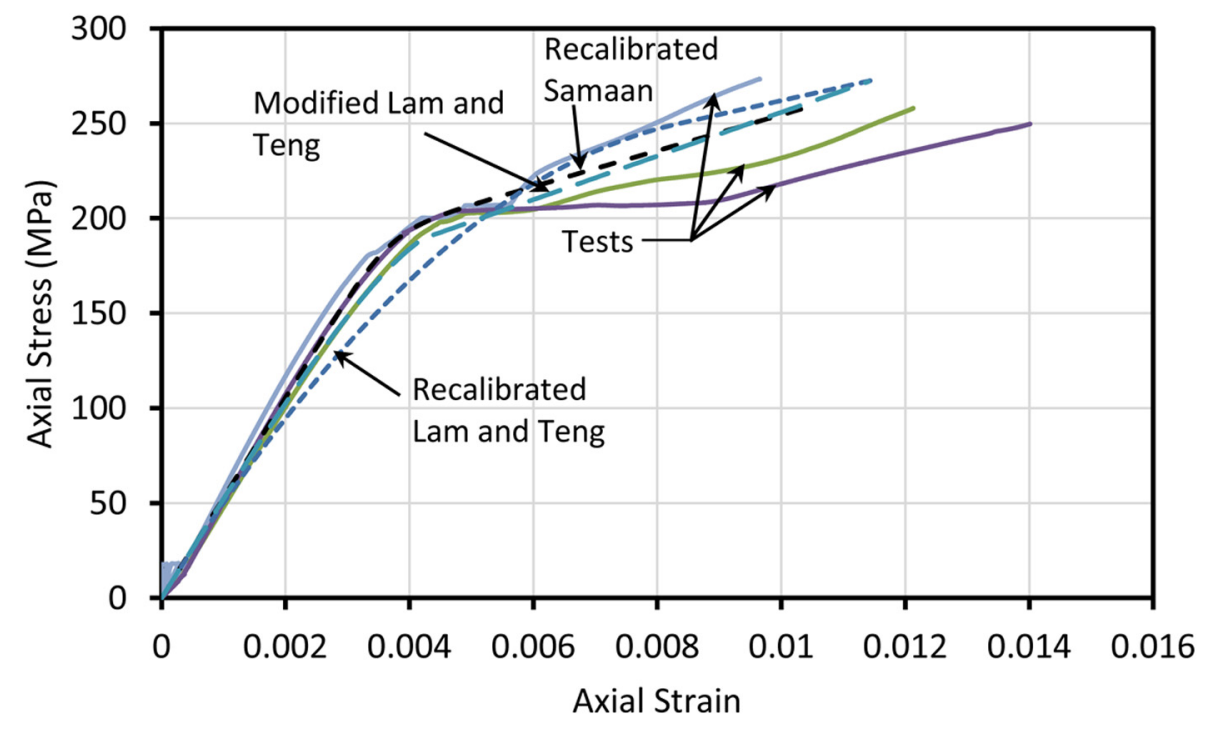

(b) 


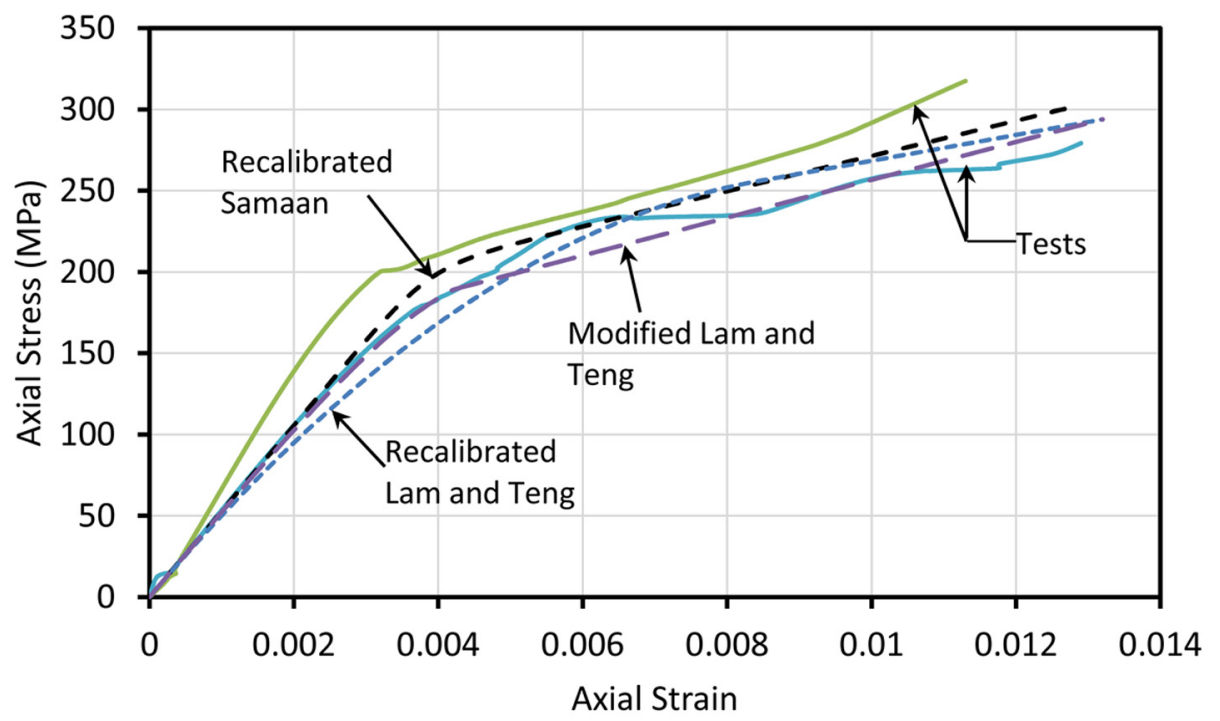

(c)

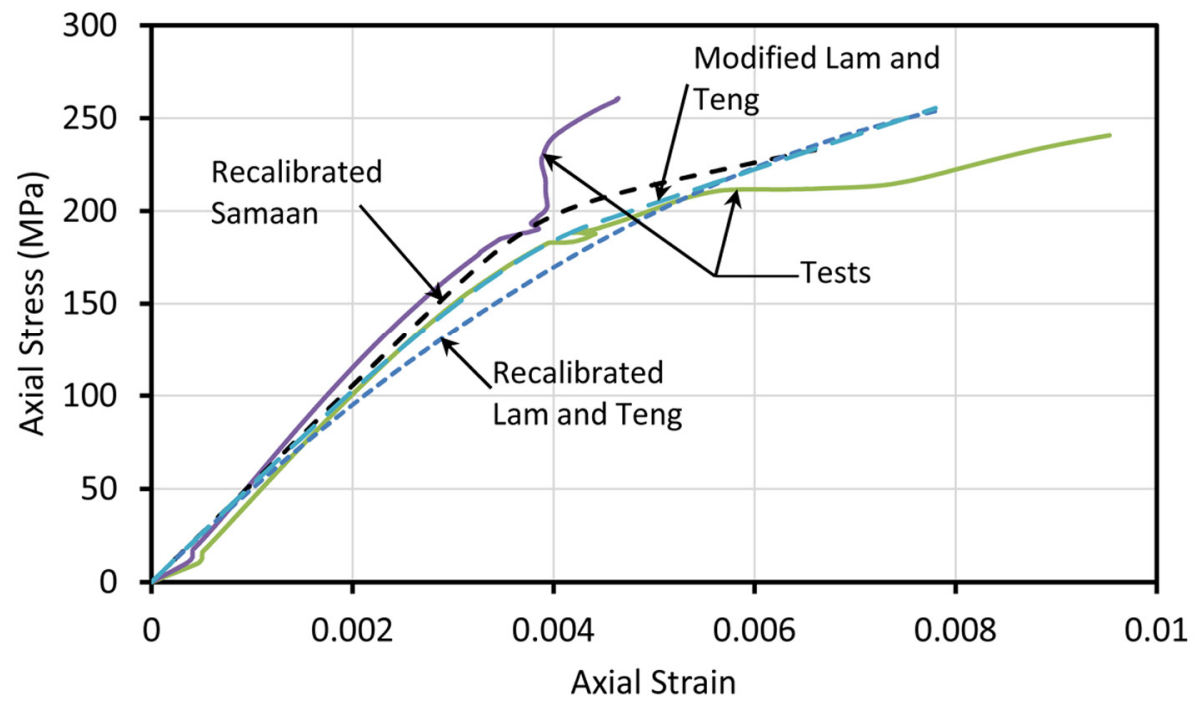

(d) 


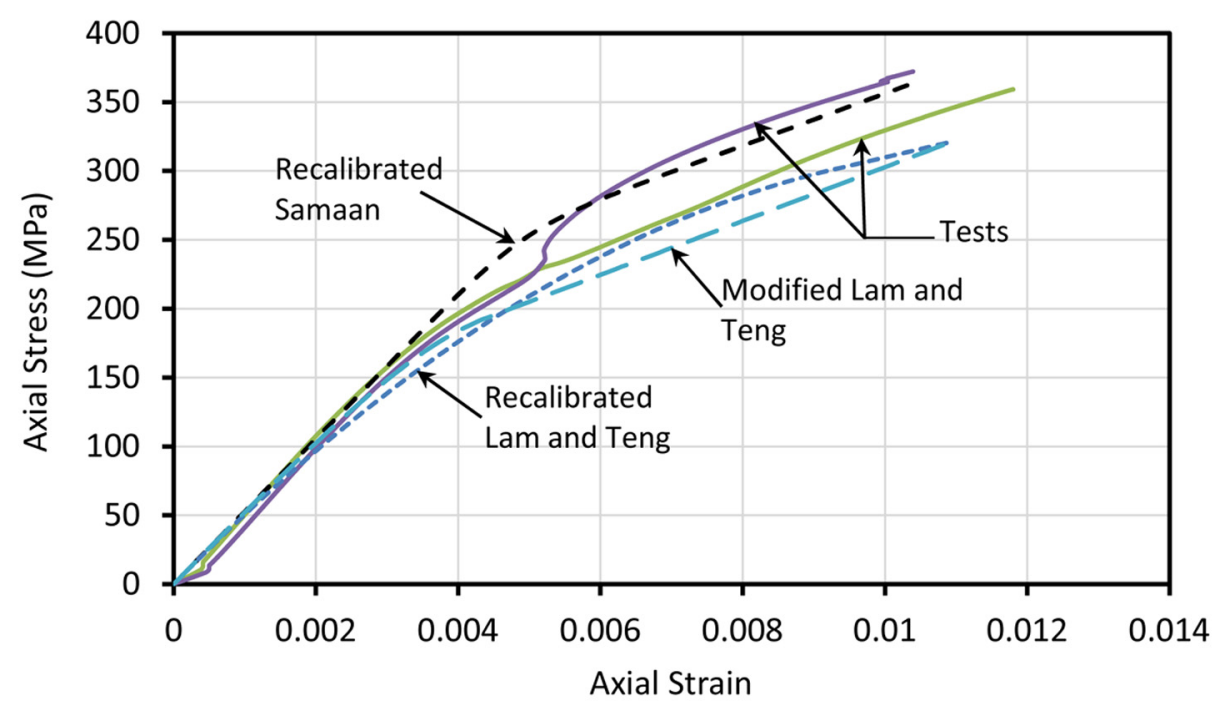

(e)

Figure 3.8 Comparison of Predicted Stress-Strain Responses for Specimens: (a) G3; (b) G4; (c) G5; (d) C2; and (e) C4

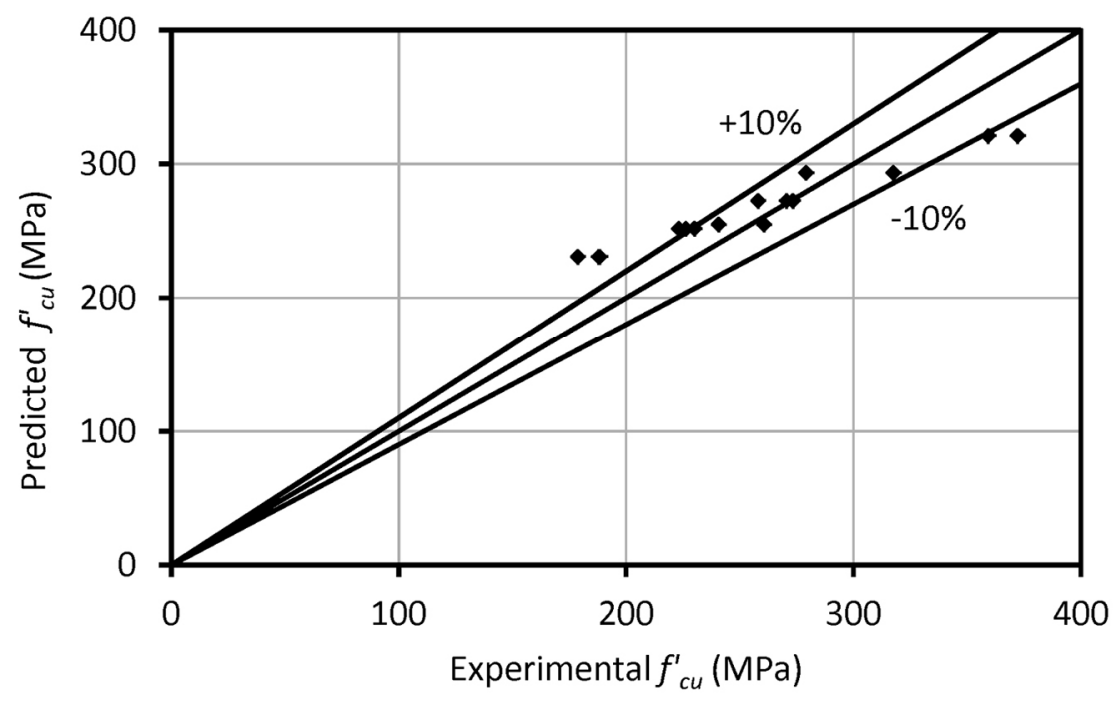

Figure 3.9 Ultimate Strengths $\left(f_{c u}^{\prime}\right)$ Predicted by the Recalibrated Model of Lam and Teng versus Test Results 


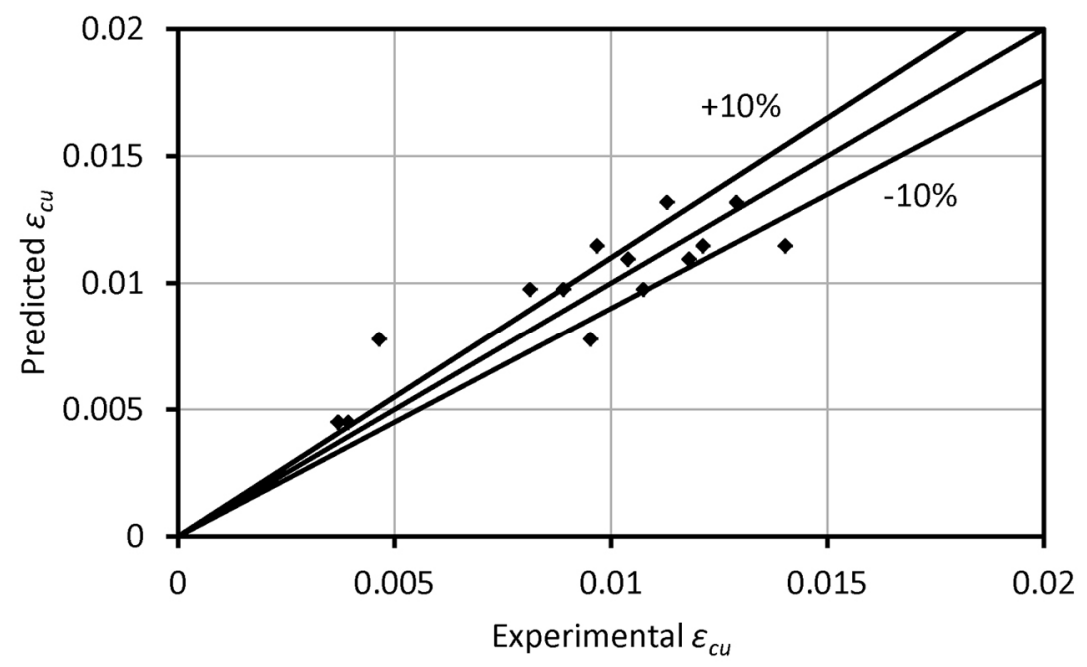

Figure 3.10 Ultimate Strains $\left(\varepsilon_{c u}\right)$ Predicted by the Recalibrated Model of Lam and Teng versus Test Results

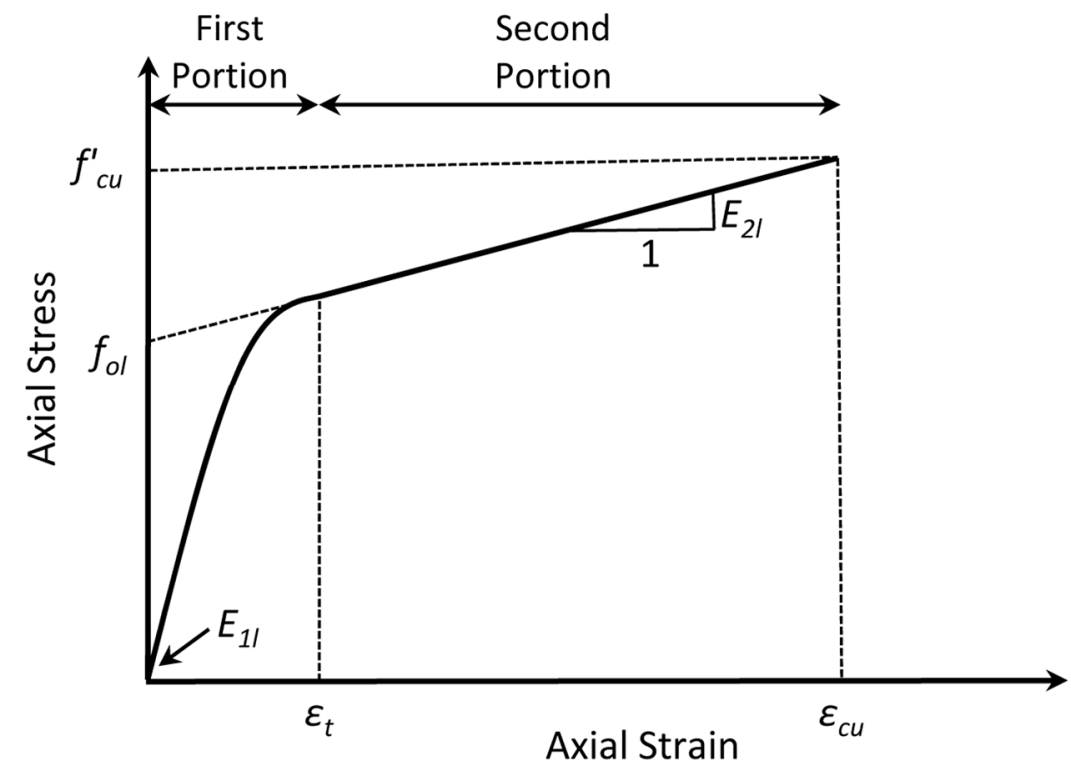

Figure 3.11 Schematic Stress-Strain Model of Lam and Teng 


\title{
4. CYCLIC BEHAVIOR OF HYBRID COLUMNS MADE OF ULTRA-HIGH PERFORMANCE CONCRETE AND FIBER-REINFORCED POLYMERS
}

\author{
Pedram Zohrevand and Amir Mirmiran
}

Accepted for publication in ASCE Journal of Composites for Construction

\begin{abstract}
Combining the unique features of ultra-high performance concrete (UHPC) in damage tolerance, energy absorption and deformability; with the superior performance of concrete-filled fiber-reinforced polymer (FRP) tubes (CFFTs), a novel hybrid system of FRP tube and UHPC was developed, and its cyclic behavior was evaluated. Four specimens were tested. Two were steel-reinforced; one with conventional concrete (RC), and the other (RUHPC) with UHPC within twice the plastic hinge length and conventional concrete for the remainder of the column length. The other two had FRP tubes, one filled with conventional concrete (CFFT), and the other (UHPCFFT) filled with UHPC within twice the plastic hinge length and conventional concrete for the remainder of the column length. Each column was tested as a cantilever under a constant axial load and reverse cyclic lateral loads applied incrementally in displacement control. Each of the tubed specimens without any internal reinforcement achieved the same flexural strength and ductility as its steel-reinforced counterpart. Specimen UHPCFFT showed significantly higher flexural strength and initial stiffness, lower residual drift, and relatively similar energy dissipation as compared to Specimen RC. The proposed hybrid system can be optimized for strength and ductility as a viable alternative to the conventional RC column.
\end{abstract}


Keywords: Columns; Concrete; Cyclic loading; Fiber-reinforced polymers (FRP); Tubes; Ultra-high performance concrete (UHPC).

\subsection{Background}

Over the last two decades, a number of studies have focused on concrete-filled fiber-reinforced polymer (FRP) tubes (CFFT). The first generation of CFFTs was proposed as an angel-ply FRP tube filled with conventional concrete without any internal steel reinforcement (Mirmiran and Shahawy 1995). The CFFT Gen-1 exhibited a relatively ductile failure and comparable strength to its conventional reinforced concrete (RC) counterpart (Mirmiran et al. 1998). Using the FRP tube as a stay-in-place formwork, protective jacket, confinement device, and the sole shear and flexural reinforcement helps speed up the construction, extends the life of the column, eliminates the costs of formwork and its removal, and reduces the maintenance costs.

Evaluation of the cyclic behavior of CFFT Gen-1 (without any steel reinforcement) revealed its limitations, and showed that its failure may be governed by an early rupture of the tube (Seible et al. 1996). Shao and Mirmiran (2005) confirmed this finding with cyclic loading tests on CFFT beam-columns. They indicated that high ductility and energy absorption could be achieved using FRP tubes with off-axis fibers and moderate amount of internal steel reinforcement (1-2\%). Hence, the second generation of CFFTs (Gen-2) was born, consisting of FRP tube with off-axis fibers, conventional concrete, and moderate amount of longitudinal steel reinforcement. The proposed system, however, did not require any transverse steel reinforcement, as the FRP tube still provided the necessary shear and confinement reinforcement. 
Parallel studies on the microstructure of concrete materials have led to the development of ultra-high performance concrete (UHPC). Improvement in material properties such as ductility, toughness, fracture energy, strain hardening, strain capacity, and deformation capacity under both tension and compression loading makes UHPC a promising material for structural applications. UHPC can prevent brittle failure and bond splitting failure, and may also result in higher ductility, smaller crack widths and enhanced damage tolerance (Fukuyama et al. 2000). Furthermore, higher shear resistance of UHPC can reduce the needs for transverse and shear reinforcement (Parra-Montesinos and Chompreda 2007).

Performance of reinforced UHPC columns under cyclic lateral loading was studied by Fischer et al. (2002). The results indicated that the ductile behavior of UHPC allows for high deformation of steel reinforcement, significantly enhances the dissipated energy, and results in full utilization of plastic deformation capacity of steel reinforcement that could not otherwise be achieved in RC members due to shear and compression failure of concrete. In another study by Billington and Yoon (2002), it was shown that higher energy dissipation and damage tolerance can be achieved up to a drift level of $3-6 \%$ in bridge piers with UHPC within the hinge regions. In a recent study by Saiidi et al. (2009), it was shown that the application of UHPC and super-elastic shape memory alloy (SMA) within the plastic hinge region of a column results in a much higher drift capacity and much less residual displacements as compared to conventional RC columns. Although UHPC can significantly increase the dissipated energy in columns, both longitudinal and transverse steel reinforcement are still necessary to achieve a reasonable hysteretic response and ductility level. 
Given the excellent properties of the UHPC, replacing conventional concrete with UHPC in a CFFT system may allow eliminating or significantly reducing the longitudinal steel reinforcement, while producing the same cyclic behavior as that of a conventional RC column. Therefore, the third generation of CFFTs (CFFT Gen-3) consisting of conventional concrete, UHPC (within the plastic hinge zone), and FRP tube with off-axis fibers was developed, and its performance under cyclic loading was investigated in this study.

\subsection{Research Significance}

A unique and novel UHPC-FRP hybrid structural system is proposed to help eliminate or reduce internal steel reinforcement from conventional RC columns. The study provides experimental data on quarter-scale bridge columns made of different concretes and reinforcement, and shows the advantages and limitations of the proposed system. It expands potential applications of UHPC in infrastructure, while highlighting the areas of need for future research.

\subsection{Experimental Program}

\subsubsection{Test Matrix and Specimen Preparation}

Four quarter-scale bridge columns with circular sections were tested in this experimental program. They were sized based on an earlier NEESR (Network for Earthquake Engineering Simulation Research) study on CFFTs (Shi et al. 2011). The test matrix is presented in Table 4.1. All columns were 1,524 $\mathrm{mm}$ high. Served as a reference, Specimen RC incorporated conventional concrete and steel reinforcement. Specimen RUHPC consisted of UHPC within twice the plastic hinge length, and conventional concrete for the remainder of the column length, and steel reinforcement. The plastic 
hinge length was taken equal to the column diameter, based on an analytical simulation using OpenSees 2.0 (http://opensees.berkeley.edu/). The diameter of both RC and RUHPC specimens was $305 \mathrm{~mm}$. Longitudinal reinforcement of $1.6 \%$ included sixteen No. 10M steel bars of Grade $414 \mathrm{MPa}$ throughout the entire length of the two columns, with 508 and $305 \mathrm{~mm}$ embedment into their footings and column heads, respectively. These two steel-reinforced columns additionally included a $4.9 \mathrm{~mm}$ diameter steel wire spiral reinforcement of Grade $414 \mathrm{MPa}$ with $279 \mathrm{~mm}$ outside diameter placed at a pitch of $32 \mathrm{~mm}$. Figure 4.1 shows the steel reinforcement of Specimens RC and RUHPC.

An off-the-shelf filament-wound FRP tube with a 75\% glass content made of 17 layers of $\pm 55^{\circ}$ E-glass fibers and a thermosetting epoxy resin was used for the other two specimens. Earlier studies (Shao and Mirmiran 2005) had verified the benefits of this particular winding angle to improve ductility of CFFT columns. The tube had an inside diameter of $312 \mathrm{~mm}$ and a wall thickness of $6 \mathrm{~mm}$. The mechanical properties of the FRP tube are presented in Table 4.2. Specimen CFFT was filled with conventional concrete for its entire length, whereas Specimen UHPCFFT was filled with UHPC within twice the equivalent plastic hinge length and conventional concrete for the remainder of the column length. No steel reinforcement was used in either column. The tubes were embedded 305 and $152 \mathrm{~mm}$ into their footings and column heads, respectively, in order to provide sufficient development length for transfer of forces. Figure 4.2 shows the FRP tubes embedded into the footing. Since there was no steel reinforcement in the tubed columns, a number of $150 \mathrm{~mm}$ long No. 10M steel bars of Grade $414 \mathrm{MPa}$ were installed as shear connectors within the embedded lengths of the tubes to prevent any potential slippage. Additional slots were cut out from the embedded tubes to accommodate PVC 
ducts and the reinforcement of the footings or the column heads. To avoid the concrete cast in the footings from entering into the embedded tubes, the bottom of FRP tubes were covered using a fine mesh window screen, which also provided a rough interface. Figure 4.3 shows the shear connectors and the screen at the bottom of FRP tubes. Similar arrangement was made at the bottom of (and around) the embedded steel bars in the two steel-reinforced specimens.

Each pair of columns was placed onto one footing, although each column was tested separately. Both footings were cast in a single batch of concrete with a 28 -day compressive strength of $33.3 \mathrm{MPa}$, measured as an average of three $152 \times 305 \mathrm{~mm}$ companion cylinders. Another batch of conventional concrete with a measured 28-day compressive strength of 50.9 MPa was used for all columns and column heads. The UHPC used in this study was an available commercial product, Ductal ${ }^{\circledR}$, made by Lafarge, and composed of premix powder, water, superplasticizer, and $2 \%$ metallic fibers by volume. The premix powder included cement, silicafume, ground quartz, and sand, but no coarse aggregate. The fibers were $13 \mathrm{~mm}$ long, with a tensile strength of 2,800 MPa. The typical axial stress-strain curve of the UHPC used in this study is shown in Figure 4.4, based on the manufacturer data, and verified through a number of studies (e.g., Graybeal 2005). Two different batches of UHPC were used for Specimens RUHPC and UHPCFFT with 28-day compressive strengths of $151.7 \mathrm{MPa}$ and $162.7 \mathrm{MPa}$, respectively, each measured as an average of three $102 \times 205 \mathrm{~mm}$ companion cylinders (see Table 4.1). 


\subsubsection{Test Setup and Instrumentation}

Each specimen was tested vertically, with the footing tied down using 16 threaded rods through two tubular steel beams. Four other threaded rods tied the footing to the steel reaction frame through a steel tie beam. The column head was connected to the actuator using a steel shoe and four threaded rods passed through the ducts inside the column head. Two 2,794 $\mathrm{mm}$ long steel beams, one on each side of the footing restrained any unintended rotation in the horizontal plane. Each specimen was subjected to an external post-tensioning force of $89 \mathrm{kN}$ to simulate the dead load acting on the column, corresponding to $0.03 \mathrm{f}^{\prime}{ }_{c} \mathrm{~A}_{\mathrm{g}}$, where $\mathrm{f}_{\mathrm{c}}$ is 28 -day compressive strength of conventional concrete, and $\mathrm{A}_{\mathrm{g}}$ is the gross cross sectional area of the column. Using two threaded rods through column head and footing, post-tensioning was carried out with two interconnected hydraulic jacks controlled by a single hand pump. All threaded rods were Grade B-7 with a diameter of $25.4 \mathrm{~mm}$ and yield strength of $724 \mathrm{MPa}$. The test setup is shown in Figure 4.5.

Figures $4.6 \mathrm{a}$ and $4.6 \mathrm{~b}$ show the instrumentation plan for the steel-reinforced and tubed specimens, respectively, following the instrumentation legend shown in Figure 4.6c. Two high-speed data acquisition systems were used synchronously to provide up to 40 simultaneous readings at a frequency of $1 \mathrm{~Hz}$, including load and displacement output from the actuator.

Four string potentiometers with a range of $305 \mathrm{~mm}$ were placed at $381 \mathrm{~mm}$ spacing starting from $152 \mathrm{~mm}$ above the column base on one side of each column to monitor lateral displacements. Slippage of FRP tube at column base was monitored using two $38 \mathrm{~mm}$ range linear potentiometers, placed on the two sides of the column in the 
loading plane. Two inclinometers were placed at the centers of the column heads, on opposite sides, to monitor their rotations. Seven strain gages were attached to the longitudinal bars on each side of steel-reinforced specimens in the loading plane at 152 $\mathrm{mm}$ spacing starting from $152 \mathrm{~mm}$ below the column base. Five surface-mounted strain gages were placed along each side of these two columns in the longitudinal direction in the loading plane at $152 \mathrm{~mm}$ spacing from the column base. The two tubed specimens were instrumented with seven surface-mounted strain gages along each side of the tubes in the longitudinal direction in the loading plane with a spacing of $152 \mathrm{~mm}$ starting from $152 \mathrm{~mm}$ below the column base. Each column was further instrumented with two strain gages placed on opposite sides of the column base in the hoop direction. One load cell was placed in line with each of the two hydraulic jacks to monitor any fluctuation in the axial load during the test.

\subsubsection{Test Procedure and Observations}

Each specimen was first subjected to the external post-tensioning force. Subsequently, a reverse cyclic lateral load was applied incrementally in displacement control. Column drift was applied in terms of displacement ductility $\mu$, i.e., the ratio of the imposed displacement to a reference displacement. The reference displacement corresponded to the first yielding of the longitudinal steel in the control RC column, found as $10.2 \mathrm{~mm}$ by monotonically pulling the column.

At each level of ductility, two full cycles of reverse lateral loading were applied. The loading rate was $0.15 \mathrm{~mm} / \mathrm{s}$ for Specimen RC. However, since this rate was later deemed too slow, it was increased to $0.3 \mathrm{~mm} / \mathrm{s}$ for the other three specimens. All 
specimens were tested past their respective peak loads for up to a maximum load drop of $30 \%$.

Specimen RC showed cracking and failure mode typical of conventional reinforced concrete columns, although it was inadvertently pushed up to $483 \mathrm{~mm}$ head displacement prior to cyclic loading. The failure of Specimen RC occurred at $\mu=10$, with concrete spalling and crushing at column base exposing the reinforcement. Specimen RUHPC failed at $\mu=7$, with cracks first visible at $\mu=3$, and increasing mainly in length and number rather than width throughout subsequent cycles. Following on to failure, thin cracks propagated around the column perimeter, without any cover spalling. In Specimen CFFT, at $\mu=5$ while being pulled, the tube suffered small cracks on the tension side at column base, accompanied with a load drop. However, the cracks did not extend further, and the load kept on increasing until $\mu=8$ when the cracks widened significantly. Specimen UHPCFFT remained intact without any noticeable matrix cracking, until failure at $\mu=7$ when the tube cracked at column base on the tension side. Both tubed specimens failed with tube rupture, a loud noise, and a noticeable load drop.

\subsection{Test Results and Discussion}

\subsubsection{Hysteretic Response}

Figure 4.7 shows the hysteretic moment-deflection responses of all specimens. The total moment includes both the primary (lateral) moment and the secondary $(P-\Delta)$ effects at column base, where $P$ is the axial load and $\Delta$ is the column head displacement. The deflection is shown both in terms of column head displacement $\Delta$ and the drift ratio $\Delta L$, where $L$ is the shear span. The failure mode for each specimen is shown in the respective figure inset. 
Since Specimen RC was inadvertently damaged by pre-loading in the push direction, an OpenSees model was used to simulate the undamaged response in that direction. The simulation was based on the nonlinear beam-column element option with pre-defined materials models. It assumed plain sections remain plane after bending, and ignored any buckling and slippage of reinforcement. The column was divided into sixteen equal segments. The cross section was divided into a core concrete, steel reinforcement and the cover concrete, each modeled with a fine mesh to capture its stress conditions. The model was previously calibrated in an earlier study by the second author (Shi et al. 2011). The simulation results are shown in Figure 4.7a as dashed line, indicating that Specimen RC was unaffected in the pull direction. Hence, test data in the pull direction and the simulation data in the push direction were used for Specimen RC.

Specimen $\mathrm{RC}$ failed at $\mu=10$, to some extent due to its lower loading rate. Specimen RUHPC reached its peak strength at $\mu=2$, after which the strength gradually decreased until $\mu=7$ by $17 \%$. The strength of Specimen CFFT continued to increase in the push direction, while it saw a $20 \%$ load drop at $\mu=5$ in the pull direction. This was associated with very small diagonal cracks on the tension side of the tube at column base. Then, the strength continued to increase until $\mu=8$, when a significant load drop was noted at the second cycle in the pull direction, as a result of sizeable cracks in the tube (see figure inset). Specimen UHPCFFT reached its peak strength at $\mu=4$, after which the strength decreased until $\mu=7$ by $37 \%$. A significant load drop occurred at the second cycle of $\mu=7$ in the pull direction, which was due to major cracks at column base on the tension side of the tube (see figure inset). 


\subsubsection{Response Envelope}

Figure 4.8 compares the moment-drift ratio envelope curves of the specimens in the pull direction. The data was calculated based on the first cycle for each level of ductility displacement. Comparing the envelope of Specimen RC with that of CFFT, and the envelope of Specimen RUHPC with that of UHPCFFT shows that replacing steel reinforcement with FRP tube may result in almost the same load and deformation capacities. Moreover, the ultimate displacements in Specimens CFFT, RUHPC, and UHPCFFT were about the same, although lower than that in Specimen RC. This may be attributed in part to the lower loading rate in Specimen RC. On the other hand, it is clear that replacing conventional concrete with UHPC within twice the plastic hinge length from the column base has significantly increased both strength and stiffness.

\subsubsection{Energy Dissipation}

Figure 4.9 compares the cumulative dissipated energy of the specimens in the pull direction. The cumulative dissipated energy is calculated based on the area within the hysteresis loops (Chopra 2008), considering only the first cycle for each level of ductility displacement. It is clear that UHPC significantly increases the dissipated energy and the rate of energy dissipation for the same level of ductility. On the other hand, tubed specimens show lower dissipated energy and dissipation rate at the same level of ductility, as compared to their steel-reinforced counterparts. Comparing Specimens UHPCFFT and RC shows that the combination of UHPC and FRP tube results in a similar energy dissipation response as that of Specimen RC up to a 3\% drift. 


\subsubsection{Performance Measures of Stiffness and Ductility}

Table 4.3 compares performance measures of the specimens in stiffness and ductility. The data represents the averages of the push and pull directions. The initial stiffness is based on the elastic slope of the response. The $R^{2}$, coefficient of determination, was derived from the linear regression analysis of the slope within the elastic range. Using FRP tube instead of steel reinforcement decreased the stiffness by $27 \%$, whereas replacing conventional concrete with UHPC increased the stiffness by $28 \%$. As such, Specimen UHPCFFT showed a comparable stiffness relative to Specimen $\mathrm{RC}$, with a modest $10 \%$ increase.

Ductility of a member is defined as its ability to sustain inelastic deformation prior to collapse, without a significant decrease of strength. It is typically measured as the ratio of the ultimate deflection to the yield deflection. The ultimate deflection is considered to be the deflection at failure as long as the load drop is no more than $15 \%$ of the capacity (Park and Paulay 1975). The yield deflection is defined as that of an equivalent elasto-plastic system with the same elastic stiffness and ultimate load as those of the real system. Table 4.3 compares the ductility of the specimens in terms of drift ratios. The yield drift ratio was computed by dividing the ultimate moment by the initial stiffness.

The table shows that replacing conventional concrete with UHPC, on average, results in a $16 \%$ drop in ductility. The drop, which is slightly more for the tubed specimen relative to the steel-reinforced specimen, may be attributed to two factors - the confinement ratio and the reinforcement index, both of which are shown in the table. Firstly, given the higher compressive strength of UHPC, confinement ratios for 
Specimens RUHPC and UHPCFFT are about $1 / 3$ of those in Specimens RC and CFFT, respectively. The lower confinement ratio may have prevented the UHPC from reaching its full dilation capacity. Secondly, the reinforcement indices for Specimens RUHPC and UHPCFFT are also about $1 / 3$ of those in Specimens RC and CFFT, respectively, again because of the higher compressive strength of UHPC. The lower reinforcement index may have prevented the UHPC from reaching its full crushing capacity. It should be noted, however, that neither the confinement ratio nor the reinforcement index was considered in the design of the experiments, the sole purpose of which was to assess the feasibility of hybrid construction. Although the high deformation capacity of UHPC was not realized fully in Specimen UHPCFFT, the trilinear stress-strain response of FRP tube resulted in a reasonable ductility for this specimen without any internal steel. The proposed system also developed higher stiffness and strength than Specimen RC, although it had a lower reinforcement index. The experiments have indeed shown the feasibility of the proposed system and the potential for optimizing its design by making the lateral and longitudinal fiber architecture of the FRP tube more compatible with the higher strength and deformability of the UHPC.

\subsubsection{Load-Strain Response and Plastic Hinge Zone}

Figure 4.10 shows strain profiles for the extreme tension steel bar in Specimen RUHPC in the pull direction at different levels of ductility. The locations of the strain gages are noted as SG on the right hand side. At all ductility levels, strains showed a slight increase at the joint between UHPC and the conventional concrete. This phenomenon, which was also observed in Specimen UHPCFFT, may be attributed to the lower stiffness of conventional concrete relative to UHPC. 


\subsubsection{Slippage and Residual Deflections}

Figures 4.11a and 4.11b show the moment-slippage of FRP tubes in Specimens CFFT and UHPCFFT, respectively, out of their footings. The Left/Right markers indicate location of the potentiometers, and Compression/Tension denotes the respective state of stress. Higher slippage is noted in the second cycle at each ductility level. Also, slippage is expectedly larger in tension than in compression. Although slippage in both specimens is insignificant, Specimen UHPCFFT shows higher slippage than Specimen CFFT, commensurate with its higher flexural strength.

Figure 4.12 compares the average residual drift ratios at zero loading for Specimens RUHPC, CFFT, and UHPCFFT at each ductility level in. It is clear that the elastic behavior of FRP tube substantially decreases the residual displacements. This realignment feature is quite valuable after a small or moderate earthquake.

\subsection{Conclusions}

The cyclic behavior of a hybrid column made of FRP tube and UHPC was studied in comparison with three other types of columns made of different combinations of conventional concrete, steel reinforcement, FRP tube, and UHPC.

Failure of Specimen RUHPC was marked with distributed small cracking, without any cover spalling or crushing, in contrast to conventional RC columns. On the other hand, tubed specimens failed with cracking of FRP tube at column base on the tension side. Slippage did not pose any issue with either of the two tubed specimens. Moreover, the elastic behavior of FRP tube substantially decreased the residual displacements, which can be viewed as a valuable re-alignment feature for seismic regions. 
Comparing the response envelopes, replacing steel reinforcement with FRP tube resulted in almost the same load and deformation capacities. On the other hand, replacing conventional concrete with UHPC within the plastic hinge length significantly increased both strength and stiffness, interestingly at a much lower reinforcement index.

On the other hand, the higher compressive strength of UHPC led to a lower confinement ratio and reinforcement index that may have prevented the UHPC from reaching its full dilation and crushing capacity. However, the proposed system still demonstrated a reasonable ductility without any internal steel. The potential exists for optimizing the proposed hybrid system by balancing its strength and ductility demands, and making the lateral and longitudinal fiber architecture of the FRP tube more compatible with the higher strength and deformability of the UHPC. Further research is also needed on the impact of minimum steel reinforcement.

\section{Acknowledgements}

This study was sponsored by the NSF-Network for Earthquake Engineering Simulation Research (NEESR) program, as part of the multi-university Grant No. CMS0420347 directed by Professor M. Saiid Saiidi at the University of Nevada, Reno. The experiments were carried out at the Titan America Structures and Construction Laboratory of the Florida International University. Findings and opinions expressed here, however, are those of the authors alone, and not necessarily the views of sponsoring agencies. 


\section{References}

Billington, S.L., and Yoon, J. (2002). "Cyclic Behavior of Precast Post-Tensioned Segmental Concrete Columns with ECC." Proceedings of the JCI International Workshop on Ductile Fiber Reinforced Cementitious Composites (DFRCC) Application and Evaluation (DRFCC-2002), Takayama, Japan, 279-288.

Chopra A.K. (2008). Dynamics of Structures (Third Edition), Prentice-Hall, New Jersey.

Fischer, G., Fukuyama, H., and Li, V.C. (2002). "Effect of Matrix Ductility on the Performance of Reinforced ECC Column Members under Reversed Cyclic Loading Conditions." Proceedings of the JCI International Workshop on Ductile Fiber Reinforced Cementitious Composites (DFRCC) - Application and Evaluation (DRFCC-2002), Takayama, Japan, 269-278.

Fukuyama, H., Sato, Y., Li, V.C., Matsuzaki, Y., and Mihashi, H. (2000). "Ductile Engineered Cementitious Composite Elements for Seismic Structural Applications." Proceedings of the 12th World Conference on Earthquake Engineering, Auckland, New Zeland, Paper 1672.

Mirmiran, A., Samaan, M., Cabrera, S., and Shahawy, M. (1998). "Design, Manufacture and Testing of a New Hybrid Column." Construction \& Building Materials, Elsevier, 12(1), 39-49.

Mirmiran, A., and Shahawy, M. (1995). "Novel FRP-Concrete Composite Construction for the Infrastructure." Proceedings of the Structures Congress, ASCE, Vol. 2, 1663-1666.

Park R. and Paulay T. (1975). Reinforced Concrete Structures, John Wiley \& Sons, New York.

Parra-Montesinos, G., and Chompreda, P. (2007). "Deformation Capacity and Shear Strength of Fiber-Reinforced Cement Composite Flexural Members Subjected to Displacement Reversals." Journal of Structural Engineering, ASCE, 133(3), 421431.

Saiidi, M., O'Brien, M., and Mahmoud, S. (2009). "Cyclic Response of Concrete Bridge Columns using Superelastic Nitinol and Bendable Concrete." Structural Journal, ACI, 106(1), 69-77.

Seible, F., Burgueño, R., Abdallah, M.G., and Nuismer, R. (1996). "Development of Advanced Composite Carbon Shell Systems for Concrete Columns in Seismic Zones." Proceedings of the 11th World Conference on Earthquake Engineering, Pergamon-Elsevier Science, 1375, Oxford, U.K. 
Shao, Y., and Mirmiran, A. (2005). "Experimental Investigation of Cyclic Behavior of Concrete-Filled Fiber Reinforced Polymer Tubes." Journal of Composites for Construction, ASCE, 9(3), 263-273.

Shi, Y., Li, B., and Mirmiran, A. (2011). "Combined Shear and Flexural Behavior of Hybrid FRP-Concrete Beams Previously Subjected To Cyclic Loading." Journal of Composites for Construction, ASCE, 15(5), 841-849. 
Table 4.1 Test Matrix

\begin{tabular}{cccccccccc}
\hline \hline Specimen & $\begin{array}{c}\text { Column } \\
\text { Length } \\
(\mathrm{mm})\end{array}$ & $\begin{array}{c}\text { UHPC } \\
\text { Length } \\
(\mathrm{mm})\end{array}$ & $\begin{array}{c}\text { Tube } \\
\text { Thickness } \\
(\mathrm{mm})\end{array}$ & $\begin{array}{c}\text { Column } \\
\text { Outside } \\
\text { Diameter } \\
(\mathrm{mm})\end{array}$ & $\begin{array}{c}\mathrm{f}_{\mathrm{cc}}^{*} \\
(\mathrm{MPa})\end{array}$ & $\begin{array}{c}\mathrm{f}^{\prime}{ }^{* *} \\
(\mathrm{MPa})\end{array}$ & $\begin{array}{c}\text { Longitudinal } \\
\text { Reinforcement }\end{array}$ & $\begin{array}{c}\text { Transverse } \\
\text { Reinforcement }\end{array}$ & FRP \\
\hline RC & 1,524 & N/A & N/A & 305 & 50.9 & N/A & 16 No.10M & W 2.9 Spiral & None \\
\hline RUHPC & 1,524 & 610 & N/A & 305 & 50.9 & 151.7 & 16 No.10M & W 2.9 Spiral & None \\
\hline CFFT & 1,524 & N/A & 5 & 323 & 50.9 & N/A & None & None & $\begin{array}{c}17 \text { Layers of } \\
\pm 55^{\circ} \text { E-Glass }\end{array}$ \\
\hline UHPCFFT & 1,524 & 610 & 5 & 323 & 50.9 & 162.7 & None & None & $\begin{array}{c}17 \text { Layers of } \\
\pm 55^{\circ} \text { E-Glass }\end{array}$ \\
\hline \hline
\end{tabular}

* 28-day compressive strength of conventional concrete

** 28-day compressive strength of UHPC 
Table 4.2 Mechanical Properties of FRP Tube ${ }^{*}$

\begin{tabular}{ccccccc}
\hline \hline $\begin{array}{c}\text { Type of } \\
\text { FRP }\end{array}$ & Product & $\begin{array}{c}\text { Tensile } \\
\text { Strength } \\
(\mathrm{MPa})\end{array}$ & $\begin{array}{c}\text { Tensile } \\
\text { Modulus } \\
(\mathrm{GPa})\end{array}$ & $\begin{array}{c}\text { Hoop } \\
\text { Strength } \\
(\mathrm{MPa})\end{array}$ & $\begin{array}{c}\text { Flexural } \\
\text { Strength } \\
(\mathrm{MPa})\end{array}$ & $\begin{array}{c}\text { Flexural } \\
\text { Modulus } \\
(\mathrm{GPa})\end{array}$ \\
\hline \hline GFRP & $\begin{array}{c}\text { Red Thread II } \\
\text { Pipe }\end{array}$ & 71.0 & 12.6 & 234 & 158 & 15.0 \\
\hline \hline
\end{tabular}

*As reported by the manufacturer, Smith Fiberglass of Little Rock, AR.

Table 4.3 Performance Measures of Stiffness and Ductility

\begin{tabular}{ccccc}
\hline Specimen & RC & RUHPC & CFFT & UHPCFFT \\
\hline \hline Initial Stiffness (kN.mm) & 96.2 & 123 & 70.5 & 105 \\
\hline$R^{2}$ & 0.998 & 0.996 & 0.985 & 0.995 \\
\hline Ultimate Moment (kN.m) & 119 & 120 & 98.8 & 126 \\
\hline Yield Drift Ratio (\%) & 1.24 & 0.98 & 1.40 & 1.21 \\
\hline Ultimate Drift Ratio (\%) & 6.67 & 4.70 & 5.30 & 3.58 \\
\hline Ductility & 5.4 & 4.8 & 3.8 & 3.0 \\
\hline Confinement Pressure (MPa) & 1.8 & 1.8 & 8.2 & 8.2 \\
\hline $\begin{array}{c}\text { Confinement Ratio } \\
\text { Longitudinal Reinforcement } \\
\text { Index }\left(\omega^{*}\right)\end{array}$ & 0.04 & 0.014 & 0.16 & 0.051 \\
\hline \hline
\end{tabular}

$* \omega=\rho \times \frac{f_{y, f}}{f_{c c, c u}^{\prime}}(\rho:$ ratio of longitudinal steel reinforcement or FRP cross-sectional area to gross sectional area of the column, $f_{y, f}$ : yield strength of steel reinforcement or longitudinal tensile strength of FRP tube, $f_{c c, c u}^{\prime}$ : 28-day compressive strength of conventional concrete or UHPC ) 


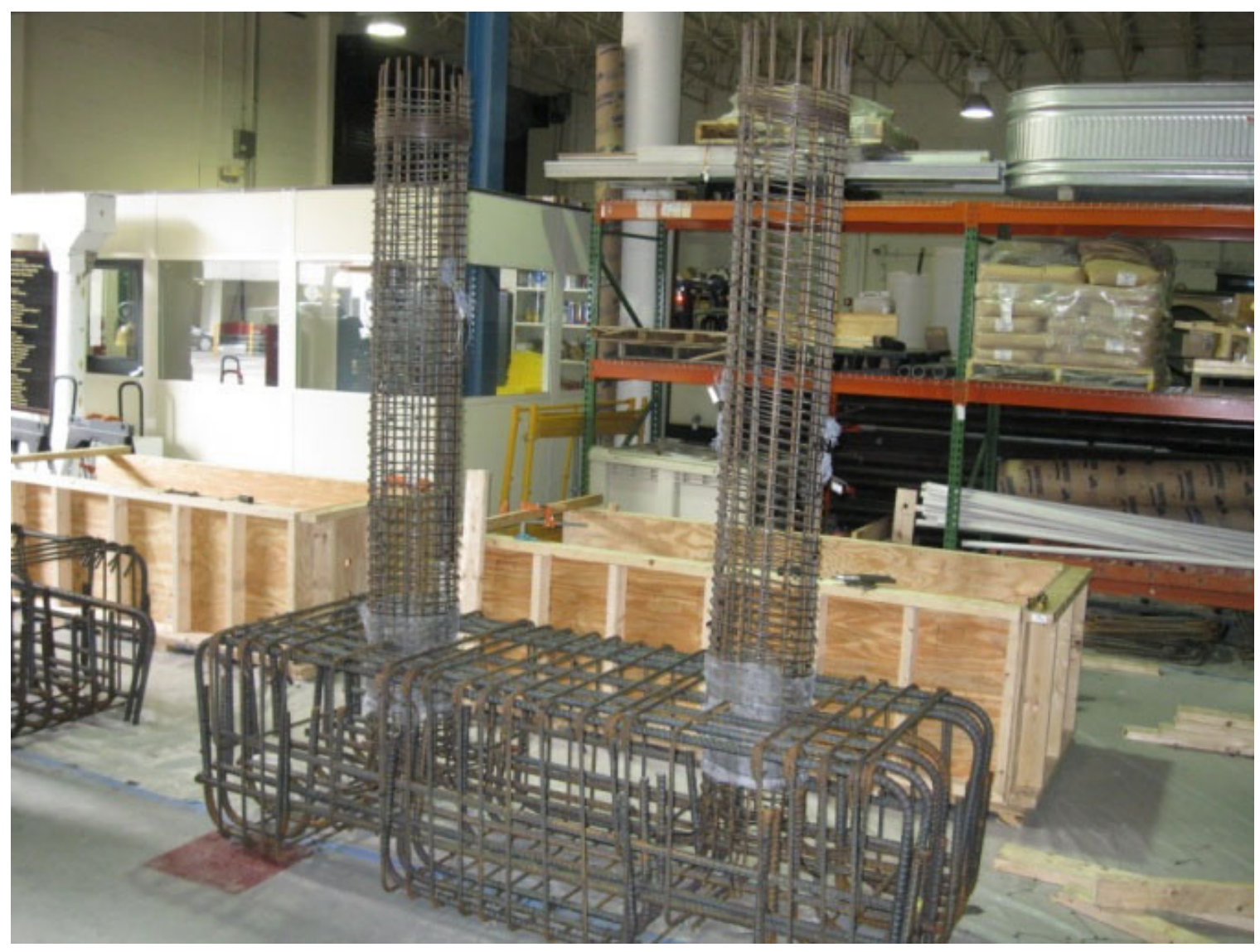

Figure 4.1 Reinforcement Cages for Specimens RC and RUHPC 


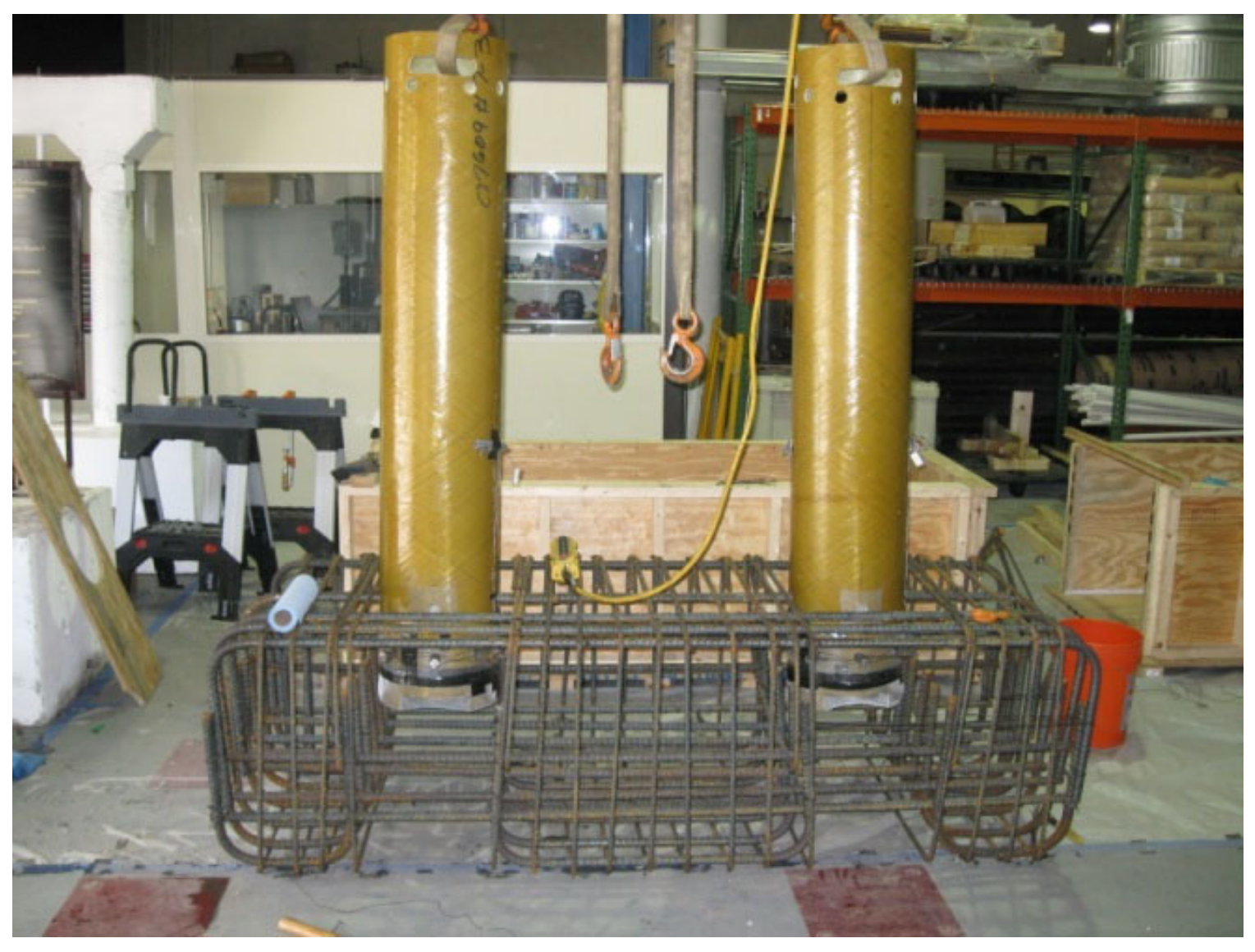

Figure 4.2 Embedded FRP Tubes for Specimens CFFT and UHPCFFT 


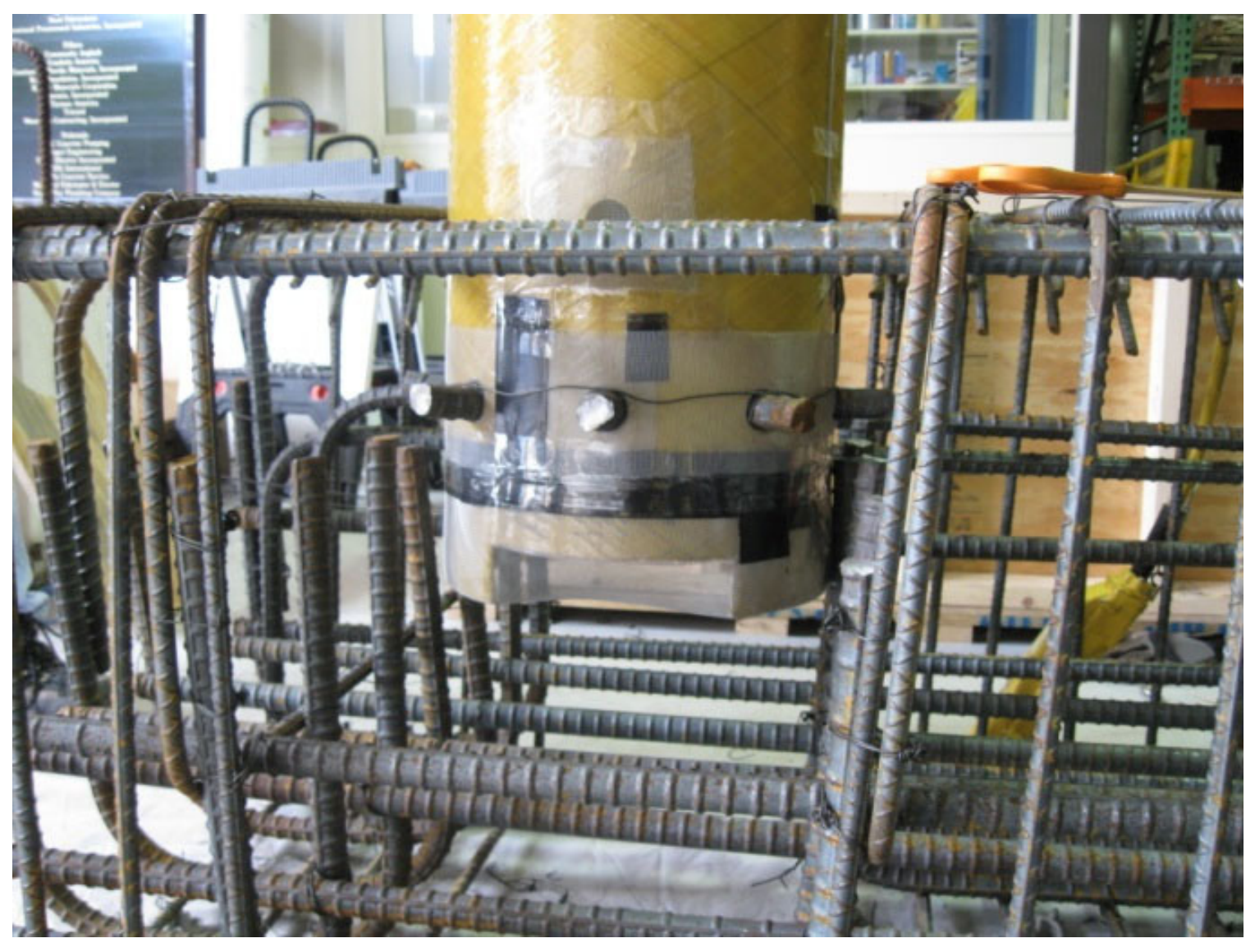

Figure 4.3 Shear Connectors and Screen at the Bottom of FRP Tube 


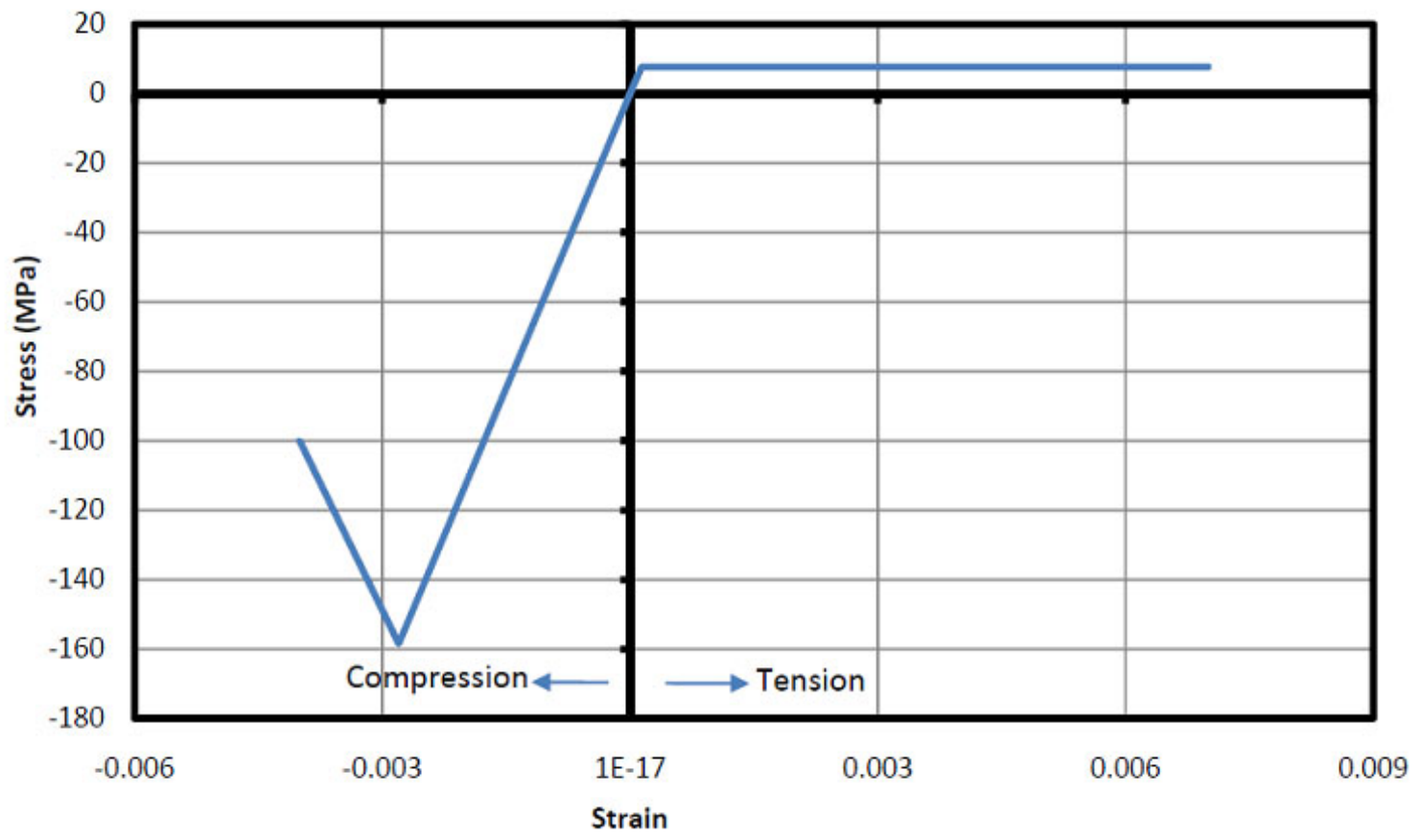

Figure 4.4 Typical Axial Stress-Strain Curve of UHPC 


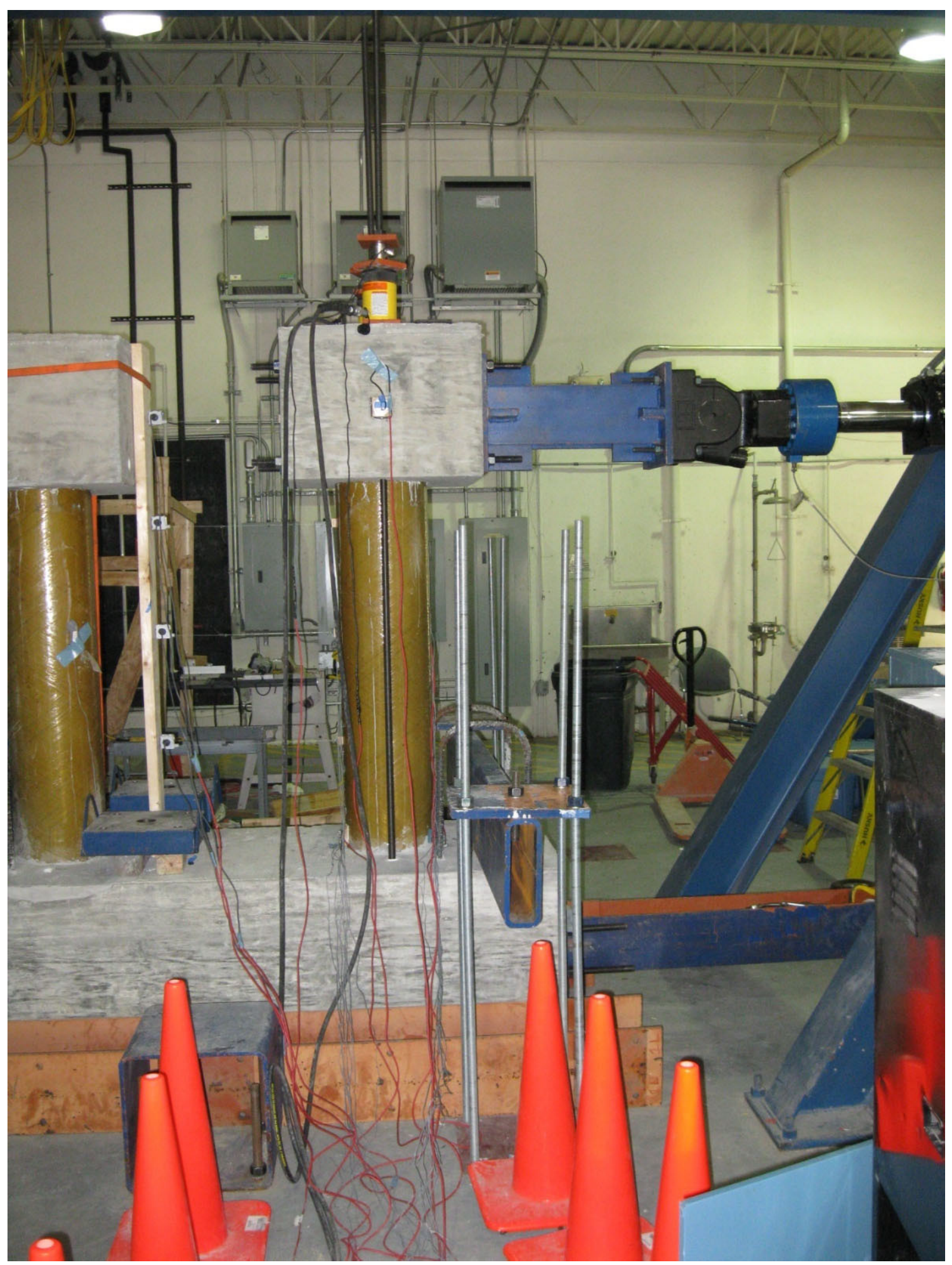

Figure 4.5 Typical Test Setup (Specimen CFFT) 


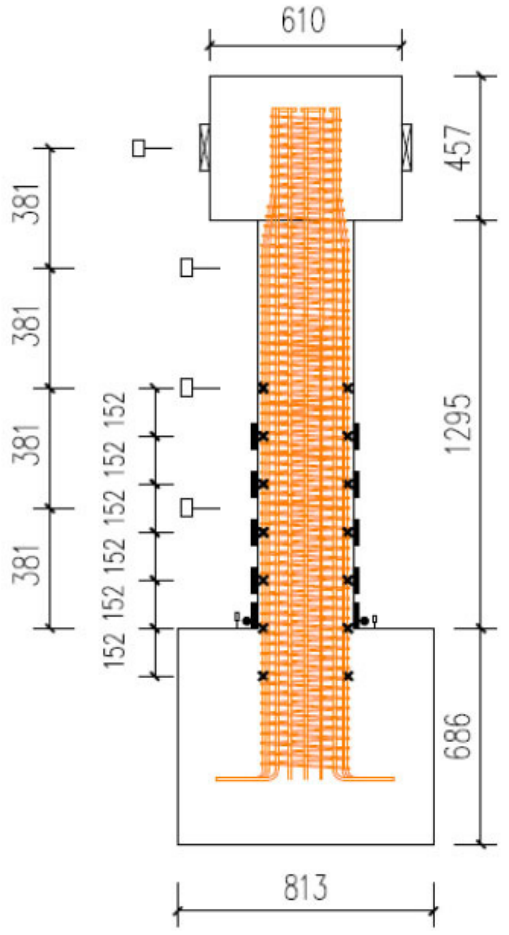

(a)

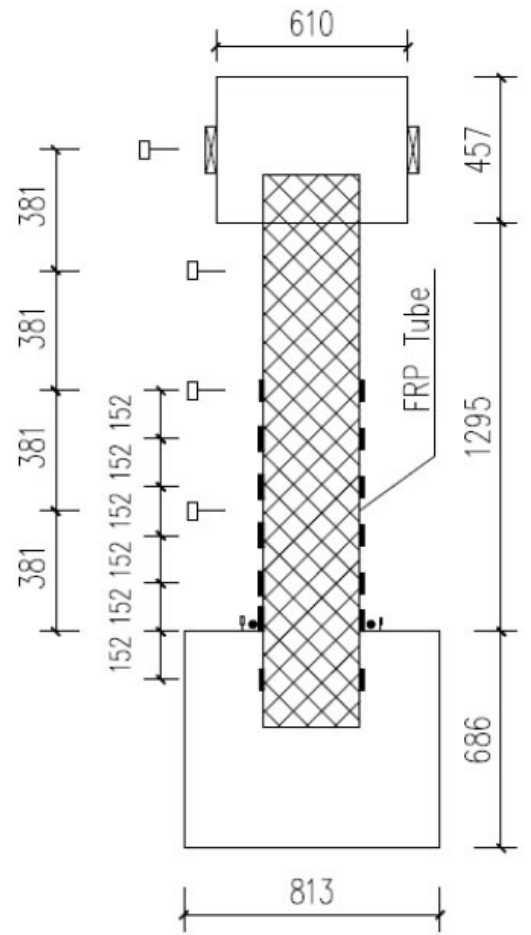

(b)

\begin{tabular}{|c|l|}
\hline Legend & Name \\
\hline$\square$ & Inclinometer \\
\hline$\square$ & String Pot \\
\hline$\square$ & Strain Gauge on Column \\
\hline$\square$ & Potentiometer \\
\hline $\mathbf{x}$ & Strain Gauge (Hoop Direction) \\
\hline $\mathbf{X}$ & Strain Gauge on Steel Bars \\
\hline
\end{tabular}

(c)

Figure 4.6 Instrumentation Plan: (a) Specimens RC and RUHPC, (b) Specimens CFFT and UHPCFFT, and (c) Instrumentation Legend 


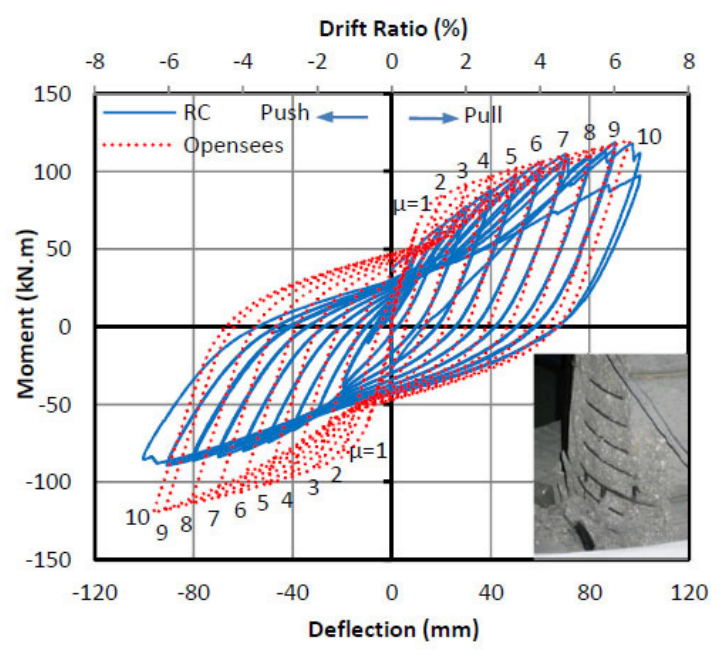

(a)

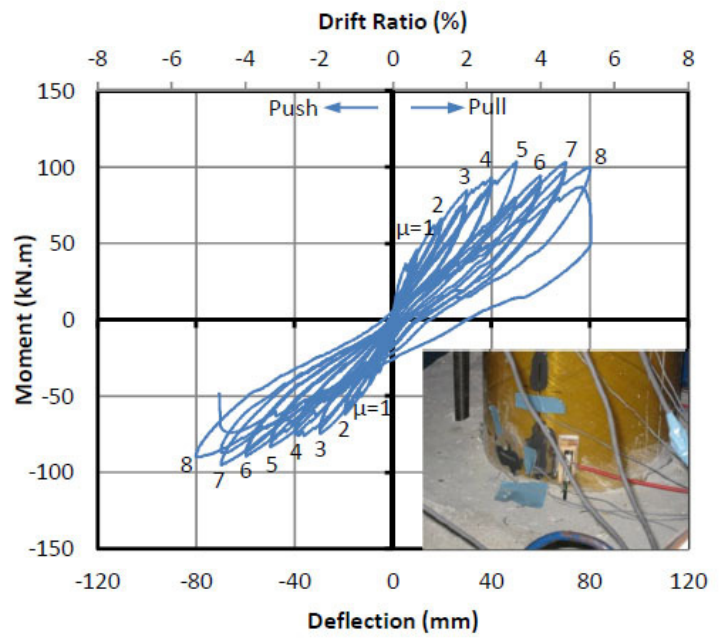

(c)

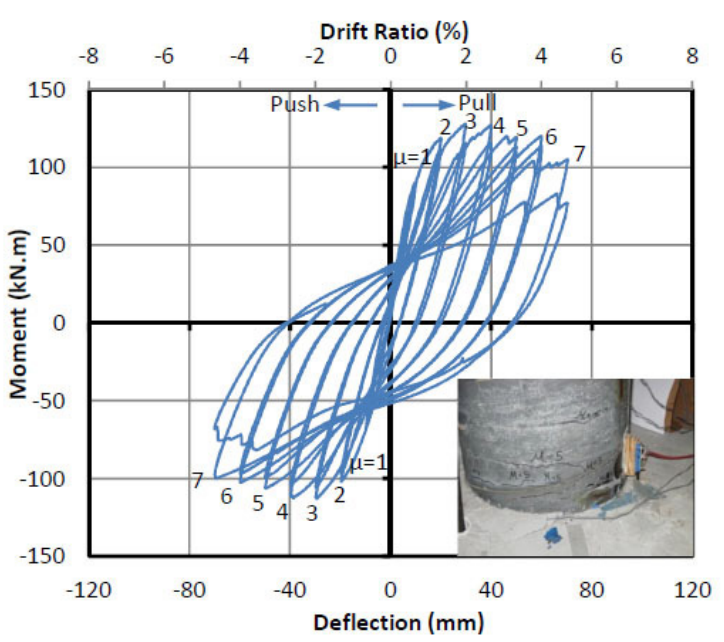

(b)

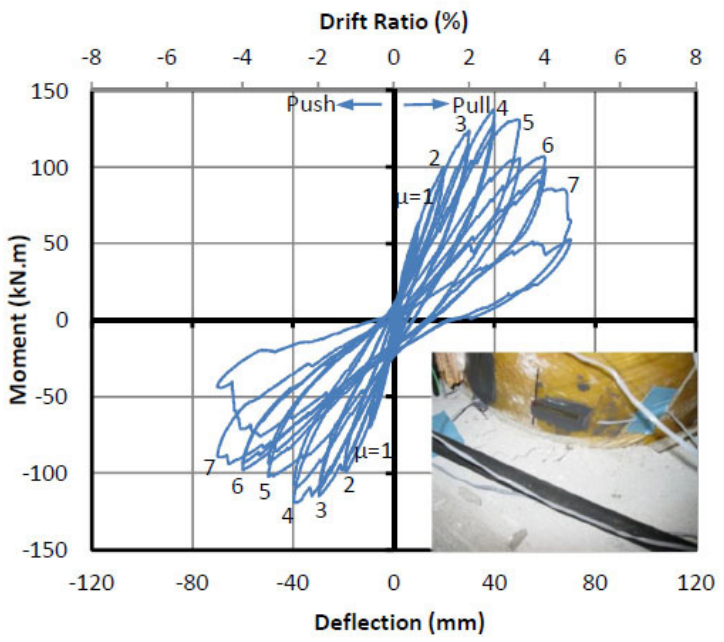

(d)

Figure 4.7 Hysteretic Moment-Deflection Response for (a) Specimen RC, (b) Specimen RUHPC, (c) Specimen CFFT, and (d) Specimen UHPCFFT 


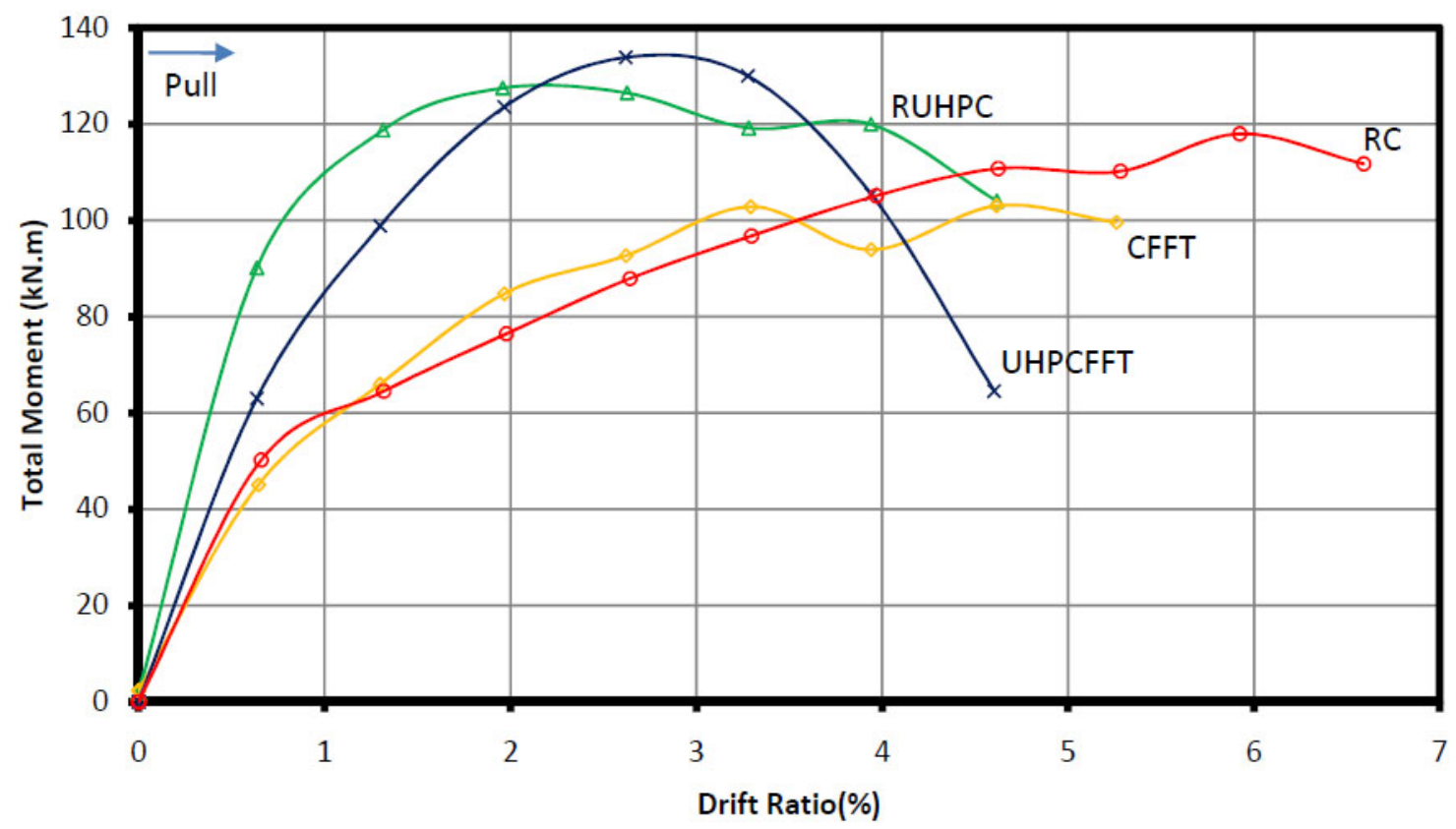

Figure 4.8 Moment-Drift Ratio Envelope Curves

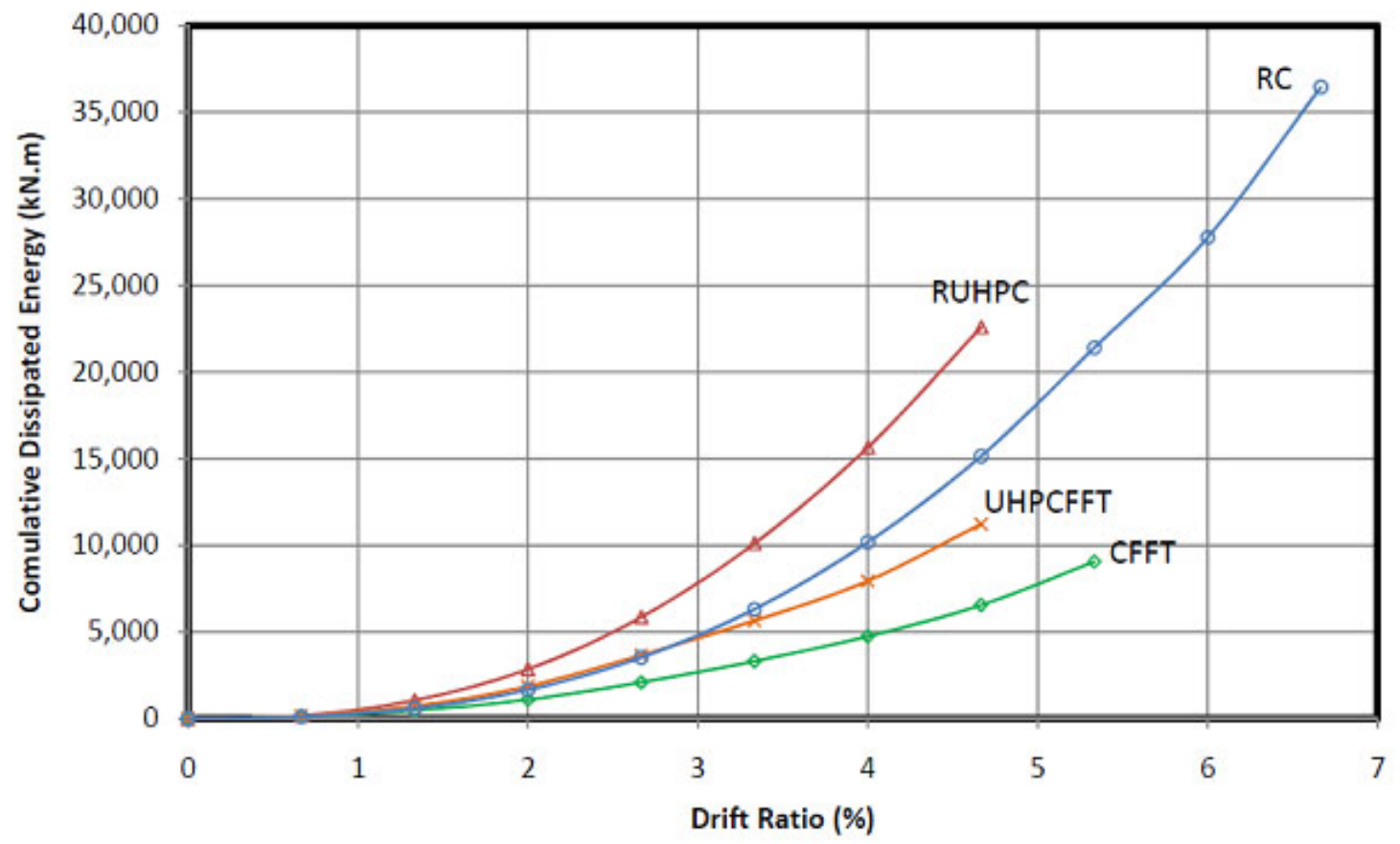

Figure 4.9 Comparison of Cumulative Dissipated Energy 


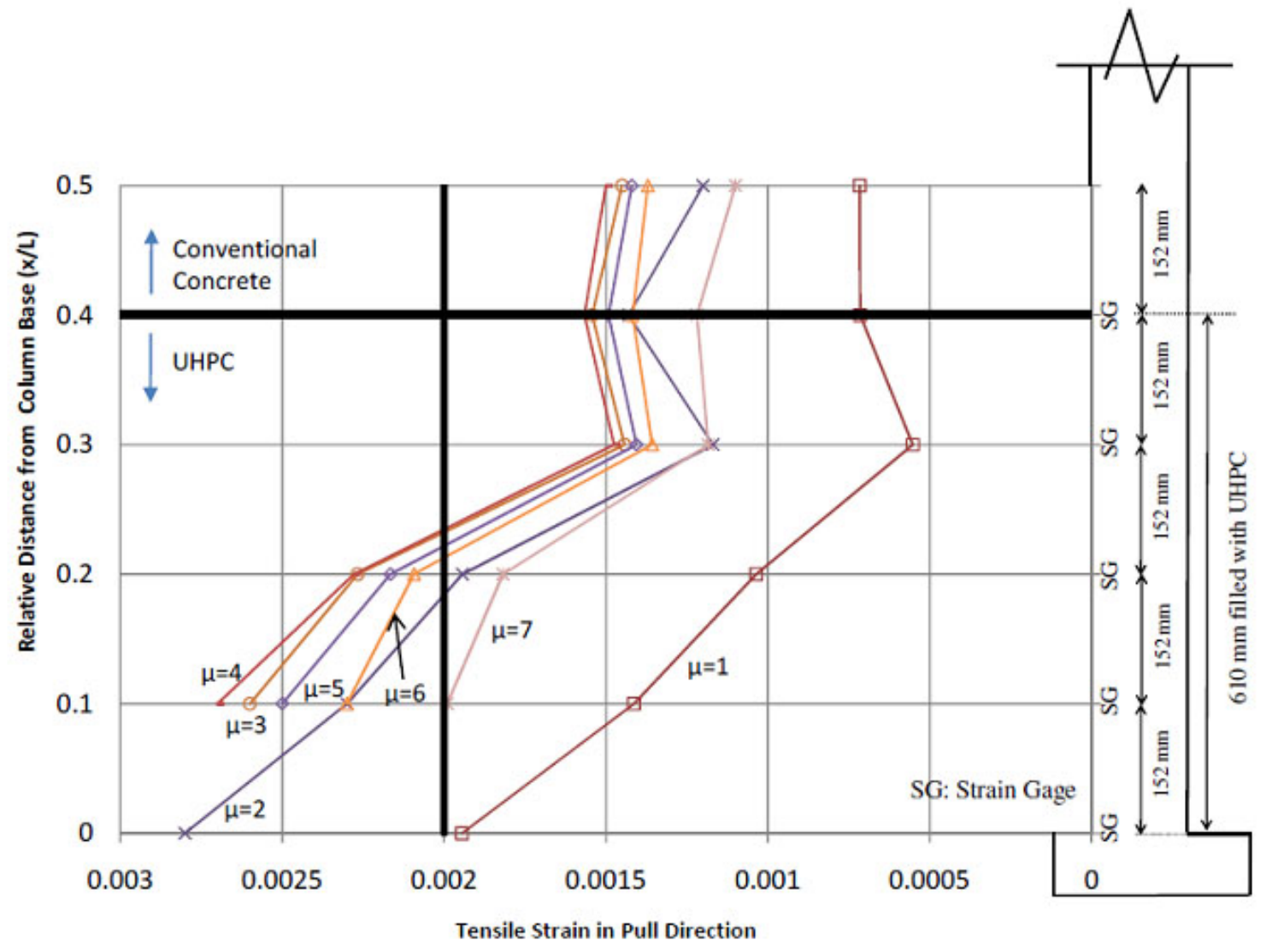

Figure 4.10 Longitudinal Rebar Strain Profile for Specimen RUHPC 


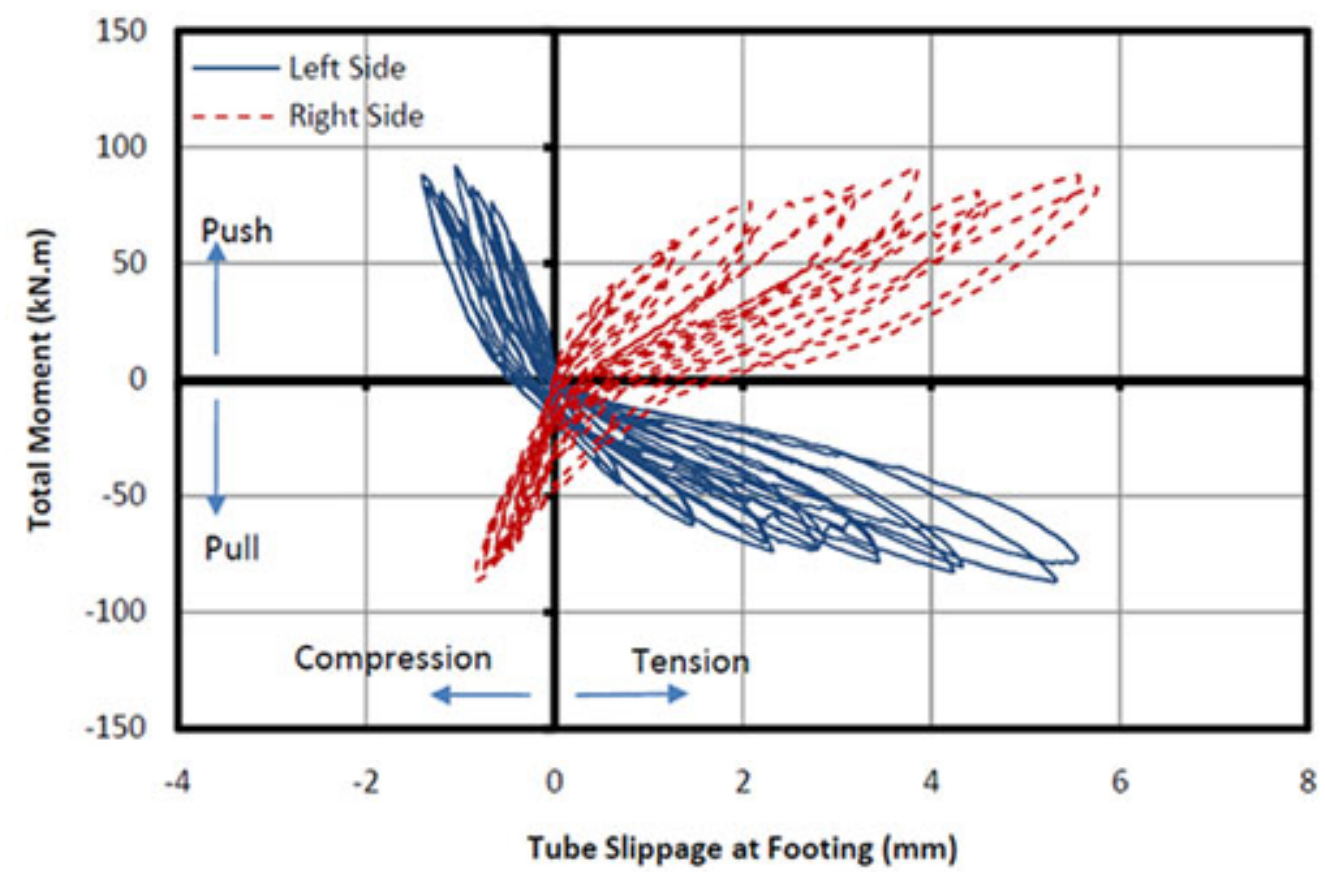

(a)

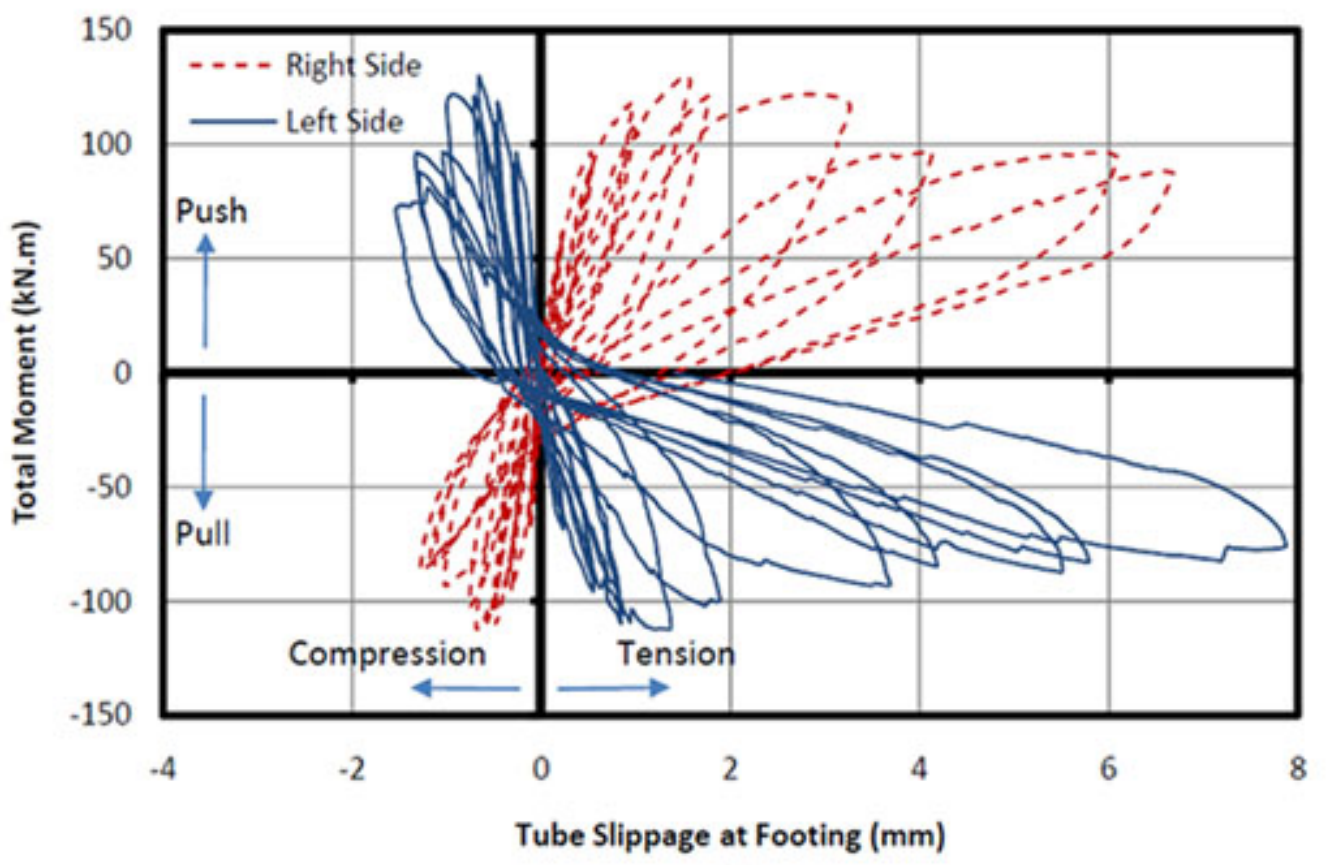

(b)

Figure 4.11 Moment-Slippage for Specimens: (a) CFFT, and (b) UHPCFFT 


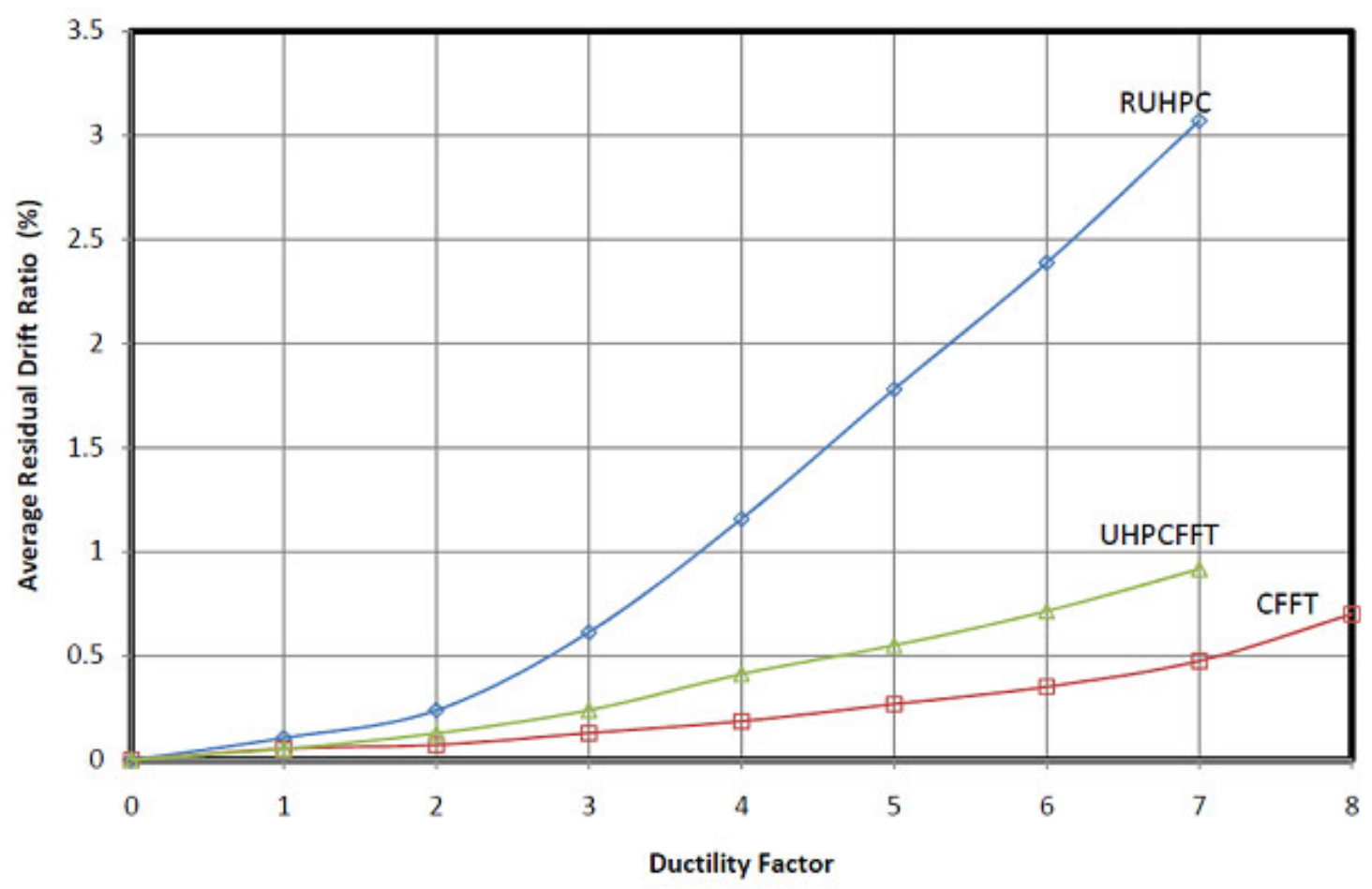

Figure 4.12 Comparison of Residual Drift Ratios 


\title{
5. EFFECT OF COLUMN PARAMETERS ON CYCLIC BEHAVIOR OF ULTRA-HIGH PERFORMANCE CONCRETE-FILLED FRP TUBES
}

\author{
Pedram Zohrevand and Amir Mirmiran \\ Submitted to ACI Structural Journal
}

\begin{abstract}
A novel hybrid column made of fiber-reinforced polymer (FRP) and ultra-high performance concrete (UHPC) was developed in a previous study by the authors. The steel-free UHPC filled FRP tube (UHPCFFT) system proved promising as an alternative to conventional reinforced concrete (RC) columns. This study investigates the effect of column cross section, type of FRP tube, and amount of longitudinal steel reinforcement on the cyclic behavior of UHPCFFT columns. Accordingly, six column specimens, including one control RC and five UHPCFFTs with different FRP tubes, steel reinforcement ratios, and diameters were made and studied under pseudo-static tests. It was shown that the initial stiffness and strength of UHPCFFT systems could be controlled by the stiffness index and reinforcement index, respectively. All UHPCFFT columns exhibited significantly lower residual displacement and slightly lower ductility, as compared to Specimen RC.
\end{abstract}

Keywords: Columns; Concrete; Cyclic loading; Fiber-reinforced polymers (FRP); Tubes; Ultra-high performance concrete (UHPC).

\subsection{Introduction}

Application of advanced materials in infrastructure has grown in recent years, in part due to their potential to ease the construction, extend service life, and improve the 
performance. Fiber-reinforced polymer (FRP) composite is one such material with excellent properties, including high strength-to-weight and stiffness-to-weight ratios, and high corrosion resistance. FRP composites were first used in retrofit and repair applications in the form of fabrics, laminates, and shells. They improve shear and flexural strengths of structural components as well as the column confinement (Mertz et al. 2003, Mirmiran et al. 2004). FRP has also been used as reinforcing bars for concrete. Concretefilled FRP tube (CFFT) is another application in which the tube acts as stay-in-place formwork, protective jacket, confinement device, and shear and flexural reinforcement. The first generation of CFFT systems (Gen-1), without any internal steel reinforcement, showed a comparable performance to its conventional RC counterparts in non-seismic regions (Mirmiran et al. 1998, Fam et al. 2003). Further studies on CFFT systems led to the development of their second generation (Gen-2) in which off-axis fibers as well as a moderate amount of longitudinal steel reinforcement (1-2\%) helped provide adequate ductility for seismic regions (Shao and Mirmiran 2005, Zhu et al. 2006).

Ultra-high performance concrete (UHPC) is another innovative material that in recent years has captured the attention of construction industry. The exclusive properties of this material include compressive strength of above $145 \mathrm{MPa}$ (21 ksi), elastic modulus of above $46 \mathrm{GPa}(6,700 \mathrm{ksi})$, usable tensile strength of above $5 \mathrm{MPa}(0.72 \mathrm{ksi})$, and significant durability, ductility, and damage tolerance (Graybeal 2005). UHPC was proven effective for retrofit and rehabilitation of concrete structures (Brühwiler and Denarié 2008, Massicotte and Boucher-Proulx 2010). Studying the flexural behavior of UHPC beams showed that the beams with steel reinforcement ratios less than $2 \%$ could exhibit a distributed multiple cracking pattern up to failure and a ductile behavior with a 
ductility index of 3.75 (Yang and Kim 2010). Application of UHPC within plastic hinge regions of frames and columns were shown to be highly effective in increasing the energy dissipation, drift capacity, and damage tolerance (Billington and Yoon 2002, Saiidi et al. 2009).

Combining the exceptional properties of FRP and UHPC, a new generation of CFFT systems (Gen-3) was developed by the authors (Zohrevand and Mirmiran 2011). The column consists of an FRP tube with off-axis fibers filled with UHPC within twice the column diameter and conventional concrete for the remainder of the column length. No steel reinforcement was used in the column. The cyclic behavior of this hybrid column was studied with respect to its RC counterpart (Zohrevand and Mirmiran 2011). The steel-free UHPC-filled FRP tube (UHPCFFT) showed considerably higher flexural strength and initial stiffness, lower residual drift, and similar energy dissipation, relative to the conventional RC column. It was also shown that the new system could be further optimized for the desired level of strength, stiffness, and ductility (Zohrevand and Mirmiran 2011). Therefore, this study focused on the effect of column parameters (cross section, type of FRP tube, and amount of longitudinal steel reinforcement) on the cyclic behavior of UHPCFFT columns.

\subsection{Research Significance}

This research provides the necessary experimental data that could be used as the foundation for the design and optimization of the novel hybrid FRP-UHPC column. This novel system has the potential to serve as an alternative to conventional RC columns, with its easier and faster constructability and higher durability. Also presented in the 
study are the advantages of combining FRP and UHPC materials which could be used in other structural applications.

\subsection{Experimental Program}

\subsubsection{Test Matrix and Material Properties}

The test matrix consisted of six quarter-scale bridge columns, as shown in Table 5.1. All columns had the same height of 1,524 $\mathrm{mm}$ (60 in.). Each pair of columns was placed onto one RC footing, while each column was tested independently. The footings were deliberately over-reinforced to avoid any base failure. Figure 5.1 shows the layout of the column specimens.

Specimen RC, which served as reference, was a conventional steel-reinforced concrete column with a diameter of $305 \mathrm{~mm}$ (12 in.), sixteen No. 10M (No. 3) longitudinal steel bars (1.6\%), and a $4.9 \mathrm{~mm}(0.19$ in.) diameter steel wire spiral reinforcement with $279 \mathrm{~mm}$ (11 in.) outside diameter at a pitch of $32 \mathrm{~mm}$ (1.25 in.).

All other specimens were UHPCFFTs in which FRP tubes filled with UHPC within twice their column diameters and conventional concrete for the remainder of the column length. All FRP tubes were off-the-shelf products made by filament winding of $\pm 55^{\circ}$ E-glass fibers and thermosetting epoxy resin. The superior performance of CFFT systems made of this type of FRP tubes was proven in earlier studies (Shao and Mirmiran 2005, Shi et al. 2009). The FRP tube used in Specimens UF1, RUF1, and RUF2 was Red $\operatorname{Thread}^{\circledR}$ II pipe, made by NOV Fiber Glass Systems of Houston, TX. The tensile strength, tensile modulus, and hoop strength of this tube are $314 \mathrm{MPa}(45.5 \mathrm{ksi}), 12.6$ $\mathrm{GPa}(1,820 \mathrm{ksi})$, and $234 \mathrm{MPa}(34 \mathrm{ksi})$, respectively, based on the manufacturer data. Another type of FRP tube used in Specimens UF2 and UF3 was Alphatic Amine ${ }^{\circledR}$ pipe 
made by the same manufacturer with the tensile strength, tensile modulus, and hoop strength of $152 \mathrm{MPa}(22 \mathrm{ksi}), 13.8 \mathrm{GPa}(2,000 \mathrm{ksi})$, and $241 \mathrm{MPa}(35 \mathrm{ksi})$, respectively, based on the manufacturer data. The FRP tube used in Specimen UF3 had the outside diameter of about $2 / 3$ of that in Specimen UF3, while both had almost the same thickness. Except for Specimen UF3, all other UHPCFFT specimens had similar diameters to that of Specimen RC. The tubes were embedded 305 and $152 \mathrm{~mm}$ (12 and 6 in.) into their footings and column heads, respectively. Also, the FRP tubes were held in place during casting (and resisted slippage during loading) with the help of two No. 25M (No. 8) and two No. 13M (No. 4) bars of the footing reinforcement passing through the embedded lengths of the tubes in the longitudinal and lateral directions of the footing, respectively (see Figure 5.2). A fine mesh window screen was used at the bottom of FRP tubes, $305 \mathrm{~mm}$ (12 in.) under the footing surface, to prevent the conventional concrete from entering into the embedded FRP tubes during casting of the footings. No steel reinforcement was used in Specimens UF1, UF2, and UF3, whereas longitudinal steel reinforcement of $0.5 \%$ (six No. $10 \mathrm{M}$ (No. 3)) and $0.9 \%$ (ten No. 10M (No. 3)) were used in Specimens RUF1 and RUF2, respectively, with 508 and $305 \mathrm{~mm}$ (20 and 12 in.) embedment into their footing and column heads, respectively. A clear cover of 13 ( 0.5 in.) was maintained for all steel bars.

All steel reinforcement was of Grade $414 \mathrm{MPa}(60 \mathrm{ksi})$. The UHPC used in this study was Ductal ${ }^{\circledR}$, made by Lafarge North America of Calgary, AB, Canada, and composed of cement, silicafume, ground quartz, and sand (no coarse aggregate), water, superplasticizer, and 2\% metallic fibers by volume. Each UHPCFFT column was made with a single batch of UHPC, with the 28-day compressive strengths ranging between 
175 and $183 \mathrm{MPa}$ (25.4 and $26.5 \mathrm{ksi}$ ), as shown in Table 5.1. A single batch of concrete with 28-day compressive strength of $51 \mathrm{MPa}(7.4 \mathrm{ksi})$ was used for all footings. All columns and column heads were cast with another batch of concrete with a 28-day compressive strength of $42 \mathrm{MPa}(6.1 \mathrm{ksi})$. A detailed work plan was arranged to mix and cast the five batches of UHPC immediately before casting the ready mixed concrete for the columns. This helped avoid the formation of cold joint at the interface of dissimilar concretes, especially in columns with no longitudinal steel reinforcement.

\subsubsection{Reinforcement and Stiffness Index}

To better understand the effect of steel reinforcement and FRP tube on the cyclic behavior of the columns, the reinforcement index $(\omega)$ for each specimen was calculated, as the summation of the contributions from steel and FRP, as

$\omega=\omega_{s}+\omega_{f}=\rho_{s} \frac{f_{y}}{f_{c, u}^{\prime}}+\rho_{f} \frac{f_{f}}{f_{c, u}^{\prime}}$

where $\omega_{s}$ and $\omega_{f}$ are the steel and FRP reinforcement indices, respectively, $\rho_{s}$ and $\rho_{f}$ are the steel and FRP reinforcement ratios, respectively, relative to the gross cross sectional area of the column, $f_{y}$ is the yield strength of steel reinforcement, $f_{f}$ is the longitudinal tensile strength of FRP tube, and $f_{c, u}^{\prime}$ is the compressive strength of concrete or UHPC in Specimen RC and the other specimens, respectively. The reinforcement ratio and index for each specimen are listed in Table 5.2. Similarly, replacing the strength of each material in Equation (1) with its modulus of elasticity, a stiffness index was calculated for each specimen, as 
Stiffness Index $=\rho_{s} \frac{E_{s}}{E_{c, u}}+\rho_{f} \frac{E_{f}}{E_{c, u}}$

where $E_{s}, E_{f}$, and $E_{c, u}$ are the moduli of elasticity of steel, FRP, and concrete (in Specimen RC) or UHPC (in the other specimens), respectively. The moduli of elasticity for conventional concrete and UHPC were calculated from their compressive strengths using the equations of ACI Committee 318 and Graybeal (2005), respectively. The stiffness index for each specimen is also presented in Table 5.2.

\subsubsection{Test Setup and Instrumentation}

The test setup is shown in Figure 5.3. Two tubular steel beams tied each footing to the strong floor using 16 threaded rods. The footing was also tied to the steel reaction frame through an $\mathrm{H}$ section steel beam and four threaded rods. Rotation of the footing in the horizontal plane was further constrained using two 2,794 mm (110 in.) long steel beams, one on each side. A constant axial load of $125 \mathrm{kN}$ (28 kips) was applied on each column simulating the dead load, equivalent to $0.04 \mathrm{f}_{\mathrm{c}} \mathrm{A}_{\mathrm{g}}$, where $\mathrm{f}_{\mathrm{c}}$ is 28-day compressive strength of the conventional concrete in the column, and $\mathrm{A}_{\mathrm{g}}$ is the gross cross sectional area of the column. Post-tensioning was carried out using two threaded rods through the column head and the footing with two inter-connected hydraulic jacks controlled by a single hand pump. Using four threaded rods and a steel shoe, the column head was connected to the actuator. Threaded rods were all of Grade B-7 with a diameter of $25.4 \mathrm{~mm}$ (1 in.) and a yield strength of $724 \mathrm{MPa}(105 \mathrm{ksi})$.

The instrumentation plan, shown earlier in Figure 5.1, included four 305 mm (12 in.) range string potentiometers attached to one side of each column to monitor lateral 
displacements. The slippage of FRP tubes in and out of the footings was monitored in the loading plane using two $38 \mathrm{~mm}$ (1.5 in.) range linear potentiometers. The rotation of each column head was monitored by two inclinometers mounted on the opposite sides of the column head parallel to the loading plane. Six pairs of surface-mounted strain gages were attached longitudinally on both sides of each column in the loading plane. Also, six pairs of strain gages were placed on the longitudinal steel bars of each steel-reinforced column in the loading plane corresponding to the strain gages attached on the column surface. Two additional surface-mounted strain gages were attached in the hoop direction of each FRP tube at the column base in the loading plane. Using two synchronized high-speed data acquisition systems, all data, including the load and displacement output from the actuator, was recorded simultaneously at a frequency of $1 \mathrm{~Hz}$.

\subsubsection{Test Procedure}

After applying the external post-tensioning axial force, each column was subjected to a reverse cyclic lateral load in displacement control. The column drift was applied in successive runs in which the displacement amplitudes were the products of the run number multiplied by the reference displacement. The reference displacement corresponded to the first yielding of the longitudinal steel reinforcement in the control $\mathrm{RC}$ column, which was measured as $15 \mathrm{~mm}(0.6 \mathrm{in}$.$) . All specimens were tested at a$ constant loading rate of $0.51 \mathrm{~mm} / \mathrm{s}$ (1.2 in./min). Two full cycles of reverse lateral loading were applied in each run. The cyclic loading regime is shown in Figure 5.4. Loading for each specimen continued until either a load drop of approximately $30 \%$ of the peak load or a noticeable irreparable damage occurred. 


\subsection{Experimental Results and Discussion}

\subsubsection{Hysteretic Response and Failure Mode}

Figures 5.5(a) to (f) show the hysteretic moment-deflection responses for all specimens. The secondary $(P-\Delta)$ effects were included in the total moment at the column base, where $P$ is the axial load and $\Delta$ is the column head displacement. The lateral deflection is depicted both as its absolute value $\Delta$ and the normalized drift ratio $\Delta L$, where $L$ is the column height. Lower response was seen for all specimens in the push direction, which may be attributed to the asymmetrical configuration of the footing for each column.

Cracks were first seen at the column base of Specimen RC in Run 2. They were further extended and accompanied by concrete spalling in Run 3. A major concrete spalling and crushing happened during Run 5 causing the failure, as shown in Figure 5.6(a). The strength in Specimen RC increased up to Run 2, thereafter remained relatively constant until failure (see Figure 5.5(a)).

The failure of all UHPCFFT columns happened by FRP tube rupture on the tension side with a loud noise, while being pulled. In all cases, the rupture occurred just below the surface of the footing between the two bars of top layer of the footing reinforcement passing through the tube, as shown in Figure 5.6(b). The slippage of the FRP tube out of the footing was insignificant in all UHPCFFT columns, ranging from 3 to $6 \mathrm{~mm}$ (0.12 to 0.24 in.). In Specimens UF2 (Figure 5.5(c)), UF3 (Figure 5.5(d)), and RUF2 (Figure 5.5(f)), the strength continued to increase until Run 5. Accordingly, the peak strength was reached at the maximum drift ratio (5\%) in Run 5, which coincided with FRP rupture. The strength in Specimens UF1 (Figure 5.5(b)) and RUF1 (Figure 
5.5(e)), however, increased until Run 4, and the tube rupture happened during Run 5 at about the same strength as that in Run 4.

\subsubsection{Response Envelope}

The moment-deflection envelope curves for all specimens are shown in Figure 5.7. Using the envelopes, the values of initial stiffness, maximum moment and drift ratio, and ductility for each specimen were calculated, and the results (averages of the push and pull directions) are presented in Table 5.2. The ductility was measured as the ratio of the ultimate drift ratio to the yield drift ratio. The yield drift ratio is that of an equivalent elasto-plastic system with the same elastic stiffness and ultimate load as those of the real system (Park and Paulay 1975).

\subsubsection{Initial Stiffness}

As compared to Specimen RC, the initial stiffness was increased by $20 \%$ in Specimen UF1, and about 75\% in Specimens RUF1, RUF2, and UF2, whereas it dropped by $40 \%$ in Specimen UF3. The latter may be explained by the smaller diameter in Specimen UF3. The relationship between the total initial stiffness and stiffness index for all UHPCFFT specimens is depicted in Figure 5.8. To remove the effect of different column diameters, the values of initial stiffness were normalized over $\mathrm{D}^{4}$, where $\mathrm{D}$ is the column core diameter. There is a clear parabolic trend between the total stiffness index and the normalized initial stiffness in UHPCFFT columns.

\subsubsection{Strength}

Table 5.2 shows that in comparison to Specimen RC, the strength improved by $30 \%, 75 \%, 95 \%$, and $200 \%$ in Specimens UF1, RUF1, RUF2, and UF2 (all with almost the same diameter), respectively. On the other hand, Specimen UF3 exhibited the same 
strength as that of Specimen RC, while its diameter was only $2 / 3$ of that of Specimen RC. Figure 5.9 shows the relationship between the flexural strength and reinforcement index for all UHPCFFT specimens. Moments were normalized over $\mathrm{D}^{3}$ to remove the effect of different diameters. There is a clear logarithmic trend between the flexural strength and reinforcement index in UHPCFFT columns.

\subsubsection{Ductility}

As compared to Specimen RC, the ductility slightly decreased by as much as $17 \%$ in Specimens UF1, RUF2, and RUF3, whereas it considerably dropped by about $40 \%$ in Specimens UF2 and UF3. Figure 5.10 compares the ductility in UHPCFFT specimens. The left side of the figure shows that increasing the FRP reinforcement ratio reduces the

ductility. On the other hand, as shown on the right side of the figure, adding $0.5 \%$ steel reinforcement leads to a minor increase in ductility, but any further increase in steel reinforcement is counterproductive. In general, one may conclude that the steel reinforcement in the proposed system has little or no effect on the ductility of the column.

\subsubsection{Energy Dissipation and Damping Ratio}

Figure 5.11 shows the cumulative dissipated energy for each specimen, calculated based on the enclosed area within the first hysteretic loop in each run. Specimens RC and UF1 showed similar dissipated energy, with Specimen UF1 performing better at higher drifts. Increasing FRP thickness or adding steel reinforcement improves the energy dissipation of the column. Specimen UF3, on the other hand, showed the least energy dissipation, due mainly to its lower column diameter, which was about $2 / 3$ of that of the other columns. 
Using the dissipated energy, the damping ratio $(\xi)$ of each column was calculated in each run, as

$\xi=\frac{E_{h}}{4 \pi E_{e}}$

where $E_{h}$ is the hysteretic dissipated energy during the first cycle of each run, and $E_{e}$ is the elastic energy calculated based on the maximum displacement and peak moment in each run. Damping ratios versus drift ratios are presented for all specimens in Figure 5.12. UHPCFFT specimens show a clearly different trend, as compared to Specimen RC. Damping ratio in Specimen RC increased continuously from a minimum value of 3\% in Run 1 to a maximum value of $20 \%$ in Run 5 . On the other hand, the higher damping ratios were seen in all UHPCFFT Specimens during Run 1, with only slight increase at higher runs. This indicates that UHPCFFT column systems could be designed more efficiently than their RC counterparts, since it is generally the minimum damping ratio at the early cycles that is used for seismic design.

\subsubsection{Load-Strain Response}

Figure 5.13 shows the ultimate strain profiles on the tension side of the FRP tubes in all UHPCFFT specimens just before their failure in the pull direction. Almost the same strain profiles were observed for Specimens UF1, RUF1, and RUF2 with the same FRP tube, whereas the latter two additionally had steel reinforcement. Specimens UF2 and UF3 also showed similar strain profiles due to their similar FRP tube properties. The lower strains in Specimens UF2 and UF3 may be attributed to the lower strain capacity of their FRP tubes. Each strain profile can be divided into three regions; (a) the region with conventional concrete, above the height of $610 \mathrm{~mm}$ (24 in.), (b) the region with UHPC, 
below the height of $305 \mathrm{~mm}(12 \mathrm{in}$.), and (c) the transition zone between the two heights. Based on this discretization, the figure inset shows schematic strain profiles for two extreme conditions; (1) when the column is filled fully with conventional concrete, and (2) when it is filled entirely with UHPC. It is clear that UHPC results in lower strains. The inset also shows how the strain profile shifts from the concrete-dominant profile to the UHPC-dominant profile within the transition zone.

\subsubsection{Residual Displacements}

The average residual displacements for all specimens are shown versus their drift ratios in Figure 5.14. All UHPCFFT columns showed lower residual displacements, as compared to Specimen RC. The higher FRP stiffness index clearly results in a lower residual displacement, mainly due to the linear elastic behavior of FRP materials. Accordingly, Specimen UF3 with the stiffness index of 7\% showed the lowest residual

displacement, whereas Specimens UF1, RUF1, and RUF2, all with the total stiffness index of $2 \%$, exhibited the highest residual displacement among UHPCFFT specimens.

\subsection{Conclusions}

The effect of column parameters, i.e., cross section, type of FRP tube, and steel reinforcement ratio, on the cyclic behavior of UHPCFFT columns was studied. The test matrix included one control RC and five UHPCFFT columns, with different diameters, FRP tubes, and steel reinforcement ratios. The following conclusions could be drawn from this experimental study:

- Failure in all UHPCFFT specimens was governed by FRP tube rupture at the column base on the tension side, while Specimen RC failed with spalling and 
crushing of the concrete. The slippage of the FRP tube out of the footing was insignificant in all UHPCFFT specimens.

- All UHPCFFT columns with almost the same diameter as that of Specimen RC showed higher initial stiffness and strength, but slightly lower ductility, as compared to Specimen RC. It was shown that in UHPCFFT column systems, the initial stiffness and moment capacity can be controlled by the stiffness index and reinforcement index, respectively. The results also indicated that increasing the FRP reinforcement ratio reduces the ductility, whereas adding steel reinforcement has little or no effect on ductility.

- All UHPCFFT columns showed higher damping ratios than Specimen RC in the early cycles, implying that they could be designed more efficiently than conventional RC columns for seismic applications.

- All UHPCFFT columns showed lower residual displacement than Specimen RC, primarily due to the linear elastic behavior of FRP materials.

This study showed that design parameters for UHPCFFT columns can influence their performance measures, such as stiffness, strength, ductility, energy dissipation, and damping to varying degrees. However, true comparison of UHPCFFT and RC systems requires a seismic response analysis and a shake table experiment.

\section{Acknowledgements}

This study was sponsored in part by the NSF-Network for Earthquake Engineering Simulation Research (NEESR) program, as part of the multi-university Grant No. CMS-0420347. The experiments were carried out at the Titan America Structures and Construction Laboratory of the Florida International University. The 
writers are grateful to Lafarge, Inc. for providing the Ductal ${ }^{\circledR}$ (UHPC) materials; and NOV Fiber Glass Systems for providing the FRP tubes. The writers also thank Brandon Mintz and Masood Hajali for their assistance during the experimental program. The first writer is also thankful to the University Graduate School for providing him with a dissertation year fellowship to complete his doctoral work. Findings and opinions expressed here, however, are those of the authors alone, and not necessarily the views of sponsoring agencies. 


\section{References}

ACI Committee 318 (2005). "Building Code Requirements for Structural Concrete (ACI 318-08) and Commentary." American Concrete Institute, Farmington Hills, MI.

Billington, S.L., and Yoon, J. (2002). "Cyclic Behavior of Precast Post-Tensioned Segmental Concrete Columns with ECC." Proceedings of the JCI International Workshop on Ductile Fiber Reinforced Cementitious Composites (DFRCC) Application and Evaluation (DRFCC-2002), Takayama, Japan, 279-288.

Brühwiler, E., and Denarié, E. (2008). "Rehabilitation of Concrete Structures Using Ultra- High Performance Fiber-Reinforced Concrete." Proceedings of the Second International Symposium on Ultra-High Performance Concrete, Kassel, Germany.

Fam, A., Pando, M., Filz, G., and Rizkalla, S. (2003). "Precasted Piles for Route 40 Bridge in Virginia using Concrete-Filled FRP Tubes.” PCI Journal, 48(3), 32-45.

Graybeal, B.A., (2005). "Characterization of the Behavior of Ultra-High Performance Concrete." PhD Dissertation, University of Maryland, College Park, MD.

Massicotte, B. and Boucher-Proulx, G. (2010). "Seismic Retrofitting of Bridge Piers with UHPFRC Jackets." Designing and Building with UHPFRC: State of the Art and Development, Wiley-ISTE, London, 531-540.

Mertz, D.R., Chajes, M.J., Gillespie, Jr.,J.W., Kukich, D.S., Sabol, S.A., Hawkins, N.M., Aquino, W., and Deen, T.B. (2003). "Application of Fiber Reinforced Polymer Composites to the Highway Infrastructure." NCHRP Report No. 503, Transportation Research Board, National Academy of Sciences, Washington D.C.

Mirmiran, A., Samaan, M., Cabrera, S., and Shahawy, M. (1998). "Design, Manufacture and Testing of a New Hybrid Column." Construction \& Building Materials, Elsevier, 12(1), 39-49.

Mirmiran, A., Shahawy, M., Nanni, A., and Karbhari, V. (2004). "Bonded Repair and Retrofit of Concrete Structures Using FRP Composites: Recommended Construction Specifications and Process Control Manual." NCHRP Report 514, Transportation Research Board, National Academy of Sciences, Washington, D.C.

Park, R. and Paulay, T. (1975). Reinforced Concrete Structures. John Wiley \& Sons, New York.

Saiidi, M., O'Brien, M., and Mahmoud, S. (2009). "Cyclic Response of Concrete Bridge Columns using Superelastic Nitinol and Bendable Concrete." Structural Journal, ACI, 106(1), 69-77. 
Shao, Y., and Mirmiran, A. (2005). "Experimental Investigation of Cyclic Behavior of Concrete-Filled Fiber Reinforced Polymer Tubes." Journal of Composites for Construction, ASCE, 9(3), 263-273.

Shi, Y. (2009). "Seismic Performance of FRP-Concrete Pier Columns." Ph.D. Dissertation, Florida International University, Miami, FL.

Yang, H., Jon, C., and Kim, B.S. (2010). "Structural Behavior of Ultra High Performance Concrete Beams Subjected to Bending." Journal of Engineering Structures, 32(11), 3789-3800.

Zhu, Z., Ahmad, I., and Mirmiran, A. (2006). "Seismic Performance of Concrete-Filled FRP Tube Columns for Bridge Substructure." Journal of Bridge Engineering, ASCE, 11(3), 359-370.

Zohrevand, P., and Mirmiran, A. (2011). "Cyclic Behavior of Hybrid Columns Made of Ultra High Performance Concrete and Fiber Reinforced Polymers." Journal of Composites for Construction, ASCE, Online posting ahead of print June. 
Table 5.1 Specimen Test Matrix

\begin{tabular}{|c|c|c|c|c|c|c|c|}
\hline Specimen & FRP Tube & $\begin{array}{c}\text { Column } \\
\text { Outside } \\
\text { Diameter } \\
\text { mm } \\
\text { (in.) } \\
\end{array}$ & $\begin{array}{c}\text { Tube } \\
\text { Thickness } \\
\text { mm } \\
\text { (in.) }\end{array}$ & $\begin{array}{l}\mathrm{f}_{\mathrm{u}}^{*} \\
\mathrm{Mpa} \\
(\mathrm{ksi})\end{array}$ & $\begin{array}{l}\mathrm{f}_{\mathrm{c}}^{* *} \\
\mathrm{Mpa} \\
(\mathrm{ksi})\end{array}$ & $\begin{array}{l}\text { Long. } \\
\text { Steel } \\
\text { Reinf. }\end{array}$ & $\begin{array}{l}\text { Trans. } \\
\text { Steel } \\
\text { Reinf. }\end{array}$ \\
\hline $\mathrm{RC}$ & None & $\begin{array}{l}305 \\
(12)\end{array}$ & - & - & $\begin{array}{c}42 \\
(6.1)\end{array}$ & $\begin{array}{c}16 \text { No. } 10 \mathrm{M} \\
\text { (No. } 3)\end{array}$ & $\begin{array}{c}4.9 \mathrm{~mm} \\
(0.19 \text { in. }) \\
\text { Spiral }\end{array}$ \\
\hline UF1 & $\begin{array}{l}\text { Red Thread } \\
\text { II Pipe }\end{array}$ & $\begin{array}{c}323 \\
(12.71) \\
\end{array}$ & $\begin{array}{c}5 \\
(0.22) \\
\end{array}$ & $\begin{array}{c}180 \\
(26.1) \\
\end{array}$ & $\begin{array}{c}42 \\
(6.1) \\
\end{array}$ & None & None \\
\hline UF2 & $\begin{array}{l}\text { Alphatic } \\
\text { Amine } \\
\text { Pipe }\end{array}$ & $\begin{array}{c}337 \\
(13.25)\end{array}$ & $\begin{array}{c}19 \\
(0.75)\end{array}$ & $\begin{array}{c}175 \\
(25.4)\end{array}$ & $\begin{array}{c}42 \\
(6.1)\end{array}$ & None & None \\
\hline UF3 & $\begin{array}{c}\text { Alphatic } \\
\text { Amine } \\
\text { Pipe }\end{array}$ & $\begin{array}{c}219 \\
(8.62)\end{array}$ & $\begin{array}{c}16 \\
(0.63)\end{array}$ & $\begin{array}{c}180 \\
(26.1)\end{array}$ & $\begin{array}{c}42 \\
(6.1)\end{array}$ & None & None \\
\hline RUF1 & $\begin{array}{l}\text { Red Thread } \\
\text { II Pipe }\end{array}$ & $\begin{array}{c}323 \\
(12.71) \\
\end{array}$ & $\begin{array}{c}5 \\
(0.22) \\
\end{array}$ & $\begin{array}{c}183 \\
(26.5)\end{array}$ & $\begin{array}{c}42 \\
(6.1)\end{array}$ & $\begin{array}{l}6 \text { No. } 10 \mathrm{M} \\
(\text { No. } 3)\end{array}$ & None \\
\hline RUF2 & $\begin{array}{c}\text { Red Thread } \\
\text { II Pipe }\end{array}$ & $\begin{array}{c}323 \\
(12.71) \\
\end{array}$ & $\begin{array}{c}5 \\
(0.22) \\
\end{array}$ & $\begin{array}{c}181 \\
(26.2) \\
\end{array}$ & $\begin{array}{c}42 \\
(6.1) \\
\end{array}$ & $\begin{array}{c}10 \text { No. } 10 \mathrm{M} \\
(\text { No. } 3)\end{array}$ & None \\
\hline
\end{tabular}

* 28-day compressive strength of UHPC

${ }^{* *} 28$-day compressive strength of conventional concrete

Table 5.2 Reinforcement Ratio, Reinforcement Index, and Stiffness Index of Specimens

\begin{tabular}{|c|c|c|c|c|c|c|c|c|}
\hline \multirow[t]{2}{*}{ Specimen } & \multicolumn{2}{|c|}{$\begin{array}{l}\text { Reinforcement } \\
\text { Ratio (\%) }\end{array}$} & \multicolumn{3}{|c|}{$\begin{array}{l}\text { Reinforcement } \\
\text { Index }(\%)\end{array}$} & \multicolumn{3}{|c|}{$\begin{array}{l}\text { Stiffness } \\
\text { Index }(\%)\end{array}$} \\
\hline & Steel & FRP & Steel & FRP & Total & Steel & FRP & Total \\
\hline $\mathrm{RC}$ & 1.6 & - & 15.4 & - & 15.4 & 10.2 & - & 10.2 \\
\hline UF1 & - & 6.7 & - & 11.7 & 11.7 & - & 1.6 & 1.6 \\
\hline UF2 & - & 21.4 & - & 18.5 & 18.5 & - & 5.7 & 5.7 \\
\hline UF3 & - & 26.9 & - & 22.7 & 22.7 & - & 7.2 & 7.2 \\
\hline RUF1 & 0.5 & 6.7 & 1.2 & 11.5 & 12.7 & 2.0 & 1.6 & 3.6 \\
\hline RUF2 & 0.9 & 6.7 & 2.0 & 11.6 & 13.6 & 3.3 & 1.6 & 4.9 \\
\hline
\end{tabular}


Table 5.3 Performance Measures of Initial Stiffness, Moment and Displacement Capacities, and Ductility

\begin{tabular}{cccccccc}
\hline \hline Specimen & Unit & RC & UF1 & UF2 & UF3 & RUF1 & RUF2 \\
\hline \hline \multirow{2}{*}{ Initial Stiffness } & kN.m & 63 & 72 & 120 & 36 & 104 & 106 \\
& (kips.in) & $(558)$ & $(637)$ & $(1,062)$ & $(319)$ & $(921)$ & $(938)$ \\
\hline \multirow{2}{*}{ Maximum Moment } & kN.m & 94 & 115 & 279 & 92 & 157 & 184 \\
& $($ kips.in) & $(832)$ & $(1,018)$ & $(2,469)$ & $(814)$ & $(1,390)$ & $(1,629)$ \\
\hline Maximum Drift Ratio & $(\%)$ & 5.0 & 4.4 & 4.9 & 4.9 & 4.6 & 4.9 \\
\hline Ductility & - & 3.3 & 2.7 & 2.1 & 2.0 & 3.1 & 2.8 \\
\hline \hline
\end{tabular}




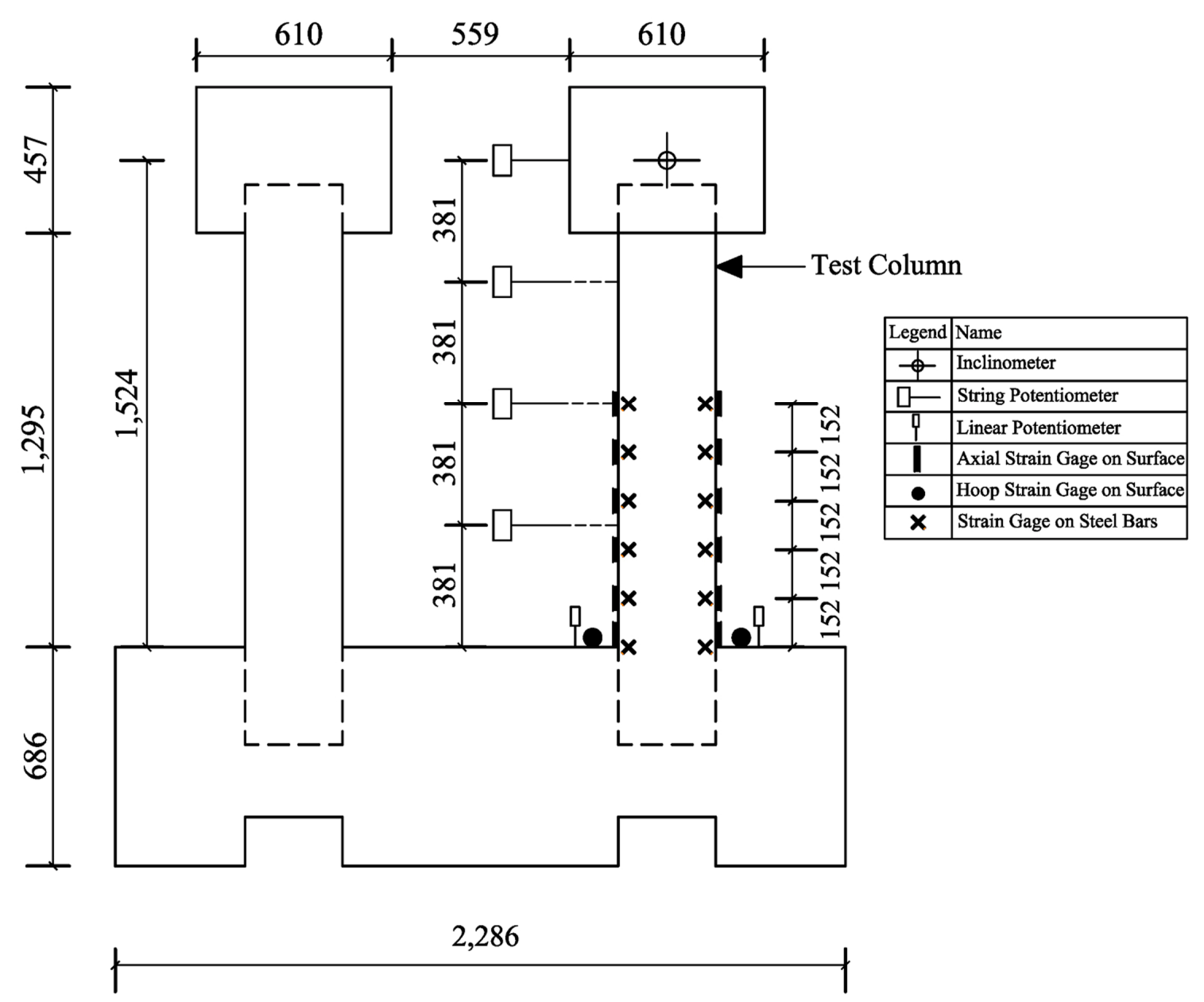

Figure 5.6 Layout of Column Specimens and Instrumentation Plan (Note: all dimensions are in $\mathrm{mm} ; 1 \mathrm{~mm}=0.039$ in.) 


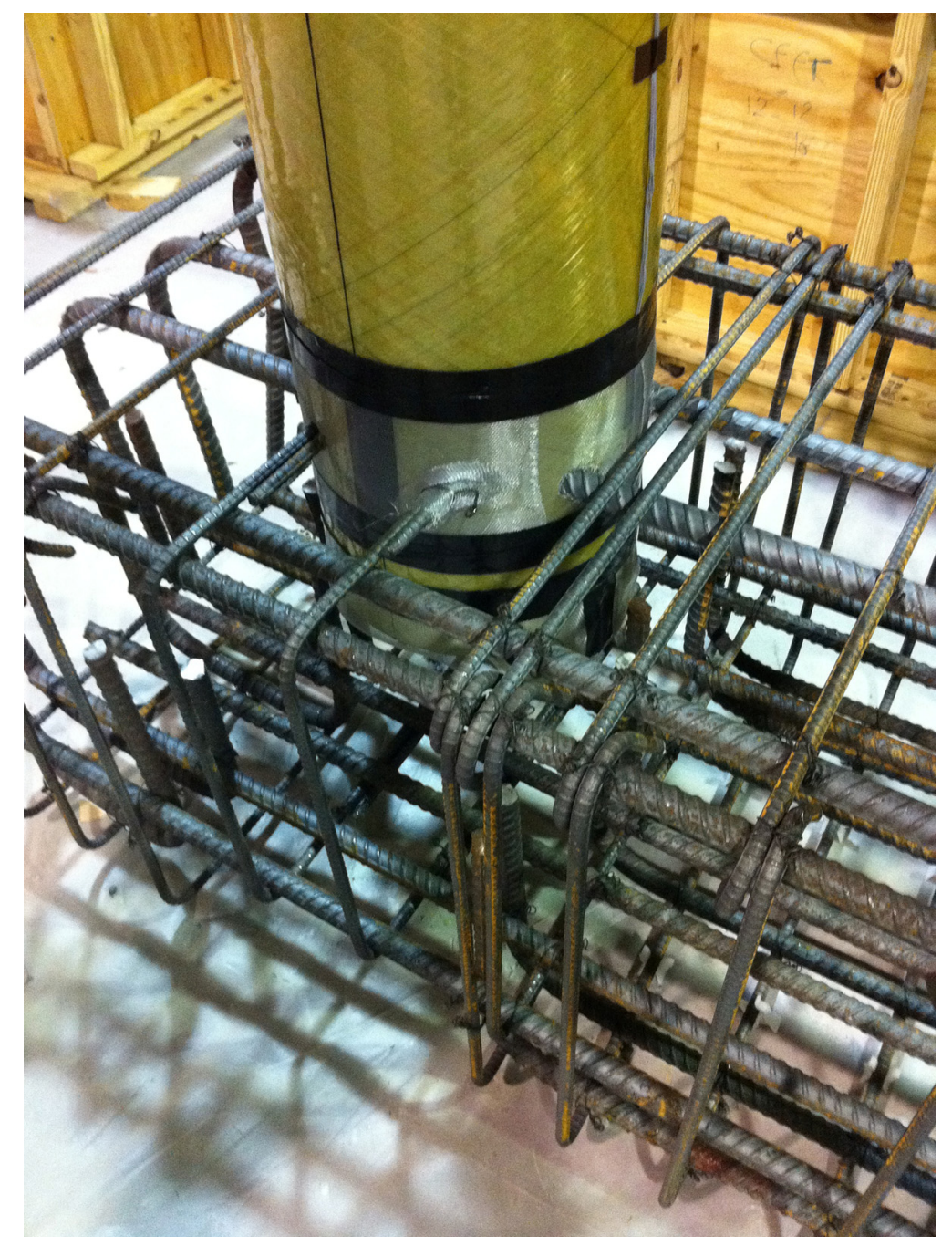

Figure 5.2 Embedment of FRP Tubes into the Footing 


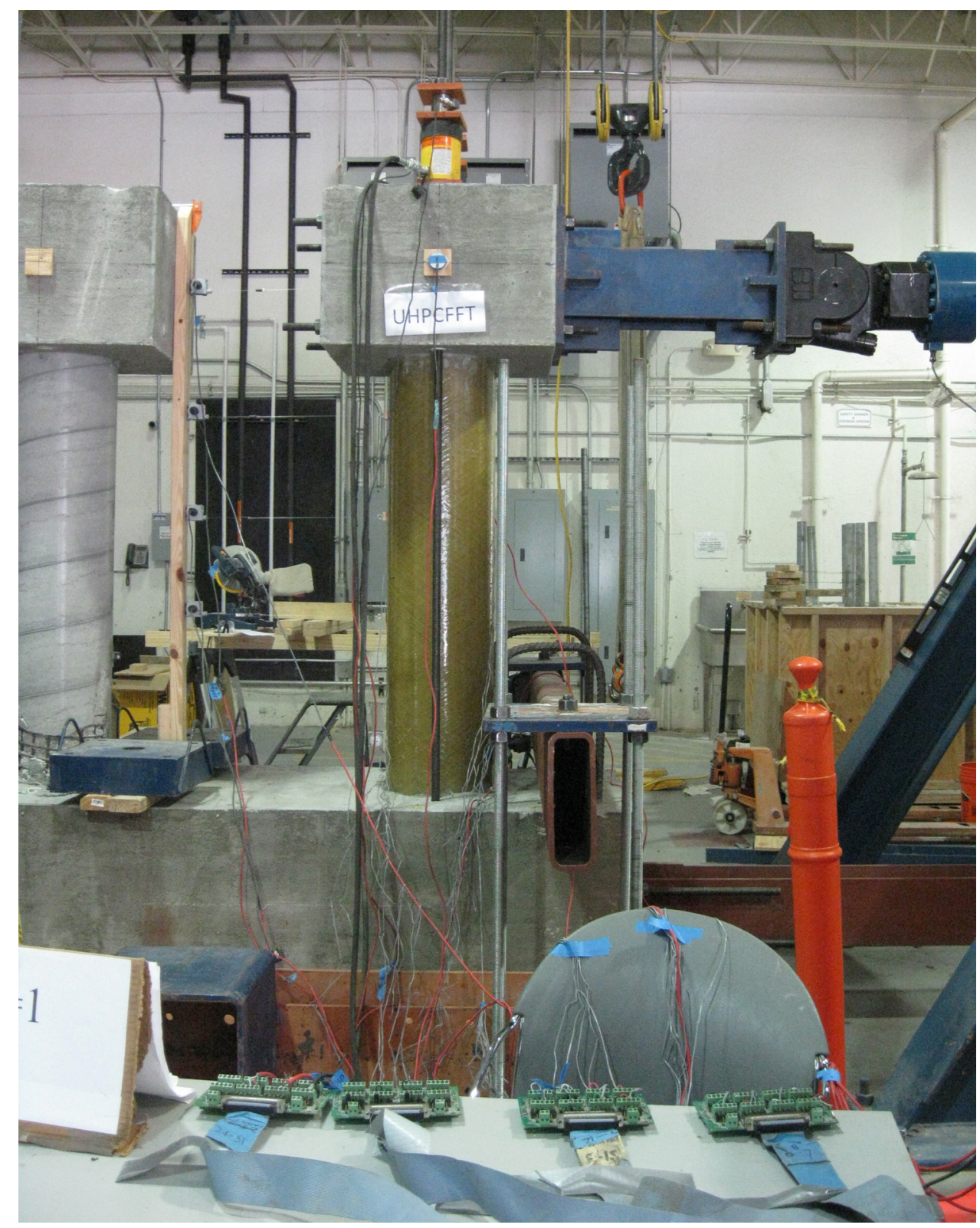

Figure 5.3 Test Setup 


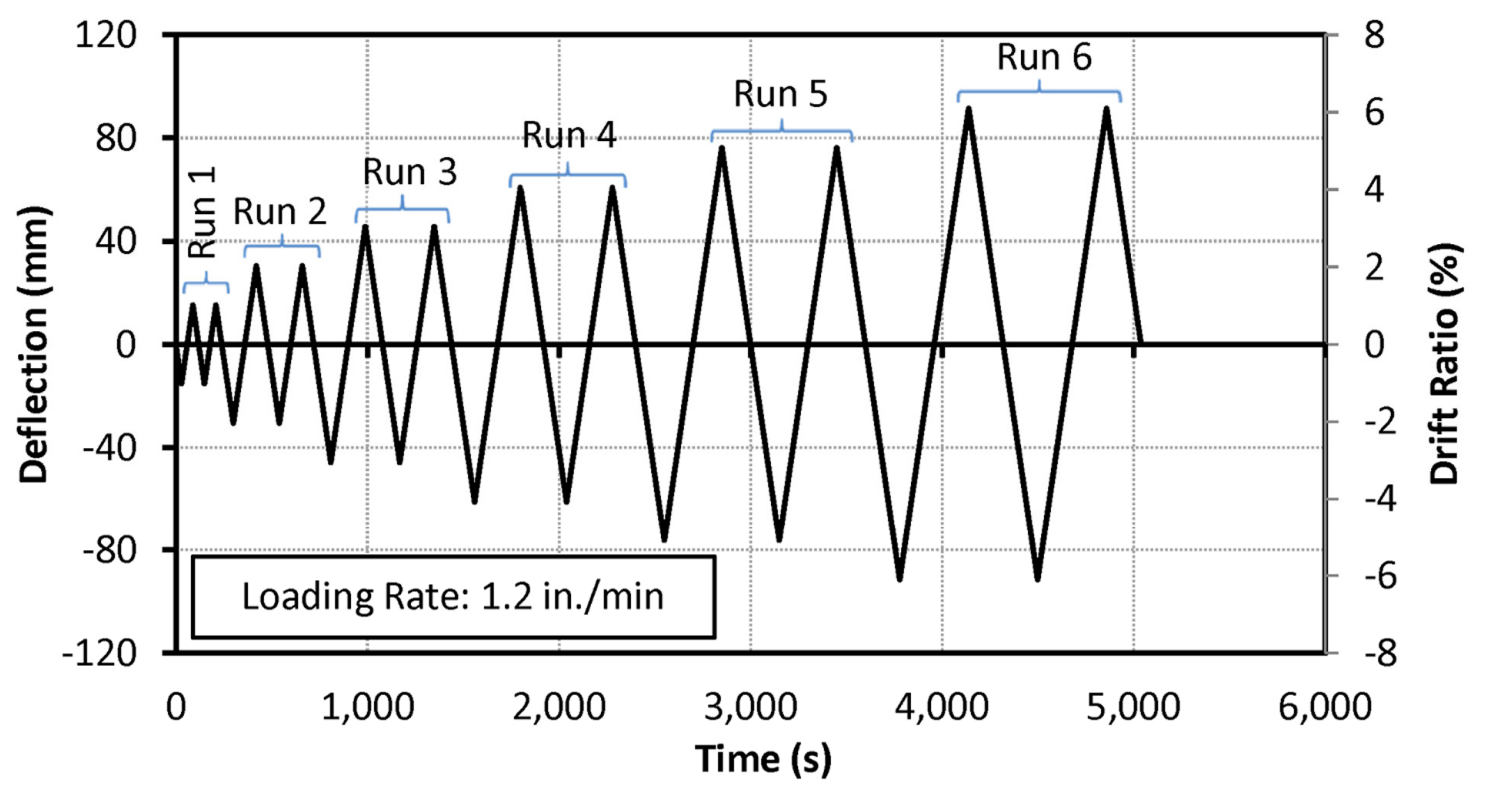

Figure 5.4 Reverse Cyclic Loading Regime (Note: $1 \mathrm{~mm}=0.039$ in.) 


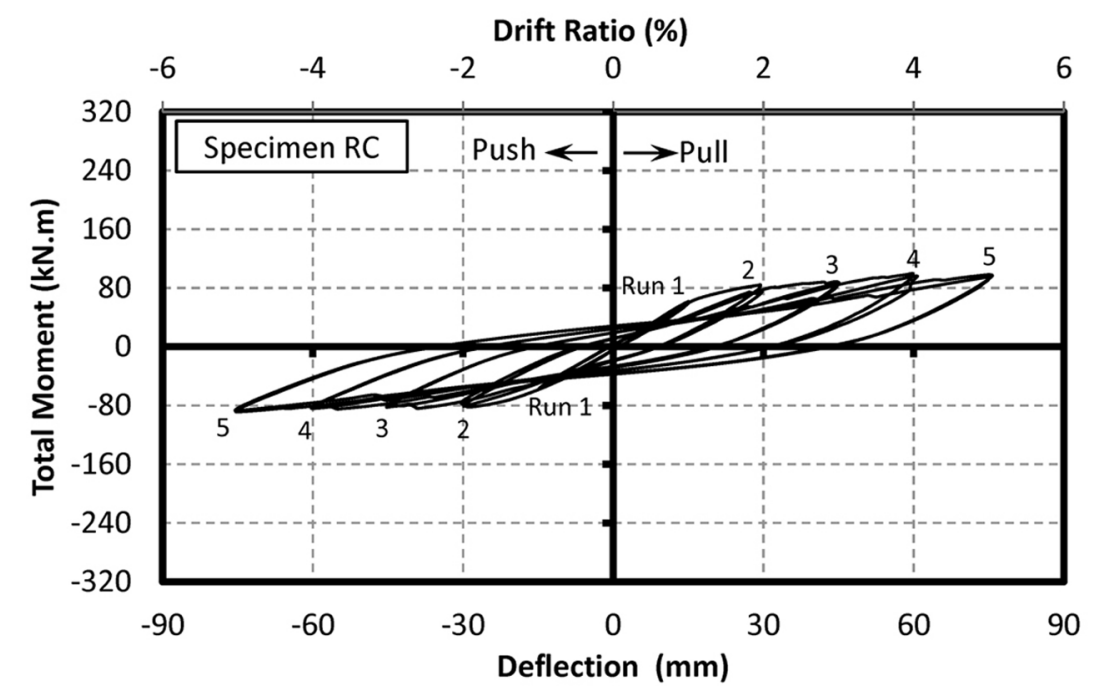

(a)

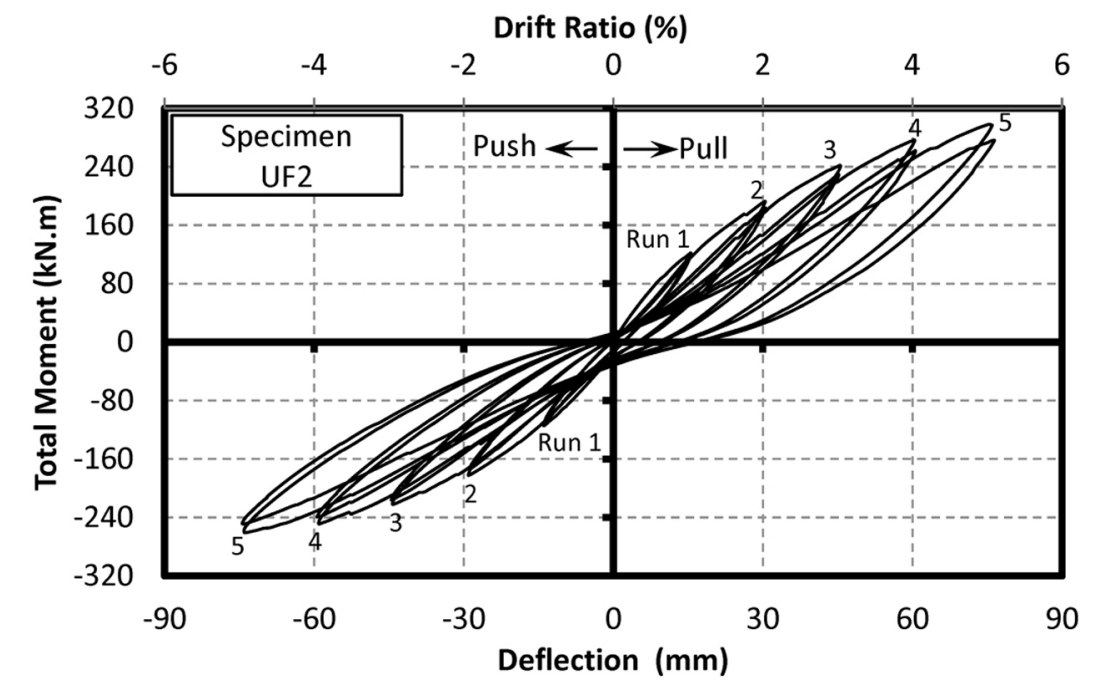

(c)

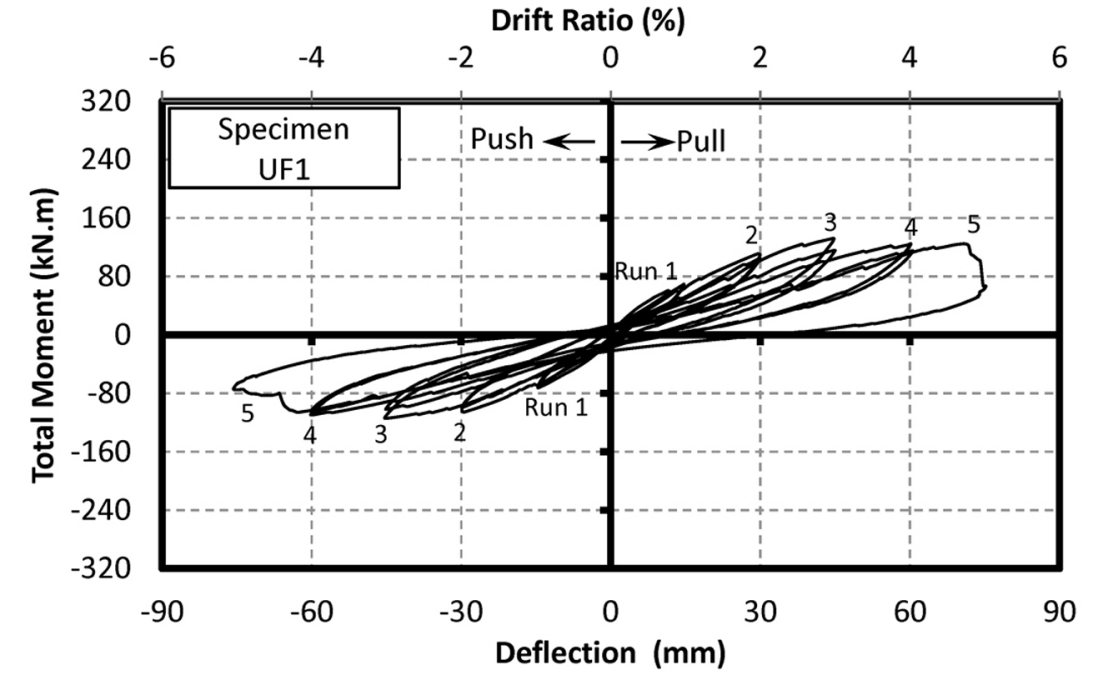

(b)

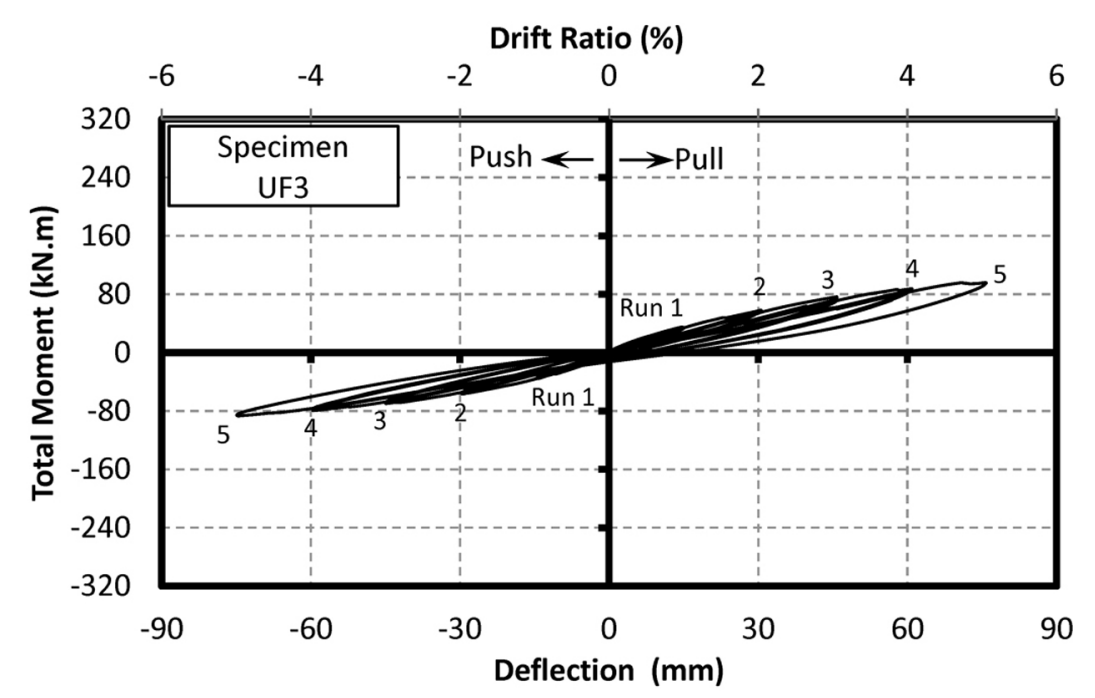

(d) 


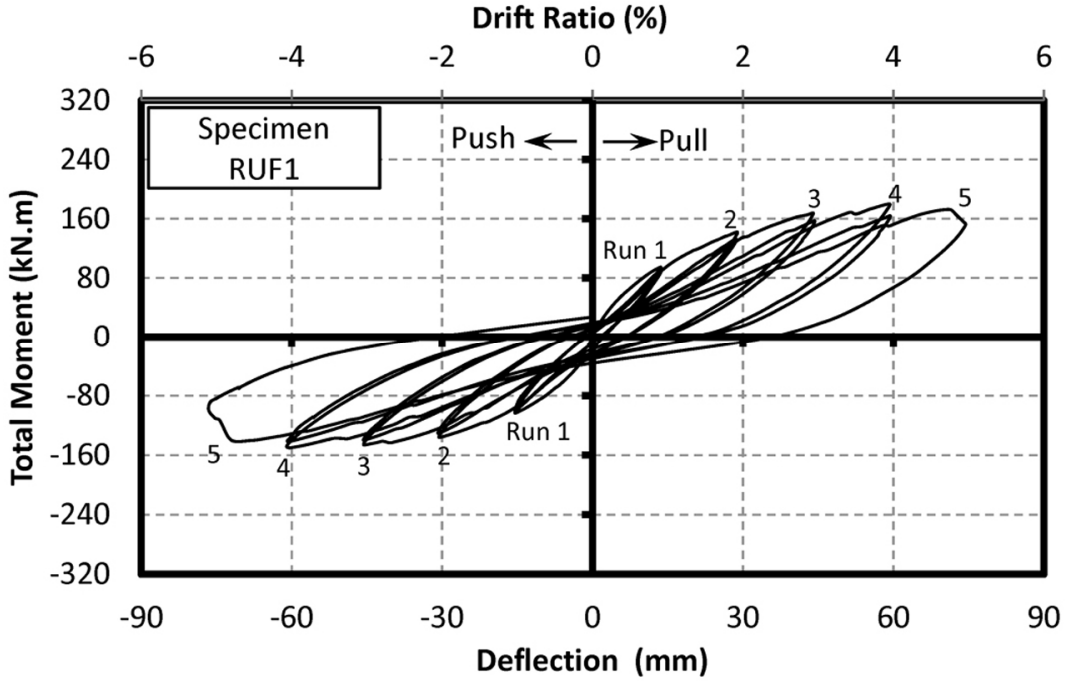

(e)

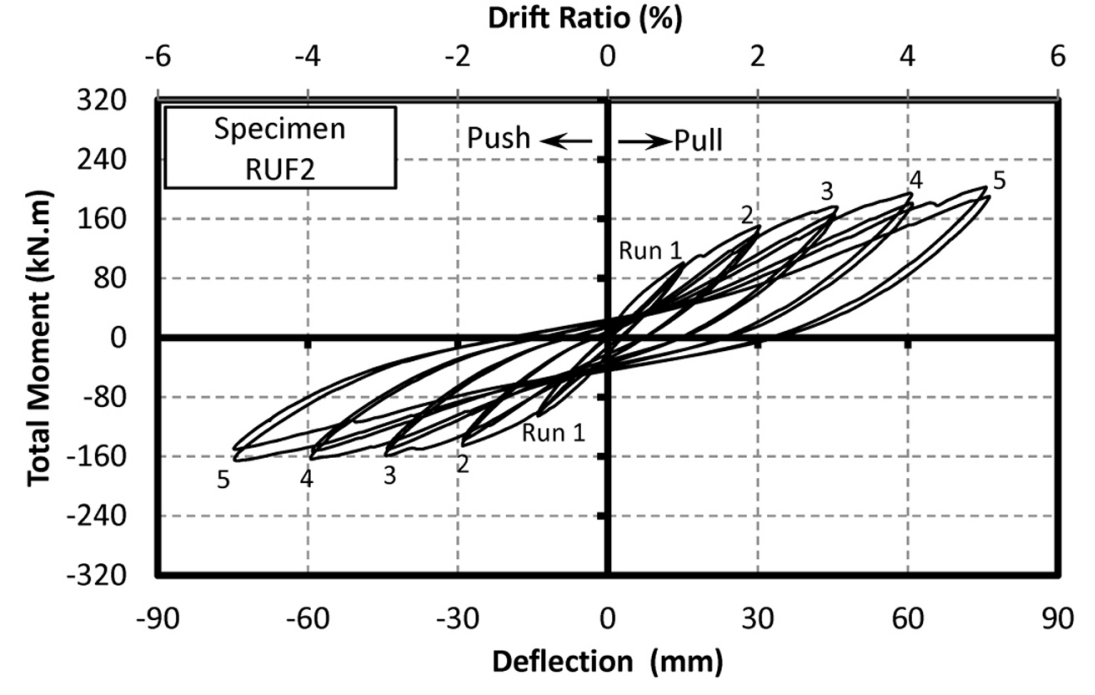

(f)

Figure 5.5 Hysteretic Moment-Deflection Response for Specimens (a) RC, (b) UF1, (c) UF2, (d) UF3, (e) RUF1, (f) and RUF2 (Notes: $1 \mathrm{~mm}=0.039$ in.; $1 \mathrm{kN} . \mathrm{m}=8.85$ kips.in) 


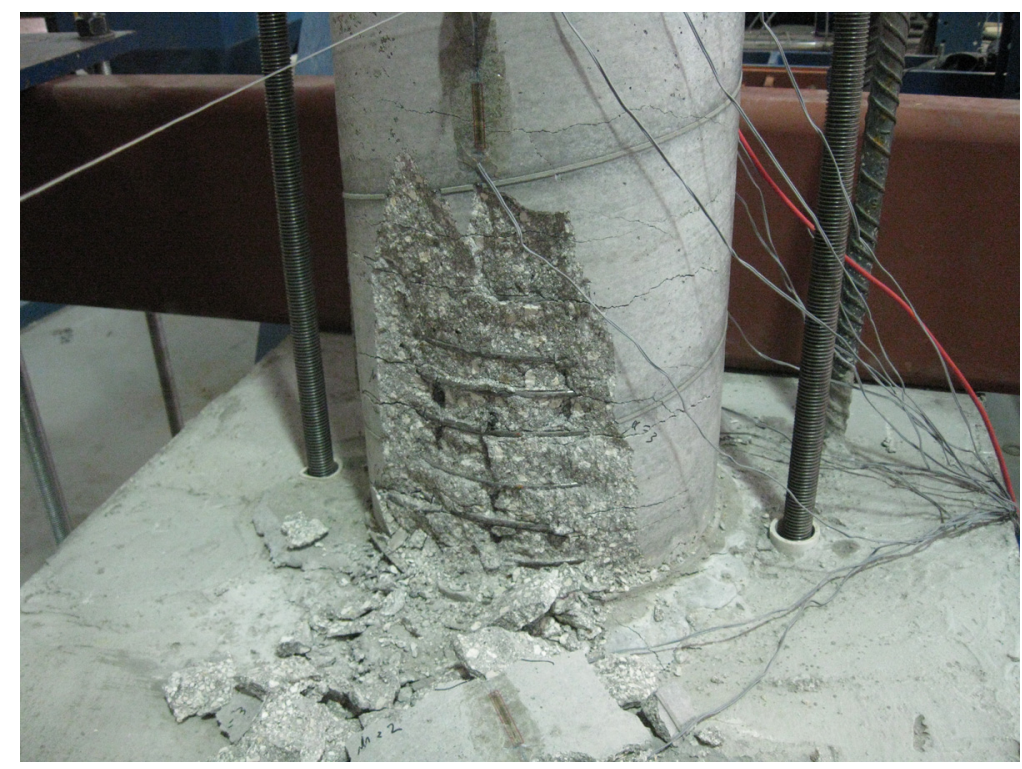

(a)

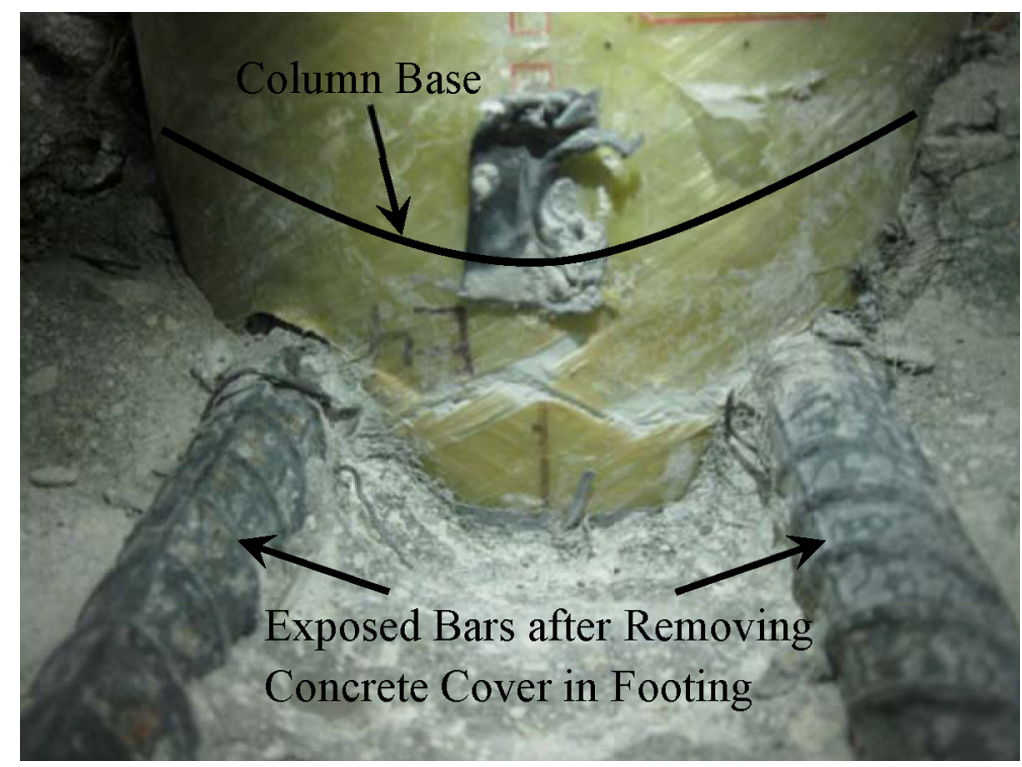

(b)

Figure 5.6 Failure Mode in (a) Specimen RC, (b) and UHPCFFT Specimens 


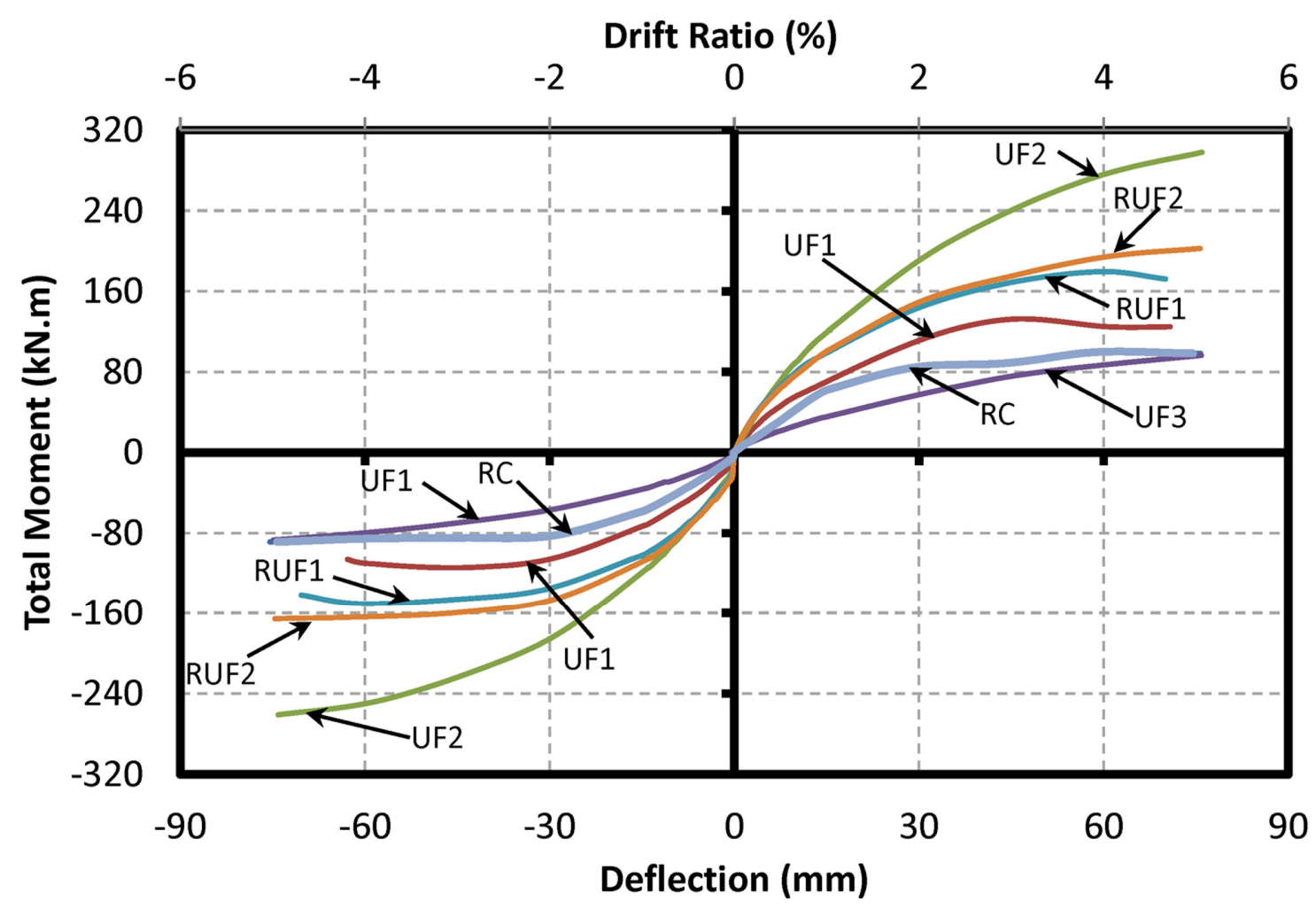

Figure 5.7 Moment-Deflection Envelope Curves (Notes: $1 \mathrm{~mm}=0.039$ in.; $1 \mathrm{kN} . \mathrm{m}=8.85$ kips.in) 


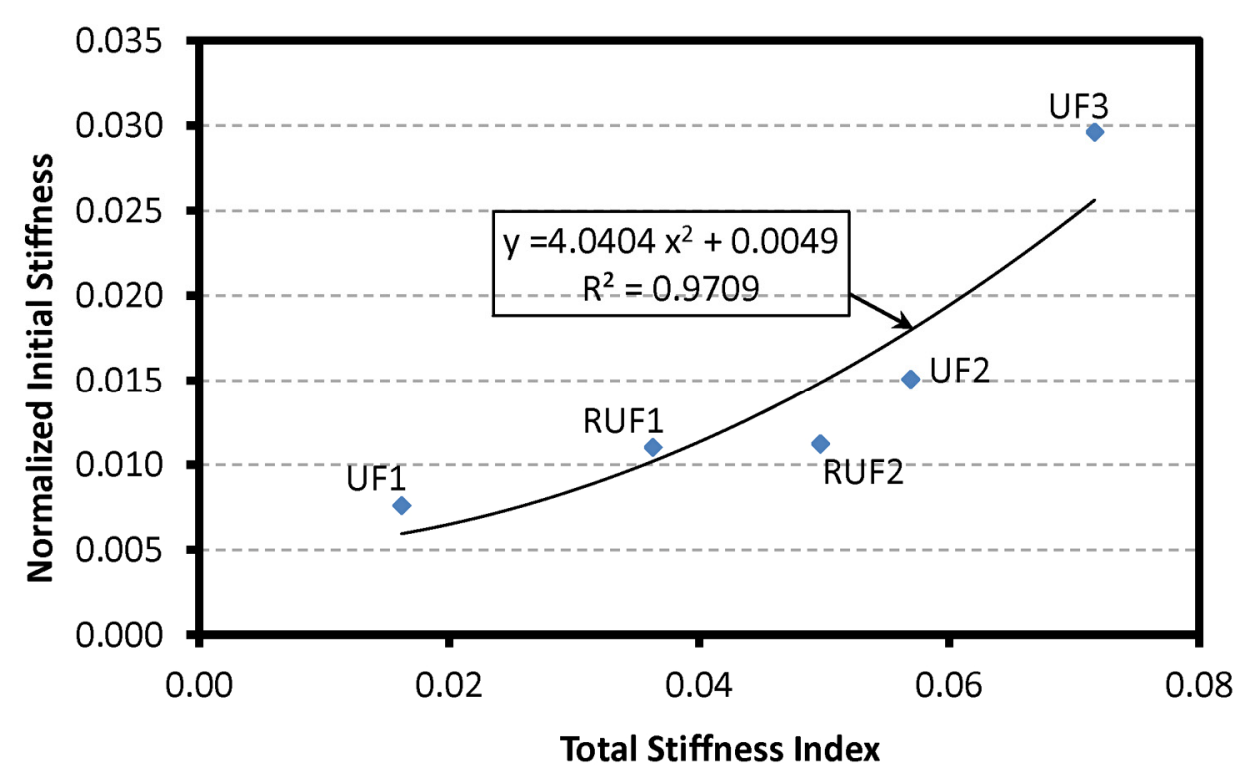

Figure 5.8 Effect of Total Stiffness Index on Initial Stiffness of UHPCFFT Specimens

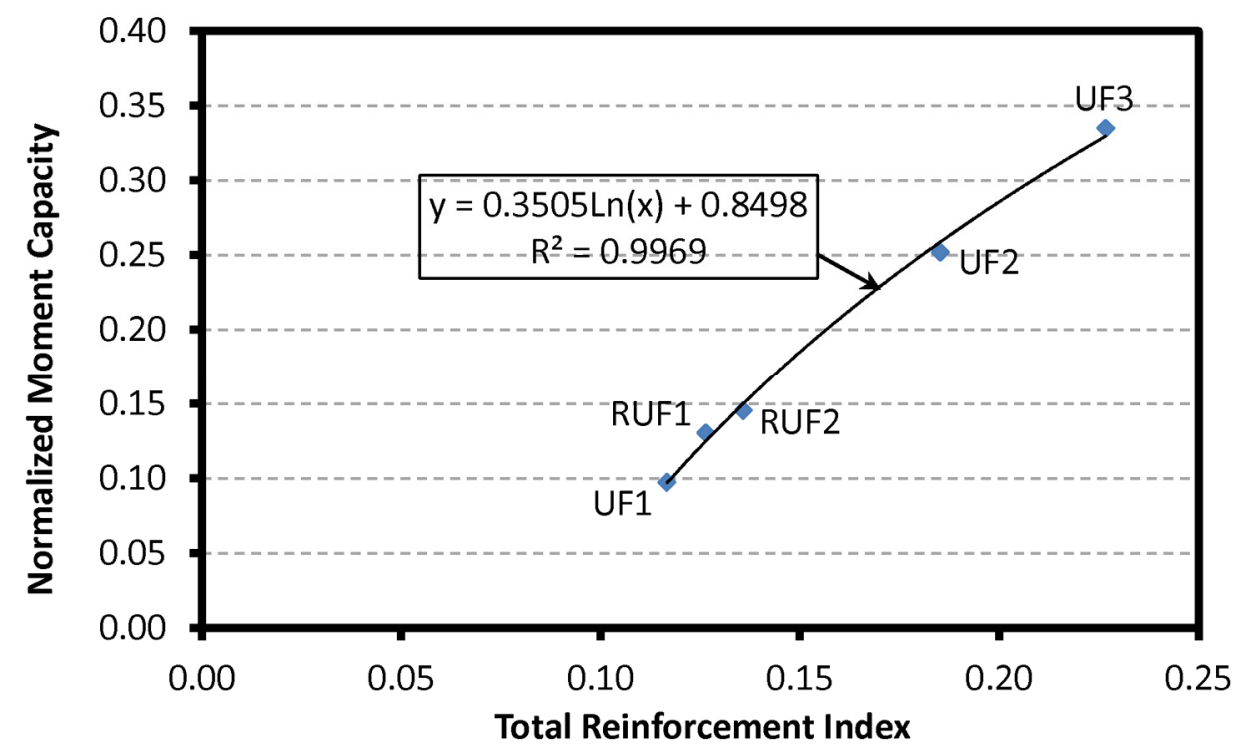

Figure 5.9 Effect of Total Reinforcement Index on the Strength of UHPCFFT Specimens 


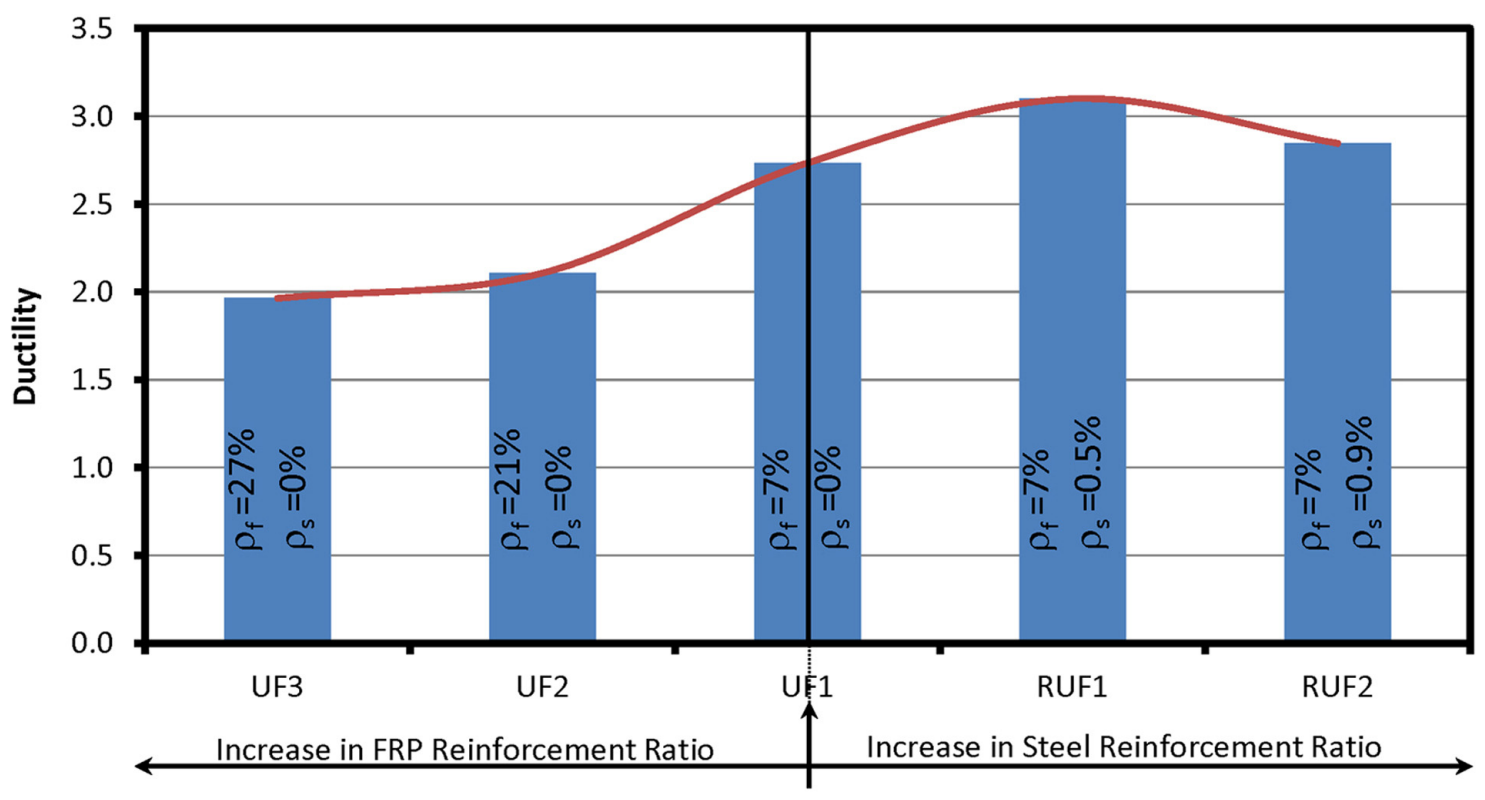

Figure 5.10 Comparison of Ductility in UHPCFFT Specimens

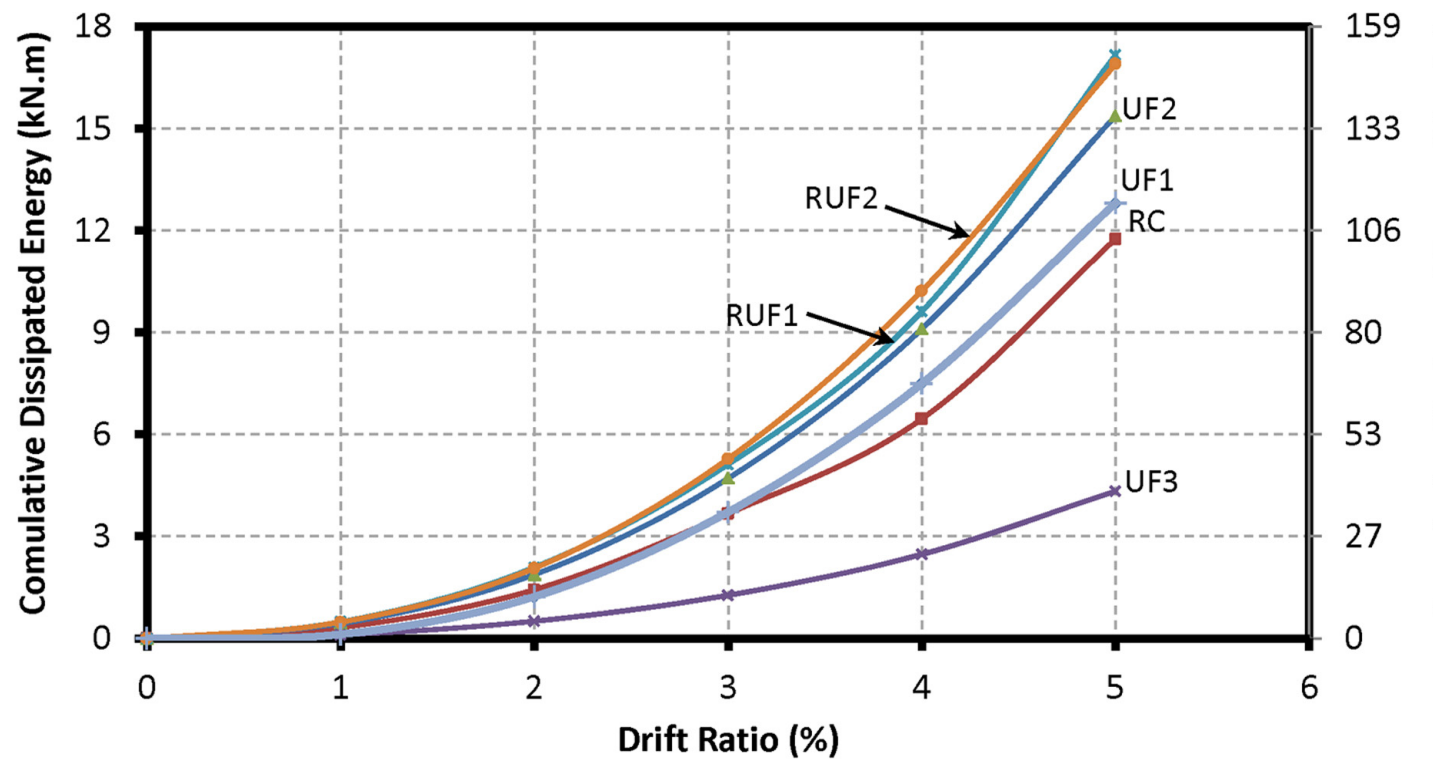

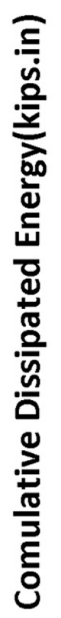

Figure 5.11 Cumulative Dissipated Energy versus Drift Ratio 


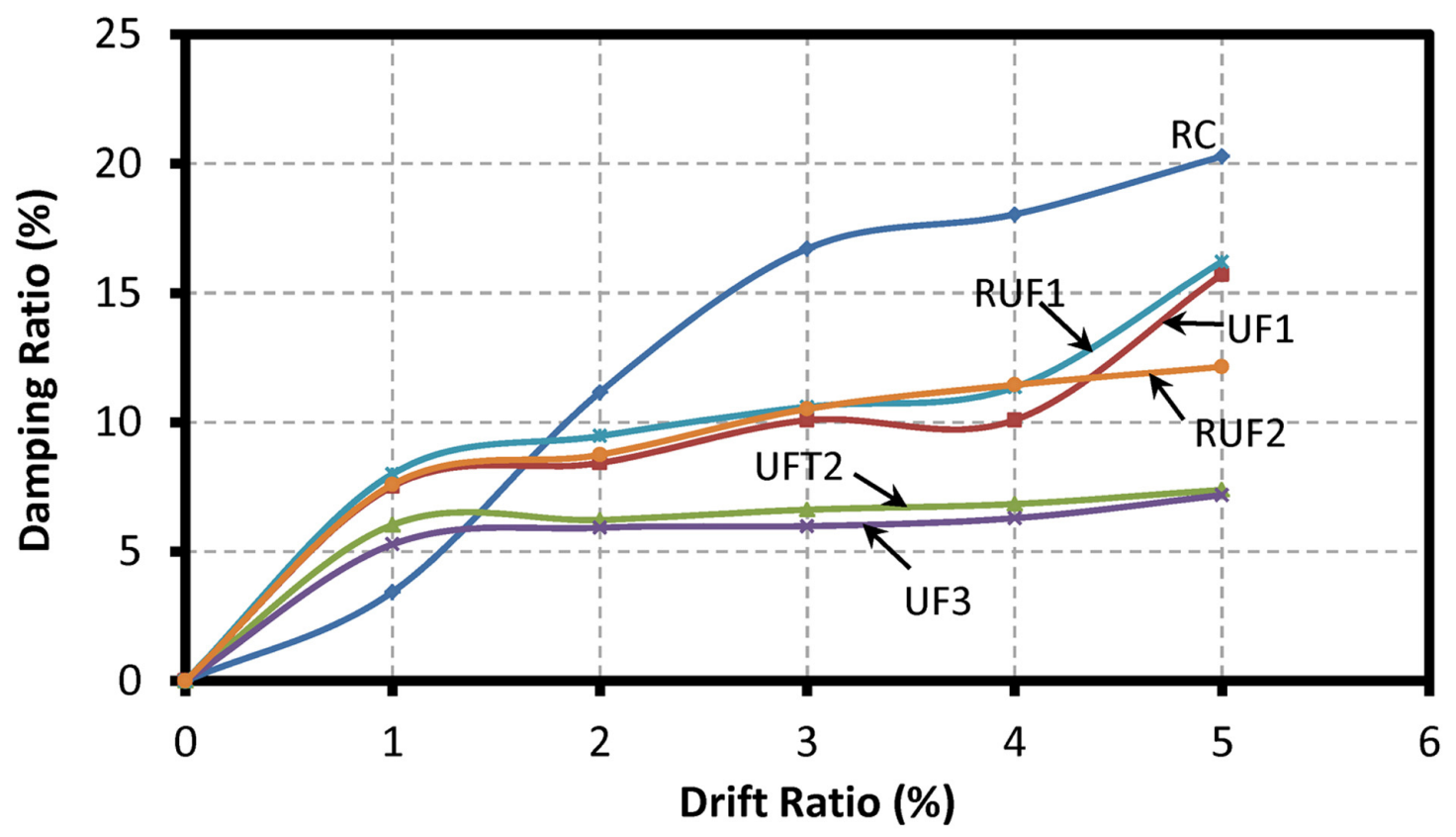

Figure 5.12 Damping Ratio versus Drift Ratio

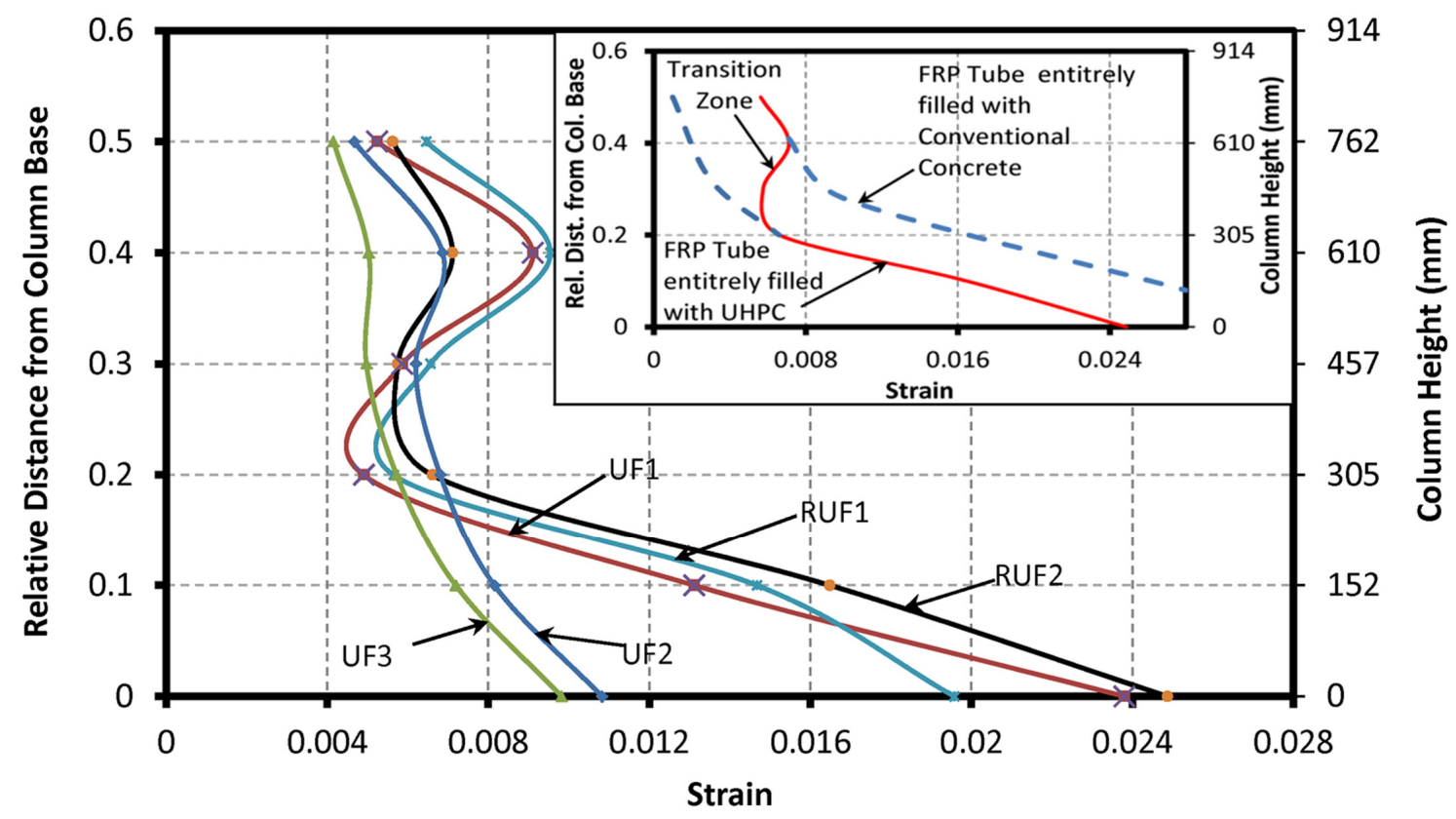

Figure 5.13 Ultimate FRP Tensile Strain Profiles in UHPCFFT Specimens (Note: 1 $\mathrm{mm}=0.039 \mathrm{in}$.) 


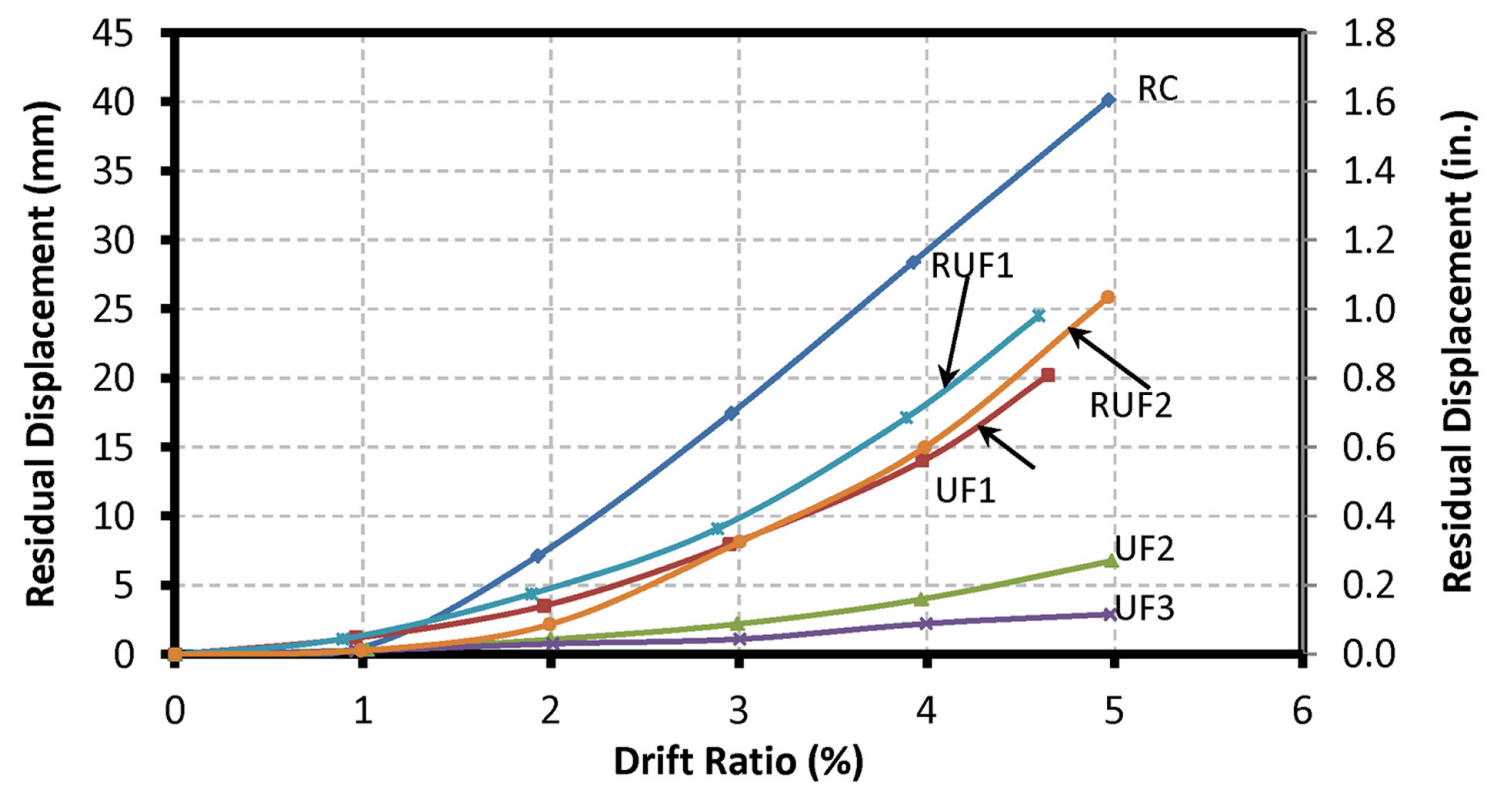

Figure 5.14 Residual Drift Ratio versus Drift Ratio 


\title{
6. SEISMIC RESPONSE OF ULTRA-HIGH PERFORMANCE CONCRETE- FILLED FRP TUBE COLUMNS
}

\author{
Pedram Zohrevand and Amir Mirmiran
}

Submitted to the Journal of Earthquake Engineering

\begin{abstract}
The seismic response of a novel hybrid column made of a fiber-reinforced polymer (FRP) tube filled with ultra-high performance concrete (UHPC) was studied. A general methodology was proposed to estimate the maximum ground acceleration capacity of five UHPC-filled FRP tubes (UHPCFFT) and one reference reinforced concrete (RC) column based on the results of their pseudo-static tests. The analysis showed 20\% higher maximum ground acceleration capacity for the steel-free UHPCFFT column with a thin FRP tube, as compared to its RC counterpart. The results were further verified using a nonlinear dynamic simulation of both columns under a major earthquake record.
\end{abstract}

Keywords: Bridge columns; Fiber-reinforced polymers (FRP); Ground acceleration; Seismic design; Tubes; and Ultra-high performance concrete (UHPC)

\subsection{Introduction}

Advanced materials such as ultra-high performance concrete (UHPC) and fiberreinforced polymer (FRP) composites have received much attention in construction industry. The excellent properties of UHPC such as ultra-high compressive strength and modulus of elasticity and usable tensile strength, and significant durability and damage tolerance make this material a promising alternative to conventional concrete, especially 
in critical structures and in seismic regions (Graybeal 2005, Brühwiler and Denarié 2008, Massicotte and Boucher-Proulx 2010). Similarly, FRP composites provide high strengthto-weight and stiffness-to-weight ratios, and excellent electrochemical corrosion resistance (Mertz et al. 2003). Application of FRP tubes as stay-in-place formwork, protective jacket, confinement device, and shear and flexural reinforcement in concretefilled FRP tubes (CFFT) has been shown to simplify and accelerate the construction process, and improve the durability and performance of the system (Mirmiran et al. 1998). On the other hand, a moderate amount (1-2\%) of longitudinal steel reinforcement was found necessary to provide adequate strength and ductility for CFFT systems in seismic regions (Shao and Mirmiran 2005, Zhu et al. 2006).

Considering the exceptional properties of UHPC and FRP, the two were combined in a new generation of CFFT system (Zohrevand and Mirmiran 2011a) - a novel hybrid column, with no steel reinforcement, made of an FRP tube with off-axis fibers filled with UHPC within the plastic hinge region and conventional concrete for the remainder of the column length. The performance of the steel-free UHPC-filled FRP tube (UHPCFFT) was studied as a cantilever column under pseudo-static tests. The UHPCFFT column showed significantly higher flexural strength and initial stiffness, but a limited plastic behavior with less residual displacements and a slightly lower ductility, as compared to its RC counterpart (Zohrevand and Mirmiran 2011a).

Traditionally, the lower ductility of a system, as measured from pseudo-static tests, is perceived to indicate either (a) an inferior seismic performance, or (b) an inefficient alternative to resist ground motion through a predominantly elastic response. 
Here, both perceptions are challenged to make room for a novel steel-free system in seismic applications.

Figure 6.1 shows the force-deflection response curves for two systems; System A with a higher ductility and lower strength, as compared to System B. Both systems are assumed to have the same initial stiffness, mass, and damping to simplify the comparison of their seismic performance. Therefore, their corresponding linear system due to the earthquake ground motion is the same, as shown in the figure. Earthquake resisting forces, which are the magnified values of the strengths of the real inelastic systems relative to their ductility, are shown on the corresponding linear system. The higher ductility in System A would lead to a higher magnification factor for its earthquake resisting force, as compared to System B. Therefore, the earthquake resisting force in System A $\left(F_{L A}\right)$ may still be lower than that in System B $\left(F_{L B}\right)$.

If both systems were RC, despite its higher earthquake resisting force, System B would traditionally be excluded from consideration due to its inefficient use of plastic capacity, perhaps implying an over reinforcement. Therefore, in RC structures, it is commonly accepted that ductility could serve as an indicator for efficient design in seismic applications. On the other hand, this conclusion may not be valid when System B is a steel-free system made from different materials with easier and faster constructability, higher durability, lower maintenance costs, and self-centering capabilities due to lower residual displacements. Therefore, the true performance indicator for two dissimilar systems is not the ductility factor, but rather the maximum ground acceleration capacity. This, however, requires a methodology to estimate the seismic response of a system from its pseudo-static test results. 
This paper presents a general methodology to estimate the maximum ground acceleration capacity of a system from its pseudo-static tests. It then applies the procedure to the case of UHPCFFT column in comparison with its RC counterpart, using the results of an earlier set of pseudo-static tests (Zohrevand and Mirmiran 2011b), described briefly herein. Finally, in order to further validate the methodology and the findings, a seismic simulation of the UHPCFFT and RC columns was conducted under a major earthquake record.

\subsection{Experimental Database}

Six quarter-scale bridge columns including one reference RC and five UHPCFFT columns were tested in a previous study (Zohrevand and Mirmiran 2011b) under reverse cyclic lateral load and a constant axial load. The test matrix and specimen details are presented in Table 6.1. The columns all had the same height of 1,524 mm. All UHPCFFTs were made of FRP tubes filled with UHPC within twice their column diameters and continuously with conventional concrete for the remainder of the column length. The FRP tubes were off-the-shelf products made by filament winding of $\pm 55^{\circ} \mathrm{E}$ glass fibers and thermosetting epoxy resin. Two types of FRP tubes were used, both

manufactured by NOV Fiber Glass Systems of Houston, TX; (1) Red Thread ${ }^{\circledR}$ II with a tensile and hoop strength of 314 and $234 \mathrm{MPa}$, respectively, and a tensile modulus of 12.6 GPa, and (2) Alphatic Amine ${ }^{\circledR}$ with a tensile and hoop strength of 152 and $241 \mathrm{MPa}$, respectively, and a tensile modulus of $13.8 \mathrm{GPa}$.

Each pair of columns was placed onto the same RC footing, while each column was tested independently. Figure 6.2 shows the layout of the column specimens. A constant axial load of $125 \mathrm{kN}$ was applied on each column simulating a dead load 
equivalent to $0.04 f^{\prime}{ }_{c} A_{g}$, where $f_{c}^{\prime}$ is 28 -day compressive strength of the conventional concrete in the columns, and $A_{g}$ is the gross cross sectional area of the RC column. After applying the external post-tensioning axial force, each column was subjected to a displacement-controlled reverse cyclic lateral load in successive runs, as shown in Figure 6.3 .

The load-deflection envelope curves for all specimens are shown in Figure 6.4. The lateral deflection is depicted both as its absolute value $(u)$ and the normalized drift ratio $(u / L)$, where $L$ is the column height. Additional details of the experimental study can be found in (Zohrevand and Mirmiran 2011b).

\subsection{Seismic Response Analysis}

Using the results of the aforementioned experimental study, the seismic response of each tested specimen will be estimated in this section.

\subsubsection{Cyclic Performance Measures}

Table 6.2 lists the values of maximum load and deflection as well as the initial stiffness of each specimen, as obtained from the response envelopes. The initial stiffness was calculated based on the linear regression analysis of the slope within the elastic range of the response envelope. Each response envelope was idealized by a bilinear elasticperfectly plastic curve with the same initial stiffness $(k)$, the same maximum deflection $\left(u_{m}\right)$, and the same area under the response curve, as shown in Figure 6.5. Using the idealized elastic-perfectly plastic response, the yield strength $\left(F_{y}\right)$, yield displacement $\left(u_{y}\right)$, and ductility $\left(\mu=u_{m} / u_{y}\right)$ were calculated for each specimen following (Chopra 2008), as listed in Table 6.2. 
Using the hysteretic load-deflection responses resulted from the pseudo-static tests, the damping ratio $(\xi)$ of each column was calculated in each cycle, as

$\xi=\frac{E_{h}}{4 \pi E_{e}}$

where $E_{h}$ is the hysteretic dissipated energy calculated based on the enclosed area within the hysteretic loops, and $E_{e}$ is the elastic energy calculated based on the maximum displacement and peak load in each cycle (Priestley et al. 1996). Variation of damping ratios relative to drift ratios are presented for all specimens in Figure 6.6, indicating that in comparison to the RC specimen, the UHPCFFTs provide a more stable damping characteristic throughout their loading history.

\subsubsection{Earthquake Response Spectrum}

\subsubsection{Elastic Design Response Spectrum}

For any recorded ground motion, the response spectra can be developed to present the peak values of deformation, pseudo-velocity, and pseudo-acceleration, with respect to the natural vibration period and damping ratio of an elastic single-degree-of-freedom (SDOF) system. A schematic linear response spectrum for a specific ground motion and damping ratio is shown in Figure 6.7. The dashed line in the figure shows the ground motion parameters, including the peak values of ground acceleration $\left(\ddot{u}_{g}\right)$, ground velocity $\left(\dot{u}_{g}\right)$, and ground displacement $\left(u_{g}\right)$. The deformation $(D)$, pseudo-velocity $(V)$, and pseudo-acceleration $(A)$ are interrelated, as: 
$D=\frac{V}{\omega_{n}}=\frac{A}{\omega_{n}^{2}}$

where $\omega_{n}$ is the natural circular vibration frequency.

An idealized elastic design response spectrum was suggested by Newmark and Hall (1982) based on a statistical analysis of the response spectra for a large ensemble of ground motions recorded on firm grounds (i.e., rock, soft rock, and competent sediments), as shown in Figure 6.8. The idealized elastic design response spectrum can be developed from $\ddot{u}_{g}, \dot{u}_{g}$, and $u_{g}$ using amplification factors $\alpha_{A}, \alpha_{V}$, and $\alpha_{D}$. These amplification factors for a non-exceedance probability of $84.1 \%$ can be calculated based on the damping ratio, following (Newmark and Hall 1982), as:

$\alpha_{A}=4.38-1.04 \ln \xi$

$\alpha_{V}=3.38-0.67 \ln \xi$

$\alpha_{D}=2.73-0.45 \ln \xi$

The fixed period values of $T_{a}, T_{b}, T_{e}$, and $T_{f}$ are $1 / 33,1 / 8,10$, and $33 \mathrm{sec}$, respectively (Newmark and Hall 1982). The period values of $T_{c}$ and $T_{d}$ are dependent on the damping ratio and the relative values of peak ground acceleration, velocity, and displacement $\left(\frac{\dot{u}_{g}}{\ddot{u}_{g}}\right.$ and $\left.\frac{u_{g}}{\dot{u}_{g}}\right)$. The intersections of the segments with constant $A\left(\alpha_{A} \ddot{u}_{g}\right)$, constant $V$ $\left(\alpha_{V} \dot{u}_{g}\right)$, and constant $D\left(\alpha_{D} u_{g}\right)$ identify the period values of $T_{c}$ and $T_{d}$, as:

$$
\begin{aligned}
& T_{c}=2 \pi\left(\frac{\alpha_{V}}{\alpha_{A}}\right)\left(\frac{\dot{u}_{g}}{\ddot{u}_{g}}\right) \\
& T_{d}=2 \pi\left(\frac{\alpha_{D}}{\alpha_{V}}\right)\left(\frac{u_{g}}{\dot{u}_{g}}\right)
\end{aligned}
$$




\subsubsection{Inelastic Design Response Spectrum}

The inelastic design response spectrum can be constructed by dividing the constant values of elastic design response spectrum $(A, V$, and $D)$ by the yield strength reduction factor $(R)$ for the elastoplastic system, as shown in Figure 6.9 (Chopra 2008). Strength reduction factor $(R)$ can be defined as a function of the ductility and natural period of the elastoplastic system (Chopra 2008), as:

$$
R_{y}= \begin{cases}1 & T_{n} \prec T_{a^{\prime}} \\ \sqrt{2 \mu-1} & T_{a^{\prime}} \prec T_{n} \prec T_{c^{\prime}} \\ \mu & T_{c^{\prime}} \prec T_{n}\end{cases}
$$

where $T_{a^{\prime}}, T_{b^{\prime}}, T_{d^{\prime}}, T_{e^{\prime}}$, and $T_{f^{\prime}}$ are the same as $T_{a}, T_{b}, T_{d}, T_{e}$, and $T_{f}$, respectively, and $T_{c^{\prime}}$ can be identified by the intersection of the segments with constant pseudo-acceleration $(A)$ and pseudo-velocity $(V)$, as:

$T_{c^{\prime}}=2 \pi\left(\frac{\alpha_{V}}{\alpha_{A}}\right)\left(\frac{\dot{u}_{g}}{\ddot{u}_{g}}\right)\left(\frac{\sqrt{2 \mu-1}}{\mu}\right)$

\subsubsection{Estimation of Maximum Ground Acceleration Capacity}

Using the results of the pseudo-static tests and the above-mentioned theory for developing the design response spectrum, the maximum ground motion capacity of each column can therefore be estimated through the following step-by-step procedure:

(1) Assuming typical relative values of peak ground acceleration, velocity, and displacement as $\frac{\dot{u}_{g}}{\ddot{u}_{g}}=1,219 \mathrm{~mm} / \mathrm{sec} / \mathrm{g}$ and $\frac{\ddot{u}_{g} \times u_{g}}{\dot{u}_{g}^{2}}=6$, following (Newmark and Hall 1982) for firm ground. 
(2) Idealizing the actual load-deflection response curve by an elastic-perfectly plastic system, as discussed in Section 3.1.

(3) Finding the average values of initial stiffness $(k)$, yield strength $\left(F_{y}\right)$, and ductility $(\mu)$ of the system (see Table 6.2).

(4) Assuming each column as an SDOF system with a lumped mass $(m)$ at the top of the column, as the summation of the column mass and the mass contribution from the superstructure, corresponding to the simulated dead load applied as post-tensioning force during the cyclic tests (see Table 6.3).

(5) Calculating the damping ratio $(\xi)$ of each column based on its hysteretic response using Equation 1, as explained in Section 3.1. Figure 6.6 shows the damping ratio in Specimen RC increasing continuously from a minimum value of $3 \%$ in Run 1 to a maximum value of $20 \%$ in Run 5, while higher damping ratios were seen in UHPCFFT specimens during Run 1, with only slight increase at higher runs. Since it is more conservative to use the minimum damping ratio at the early cycles, a $5 \%$ damping ratio was chosen for all columns (see Table 6.3).

(6) Calculating natural period $\left(T_{n}\right)$ of each SDOF column using its stiffness and mass (Table 6.3).

(7) Computing the amplification factors $\left(\alpha_{A}, \alpha_{V}\right.$, and $\left.\alpha_{D}\right)$ for the $84.1^{\text {th }}$ percentile spectrum using Equations 3-5 (see Table 6.3).

(8) Finding $T_{d^{\prime}}$ and $T_{c^{\prime}}$ using Equations 7 and 9, respectively, noting that period values of $T_{a^{\prime}}, T_{b^{\prime}}, T_{e^{\prime}}$, and $T_{f^{\prime}}$ are known from Figure 6.9 (see Table 6.3).

(9) Calculating the strength reduction factor $(R)$ using Equation 8 (see Table 6.3). 
(10) Identifying the region of the response spectrum for each column by comparing $T_{n}$ with $T_{a^{\prime}}, T_{b^{\prime}}, T_{c^{\prime}}, T_{d^{\prime}}, T_{e^{\prime}}$, and $T_{f^{\prime}}$ (see Figure 6.9), and accordingly, calculating the maximum ground acceleration capacity $\left(\ddot{u}_{g c}\right)$ of each column as:

$$
\ddot{u}_{g c}= \begin{cases}\frac{f_{y}}{m} & T_{n} \prec T_{a^{\prime}} \\ \frac{R_{y} f_{y}}{m\left(10.56\left(\alpha_{A}-1\right) T_{n}-0.32 \alpha_{A}+1.32\right)} & T_{a^{\prime}} \prec T_{n} \prec T_{b^{\prime}} \\ \frac{R_{y} f_{y}}{m \alpha_{A}} & T_{b^{\prime}} \prec T_{n} \prec T_{c^{\prime}} \\ \frac{R_{y} f_{y} T_{n}}{0.25 \pi \alpha_{V} m} & T_{c^{\prime}} \prec T_{n} \prec T_{d^{\prime}} \\ \frac{R_{y} f_{y} T_{n}^{2}}{0.37 \pi^{2} \alpha_{D} m} & T_{d^{\prime}} \prec T_{n} \prec T_{e^{\prime}} \\ \frac{R_{y} f_{y} T_{n}^{2}}{0.37 \pi^{2}\left(-14.35 T_{n}+14.35 \alpha_{D} T_{n}+1.43-\alpha_{D}\right) m} & T_{e^{\prime}} \prec T_{n} \prec T_{f^{\prime}} \\ \frac{R_{y} f_{y} T_{n}^{2}}{0.37 \pi^{2} m} & T_{f^{\prime}} \prec T_{n}\end{cases}
$$

Table 6.3 lists the maximum ground acceleration capacity of each column. It should be mentioned that the results achieved from the proposed analytical procedure are the conservative estimations of the seismic resistance of the columns, since the analytical procedure is based on a conservative design response spectrum following (Newmark and Hall 1982).

Figure 6.10 compares the maximum ground acceleration capacities of the six column specimens. It shows that Specimen UF1 with the thinnest FRP tube and no steel reinforcement has $20 \%$ higher ground acceleration capacity, while it had $20 \%$ lower ductility, as compared to Specimen RC. Increasing the FRP tube thickness with the same 
column diameter enhanced the maximum ground acceleration capacity of Specimen UF2 by $88 \%$, as compared to Specimen UF1. On the other hand, Specimen UF3, with a diameter of about $2 / 3$ of that in other specimens and a tube thickness similar to that of Specimen UF2, showed 30\% lower maximum ground acceleration capacity, as compared to Specimen RC. Adding $0.5 \%$ and $0.9 \%$ longitudinal steel reinforcement to Specimen UF1 increased the maximum ground acceleration capacity by $35 \%$ and $55 \%$ in Specimens RUF1 and RUF2, respectively, as compared to Specimen UF1.

\subsection{Analytical Modeling}

The seismic response of Specimens RC and UF1 was further studied through a seismic simulation to verify the results achieved from the analytical approach presented in the previous section. Specimen UF1 was chosen for seismic simulation among all other UHPCFFT specimens since it showed the most similar response to Specimen RC. The analytical modeling was carried out using OpenSees (McKenna et al. 2006), an open source non-linear finite element software.

\subsubsection{Modeling of the Columns}

A two-dimensional model was assembled for each column specimen to accommodate an in-plane analysis. The pre-defined material models of the program were used for each material. The cover concrete was modeled using a uniaxial concrete model neglecting the tensile strength of the concrete. The concrete core confined by spiral steel reinforcement was defined based on the model of Mander et al. (1988). The confined concrete in UHPCFFT columns was defined based on the FRP confinement model of Samaan et al. (1998). A uniaxial concrete model with tensile strength was used for the UHPC material. Due to the lack of any FRP confinement model for UHPC materials, the 
model of Samaan et al. (1998) was also used for FRP-confined UHPC. A uniaxial bilinear steel model was used for the steel reinforcement. A uniaxial tri-linear hysteretic model was used to model the FRP tube, as proposed by Shao and Mirmiran (2004).

The nonlinear beam-column element option of the program was chosen to model each column assuming plain sections remaining plane after bending, and ignoring any buckling and slippage of the FRP tube. Each column was divided into sixteen equal elements of $95^{1 / 4} \mathrm{~mm}$ long each. The column base was modeled as a fixed support. The cross sections were modeled using fiber sections divided into the core (confined conventional concrete or UHPC), steel reinforcement (in Specimen RC), and cover (unconfined conventional concrete in Specimen RC or FRP tube in UHPCFFT specimens). Each component was modeled with a fine mesh to capture stress conditions across the section. The mass and the dead load were lumped at top column nodes based on the experimental data.

The comparison between the experimental response envelope curves and those resulted from the reversed cyclic analysis of the models are shown for Specimens UF1 and RC in Figures 6.11(a) and (b), respectively. A very close agreement is noted between the models and experiments with respect to the initial stiffness, maximum load and deflection, and the general trend of the load-deflection relation. The lower response of column specimens in the push direction which was attributed to the asymmetrical footing configuration for each column resulted in slight discrepancy between the models and the experiments in the push direction. In Specimen $\mathrm{RC}$, the maximum load and deflection were predicted by the analytical model with more than $95 \%$ accuracy in the pull direction. In Specimen UF1, the differences between the predicted and measured values 
of maximum load and deflection were $1 \%$ and $14 \%$, respectively, in the pull direction. The latter may be attributed to the cracking and slippage of the FRP tube at the column base causing some degradation after the peak load, although this feature was captured in part by introducing a damage factor for the FRP material model.

\subsubsection{Seismic Simulation}

The ground motion Tab-TR, recorded at 9101 Tabas station during the 1978 Tabas, Iran earthquake, with an original peak ground acceleration (PGA) of $0.852 g$, where $g$ is the ground acceleration of $9.8 \mathrm{~m} / \mathrm{sec}^{2}$, was chosen for seismic simulation (Record Number NGA 0143, PEER, 2006). The ground acceleration record is shown in Figure 6.12. The selected ground motion has a relatively high acceleration and an extended period of shake.

Both RC and UF1 models were subjected to a series of excitations with gradually increasing amplitudes resulted from the acceleration factors starting from 0.1 and increasing by an increment of 0.1 until they caused failure of the column. A damping ratio of 5\% was used in the analysis, as discussed earlier. Column RC could sustain the earthquake motion up to the acceleration factor of $0.5(\mathrm{PGA}=0.43 g)$, but failed during the first ten seconds of the earthquake with the acceleration factor of $0.6(\mathrm{PGA}=0.51 \mathrm{~g})$. The failure happened by crushing of concrete. The time histories of the column base shear for the acceleration factors of 0.5 and 0.6 are both shown in Figure 6.13. However, Column UF1 could resist the earthquake up to an acceleration factor of 0.7 (PGA $=0.60 g)$. The failure of the column happened by tensile rupture of FRP tube (similar to the pseudostatic tests) early on in the following earthquake with an acceleration factor of 0.8 $(\mathrm{PGA}=0.68 \mathrm{~g})$. The time histories of UF1 column base shear for the acceleration factors of 
0.7 and 0.8 are both shown in Figure 6.14. Similar to the results achieved from the theoretical approach presented in Section 3.3, Column UF1 showed a peak ground acceleration (PGA) capacity of about 1.4 times higher than that of Column RC under the same earthquake ground motion. Since the proposed analytical approach was based on the design response spectrum which conservatively represents a large ensemble of recorded ground motions, the simulation results for the specific earthquake ground motion (Tabas) are higher than the maximum ground acceleration capacities estimated by the proposed analytical approach.

\subsection{Conclusions}

The seismic response of six quarter scale bridge columns including one reference RC and five novel UHPCFFT columns were studied. A general methodology was proposed to estimate the maximum ground acceleration capacity of the columns based on their pseudo-static test data.

The results showed 20\% higher ground acceleration capacity for Specimen UF1 with the thinnest FRP tube and no steel reinforcement, even though it had $20 \%$ lower ductility, as compared to Specimen RC. Increasing either the FRP or longitudinal steel reinforcement enhanced the estimated maximum ground acceleration capacity in other UHPCFFT specimens with similar diameters to that of Specimen RC. The maximum ground acceleration capacity of Specimen UF3 with the column diameter of about $2 / 3$ of that in other specimens was estimated as $76 \%$ of that in Specimen RC.

The seismic response of Specimens RC and UF1 was further studied through the simulation analysis of the columns under 1978 Tabas earthquake. The simulation results showed 40\% higher peak ground acceleration (PGA) capacity for Specimen UF1, 
confirming the results achieved from the proposed analytical approach. The lower responses estimated from the proposed analytical procedure may be attributed to the design response spectrum based on a conservative representation of a large ensemble of recorded ground motions. Accordingly, the proposed analytical approach offers an efficient way to compare the seismic response of the structures which are tested under pseudo-static loading.

In general, this study showed the better seismic performance of the novel UHPCFFT column system, as compared to its RC counterpart, despite its seemingly lower ductility. This result along with the other advantages such as ease and speed of construction, higher durability, lower maintenance costs, and self-centering capabilities due to lower residual displacements, make the steel-free UHPCFFT system a viable alternative to conventional RC columns in seismic regions.

\section{Acknowledgements}

This study was funded in part by the NSF-Network for Earthquake Engineering Simulation program, as part of the multi-university Grant CMS-0420347. Findings and opinions expressed here are those of the authors alone, and not necessarily the views of sponsoring agencies. 


\section{References}

Brühwiler, E. and Denarié, E. (2008). "Rehabilitation of Concrete Structures Using UltraHigh Performance Fiber-Reinforced Concrete." Proc. of the Second International Symposium on Ultra-High Performance Concrete, Kassel, Germany.

Chopra A. K. (2008). Dynamics of Structures, 3rd Ed., Prentice-Hall, Upper Saddle River, New Jersey.

Graybeal, B. A. (2005). "Characterization of the Behavior of Ultra-High Performance Concrete." PhD Dissertation, Department of Civil and Environmental Engineering, University of Maryland, College Park, Maryland.

Mander, J. B., Priestley, M. J. N., and Park, R. (1988). “Theoretical Stress-Strain Model for Confined Concrete.” Journal of Structural Engineering, ASCE, 114(8), 18041826.

Massicotte, B., and Boucher-Proulx, G. (2010). "Seismic Retrofitting of Bridge Piers with UHPFRC Jackets." Designing and Building with UHPFRC: State of the Art and Development, ed. F. Toulemonde and J. Resplendino, Wiley-ISTE, London, 531-540.

McKenna, F., et al. (2006). “OpenSees-Open System for Earthquake Engineering Simulation." http://opensees.berkeley.edu, University of California, Berlekey, California.

Mertz, D. R., Chajes, M. J., Gillespie, Jr., J. W., Kukich, D. S., Sabol, S. A., Hawkins, N. M., Aquino, W., and Deen, T. B. (2003). "Application of Fiber Reinforced Polymer Composites to the Highway Infrastructure." NCHRP Report No. 503, Transportation Research Board, National Academy of Sciences, Washington D.C.

Mirmiran, A., Samaan, M., Cabrera, S., and Shahawy, M. (1998). "Design, Manufacture and Testing of a New Hybrid Column." Journal of Construction \& Building Materials, Elsevier, 12(1), 39-49.

Newmark, N. M., and Hall, W. J. (1982). Earthquake Spectra and Design, Earthquake Engineering Research Institute, Berkeley, California.

Pacific Earthquake Engineering Research (PEER) Center (2006). "Next Generation Attenuation Database.' http://peer.berkeley.edu/nga/index.html.

Priestley, M. J. N., Seible, F., and Calvi, G. M. (1996). Seismic Design and Retrofit of Bridges, John Wiley \& Sons, New York. 
Samaan, M., Mirmiran, A., and Shahawy, M. (1998). "Model of Concrete Confined by Fiber Composites." Journal of Structural Engineering, ASCE, 124(9), 10251031.

Shao, Y., and Mirmiran, A. (2004). "Nonlinear Cyclic Response of Laminated Glass FRP Tubes Filled with Concrete." Journal of Composite Structures, Elsevier, 65(1), 91-101.

Shao, Y., and Mirmiran, A. (2005). "Experimental Investigation of Cyclic Behavior of Concrete-Filled Fiber Reinforced Polymer Tubes." Journal of Composites for Construction, ASCE, 9(3), 263-273.

Zhu, Z., Ahmad, I., and Mirmiran, A. (2006). "Seismic Performance of Concrete-Filled FRP Tube Columns for Bridge Substructure." Journal of Bridge Engineering, ASCE, 11(3), 359-370.

Zohrevand, P., and Mirmiran, A. (2011a). "Cyclic Behavior of Hybrid Columns Made of Ultra-high Performance Concrete and Fiber Reinforced Polymers." Journal of Composites for Construction, ASCE, Online posting ahead of print June 2011.

Zohrevand, P., and Mirmiran, A. (2011b). "Effect of Column Parameters on Cyclic Behavior of Ultra-high Performance Concrete-Filled FRP Tubes." Report No. TASCTL-11-4, Titan America Structures and Construction Testing Laboratory, Florida International University, Miami, Florida. 
Table 6.1 Specimen Test Matrix of the Experimental Study

\begin{tabular}{|c|c|c|c|c|c|c|c|}
\hline \multirow{2}{*}{ Specimen } & \multirow{2}{*}{$\begin{array}{l}\text { Column } \\
\text { Outside } \\
\text { Diameter } \\
(\mathrm{mm}) \\
\end{array}$} & \multicolumn{2}{|c|}{ FRP Tube } & \multirow{2}{*}{$\begin{array}{c}\mathrm{f}_{\mathrm{u}}^{1} \\
(\mathrm{Mpa})\end{array}$} & \multirow{2}{*}{$\begin{array}{c}\mathrm{f}_{\mathrm{c}}^{2} \\
(\mathrm{Mpa})\end{array}$} & \multicolumn{2}{|c|}{ Steel Reinforcement ${ }^{3}$} \\
\hline & & Type & $\begin{array}{c}\text { Thickness } \\
(\mathrm{mm})\end{array}$ & & & Long. & Lateral \\
\hline $\mathrm{RC}$ & 305 & None & - & - & 42 & $\begin{array}{c}16 \mathrm{No} . \\
10 \mathrm{M}\end{array}$ & $\begin{array}{c}4.9 \mathrm{~mm} \\
\text { Spiral }\end{array}$ \\
\hline UF1 & 323 & $\begin{array}{c}\text { Red } \\
\text { Thread } \\
\text { II Pipe }\end{array}$ & 5 & 180 & 42 & None & None \\
\hline UF2 & 337 & $\begin{array}{c}\text { Alphatic } \\
\text { Amine } \\
\text { Pipe }\end{array}$ & 19 & 175 & 42 & None & None \\
\hline UF3 & 219 & $\begin{array}{c}\text { Alphatic } \\
\text { Amine } \\
\text { Pipe }\end{array}$ & 16 & 180 & 42 & None & None \\
\hline RUF1 & 323 & $\begin{array}{c}\text { Red } \\
\text { Thread } \\
\text { II Pipe }\end{array}$ & 5 & 183 & 42 & $\begin{array}{c}6 \mathrm{No} . \\
10 \mathrm{M}\end{array}$ & None \\
\hline RUF2 & 323 & $\begin{array}{c}\text { Red } \\
\text { Thread } \\
\text { II Pipe }\end{array}$ & 5 & 181 & 42 & $\begin{array}{c}10 \text { No. } \\
10 \mathrm{M}\end{array}$ & None \\
\hline
\end{tabular}


Table 6.2 Performance Measures of the Columns Tested in the Experimental Study

\begin{tabular}{cccccccc}
\hline \hline Specimen & Direction & RC & UF1 & UF2 & UF3 & RUF1 & RUF2 \\
\hline \hline \multirow{2}{*}{ Initial Stiffness, } & Pull & 2,613 & 3,513 & 5,073 & 1,484 & 4,472 & 4,307 \\
$k(\mathrm{~N} . m)$ & Push & 2,472 & 3,169 & 5,281 & 1,540 & 4,281 & 4,865 \\
& Average & 2,542 & 3,341 & 5,177 & 1,512 & 4,377 & 4,586 \\
\hline \multirow{2}{*}{ Maximum Load } & Pull & 60.5 & 83.1 & 189.3 & 57.1 & 113.0 & 126.8 \\
$(\mathrm{kN})$ & Push & 52.0 & 71.3 & 165.2 & 50.8 & 93.6 & 102.6 \\
& Average & 56.3 & 77.2 & 177.3 & 54.0 & 103.3 & 114.7 \\
\hline \multirow{2}{*}{ Maximum } & Pull & 75.7 & 70.8 & 76.0 & 75.8 & 70.0 & 75.7 \\
Deflection (mm) & Push & 75.4 & 62.8 & 74.1 & 74.9 & 70.3 & 74.6 \\
& Average & 75.6 & 66.8 & 75.0 & 75.4 & 70.2 & 75.1 \\
\hline \multirow{2}{*}{ Yield Strength, } & Pull & 55.3 & 74.0 & 159.9 & 47.4 & 100.6 & 118.8 \\
$F_{y}(\mathrm{kN})$ & Push & 51.1 & 68.2 & 143.7 & 42.9 & 88.4 & 100.6 \\
& Average & 53.2 & 71.1 & 151.8 & 45.1 & 94.5 & 109.7 \\
\hline Yield & Pull & 21.2 & 21.1 & 31.5 & 31.9 & 22.5 & 27.6 \\
Displacement & Push & 20.7 & 21.5 & 27.2 & 27.8 & 20.6 & 20.7 \\
(mm) & Average & 21.0 & 21.3 & 29.4 & 29.9 & 21.6 & 24.2 \\
\hline \multirow{2}{*}{ Ductility, $\mu$} & Pull & 3.6 & 3.4 & 2.4 & 2.4 & 3.1 & 2.7 \\
& Push & 3.7 & 2.9 & 2.7 & 2.7 & 3.4 & 3.6 \\
\hline \hline
\end{tabular}

Table 6.3 Estimation of the Maximum Ground Acceleration Capacity

\begin{tabular}{ccccccc}
\hline Specimen & RC & UF1 & UF2 & UF3 & RUF1 & RUF2 \\
\hline $\begin{array}{c}\text { Mass, } m \\
\left(\mathrm{~N} . \mathrm{sec}^{2} / \mathrm{mm}\right)\end{array}$ & 13.4 & 13.4 & 13.4 & 13.2 & 13.4 & 13.4 \\
\hline$\xi(\%)$ & 5.0 & 5.0 & 5.0 & 5.0 & 5.0 & 5.0 \\
\hline$T_{n}(\mathrm{sec})$ & 0.46 & 0.40 & 0.32 & 0.59 & 0.35 & 0.34 \\
\hline$\alpha_{A}$ & 2.7 & 2.7 & 2.7 & 2.7 & 2.7 & 2.7 \\
\hline$\alpha_{V}$ & 2.3 & 2.3 & 2.3 & 2.3 & 2.3 & 2.3 \\
\hline$\alpha_{D}$ & 2.0 & 2.0 & 2.0 & 2.0 & 2.0 & 2.0 \\
\hline$T_{a^{\prime}}(\mathrm{sec})$ & 0.03 & 0.03 & 0.03 & 0.03 & 0.03 & 0.03 \\
\hline$T_{b^{\prime}}(\mathrm{sec})$ & 0.13 & 0.13 & 0.13 & 0.13 & 0.13 & 0.13 \\
\hline$T_{c^{\prime}}(\mathrm{sec})$ & 0.46 & 0.49 & 0.53 & 0.53 & 0.48 & 0.48 \\
\hline$T_{d^{\prime}}(\mathrm{sec})$ & 4.08 & 4.08 & 4.08 & 4.08 & 4.08 & 4.08 \\
\hline$T_{e^{\prime}}(\mathrm{sec})$ & 10 & 10 & 10 & 10 & 10 & 10 \\
\hline$T_{f^{\prime}}(\mathrm{sec})$ & 33 & 33 & 33 & 33 & 33 & 33 \\
\hline$R_{y}$ & 2.5 & 2.3 & 2.0 & 2.5 & 2.3 & 2.3 \\
\hline$\ddot{u}_{g c}(\mathrm{~g})$ & 0.37 & 0.46 & 0.87 & 0.29 & 0.62 & 0.71 \\
\hline \hline
\end{tabular}




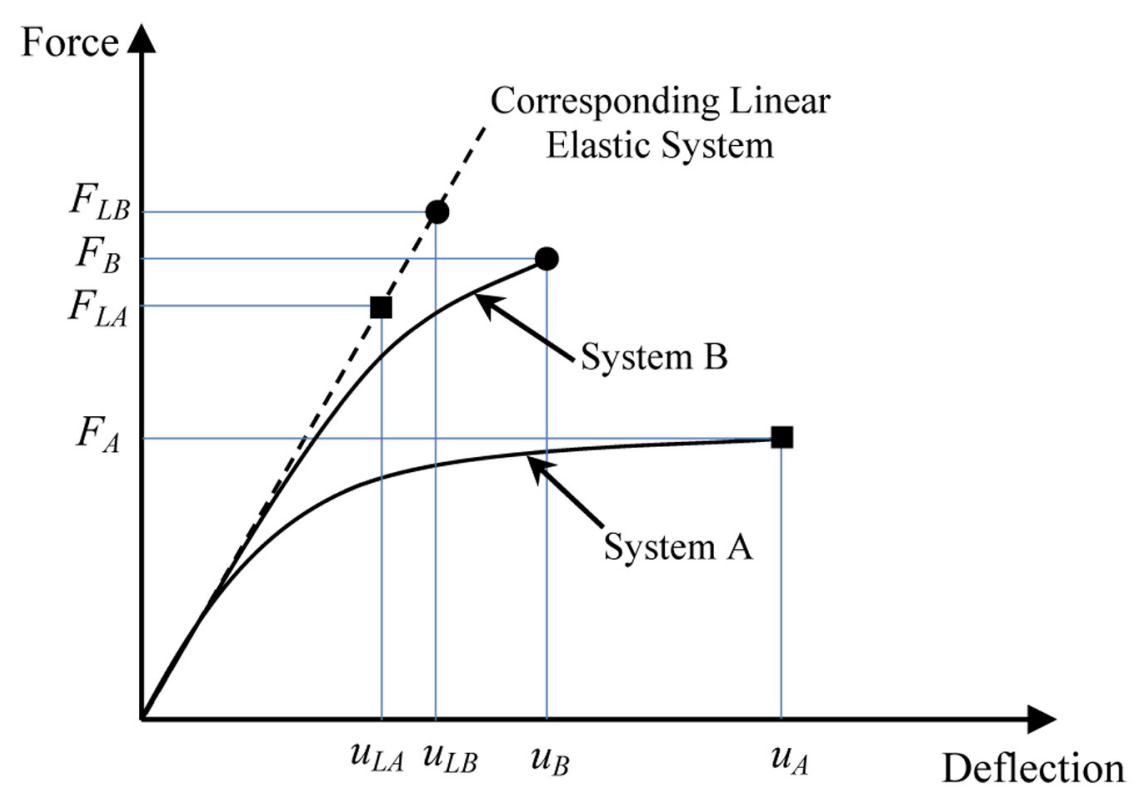

Figure 6.1 Schematic Force-Deflection Response Curves of Two Nonlinear Systems with the Corresponding Linear System 


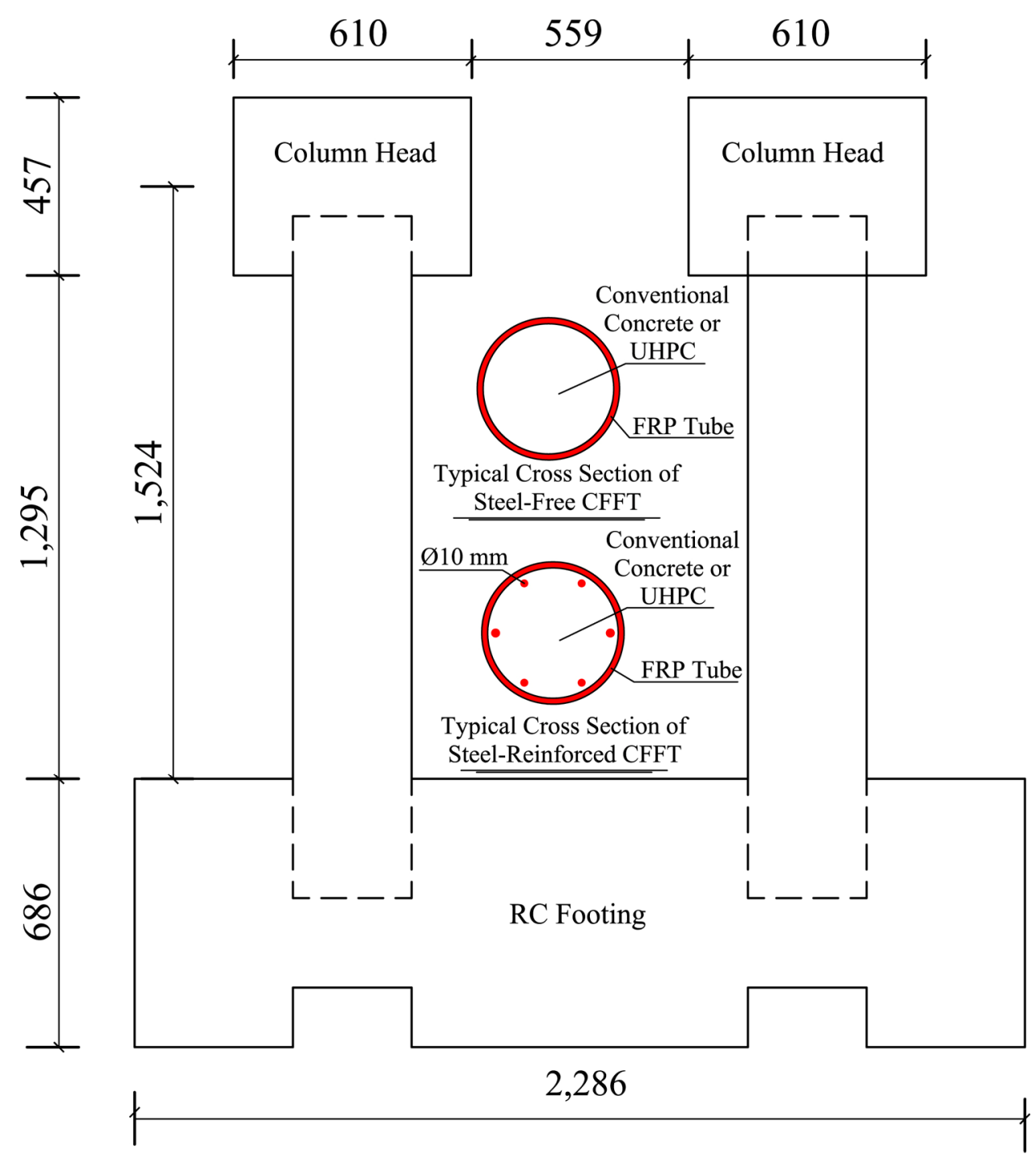

Figure 6.2 Layout of Column Specimens (All dimensions are in $\mathrm{mm}$ ) 


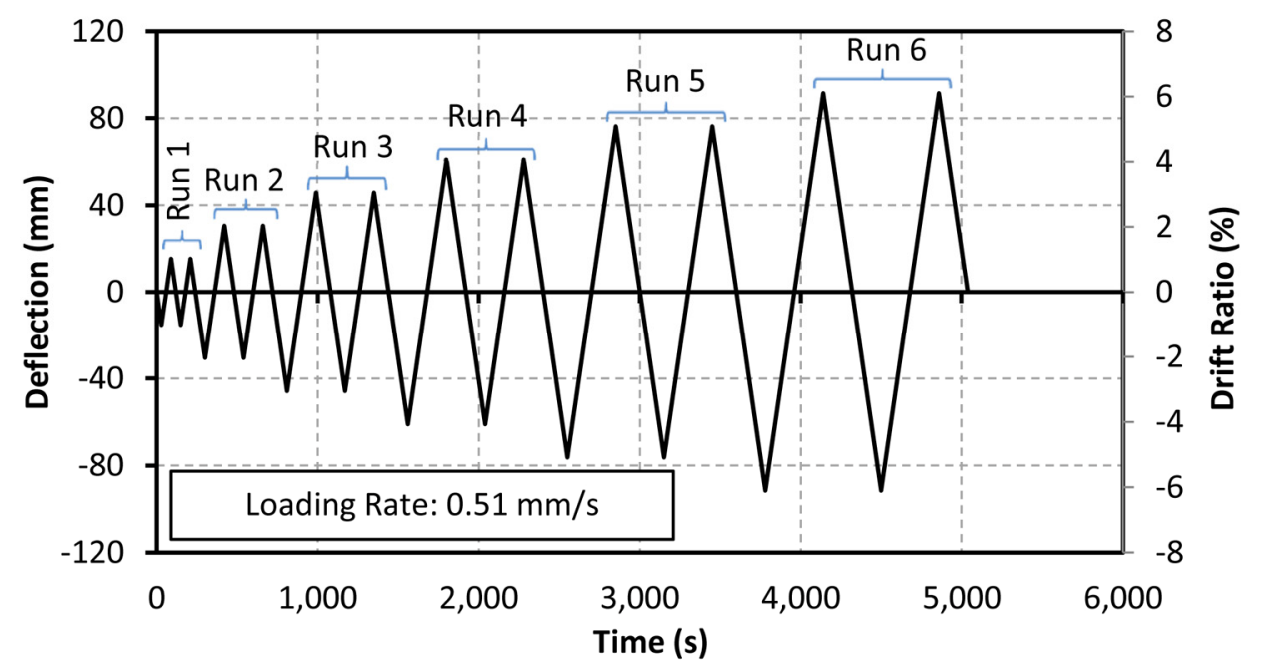

Figure 6.3 Reverse Cyclic Loading Regime

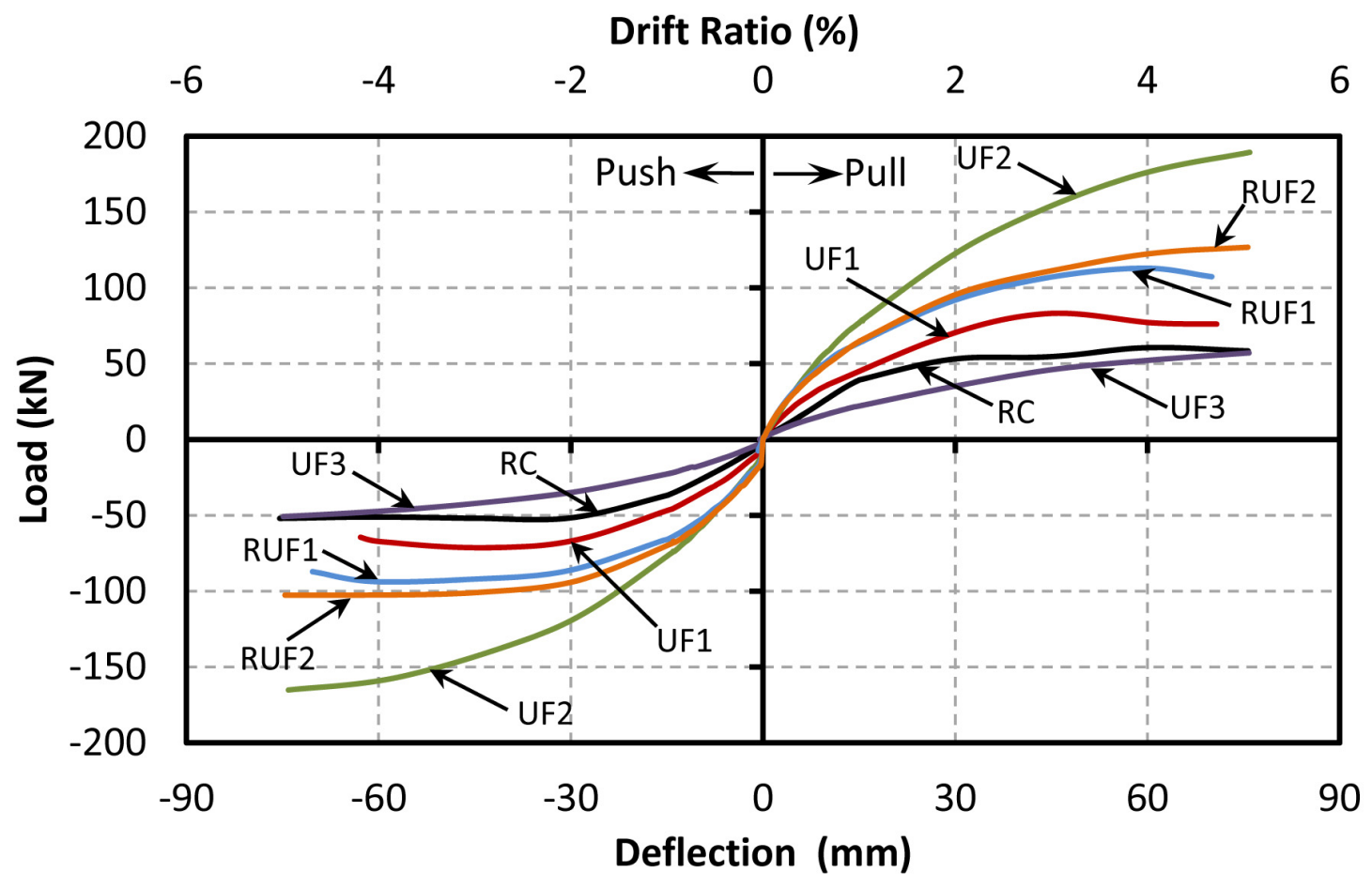

Figure 6.4 Load-Deflection Envelope Curves of the Column Specimens 


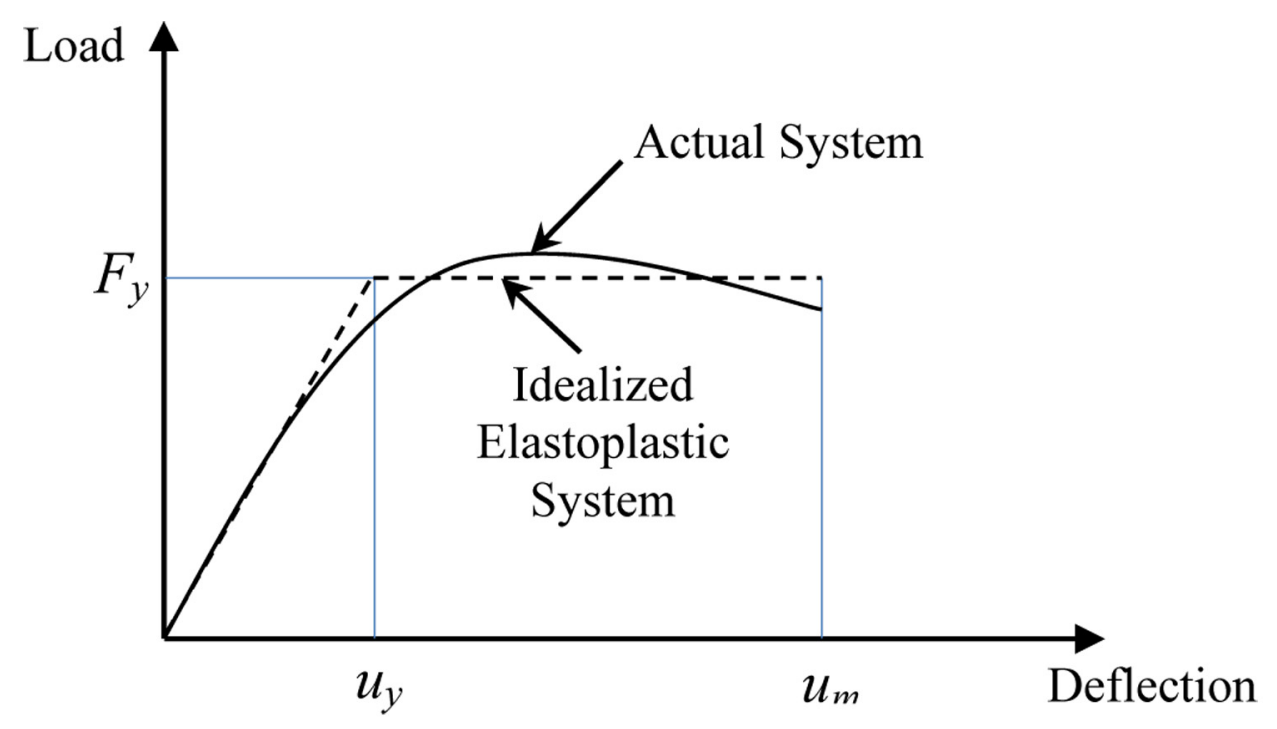

Figure 6.5 Schematic Load-Deflection Curves of the Actual System and its Idealized Elastoplastic System

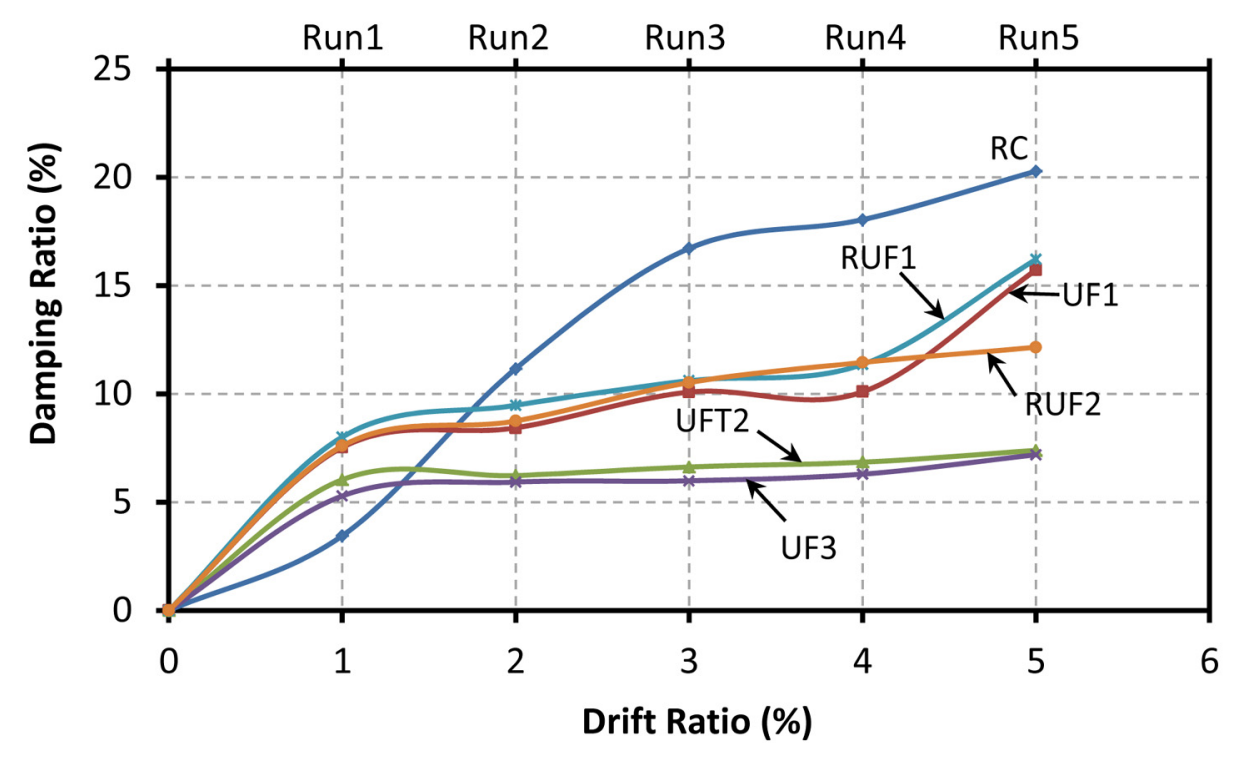

Figure 6.6 Variation of Damping Ratio Relative to Drift Ratio for Tested Columns 


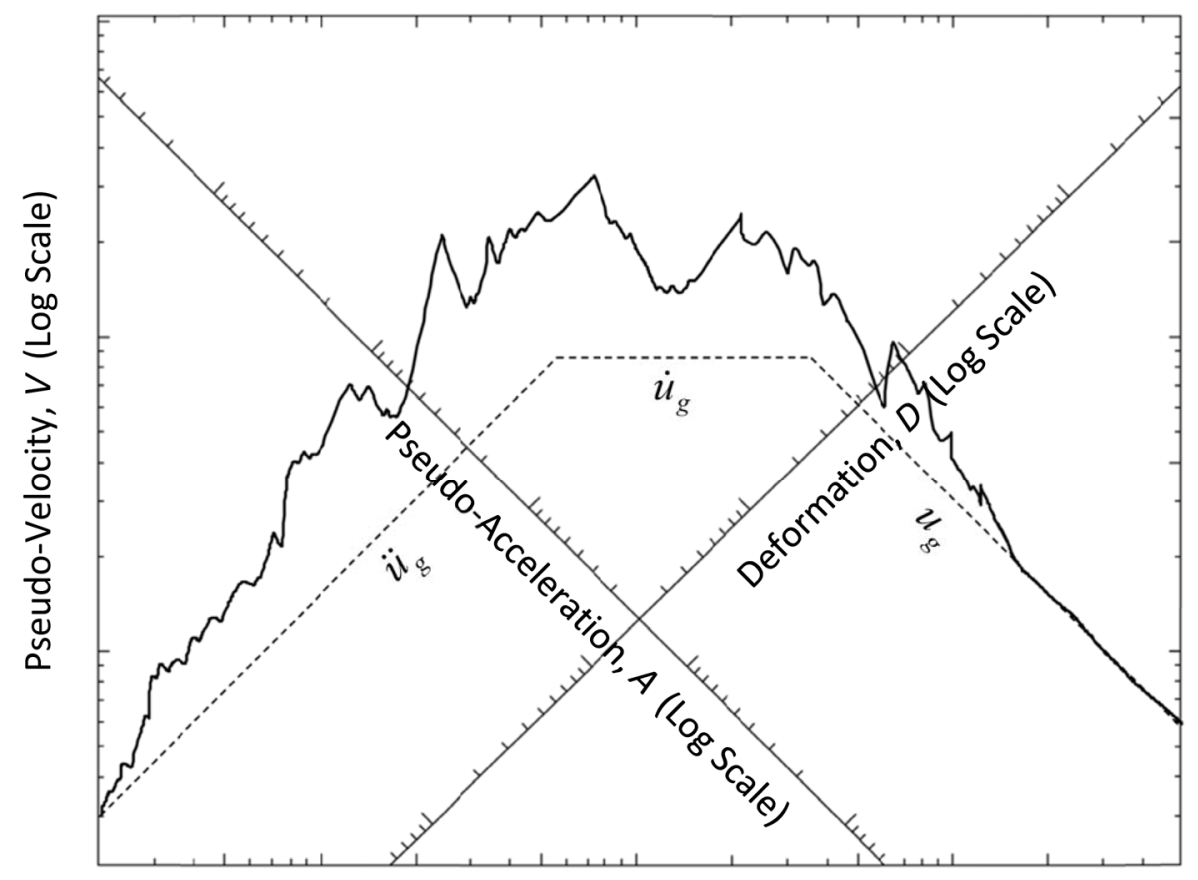

Natural Vibration Period, $T_{n}$ (Log Scale)

Figure 6.7 Schematic Linear Response Spectrum for a Specific Ground Motion and Damping Ratio 


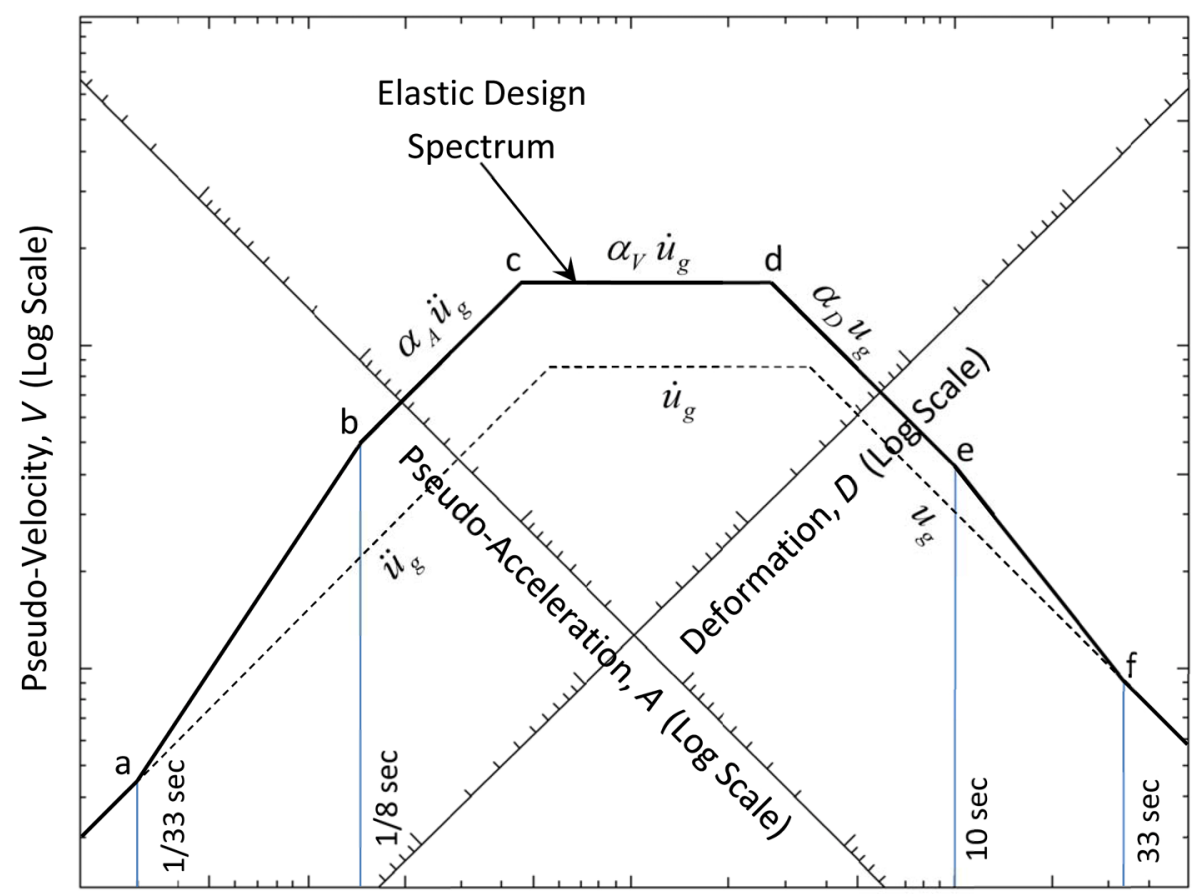

Natural Vibration Period, $T_{n}$ (Log Scale)

Figure 6.8 Idealized Elastic Design Response Spectrum Following Newmark and Hall (1982) 


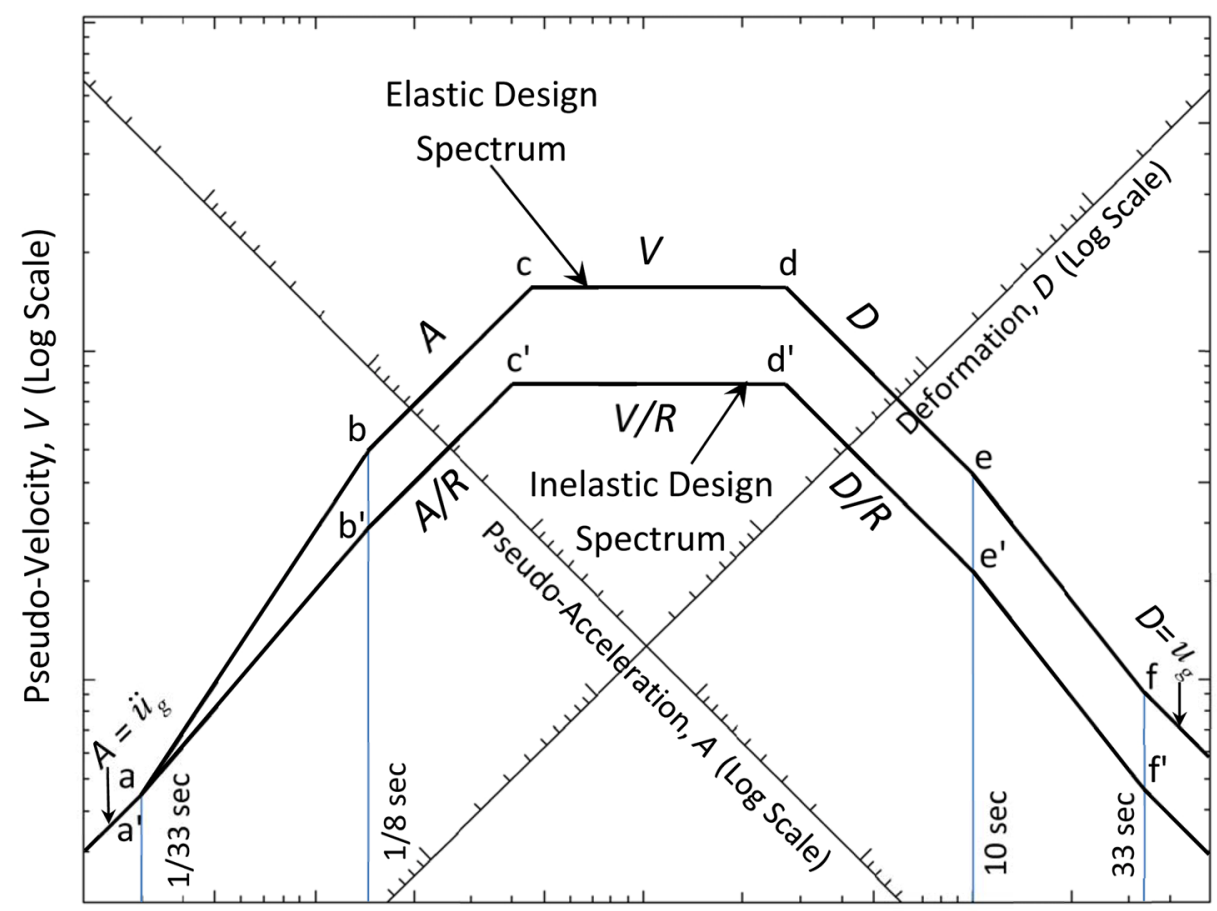

Natural Vibration Period, $T_{n}$ (Log Scale)

Figure 6.9 Inelastic Design Response Spectrum Following Chopra (2008)

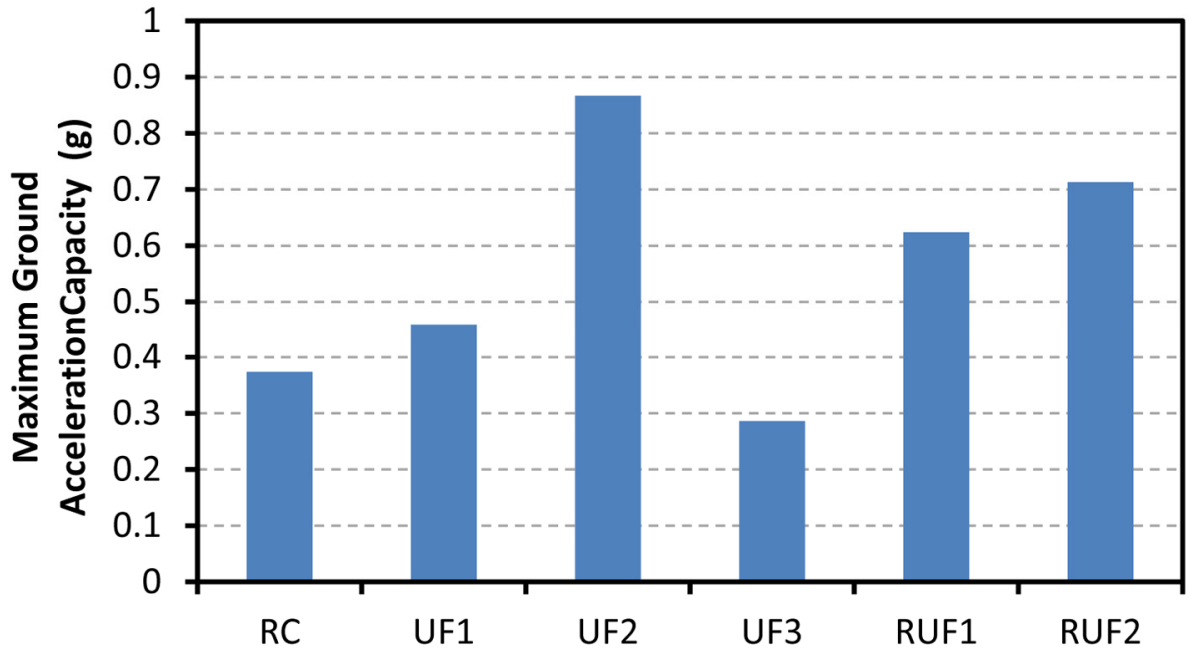

Figure 6.10 Maximum Ground Acceleration Capacities of Tested Columns 


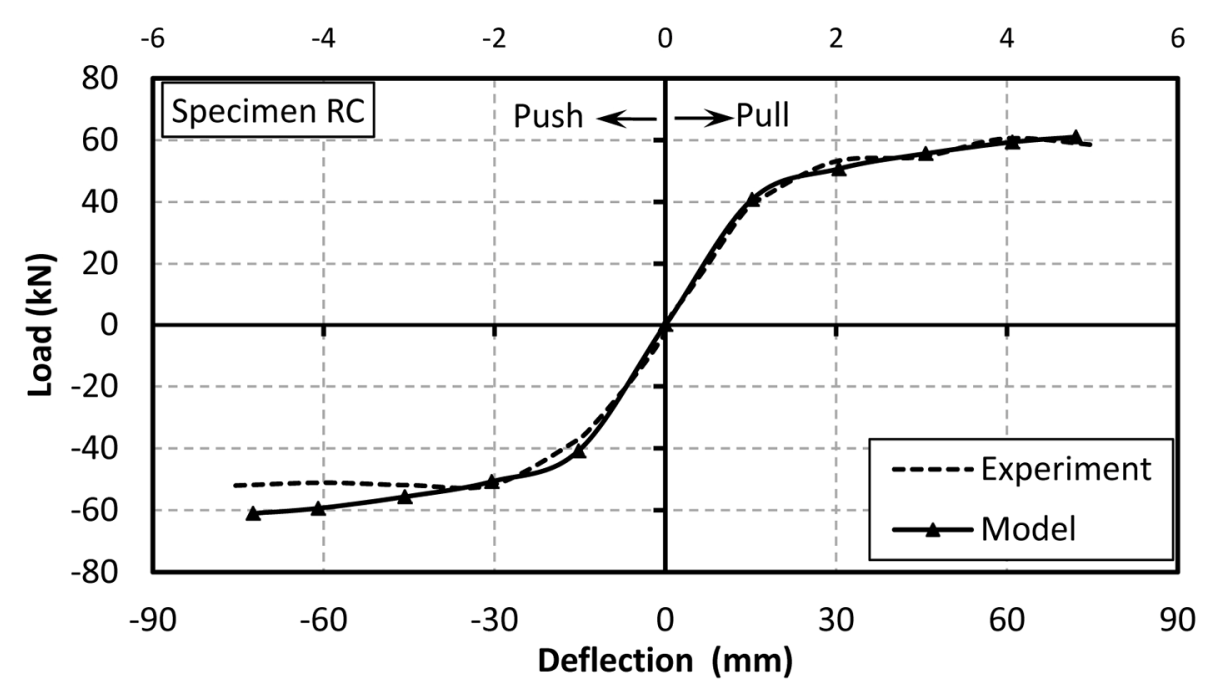

(a)

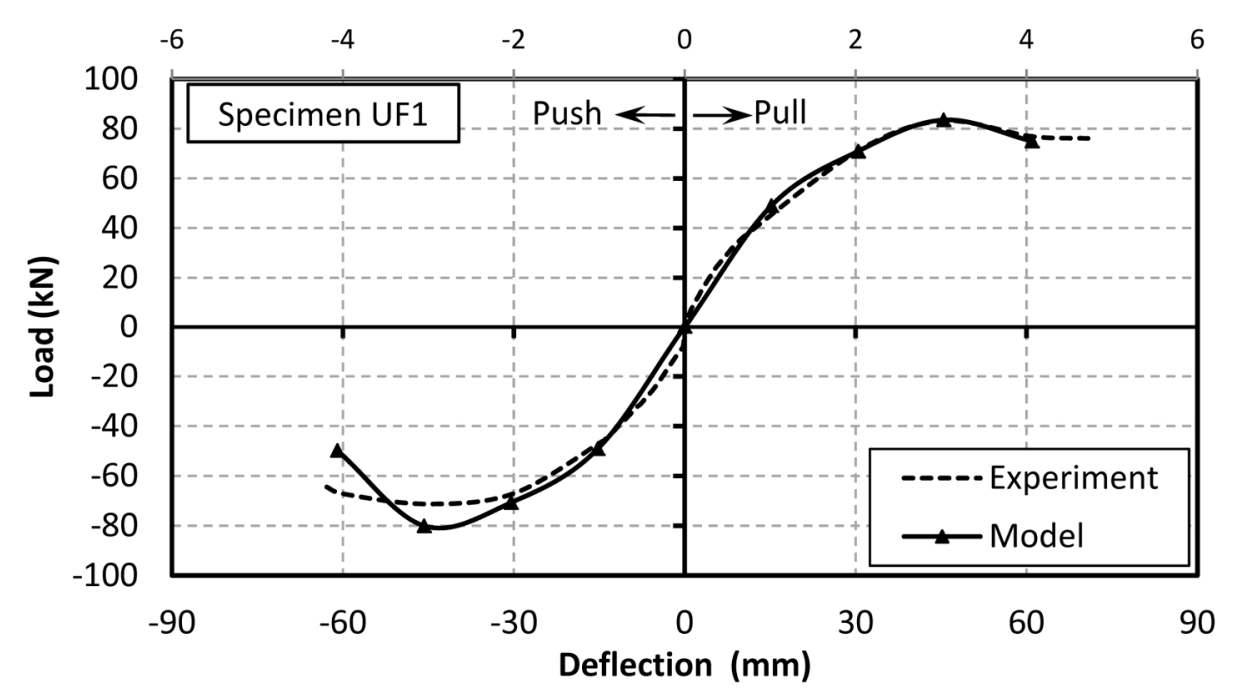

(b)

Figure 6.11 Comparison of Analytical and Experimental Load-Deflection Response Envelopes for (a) Specimen RC and (b) Specimen UF1 


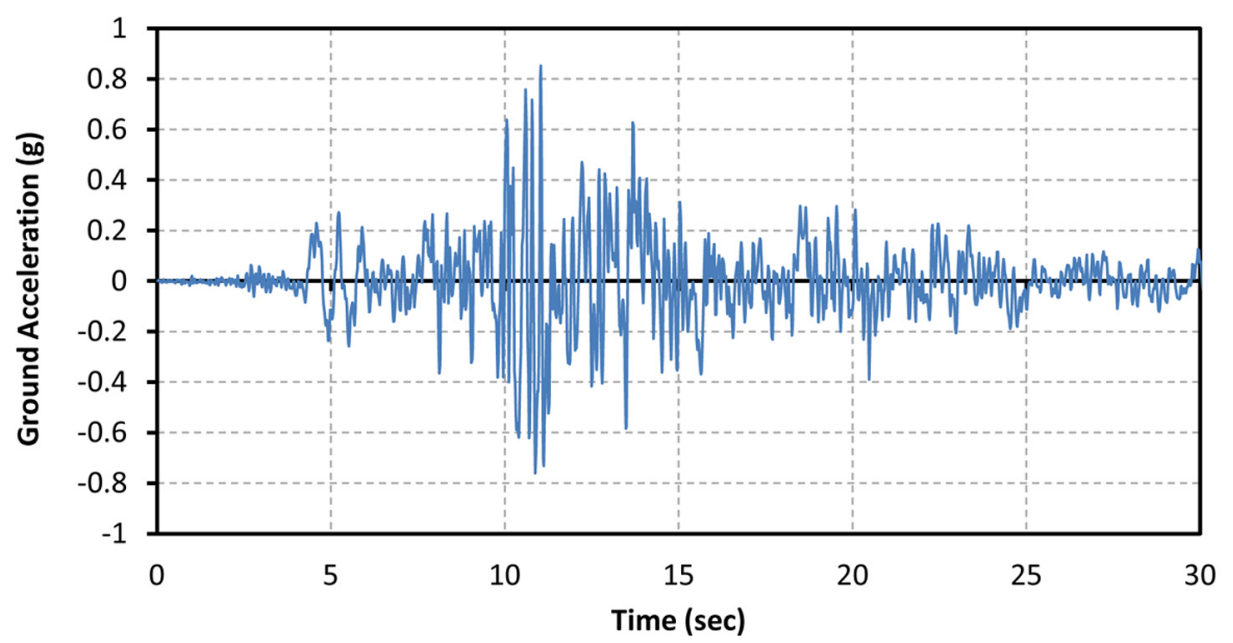

Figure 6.12 Ground Acceleration Record of 1978 Tabas, Iran Earthquake 


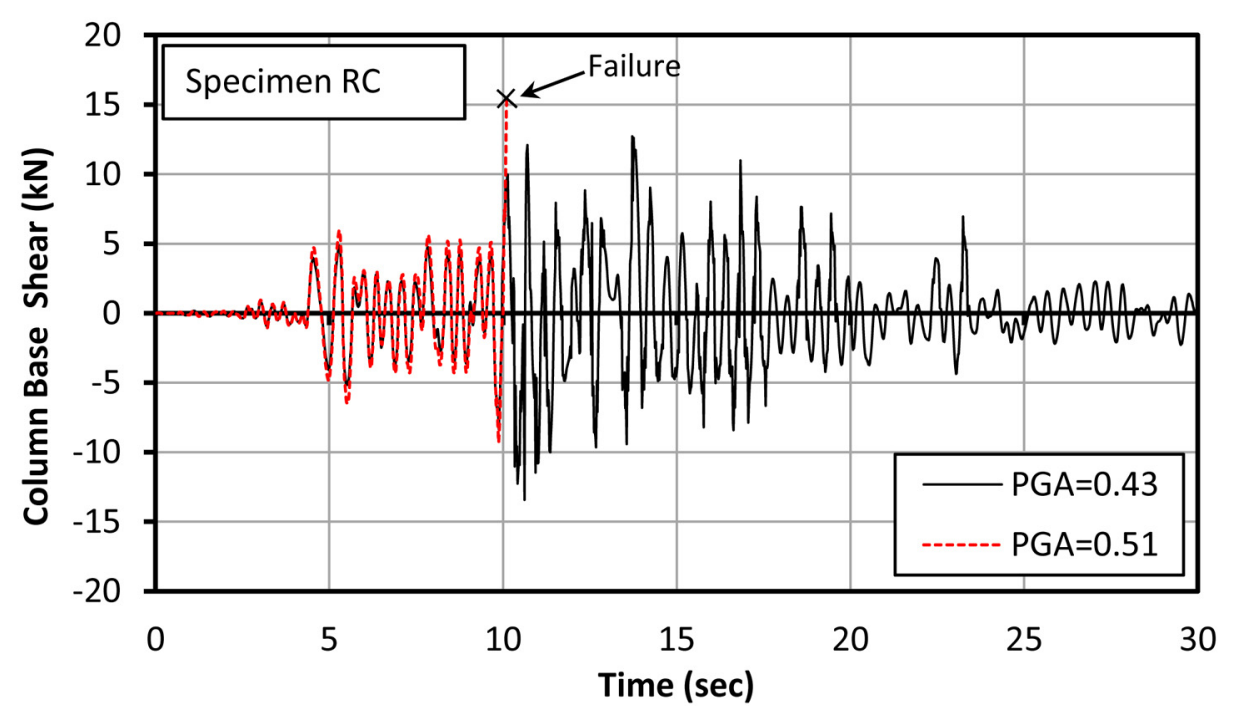

Figure 6.13 Time History of the Column Base Shear Response for Specimen RC

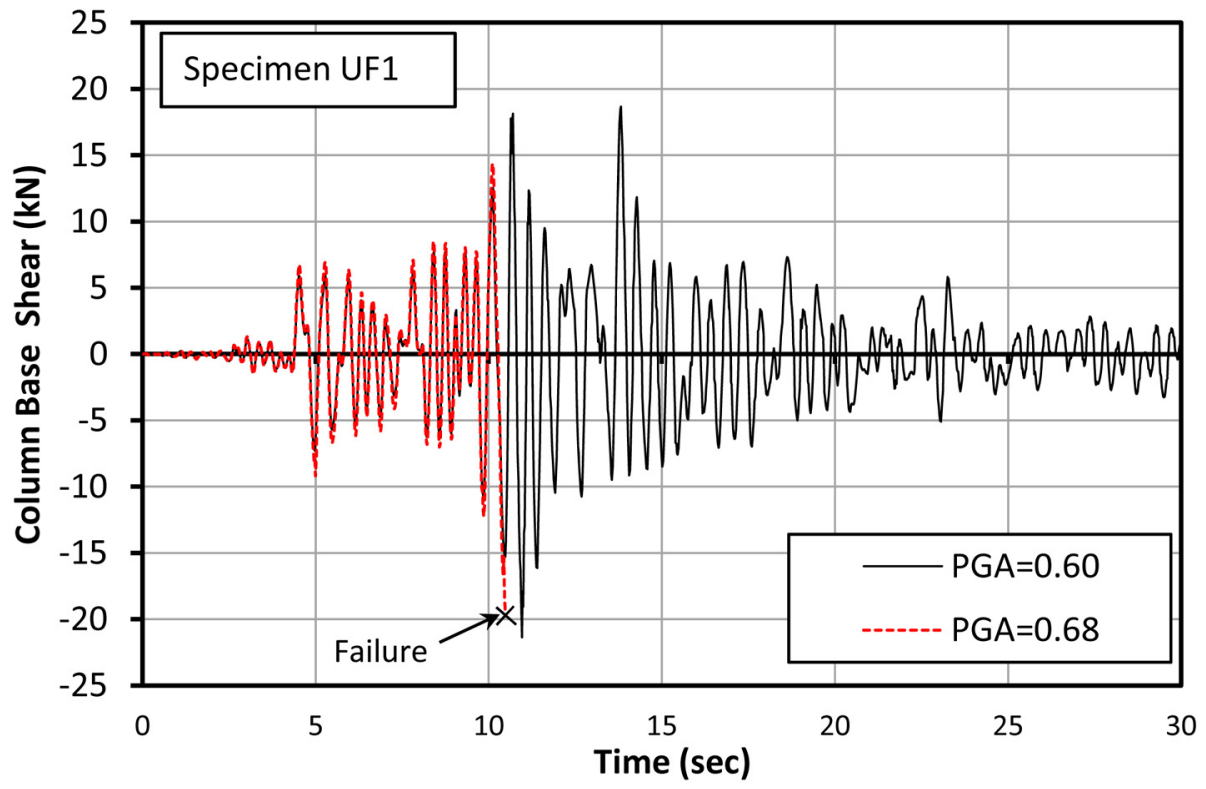

Figure 6.14 Time History of the Column Base Shear Response for Specimen UF1 


\section{SUMMARY AND CONCLUSIONS}

The two major objectives of this research were studying the stress-strain behavior of FRP-confined UHPC and developing a novel steel-free hybrid FRP-UHPC column as a viable alternative to conventional RC columns. Accordingly, the stress-strain behavior of a series of UHPC-filled FRP tube specimens was studied under uniaxial compression and compared with a number of existing confinement models. The experimental results were further used to recalibrate and modify two commonly FRP confinement models to propose a suitable stress-strain model for FRP-confinement UHPC. In the second part of this research, a novel steel-free UHPC-filled FRP tube (UHPCFFT) column system was developed and its cyclic behavior was studied. Using the results of the first group of column tests, another series of UHPCFFT columns were made and tested under pseudostatic loading to investigate the effect of column parameters on the cyclic behavior of UHPCFFT columns. Finally, the seismic responses of the UHPCFFT columns were identified through an analytical study based on their pseudo-static test data. The conclusions and recommendations drawn from the above-mentioned experimental and analytical studies are presented in the following sections.

\subsection{Behavior of FRP-Confined UHPC}

Sixteen FRP-confined and three unconfined UHPC cylinders were tested under uniaxial compression and their behavior were compared with four existing confinement models. Using the experimental results, two commonly used FRP confinement models, Samaan and Lam and Teng, were recalibrated. The model of Lam and Teng was further modified based on the stress-strain model of unconfined UHPC. Detailed experimental 
and analytical studies on the behavior of FRP-confined UHPC resulted in the following conclusions:

1- All FRP-confined UHPC specimens failed by the rupture of FRP tube at or near the mid-height.

2- Similar to conventional concrete, but in contrast with high-strength concrete (HSC), the FRP confinement was shown to significantly enhance both the strength and ductility of UHPC.

3- None of the four existing confinement models could yield reasonable predictions of the behavior of the FRP-confined UHPC specimens.

4- The recalibrated model of Samaan outperformed the other two models, the recalibrated and modified model of Lam and Teng, in predicting both the stress-strain curve and the ultimate condition of FRP-confined UHPC. Also, the single-equation format of the recalibrated model of Samaan makes it easier to use, as compared to the other two models with two-equation stressstrain models. Therefore, due to its higher accuracy and simpler format, the recalibrated model of Samaan is proposed as a suitable model for FRPconfined UHPC.

The following recommendations are made for further research in this field:

1- More FRP-confined UHPC specimens within a larger range of confinement ratios and with different geometries and aspect ratios need to be tested under uniaxial compression to improve the proposed confinement model.

2- The stress-strain behavior of UHPC confined with transverse steel also needs to be investigated. 


\subsection{Novel Hybrid UHPCFFT Column Systems}

In the first phase of column tests, the cyclic behavior of a column made of an FRP tube filled with UHPC within twice the plastic hinge length and conventional concrete for the remainder of the column length was studied in comparison with three other types of columns made of different combinations of conventional concrete, steel reinforcement, FRP tube, and UHPC. In the second phase of column tests, six column specimens including one RC and five UHPCFFTs with different FRP tubes, steel reinforcement ratios, and diameters were studied under pseudo-static loading. A thorough analytical study was further carried out to develop a general methodology to estimate the maximum ground acceleration capacity of UHPCFFT columns. The following conclusions could be drawn from these detailed experimental and analytical studies on UHPCFFT column systems:

1- Failure in all UHPCFFT specimens was governed by FRP tube rupture at the column base on the tension side. The slippage of the FRP tube was insignificant in all UHPCFFT specimens. Also, all UHPCFFT columns showed lower residual displacement than that in their RC counterpart, which can be viewed as a valuable re-alignment feature in seismic regions.

2- The steel-free UHPCFFT column showed significantly enhanced strength and stiffness, with a reasonable ductility, as compared to its conventional RC counterpart.

3- In UHPCFFT column systems, there are clear and strong correlations between the initial stiffness and the stiffness index and between the moment capacity and the reinforcement index. It was also shown that increasing the FRP 
reinforcement ratio reduces the ductility, whereas adding steel reinforcement has little or no effect on ductility within the bounds of the study.

4- All UHPCFFT columns showed higher damping ratios than their RC counterpart in the early cycles, implying that they could be designed more efficiently than conventional RC columns for seismic applications.

5- The results of both the proposed analytical approach and seismic simulation showed almost $20 \%$ higher ground acceleration capacity for the basic UHPCFFT column system (with the thinnest FRP tube and no steel reinforcement), even though it had $20 \%$ lower ductility, as compared to its $\mathrm{RC}$ counterpart.

6- The proposed analytical approach offers an efficient and robust technique to compare the seismic response of structures tested under pseudo-static loading.

7- The better seismic performance of the novel steel-free UHPCFFT column system, as compared to its RC counterpart, along with its other advantages such as ease and speed of construction, higher durability, lower maintenance costs, and self-centering capabilities, make it a viable alternative to conventional RC columns in seismic regions.

The study on the novel hybrid UHPCFFT system led to the following recommendations for future research:

1- Shake table study of the proposed UHPCFFT column system may shed further light on its seismic response, and help verify the achieved results of this research. 
2- The study on the novel hybrid UHPCFFT column system may be expanded to include other types of FRP materials, hence optimizing its design to achieve a desired behavior in terms of strength, ductility, stiffness, and serviceability.

3- The results of this research may be used to develop other novel hybrid systems with UHPC and FRP, including structural beams and slabs. 
VITA

PEDRAM ZOHREVAND

Sep. 17, 1980

1999-2004

2004-2007

2008-2012

$2008-2012$

2004-2008
Born, Tehran, Iran

B.Sc. Civil Engineering Isfahan University of Technology Isfahan, Iran

M.Sc. Civil Engineering Iran University of Science and Technology Tehran, Iran

Ph.D. Candidate, Civil Engineering Florida International University Miami, Florida, US

Research/Teaching Assistant Florida International University Miami, Florida, US

Structural Engineer Mojda \& Associates, Consulting Eng. Co. Tehran, Iran 